\title{
Phase II Documentation Overview of Corrective Action Unit 98: Frenchman Flat, Nevada Test Site, Nye County, Nevada
}

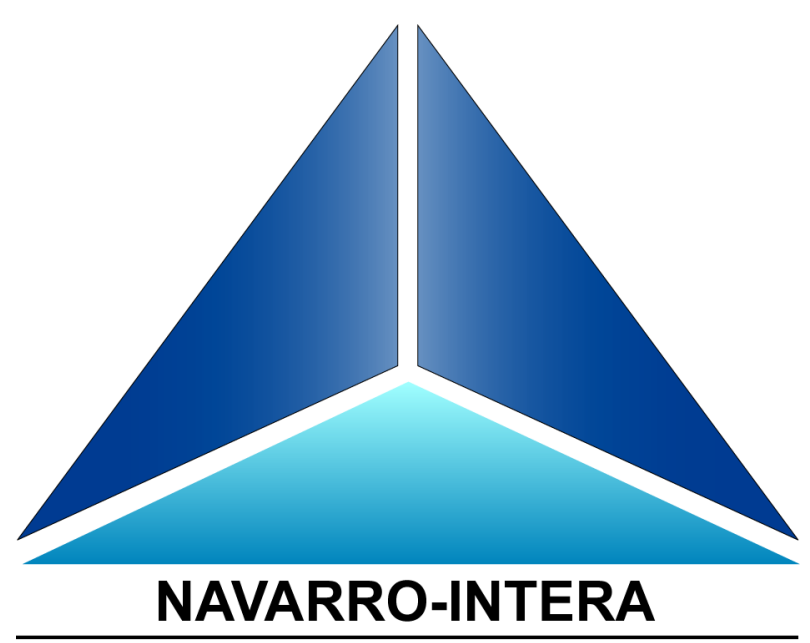

\author{
Revision No.: 1 \\ April 2010
}

Prepared for U.S. Department of Energy under Contract No. DE-AC52-09NA28091. 
Available for sale to the public from:

U.S. Department of Commerce

National Technical Information Service

5301 Shawnee Road

Alexandria, VA 22312

Telephone: 800.553 .6847

Fax: 703.605.6900

E-mail: orders@ntis.gov

Online Ordering: http://www.ntis.gov/help/ordermethods.aspx

Available electronically at http://www.osti.gov/bridge

Available for a processing fee to U.S. Department of Energy and its contractors, in paper, from:

\section{U.S. Department of Energy}

Office of Scientific and Technical Information

P.O. Box 62

Oak Ridge, TN 37831-0062

Phone: 865.576 .8401

Fax: 865.576.5728

Email: reports@adonis.osti.gov

Reference herein to any specific commercial product, process, or service by trade name, trademark, manufacturer, or otherwise, does not necessarily constitute or imply its endorsement, recommendation, or favoring by the United States Government or any agency thereof or its contractors or subcontractors. 


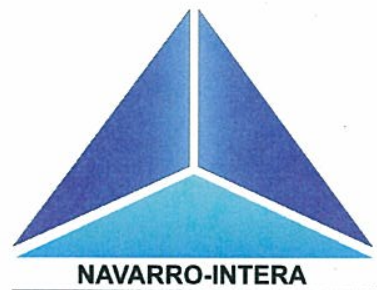

\section{PHASE II DOCUMENTATION OVERVIEW OF CORRECTIVE ACTION UNIT 98: FRENCHMAN FLAT, NEVADA TEST SITE, NYE COUNTY, NEVADA}

Revision No.: 1

April 2010

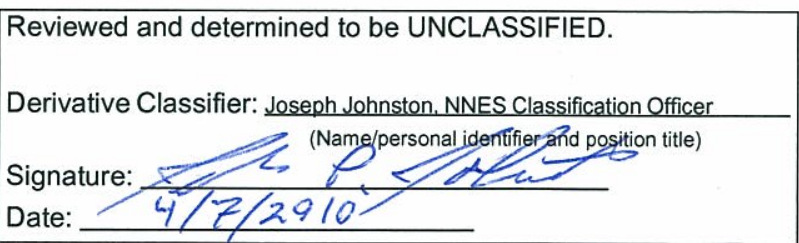

Navarro Nevada Environmental Services, LLC c/o U.S. DOE

P.O. Box 98952

Las Vegas, NV 89193-8952

Prepared for U.S. Department of Energy under Contract No. DE-AC52-09NA28091.

Approved for public release; further dissemination unlimited. 
PHASE II DOCUMENTATION OVERVIEW OF CORRECTIVE ACTION UNIT 98: FRENCHMAN FLAT, NEVADA TEST SITE, NYE COUNTY, NEVADA

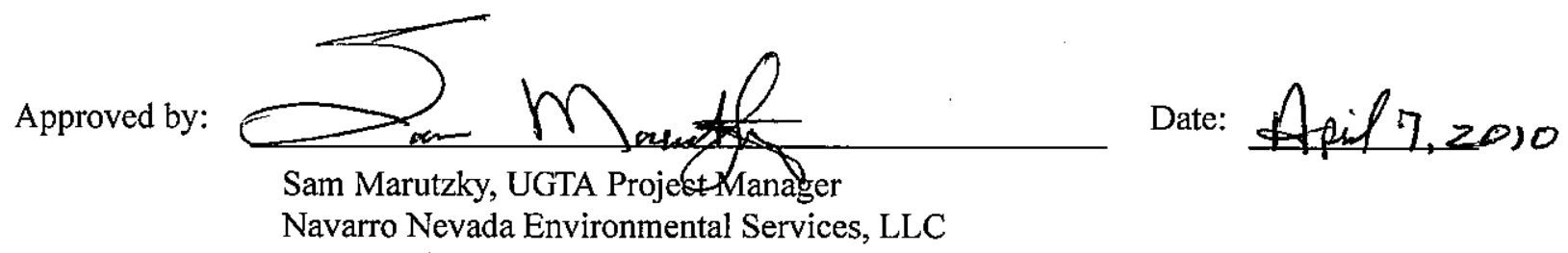




\section{TABLE OF CONTENTS}

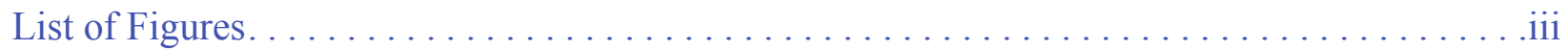

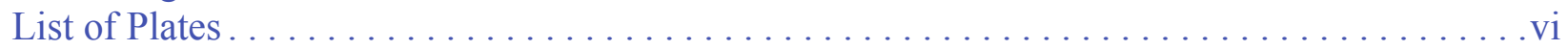

List of Tables $\ldots \ldots \ldots \ldots \ldots \ldots \ldots \ldots \ldots \ldots \ldots \ldots \ldots \ldots \ldots \ldots \ldots \ldots \ldots$ vii

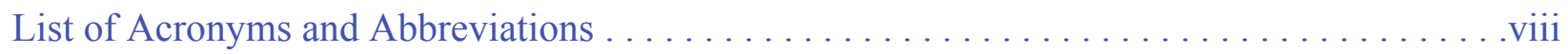

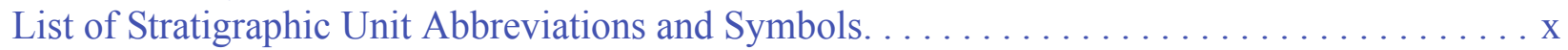

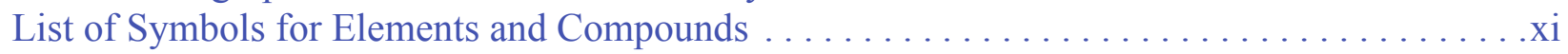

$1.0 \quad$ Introduction. . . . . . . . . . . . . . . . . . . . . . . . .

1.1 Corrective Action Strategy . . . . . . . . . . . . . . . . . . 1-6

1.2 Preliminary Remediation Strategies . . . . . . . . . . . . . . . . 1-9

2.0 Background. . . . . . . . . . . . . . . . . . .

2.1 Operational History of Underground Nuclear Tests on Frenchman Flat . . . . 2-1

2.2 Radionuclide Migration Experiment . . . . . . . . . . . . . . . . . 2-1

2.3 Corrective Action Investigation Project History $\ldots \ldots \ldots \ldots \ldots \ldots \ldots .2$

3.0 Conceptual Model. . . . . . . . . . . . . . . . . . . . . . . . . 3-1

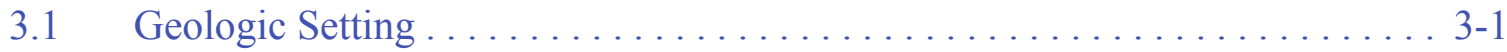

3.2 Regional Groundwater Flow. . . . . . . . . . . . . . . . . . 3-2

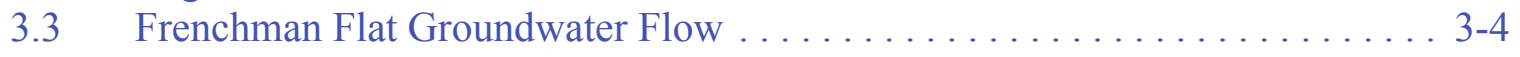

3.3.1 Vertical Head Gradients . . . . . . . . . . . . . . . . . 3-7

3.3.2 Structural Controls . . . . . . . . . . . . . . . . . . . . 3-9

3.3.3 Precipitation and Recharge. . . . . . . . . . . . . . . . 3-10

3.3 .4 Groundwater Discharge ... . . . . . . . . . . . . . . . . . 3-10

3.4 Development of the Frenchman Flat Transport Conceptual Model . . . . . . . 3-11

3.4.1 Underground Nuclear Test Phenomenology and Radionuclide Inventory . . . . . . . . . . . . . . . . 3-11

3.4.2 Radionuclide Transport ..................... 3-16

4.0 Modeling Approach and Model Construction . . . . . . . . . . . . . . 4-1

$4.1 \quad$ Hydrostratigraphic Framework Model . . . . . . . . . . . . . . . . 4-1

4.2 Groundwater Flow Model. . . . . . . . . . . . . . . . . . . 4-6

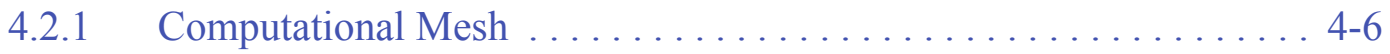

4.2.2 Material Properties . . . . . . . . . . . . . . . . . . 4-6

4.2.3 Boundary Condition Uncertainty . . . . . . . . . . . . . . 4-10

4.2.3.1 Precipitation Recharge. . . . . . . . . . . . . 4-10

4.2.3.2 Inflow and Outflow

(Lateral Boundary Flows and Boundary Heads) . . . . . . 4-11

4.2.3.3 Groundwater Discharge. . . . . . . . . . . . . . . 4 4-12

4.2.4 CAU-Scale Calibration Constraints . . . . . . . . . . . . . . . . 4 4-13

4.2.5 Transient Central Testing Area Calibration Constraints . . . . . . . . 4 4-19

4.3 Contaminant Transport Models . . . . . . . . . . . . . . . . . . . 4-19

4.3.1 Contaminant Source Term for Transport Calculations . . . . . . . . . 4-19 


\section{TABLE OF CONTENTS (CONTINUED)}

4.3.2 Computational Approach . . . . . . . . . . . . . . . . . . 4-20

4.3.3 Transport Parameters . . . . . . . . . . . . . . . . 4-22

4.3.4 Contaminant Boundary and Uncertainty Calculations . . . . . . . . . 4-23

$5.0 \quad$ Model Results . . . . . . . . . . . . . . . . . . . . . . . .

$5.1 \quad$ Steady-State Groundwater Flow . . . . . . . . . . . . . . . . . . . 5-2

$5.1 .1 \quad$ HFM Uncertainty . . . . . . . . . . . . . . . . . . 5-7

5.1 .2 Boundary Condition Uncertainty . . . . . . . . . . . . . . . 5-8

5.1.3 Flow Model Parameter Assignment Uncertainty . . . . . . . . . . . . . . 5-12

5.1.4 Flow Model Uncertainty Summary . . . . . . . . . . . . . . . . . 5-13

5.1.5 Selection and Evaluation of Models Using Corroborative Data . . . 5-13

5.2 Transient Groundwater Flow (Central Testing Area Sub-CAU Model) . . . 5 5-24

5.3 Transport Model . . . . . . . . . . . . . . . . . . . . . . . . . . 5-28

5.3.1 Hydrologic Source Term Models . . . . . . . . . . . . . . . . . . 5-28

5.3.1.1 Steady-State CAMBRIC Hydrologic Source Term. . . . . 5-28

5.3.1.2 Transient CAMBRIC Hydrologic Source Term . . . . . . 5-29

5.3.1.3 Simplified Source Term Models . . . . . . . . . . . . . 5-35

5.3.1.4 Simplified Process Models . . . . . . . . . . . . . 5-35

5.3.2 Contaminant Boundary. .................. 5-38

5.3.2.1 Northern Testing Area ................. 5-42

5.3.2.2 Central Testing Area ................... 5-44

5.3.3 Transport Model Uncertainty and Sensitivity . . . . . . . . . . . . 5-46

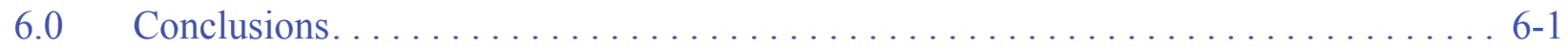

$7.0 \quad$ References. .............................

Appendix A - Phase II CAI Approach to Key Issues of Concern from Phase I External Peer Review

Appendix B - Reference Synopsis

Appendix C - CAU Model Naming Conventions and Comparison Table

Appendix D - Nevada Division of Environmental Protection Comment Responses 


\section{LIST OF FIGURES}

NUMBER

TITLE

PAGE

1-1 Location of the Frenchman Flat Corrective Action Unit . . . . . . . . . . . . . 1-2

1-2 Location of Underground Nuclear Tests in Frenchman Flat . . . . . . . . . . . 1-3

1-3 UGTA Strategy Flow Chart $\ldots \ldots \ldots \ldots \ldots \ldots \ldots \ldots \ldots \ldots \ldots \ldots \ldots \ldots$

3-1 Features of the UGTA Regional Groundwater Flow System. . . . . . . . . . . . . . 3-3

3-2 Overview of the Frenchman Flat Area Physiographic and Groundwater Features . . . . . . . . . . . . . . . . . . . . 3-8

3-3 Conceptual Illustration Phenomenology of an Underground Nuclear Explosion in Competent Rock . . . . . . . . . . . . . . . . . 3-12

3-4 Schematic of Slanted RNM-1 Monitoring Hole, Measured Gamma Intensity Profile, and Measured Aqueous ${ }^{3} \mathrm{H}$ (HTO) Concentration Profiles . . . . . 3-14

4-1 Hydrostratigraphic Unit Surface Map of the Frenchman Flat Model Area . . . . . . 4-4

4-2 Frenchman Flat Hydraulic Property Data Locations . . . . . . . . . . . . . . . . 4-9

4-3 Map Showing the New and the Original Sub-CAU Model Domains along with Selected Wells ...................... 4-14

4-4 Alluvial Aquifer Well Locations and Steady-State Heads . . . . . . . . . . . . . . 4-16

4-5 Volcanic Aquifer and Confining Unit Well Locations and Steady-State Heads . . . 4-17

4-6 Lower Carbonate Aquifer Well Locations and Steady-State Heads . . . . . . . . . 4-18

5-1 Observed Versus Simulated Well Head - BASE-USGSD Flow Model. . . . . . . . . 5-3

5-2 Water-Table Contours for the Calibrated BASE-USGSD Model . . . . . . . . . 5-5

5-3 Calibrated Intrinsic Permeability at the Water Table for the BASE-USGSD Model . . . . . . . . . . . . . . . . . . . . . . 5-6

5-4 Water-Table Contours and Spatial Distribution of Weighted Residuals for the "NHA" Model. .......................... 5-11

5-5 Model Objective Functions Based on Geochemistry Velocity and Flow Angle Observations . . . . . . . . . . . . . . . . . . . 


\section{LIST OF FIGURES (CONTINUED)}

NUMBER

5-6 Null-Space Monte Carlo (NSMC) and Discrete Model Comparison

to Flow Velocity and Direction from Well UE-5 PW-2 to UE-5 PW-1

5-7 Null-Space Monte Carlo (NSMC) and Discrete Model Comparison

to Flow Velocity and Direction from Well UE-5 PW-1 to ER 5-4 . . . . . . . . . 5-19

5-8 Null-Space Monte Carlo (NSMC) and Discrete Model Comparison to Flow Velocity and Direction from WW-5b to WW-5c . . . . . . . . 5-20

5-9 Null-Space Monte Carlo (NSMC) and Discrete Model Comparison to Flow Velocity and Direction from Well UE-5c to ER 5-4. . . . . . . . . 5-21

5-10 Null-Space Monte Carlo (NSMC) and Discrete Model Comparison to Flow Velocity and Direction from Well UE-5 PW-1 to WW-1.

5-11 Cumulative Probability Plot for CAMBRIC Cavity Flux for All Flow Models . .

5-12 Cumulative Probability Plot for NEWPOINT Cavity Flux for All Flow Models . .

5-13 Cumulative Probability Plot for PIN STRIPE Cavity Flux for All Flow Models . .

5-14 Results of RNM-2S MWAT Calibration (a) BASE-USGSD Alternative, (b) BASE-USGSD with no AA/OAA Depth Decay, (c) CPBA-USGSD,

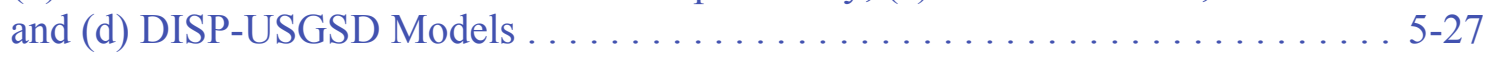

5-15 Schematic of the CAMBRIC Test Area in Frenchman Flat at the NTS . . . . . 5-30

5-16 Calibration of NUFT Model Alluvial Layer Hydraulic Properties

to Tracer Breakthrough (Green Line) to Measured Decay-Corrected

${ }^{3} \mathrm{H}$ Breakthrough Data (Red Circles) at RNM-2S Pumping Well during the RNM Experiment . . . . . . . . . . . . . . . $\ldots \ldots \ldots$

5-17 Comparison of the BASE-USGSD with Alternative Boundary Conditions Model Results to the UE-5n Data (a) Hydraulic Heads

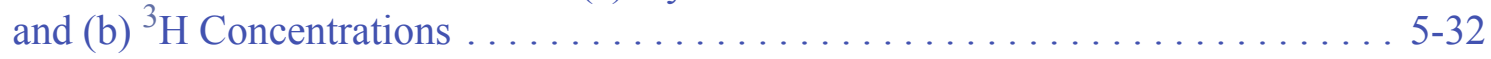

5-18 BASE-USGSD Alternative Model Results: (a) Head Changes and (b) ${ }^{3} \mathrm{H}$ Concentrations after 13,612 days $(08 / 20 / 2002) \ldots \ldots \ldots \ldots$. . . . . . 5-34 


\section{LIST OF FIGURES (CONTINUED)}

NUMBER

5-19 Median Source Term for the BASE-USGSD No Depth Decay, BASE-USGSD with Alternative Calibration, CPBA-USGSD, and DISP-USGSD Flow Models for the DIANA MOON SSM

5-20 Process Model and SSM ${ }^{14} \mathrm{C}$ Breakthrough for the PIN STRIPE and MILK SHAKE Tests . . . . . . . . . . . . . . . . . . . 5-37

5-21 Northern Testing Area Composite of All Northern Testing Area Transport Models Time-Cumulative Contaminant Boundary . . . . . . . . . . . . . 5-44

5-22 Central Testing Area Composite of All Central Testing Area Transport Models Time-Cumulative Contaminant Boundary . . . . . . . . . . . . . . 5-46 


\section{LIST OF PLATES}

NUMBER

TITLE

PAGE

1 Cross Sections for BASE HFM $\ldots \ldots \ldots \ldots \ldots \ldots \ldots \ldots \ldots \ldots \ldots$. . . . . . . . . . . . . . . .

2 HFM Sliced at the Estimated Water Table Showing HSUs and Faults . . . . . . . . Pocket

3 Cross Sections and Plan View for Alternative HFMs

Compared with BASE HFM. . . . . . . . . . . . . . . . . . . . . . . . Pocket 


\section{LIST OF TABLES}

NUMBER

TITLE

PAGE

1-1 Corrective Action Sites in the Frenchman Flat Corrective Action Unit . . . . . . . . 1-4

3-1 Terminology Used To Describe Nuclear Test Cavity and Near-field Environment . . . . . . . . . . . . . . . . . . . . . . . 3-13

3-2 Radionuclide Inventory for Frenchman Flat CAU . . . . . . . . . . . . 3-15

3-3 Estimated Accuracies for Groups of Radionuclides . . . . . . . . . . . . . . 3-16

4-1 Hydrostratigraphic Units of the Frenchman Flat HFM . . . . . . . . . . . . . 4-2

4-2 Summary of Alternative HFMs Considered $\ldots \ldots \ldots \ldots \ldots \ldots \ldots \ldots$

4-3 Summary of Measured Permeability for HSUs

within the Frenchman Flat CAU Model Domain . . . . . . . . . . . . . . . . . 4 4-7

4-4 Total Recharge over the Frenchman Flat Model Area . . . . . . . . . . . . . . . . 4-11

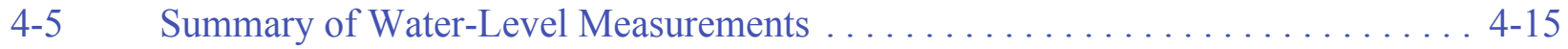

4-6 Required Hydrologic Code Attributes . . . . . . . . . . . . . . . . . . . 4-21

5-1 Radionuclide Regulatory Groups. . . . . . . . . . . . . . . . . . . 5-39

5-2 Activity Concentrations Equal to 4-Millirem-per-Year Dose . . . . . . . . . . . . . 5-39

5-3 Saturated Zone Dimensions of Contaminant Boundary for Each Source . . . . . . . 5-43

A.1-1 Phase II CAI Approach to Key Phase I Concerns . . . . . . . . . . . . . . . . A-1

B.1-1 Frenchman Flat CAIP and Phase II Document UGTA References............. B-1

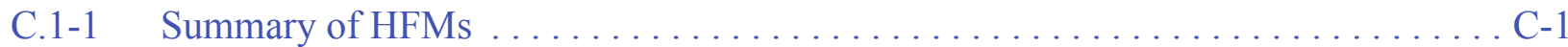

C.1-2 Recharge Models Used for Frenchman Flat Groundwater Flow Modeling . . . . . . C-2

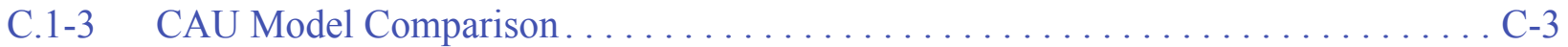




\section{LIST OF ACRONYMS AND ABBREVIATIONS}

\begin{tabular}{|c|c|}
\hline $3-\mathrm{D}$ & Three-dimensional \\
\hline amsl & Above mean sea level \\
\hline BLFA & Basalt lava-flow aquifer alternative HFM \\
\hline $\mathrm{BN}$ & Bechtel Nevada \\
\hline CADD & Corrective action decision document \\
\hline CAI & Corrective action investigation \\
\hline CAIP & Corrective action investigation plan \\
\hline CAP & Corrective action plan \\
\hline CAS & Corrective action site \\
\hline CAU & Corrective action unit \\
\hline CD-ROM & Compact disc-read only memory \\
\hline counts $/ \mathrm{min}$ & Counts per minute \\
\hline CPBA & $\mathrm{CP}$ thrust fault alternative HFM \\
\hline CR & Closure report \\
\hline DETA & Detachment fault alternative HFM \\
\hline DISP & Displacement fault (aquifer juxtaposition) alternative HFM \\
\hline DOE & U.S. Department of Energy \\
\hline DRI & Desert Research Institute \\
\hline DRIA & Desert Research Institute recharge with alluvial mask \\
\hline DRIAE & Desert Research Institute recharge with alluvial and elevation masks \\
\hline DVRFS & Death Valley Regional Ground-Water Flow System \\
\hline EPA & U.S. Environmental Protection Agency \\
\hline FEHM & Finite element heat-mass \\
\hline FFACO & Federal Facility Agreement and Consent Order \\
\hline $\mathrm{ft}$ & Foot \\
\hline HFM & Hydrostratigraphic framework model \\
\hline HST & Hydrologic source term \\
\hline HSU & Hydrostratigraphic unit \\
\hline ID & Identification \\
\hline in. & Inch \\
\hline IT & IT Corporation \\
\hline $\mathrm{K}_{\mathrm{d}}$ & Distribution coefficient \\
\hline $\mathrm{kg} / \mathrm{s}$ & Kilograms per second \\
\hline $\mathrm{km}$ & Kilometer \\
\hline $\mathrm{kt}$ & Kiloton \\
\hline LANL & Los Alamos National Laboratory \\
\hline LLNL & Lawrence Livermore National Laboratory \\
\hline
\end{tabular}




\section{LIST OF ACRONYMS AND ABBREVIATIONS (CONTINUED)}

\begin{tabular}{|c|c|}
\hline $\mathrm{m}$ & Meter \\
\hline $\mathrm{m} / \mathrm{yr}$ & Meters per year \\
\hline $\mathrm{m}^{-1}$ & Inverse meter \\
\hline $\mathrm{m}^{2}$ & Square meter \\
\hline $\mathrm{m}^{3}$ & Cubic meter \\
\hline $\mathrm{m}^{3} / \mathrm{d}$ & Cubic meters per day \\
\hline $\mathrm{mm} / \mathrm{yr}$ & Millimeters per year \\
\hline MME & Modified Maxey-Eakin recharge distribution \\
\hline $\mathrm{mol} / \mathrm{day}$ & Moles per day \\
\hline $\mathrm{mol} / \mathrm{kg}$ & Moles per kilogram \\
\hline $\mathrm{mol} / \mathrm{yr}$ & Moles per year \\
\hline MWAT & Multiple-well aquifer test \\
\hline N/A & Not applicable \\
\hline NAD & North American Datum \\
\hline NDEP & Nevada Division of Environmental Protection \\
\hline NHA & Northern Hydrologic Alternative \\
\hline NNES & Navarro Nevada Environmental Services, LLC \\
\hline NNSA/NSO & $\begin{array}{l}\text { U.S. Department of Energy, National Nuclear Security Administration } \\
\text { Nevada Site Office }\end{array}$ \\
\hline NSMC & Null-space Monte Carlo \\
\hline NSTec & National Security Technologies, LLC \\
\hline NTS & Nevada Test Site \\
\hline NUFT & Nonisothermal Unsaturated-Saturated Flow and Transport \\
\hline OME & Original Maxey-Eakin recharge distribution \\
\hline PEST & Parameter estimation software \\
\hline RNM & Radionuclide migration \\
\hline SD & Standard deviation \\
\hline SDWA & Safe Drinking Water Act \\
\hline SNJV & Stoller-Navarro Joint Venture \\
\hline SSM & Simplified source term model \\
\hline UGTA & Underground Test Area \\
\hline USGS & U.S. Geological Survey \\
\hline USGSD & U.S. Geological Survey recharge with redistribution \\
\hline USGSND & U.S. Geological Survey recharge without redistribution \\
\hline UTM & Universal Transverse Mercator \\
\hline WW & Water Well \\
\hline$\mu \mathrm{Ci} / \mathrm{L}$ & Microcuries per liter \\
\hline
\end{tabular}




\section{LIST OF StRATIGRAPHIC UNIT ABBREVIATIONS AND SYMBOLS}

$\begin{array}{ll}\text { AA, AA1, AA2, AA3 } & \text { Alluvial aquifer } \\ \text { BLFA } & \text { Basalt lava-flow aquifer } \\ \text { CA } & \text { Carbonate aquifer } \\ \text { CCU } & \text { Clastic confining unit } \\ \text { LCA } & \text { Lower carbonate aquifer } \\ \text { LCA3 } & \text { Lower carbonate aquifer-thrust plate } \\ \text { LCCU } & \text { Lower clastic confining unit } \\ \text { LFA } & \text { Lava-flow aquifer } \\ \text { LTCU, LTCU1 } & \text { Lower tuff confining unit } \\ \text { LVTA } & \text { Lower vitric-tuff aquifer } \\ \text { OAA, OAA1 } & \text { Older alluvial aquifer } \\ \text { PCU, PCU2T } & \text { Playa confining unit } \\ \text { PCU1L, PCU1U } & \text { Older playa confining unit } \\ \text { TCU } & \text { Tuff confining unit } \\ \text { Tma } & \text { Ammonia Tanks tuff } \\ \text { TM-LVTA } & \text { Timber Mountain lower vitric-tuff aquifer } \\ \text { Tmr } & \text { Rainier Mesa tuff } \\ \text { TM-WTA } & \text { Timber Mountain welded-tuff aquifer } \\ \text { Tpt } & \text { Topopah Spring tuff } \\ \text { TSA } & \text { Topopah Spring aquifer } \\ \text { UCCU } & \text { Upper clastic confining unit } \\ \text { UTCU } & \text { Upper tuff confining unit } \\ \text { VA } & \text { Volcanic aquifer } \\ \text { VCU } & \text { Volcaniclastic confining unit } \\ \text { VTA } & \text { Vitric-tuff aquifer } \\ \text { WCU } & \text { Welded-tuff aquifer } \\ \text { WTA } & \\ \text { Thmonie confining unit } \\ \text { The }\end{array}$




\section{LIST OF SYMBOLS FOR ELEMENTS AND COMPOUNDS}

\begin{tabular}{|c|c|}
\hline $\mathrm{Al}$ & Aluminum \\
\hline $\mathrm{Am}$ & Americium \\
\hline $\mathrm{Ar}$ & Argon \\
\hline $\mathrm{C}$ & Carbon \\
\hline $\mathrm{Ca}$ & Calcium \\
\hline $\mathrm{Cd}$ & Cadmium \\
\hline $\mathrm{Cl}$ & Chlorine \\
\hline $\mathrm{Cm}$ & Curium \\
\hline Cs & Cesium \\
\hline DIC & Dissolved inorganic carbon \\
\hline $\mathrm{Eu}$ & Europium \\
\hline${ }^{3} \mathrm{H}$ & Tritium \\
\hline Ho & Holmium \\
\hline HTO & Tritiated water \\
\hline I & Iodine \\
\hline $\mathrm{K}$ & Potassium \\
\hline $\mathrm{Kr}$ & Krypton \\
\hline $\mathrm{Nb}$ & Niobium \\
\hline $\mathrm{Ni}$ & Nickel \\
\hline $\mathrm{Np}$ & Neptunium \\
\hline $\mathrm{Pd}$ & Palladium \\
\hline $\mathrm{Pu}$ & Plutonium \\
\hline $\mathrm{Ru}$ & Ruthenium \\
\hline $\mathrm{Sm}$ & Samarium \\
\hline Sn & Tin \\
\hline $\mathrm{Sr}$ & Strontium \\
\hline Tc & Technetium \\
\hline $\mathrm{Th}$ & Thorium \\
\hline $\mathrm{U}$ & Uranium \\
\hline $\mathrm{Zr}$ & Zirconium \\
\hline
\end{tabular}




\subsection{INTRODUCTION}

Underground testing of nuclear weapons in deep vertical shafts and tunnels was conducted from 1951 to 1992 at the Nevada Test Site (NTS), which is approximately 65 miles northwest of Las Vegas, Nevada. The Frenchman Flat area (Figure 1-1), the subject of this overview document, was used for seven years with 10 underground nuclear tests conducted (Figure 1-2). Seven tests were detonated in the northern part of the basin (called the Northern Testing Area), and three were detonated in the central part of the basin (called the Central Testing Area). All underground nuclear tests in Frenchman Flat were conducted in shafts. Shaft nuclear tests were exploded at the bottom of drilled or mined vertical holes (DOE/NV, 1994).

Table 1-1 presents information relative to the 11 corrective action sites in Frenchman Flat. The corrective action sites comprise the 10 underground nuclear tests and a well used for the CAMBRIC radionuclide migration experiment, RNM-2S; see Section 2.2 for more information. All underground nuclear tests conducted in Frenchman Flat, except for two, have yield ranges specified as less than 20 kilotons (kt) (DOE/NV, 2000).

The U.S. Department of Energy (DOE), National Nuclear Security Administration Nevada Site Office (NNSA/NSO) initiated the Underground Test Area (UGTA) Subproject to assess and evaluate radiologic groundwater contamination resulting from underground nuclear testing at the NTS. These activities are overseen by the Federal Facility Agreement and Consent Order (FFACO) (1996, as amended March 2010). For Frenchman Flat, the UGTA Subproject addresses media contaminated by the underground nuclear tests, which is limited to geologic formations within the saturated zone or 100 meters (m) or less above the water table. Transport in groundwater is judged to be the primary mechanism of migration for the subsurface contamination away from the Frenchman Flat underground nuclear tests.

The intent of the UGTA Subproject is to assess the risk to the public from the groundwater contamination produced as a result of nuclear testing. The primary method used to assess this risk is 


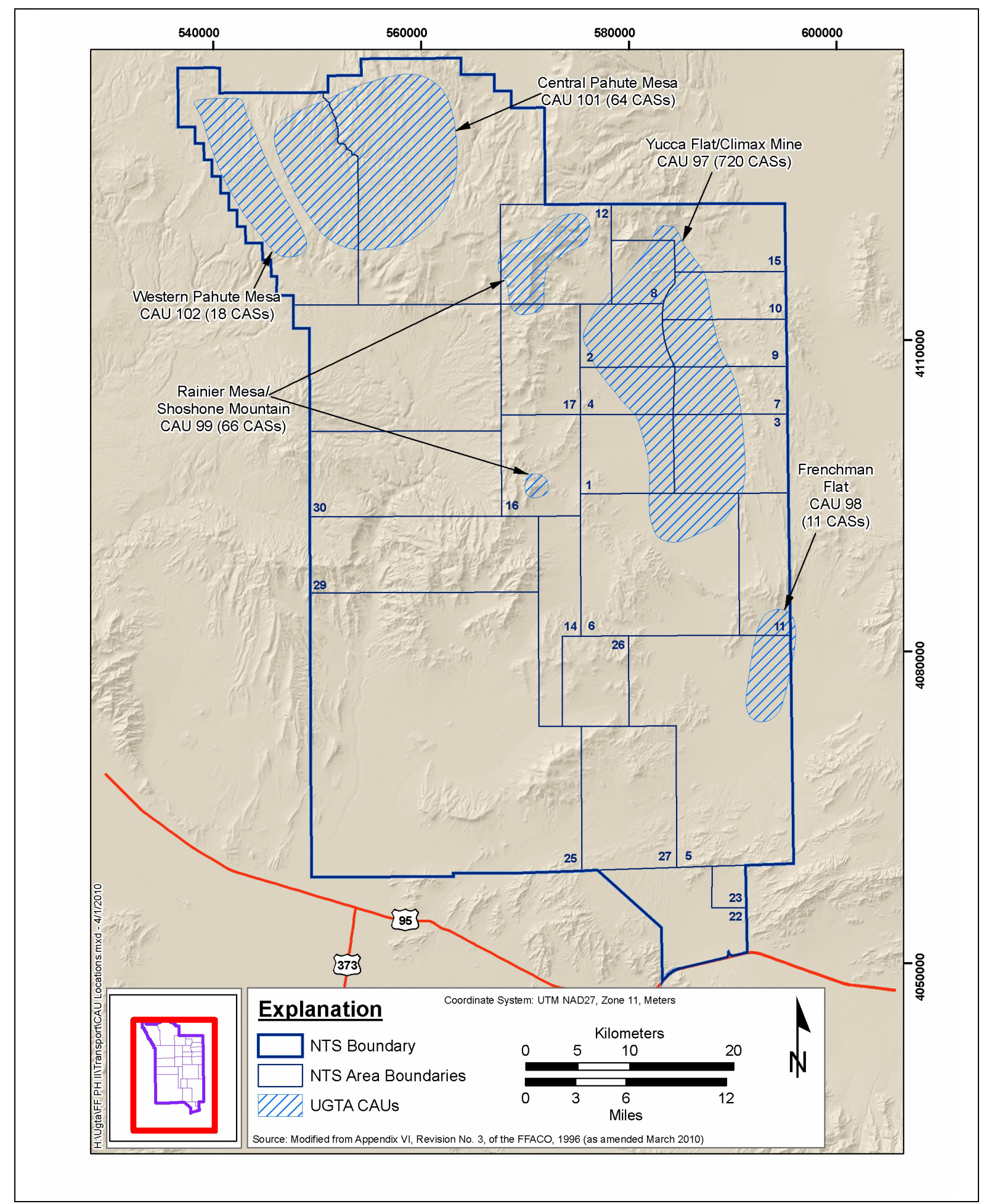

Figure 1-1

Location of the Frenchman Flat Corrective Action Unit 


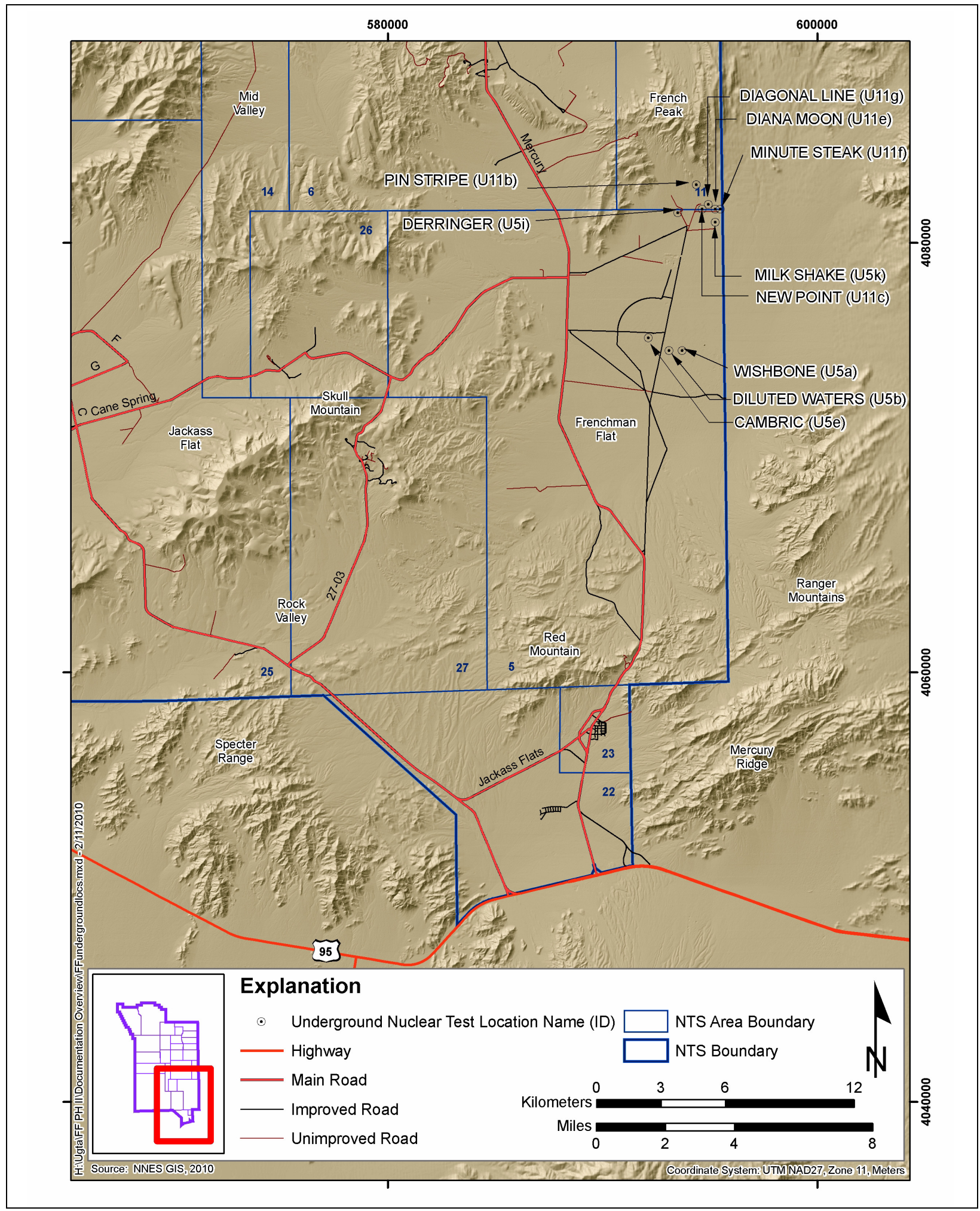

Figure 1-2

Location of Underground Nuclear Tests in Frenchman Flat 
Table 1-1

Corrective Action Sites in the Frenchman Flat Corrective Action Unit

\begin{tabular}{|c|c|c|c|c|c|c|c|c|}
\hline Test Name & $\begin{array}{c}\text { CAS } \\
\text { Number }\end{array}$ & Test Date & $\begin{array}{l}\text { Hole } \\
\text { Name }\end{array}$ & $\begin{array}{l}\text { UTM Zone 11, } \\
\text { NAD } 27 \\
(\mathrm{~m})\end{array}$ & $\begin{array}{c}\text { Yield } \\
\text { Range } \\
\text { (kt) }\end{array}$ & $\begin{array}{l}\text { Hole } \\
\text { Depth } \\
\text { (m) }\end{array}$ & $\begin{array}{c}\text { Surface } \\
\text { Elevation a } \\
\text { (m) }\end{array}$ & $\begin{array}{c}\text { Bottom of Hole } \\
\text { Elevation } \\
\text { (m amsl) }\end{array}$ \\
\hline CAMBRIC & $05-57-003$ & 05/14/1965 & U5e & $\begin{array}{c}\text { E 592142.7 } \\
\text { N } 4075575.4\end{array}$ & 0.75 & 304.8 & 956.2 & 651.4 \\
\hline DERRINGER & $05-57-004$ & 09/12/1966 & U5i & $\begin{array}{c}\text { E 593518.3 } \\
\text { N } 4081415.4\end{array}$ & 7.8 & 249.9 & $1,034.8$ & 784.9 \\
\hline DIAGONAL LINE & $11-57-005$ & $11 / 24 / 1971$ & U11g & $\begin{array}{c}\text { E 594939.1 } \\
\text { N 4081801.6 }\end{array}$ & $<20$ & 277.4 & $1,037.8$ & 760.4 \\
\hline DIANA MOON & $11-57-003$ & 08/27/1968 & U11e & $\begin{array}{c}\text { E 595265.3 } \\
\text { N } 4081581.8\end{array}$ & $<20$ & 254.5 & $1,031.8$ & 777.3 \\
\hline DILUTED WATERS & $05-57-002$ & 06/16/1965 & U5b & $\begin{array}{c}\text { E 593110.1 } \\
\text { N } 4074994.0\end{array}$ & $<20$ & 205.7 & 943.4 & 737.7 \\
\hline MILK SHAKE & $05-57-005$ & 03/25/1968 & U5k & $\begin{array}{c}\text { E 595267.2 } \\
\text { N 4080972.3 }\end{array}$ & $<20$ & 275.7 & $1,020.8$ & 745.0 \\
\hline NEW POINT & $11-57-002$ & $12 / 13 / 1966$ & U11c & $\begin{array}{c}\text { E } 594655.9 \\
\text { N } 4081579.7\end{array}$ & $<20$ & 559.3 & $1,030.5$ & 471.2 \\
\hline MINUTE STEAK & $11-57-004$ & 09/12/1969 & U11f & $\begin{array}{c}\text { E 595494.8 } \\
\text { N 4081584.4 }\end{array}$ & $<20$ & 277.4 & $1,034.2$ & 756.8 \\
\hline WISHBONE & $05-57-001$ & 02/18/1965 & U5a & $\begin{array}{c}\text { E } 593719.6 \\
\text { N } 4074996.1\end{array}$ & $<20$ & 191.4 & 940.6 & 749.2 \\
\hline PIN STRIPE & $11-57-001$ & $04 / 25 / 1966$ & U11b & $\begin{array}{c}\text { E } 594386.2 \\
\text { N } 4082708.0\end{array}$ & $<20$ & 298.7 & $1,093.0$ & 794.3 \\
\hline RNM-2S Well b,c & $05-20-02$ & N/A & RNM-2S & $\begin{array}{c}\text { E 593528.7 } \\
\text { N } 4074490.0\end{array}$ & $\mathrm{~N} / \mathrm{A}$ & 352.4 & 954.2 & 601.8 \\
\hline
\end{tabular}

Source: Modified from SNJV, 2005d

a Updated from information in DOE/NV, 2000

${ }^{\mathrm{b}}$ Elevation data from SNJV, 2004c and 2006.

${ }^{6 N M-2 S}$ Well was not an underground nuclear test; this CAS was used for the CAMBRIC radionuclide experiment.

amsl = Above mean sea level

$\mathrm{NAD}=$ North American Datum

CAS $=$ Corrective action site

UTM = Universal Transverse Mercator

$\mathrm{N} / \mathrm{A}=$ Not applicable 
the development of models of flow and contaminant transport to forecast the extent of potentially contaminated groundwater for the next 1,000 years, establish restrictions to groundwater usage, and implement a monitoring program to verify protectiveness. For the UGTA Subproject, contaminated groundwater is that which exceeds the radiological standards of the Safe Drinking Water Act (CFR, 2009) the State of Nevada's groundwater quality standard to protect human health and the environment. Contaminant forecasts are expected to be uncertain, and groundwater monitoring will be used in combination with land-use control to build confidence in model results and reduce risk to the public.

Modeling forecasts of contaminant transport will provide the basis for negotiating a compliance boundary for the Frenchman Flat Corrective Action Unit (CAU). This compliance boundary represents a regulatory-based distinction between groundwater contaminated or not contaminated by underground testing. Transport modeling simulations are used to compute radionuclide concentrations in time and space within the CAU for the 1,000-year contaminant boundary. These three-dimensional (3-D) concentration simulations are integrated into probabilistic forecasts of the likelihood of groundwater exceeding or remaining below the radiological standards of the Safe Drinking Water Act (CFR, 2009) defined as the contaminant boundary. Contaminant boundaries are not discrete predictions of the location or concentration of contaminants, but instead are spatial representations of the probability of exceeding Safe Drinking Water Act radiological standards. The forecasts provide planning tools to facilitate regulatory decisions designed to protect the health and safety of the public.

A compliance boundary will be negotiated between the Nevada Division of Environmental Protection (NDEP) and NNSA/NSO for the Frenchman Flat CAU. Monte Carlo analysis of multiple models is used to generate an ensemble of contaminant boundary forecasts (see Section 5.3). The ensemble of contaminant boundary forecasts for the CAU will provide the initial technical basis for negotiation of the compliance boundary. The NNSA/NSO must demonstrate with an acceptable level of confidence (reasonable expectation), gained through implementation of the UGTA corrective action strategy, that groundwater outside the compliance boundary meets the radiological standards of the Safe Drinking Water Act (CFR, 2009). 
This document summarizes and provides linkages among the data collection and modeling activities - and associated technical reports - that have been completed for the Frenchman Flat area in support of the Subproject and FFACO goals. This document does not present new information, but instead provides a synopsis of more than 50 years of characterization and modeling activities and how these activities support the UGTA Subproject objectives and, specifically, the Phase II Corrective Action Investigation (CAI), which was initiated in 2001.

\subsection{Corrective Action Strategy}

The development of a flow and contaminant transport model for Frenchman Flat is a key element of the FFACO (1996, as amended March 2010) corrective action strategy. The model, in its entirety, is a group of interdependent models developed by numerous project participants (NNSA/NV, 2001). The site-scale flow model, presented by Stoller-Navarro Joint Venture (SNJV) (2006), incorporated data from multiple component models (e.g., geologic framework, recharge, groundwater flow) for the Frenchman Flat hydrogeologic system. The transport analysis (NNES, 2010) incorporated the flow-model simulated heads and flows, along with additional data on radionuclide transport and source term, to create a transport model. The flow and transport modeling analyses recognized the uncertainty inherent in the complex basin setting and the 1,000-year time frame of the analysis.

The corrective action strategy for the UGTA Subproject is defined in Appendix VI of the FFACO (1996, as amended March 2010) as follows:

1. Identifying corrective action sites that may require attention.

2. Grouping these corrective action sites into CAUs, which are grouped geographically, by technical similarity or agency responsibility, or for other appropriate reasons.

3. Prioritizing the CAUs for funding and work.

4. Implementing the CAIs and/or corrective actions, as applicable.

Under this corrective action strategy, the UGTA Subproject focuses on corrective action sites with "local or regional impacts to groundwater resources." Corrective action activities are implemented through a four-stage approach (Figure 1-3):

1. The corrective action investigation plan (CAIP) stage

2. The corrective action investigation (CAI) stage 


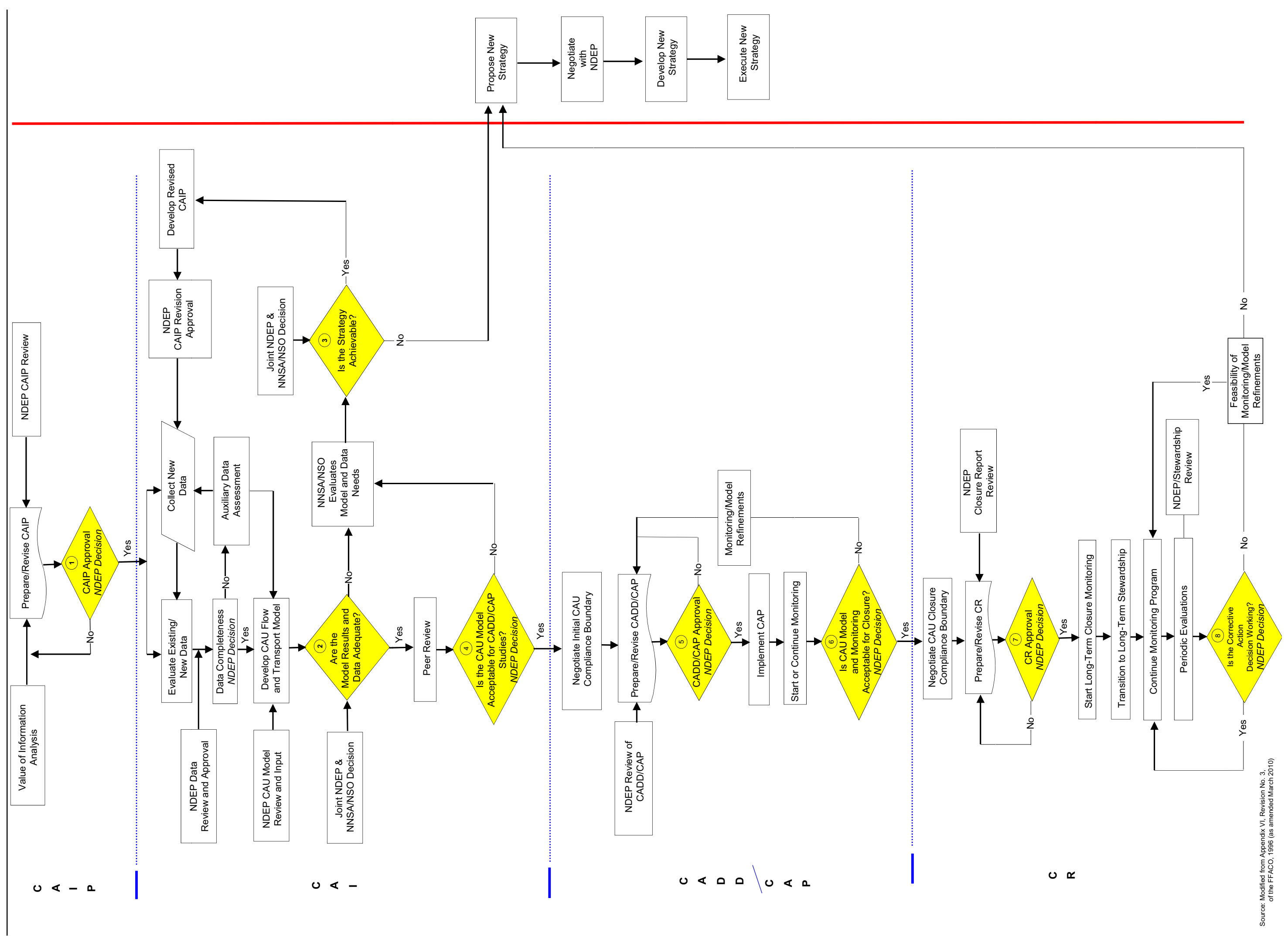


3. The corrective action decision document (CADD)/corrective action plan (CAP) stage

4. The closure report (CR) stage

The technical basis for achieving the UGTA strategy is through an evaluation of each CAU using a combination of approaches, including:

- Collecting data that consist of, but are not limited to, drilling exploration, hydrologic testing, and field and laboratory studies designed to characterize the hydrogeological setting.

- Modeling the hydrogeological setting, the radiological source term, and flow and contaminant transport to forecast areas of current and future contamination for 1,000 years.

- Conducting iterative model evaluations and groundwater monitoring near and downgradient of areas of past underground testing.

- Identifying and documenting land-use policies (institutional controls) designed to restrict future public access to groundwater contaminated by underground testing.

The integration and balancing of modeling studies, monitoring, and institutional control provide the foundation for regulatory decision making. This approach is consistent with guidance on the use of models in environmental regulatory decision making (NRC, 2007; EPA, 2009) and uses an in-depth approach to achieve strategic objectives. Confidence in model results leading to their eventual use in regulatory decisions will be developed through model evaluation and monitoring studies (CADD/CAP phase), and the uncertainty in model forecasts will be managed through institutional control of areas of forecast groundwater contamination (CR phase).

Presently, the UGTA Subproject for the Frenchman Flat area has completed the CAI phase of the strategy. Sufficient confidence has been developed in the models to conduct an external peer review as part of the process of model evaluation and provides an opportunity to gain confidence in the model forecast as the UGTA Subproject moves into different phases of the strategy. A multicomponent strategy has been adopted for the model evaluation that will include external peer review as well as data collection monitoring that is designed to test the model results. The goal of the external peer review is to provide technical evaluation of the studies and assist in assessing the readiness of the UGTA Subproject to initiate monitoring activities for further model evaluation. Functionally, model evaluation for Frenchman Flat has been an ongoing process that has included regular review and adjustments in approach by the model developers and through an internal review 
process. The internal reviews are conducted by knowledgeable scientists with site-specific understanding from organizations including:

- U.S. Geological Survey (USGS)

- Lawrence Livermore National Laboratory (LLNL)

- National Security Technologies, LLC (NSTec)

- Los Alamos National Laboratory (LANL)

- Nevada Division of Environmental Protection (NDEP)

- $\quad$ Desert Research Institute (DRI)

In addition to the external peer review, other model evaluation activities will be undertaken, including additional data collection and monitoring within the model area. These activities are in the initial planning stages with the expectation that monitoring wells will be installed during fiscal year 2012.

\subsection{Preliminary Remediation Strategies}

The UGTA strategy as documented in the FFACO (1996, as amended March 2010) assumes active remediation is neither cost-effective nor technically achievable with current technology. As a result, closure for the Frenchman Flat CAU is expected to be based on a combination of characterization and modeling studies, monitoring, and institutional controls.

An evaluation of selected remedial alternatives for the UGTA Subproject was conducted using standard approaches accepted by the U.S. Environmental Protection Agency (EPA) for assembling, screening and cross-comparing remediation alternatives (DOE, 1997). The EPA screening matrix guide (EPA, 1994) was used to identify five reasonable remedial alternatives, and each alternative was evaluated against cost criteria, and criteria for effectiveness and practicality of implementation, including qualitative assessments of worker safety and radiation exposure (note that all remediation costs are reported in 1996 dollars). These alternatives are:

- No Action Alternative

- Intrinsic Remediation Alternative - Natural Attenuation

- Institutional Control

- Pump and In Situ Treatment

- Excavation, Physical Separation/Chemical Extraction, and On-Site Disposal 


\section{No Action Alternative}

A no action alternative was evaluated in the 1996 Environmental Impact Statement (DOE/NV, 1996) using a baseline risk assessment. This assessment assumes no remedial actions or degradation of the contaminant sources generated from underground testing. Peak concentrations of tritium in plumes were used for a maximally exposed member of the public, drinking water from a contaminated aquifer. The probabilities of lifetime cancer mortality and other detrimental effects were calculated and compared with the EPA risk metrics of $10^{-4}$ to $10^{-6}$ per person increase in fatal cancer development. The lifetime probability of a fatal cancer and other detrimental effects both exceed the $10^{-4}$ limit per person. The no action alternative was identified as a non-viable alternative, and no further analyses were conducted.

\section{Intrinsic Remediation Alternative - Natural Attenuation}

This alternative evaluates natural subsurface processes of decay, dilution, volatilization, adsorption, and chemical reactions with subsurface materials, leading to reduction in contaminant concentrations sufficient to be protective of human health and the environment. Maximum estimated costs for the alternative are $\$ 220$ million to $\$ 240$ million for all CAUs.

\section{Institutional Control}

This approach assumes passive and active approaches would be used to restrict public access to contaminated groundwater recognizing that federal regulations may prohibit institutional controls as a sole remedy (CFR, 1996). This option is assumed to be technically feasible based on the more than 50-year experience with controlling access to the NTS. Estimated costs for institutional control over 50 years are $\$ 760$ million for access control and $\$ 119$ million for infrastructure maintenance (installation and maintenance of a perimeter fence) for all CAUs. This remedial alternative does not consider the current UGTA strategy, which proposes a balanced incorporation of institutional controls in combination with characterization and modeling studies and evaluation and closure monitoring.

\section{Pump and In Situ Treatment}

Three options were evaluated for the pump and treatment alternative. The first two assume use of recovery wells to capture groundwater at each corrective action site and treatment by in situ injection 
through the unsaturated zone of the collapse chimney. The cost of removal of radionuclides from groundwater before reinjection is also assessed. The third option withdraws uncontaminated groundwater upgradient from tests and transports the water downgradient before reinjection. The alternative assumes no withdrawal of contaminated water. Concerns were identified for the capture/injection options with limited retardation of non-sorbing radionuclides (except tritium), worker radiation exposure and the capture/injection system would have to remain active in perpetuity to achieve remediation. The specifications for estimations of the life cycle costs of the three options are provided in the alternative remediation options report (DOE, 1997, pp. 5-58 to 5-61). Aggregate cost for the three options implemented for all CAUs range from $\$ 1.4$ billion to $\$ 2.5$ billion.

\section{Excavation, Physical Separation/Chemical Extraction, and On-Site Disposal}

Two alternative approaches (braced-shaft excavation or open-pit mining) were evaluated for excavation of contaminated rock from the test cavities, treatment, and re-disposal. Significant health and safety concerns associated with construction and radiation exposure were identified for both approaches. Estimated costs are at least $\$ 3.7$ trillion for braced-shaft excavation and disposal, and $\$ 6.2$ trillion for open-pit excavation and waste treatment for all CAUs.

The exceptionally high costs of the final two remedial alternatives make them effectively non-viable, and the no action and institutional control alternatives are judged to be individually unacceptable. The UGTA Subproject strategy assumes that a combination of characterization and modeling studies, monitoring, and institutional controls will lead to site closure (FFACO, 1996; as amended March 2010). This strategy includes elements of both the institutional control and intrinsic remediation option as recommended in the alternative remediation options report (DOE, 1997, p. 8-1). 


\subsection{BACKGROUND}

\subsection{Operational History of Underground Nuclear Tests on Frenchman Flat}

The first series of underground nuclear tests detonated in Frenchman Flat in 1965 comprised WISHBONE, CAMBRIC, and DILUTED WATERS under Operation Whetstone (Figure 1-2). The second series of tests detonated in 1966 comprised PIN STRIPE under Operation Flintlock, and DERRINGER and NEW POINT under Operation Latchkey (Figure 1-2).

After NEW POINT, underground nuclear testing on Frenchman Flat stopped and did not resume until March 25, 1968, when the MILK SHAKE test was detonated under Operation Crosstie.

DIANA MOON was then conducted under Operation Bowline on August 27, 1968. The last two tests conducted in Frenchman Flat were MINUTE STEAK and DIAGONAL LINE (Figure 1-2). MINUTE STEAK was detonated on September 12, 1969. DIAGONAL LINE, which was the last underground nuclear test conducted in Frenchman Flat, was detonated on November 24, 1971.

All tests were detonated in the alluvium except for PIN STRIPE, which was detonated within vitric tuff. Five of the tests were detonated near or at the alluvium/Tertiary sediments contact. As a result, their cavities may span both the alluvium and volcanic units. All of the Frenchman Flat tests were conducted above but near the water table, except for CAMBRIC, which was detonated $77 \mathrm{~m}$ below the water table.

\subsection{Radionuclide Migration Experiment}

The CAMBRIC radionuclide migration (RNM) experiment was initiated in 1974 to provide data on the migration of radionuclides away from the site of the CAMBRIC underground nuclear test. One well drilled in support of the RNM experiment, RNM-1, was slant-drilled through the radioactive debris and cavity formed by the CAMBRIC test. Another well, RNM-2S, was installed $91 \mathrm{~m}$ south of the center of the CAMBRIC detonation point. Groundwater flow from the detonation point to Well RNM-2S was induced by pumping Well RNM-2S from October 1975 to August 1991 (Bryant, 1992). 
Pumping was necessary to produce an artificial gradient so that water would move to Well RNM-2S in a reasonable length of time. Approximately $1.7 \times 10^{7}$ cubic meters $\left(\mathrm{m}^{3}\right)$ of water was discharged during this radionuclide migration experiment (Finnegan and Thompson, 2002). A multiple-well aquifer test (MWAT) was later conducted (April 10 to November 11, 2003) in order to acquire data for use in estimating hydraulic properties of the alluvium in the vicinity of Well RNM-2S (SNJV, 2004a). Well RNM-2S was pumped continuously for a period of 75 days at an average rate of 595.5 gallons per minute. Groundwater characterization samples were collected from Well RNM-2S by SNJV, LLNL, and LANL at the beginning and again at the end of this test. Radiological groundwater samples are still collected from one of the observation holes (UE-5n) for long-term monitoring purposes.

\subsection{Corrective Action Investigation Project History}

Investigations of the geology and hydrogeology of Frenchman Flat and the surrounding region have taken place from the early 1950 s to the present. These studies range in scope from investigations that encompass all of the NTS, to studies of individual exploratory holes associated with specific tests in Frenchman Flat. Investigative methods include geologic mapping, geophysical mapping and logging, analysis of water chemistry, and hydraulic testing.

In 1999, a corrective action investigation plan (DOE/NV, 1999a) was approved by NDEP that provided the data collection and modeling guidelines for the Phase I CAI for Frenchman Flat. The Phase I CAI for Frenchman Flat included hydrologic and transport data compilation, analysis, and model development. During the Phase I CAI, data from the Frenchman Flat area were compiled from both regional and local data sources. The CAI strategy for Frenchman Flat was predicated on the assumption that no new data would be collected to characterize the site before the Phase I CAU groundwater flow and contaminant transport modeling. The Phase I CAI was completed during 1999.

For the Phase I investigation, geologic information was obtained from the Nevada state geologic map (Stewart and Carlson, 1978) and USGS geologic quadrangle maps as well as several studies that covered the NTS and surrounding areas (Sinnock, 1982; Ponce et al., 1988; and Wahl et al., 1997). These studies provided stratigraphic and structural geologic data on a regional basis. Using the data from these sources as well as others, the then Environmental Restoration contractor (IT Corporation 
[IT]) in cooperation with several other organizations developed a regional geologic model for the NTS (IT, 1996e). Other studies provided geologic data related to specific areas of Frenchman Flat, including Poole (1964 and 1965); Carr et al. (1975); Istok et al. (1994); Reynolds Electrical \& Engineering Co., Inc. (1994); Blout et al. (1995); Drellack (1995); and Grauch and Hudson (1995). In addition to these studies, USGS prepared geologic maps for all of the topographic quadrangles within the Frenchman Flat study area. Detailed geologic logs and stratigraphic data were available from several studies of individual exploratory drill holes associated with specific nuclear tests conducted in Frenchman Flat: Meyer and Young (1962), Dixon et al. (1965 and 1967), Fernald et al. (1965), Prather (1965), Byers and Miller (1966), Miller et al. (1967), Howard (1976), and Ramspott and McArthur (1977). Although these studies provided very detailed information, they were limited to the depth of the particular borehole being logged, which in most cases was terminated in the weakly to moderately consolidated alluvial material.

The hydrogeologic studies also ranged from specific areas of Frenchman Flat to regional in scope. Such studies included those of Eakin et al. (1951), Winograd and Thordardson (1975), Borg et al. (1976), Buddemeier (1988), Buddemeier and Hunt (1988), Arteaga et al. (1991), Marsh (1991 and 1992), and Chapman et al. (1995). Some hydrologic studies were conducted within Frenchman Flat at exploratory drill hole locations: Meyer and Young (1962) and Prather (1965). As noted with the site-specific geologic studies, the hydrologic studies completed at exploratory drill hole locations were limited to providing data within alluvium and volcanic units. No hydrologic information was provided for the deeper bedrock units except at the edges of the Frenchman Flat basin where they outcrop. A 1996 report (Laczniak et al., 1996) summarized the hydrogeologic controls of groundwater flow at the NTS. Among the first studies produced by the UGTA Subproject was the NTS regional groundwater flow model (IT, 1996a through e; DOE/NV, 1997; IT, 1997a and b). This regional, hydrogeologic model was developed to evaluate the NTS underground test areas including Frenchman Flat.

The majority of groundwater quality and radiologic chemistry data for the Phase I investigation was related to broad NTS studies such as Borg et al. (1976); Daniels (1981, 1982, and 1983); Daniels and Thompson (1984); Thompson (1991); and Marsh (1992). Site-specific water chemistry data were mostly related to the CAMBRIC experiment that began in 1974 and was completed in 1991. CAMBRIC experiment studies included Hoffman et al. (1977), Bryant (1992), and Travis et al. 
(1983). Although some studies have dealt with migration of various radionuclides, no assessment of human health risk was completed for the Frenchman Flat area. A regional risk assessment of the UGTA Subproject sites was completed as part of the regional model studies in 1997 (DOE/NV, 1997).

After the completion and documentation of the Phase I work, comprehensive internal and external peer reviews were conducted. The results of these reviews identified and documented deficiencies in the Phase I work, and a decision was made to archive the Phase I work and initiate a second phase of the CAI including data collection and new modeling approaches.

The findings of the external peer review were documented in External Peer Review Group Report on Frenchman Flat Data Analysis and Modeling Task, Underground Test Area Project (IT, 1999a).

This peer review document recommended addressing key concerns by identifying general and specific data enhancement and data acquisition needs; incorporating alternative conceptual models to evaluate potential transport scenarios; changing the modeling approach from finite-difference to one that uses a finite-element platform to better address discrete geologic features (e.g., faults and fracture zones); and developing and applying uncertainty analysis techniques applicable to the scale of transport (see Appendix A).

The internal peer review results were documented in Lessons Learned from the Frenchman Flat Corrective Action Groundwater Flow and Radionuclide Transport Model (IT, 2000). This lessons-learned document concluded that the Phase I Frenchman Flat CAU model was a good first model of groundwater flow and radionuclide transport at the CAU scale. The modeling successfully represented the flow system as defined in the conceptual model and predicted limited radionuclide travel distances. However, the work was not complete, did not include assessment of alternative model components and their uncertainty and, as recommended by the peer reviews, needed refinement. Summary comments from the Phase I peer review and the Phase II approach to addressing these comments are provided in Appendix A.

The Addendum to Revision 1 of the Corrective Action Investigation Plan for Corrective Action Unit 98: Frenchman Flat, Nevada Test Site, Nevada (NNSA/NV, 2001) detailed the new data collection and modeling activities to address the documented deficiencies in the Phase I Frenchman Flat CAI and was the initiation of the Phase II CAI. 
Phase II investigations have included site-specific data collection activities, development of new groundwater flow and contaminant transport models, and the explicit incorporation of conceptual and parametric uncertainty in modeling analyses. The Phase II investigations were conducted by numerous UGTA Subproject participants, including USGS, DRI, Bechtel Nevada (BN), SNJV, LANL, LLNL, Navarro Nevada Environmental Services, LLC (NNES), and NSTec.

Phase II data collection activities included well drilling, geophysical investigations, and hydrogeologic and geochemical investigations. The Phase II exploration data significantly increased the thickness of the alluvial fill in the basin and the thickness and spatial extent of volcanic hydrostratigraphic units (HSUs) in the vicinity of the underground tests. The exploration studies assisted in the identification of alternative geologic framework models for the Frenchman Flat basin, increased the transport parameter database for Frenchman Flat, and provided geochemical data for use in testing alternative conceptual models for flow in the basin. A list of applicable site-specific, NTS (regional), and UGTA Subproject documents for the Frenchman Flat CAU with brief descriptions of applicable content is provided in Appendix B.

\section{Phase II site-specific data reports include:}

- Analysis of Water Levels in the Frenchman Flat Area, Nevada Test Site (Bright et al., 2001)

- Preliminary Gravity Inversion Model of Frenchman Flat Basin, Nevada Test Site, Nevada (Phelps and Graham, 2002)

- Alluvial Layering and Distribution of Reactive Phases within Drill Holes ER5/4 and UE5N of Frenchman Flat (Warren et al., 2002)

- Evaluation of Cesium, Strontium, and Lead Sorption, Desorption, and Diffusion in Volcanic Tuffs from Frenchman Flat, Nevada Test Site: Macroscopic and Spectroscopic Investigations (Papelis and Um, 2003)

- Integrated Analysis Report for Single- and Multiple-Well Aquifer Testing at Frenchman Flat Well Cluster RNM-2s, Nevada Test Site, Nevada (SNJV, 2004a)

- Interpretation of Hydraulic Test and Multiple-Well Aquifer Test Data at Frenchman Flat Well Cluster ER-5-3 (SNJV, 2004b)

- Phase II Hydrologic Data for the Groundwater Flow and Contaminant Transport Model of Corrective Action Unit 98: Frenchman Flat, Nye County, Nevada (SNJV, 2004c) 
- Phase II Contaminant Transport Parameters for the Groundwater Flow and Contaminant Transport Model of Corrective Action Unit 98: Frenchman Flat, Nye County, Nevada (SNJV, 2005b)

- Letter Report: Analysis of Hydraulic Conductivity and Fracture Porosity in ER-5-3\#2 and ER-5-4\#2 Based on Fracture Data from Borehole Image Logs with Implications for the Tuff Confining Unit Flow Framework, Nevada Test Site, Nevada (SNJV, 2005c)

- Underground Test Area Fracture Analysis Report for Frenchman Flat Well Clusters ER-5-3 and ER-5-4, Nevada Test Site, Nevada (SNJV, 2005e)

- Evaluation of Groundwater Movement in the Frenchman Flat CAU Using Geochemical and Isotopic Analysis (Hershey et al., 2005)

- Site Characterization and Monitoring Data from Area 5 Pilot Wells, Nevada Test Site, Nye County, Nevada (BN, 2005b)

\section{Phase II site-specific modeling reports include:}

- Modeling Approach for Corrective Unit 98, Frenchman Flat (IT, 2001)

- Geostatistical Analysis of Spatial Variability of Mineral Abundance and $K_{d}$ in Frenchman Flat, NTS, Alluvium (Carle et al., 2002)

- Methods for Calculating a Simplified Hydrologic Source Term for Frenchman Flat: Sensitivity Studies of Radionuclide Transport Away from Underground Nuclear Tests (Tompson et al., 2004)

- A Hydrostratigraphic Framework Model and Alternatives for the Groundwater Flow and Contaminant Transport Model of Corrective Action Unit 98: Frenchman Flat, Clark, Lincoln and Nye Counties, Nevada (BN, 2005a)

- Unclassified Source Term and Radionuclide Data for Corrective Action Unit 98: Frenchman Flat Nevada Test Site, Nevada (SNJV, 2005d)

- Evaluation of the Non-Transient Hydrologic Source Term from the CAMBRIC Underground Nuclear Test in Frenchman Flat, Nevada Test Site (Tompson et al., 2005)

- Phase II Groundwater Flow Model of Corrective Action Unit 98: Frenchman Flat, Nye County, Nevada (SNJV, 2006)

- Addendum to the Phase II Groundwater Flow Model of Corrective Action Unit 98: Frenchman Flat, Nevada Test Site, Nye County, Nevada (SNJV, 2007) 
- Evaluation of the Transient Hydrologic Source Term for the Cambric Underground Nuclear Test at Frenchman Flat, Nevada Test Site (Carle et al., 2007)

- Phase II Transport Model of Corrective Action Unit 98: Frenchman Flat, Nevada Test Site, Nye County, Nevada (NNES, 2010)

The Phase II CAI approach includes incorporating old and newly collected data into an uncertainty framework that attempts to quantify the impact of data and conceptual uncertainty throughout the modeling process to forecast the contaminant boundary. This is accomplished through development of alternative interpretations of the geologic framework (BN, 2005a) that are translated into flow and transport models, water balance uncertainty via alternative recharge models in regional models (SNJV, 2006), flow and transport model parameters (SNJV, 2004c and 2005b), and alternative conceptualizations of parameter assignment in flow and transport models (SNJV, 2006; NNES, 2010). Monte Carlo analysis of multiple models is used to generate an ensemble of contaminant boundary forecasts (NNES, 2010) (see Section 4.0 for more information). The documents produced during the Phase II CAI represent an evolving process of data collection, data analysis, and modeling activities. In several instances, modeling activities resulted in additional insight into data and indicated that additional and sometimes reworked data analyses were appropriate; therefore, some data interpretations have evolved during the Phase II investigation.

Early work during the Phase II CAI relied on the strategy presented in the FFACO (1996) that assumed modeling was the primary work required to complete the investigation and that completion of the CAI would result in site closure and compliance monitoring. Model validation under the FFACO (1996) (called model verification) preceded closure. Difficulties in implementing the original UGTA strategy included:

- Structured and sequenced modeling steps with limited flexibility to adapt to the process of scientific discovery inherent in studies of complex environmental systems.

- Insufficient assessment of the impacts of uncertainty.

- Regulatory overview was not integrated into all of the stages.

- Uncertainty reduction and the ability to achieve regulatory goals are based entirely on modeling studies. 
The following changes and updates were implemented in the revised UGTA strategy (FFACO, 1996; as amended March 2010) with full involvement and review by NDEP, and are the foundation for the Phase II CAI model evaluation summarized in this overview document:

- Modeling studies are divided into the three overlapping categories of model development, model evaluation, and model application.

- Modeling studies follow an iterative process that is integrated with site characterization studies, are guided by sensitivity and uncertainty analysis, and are focused on the decision requirements. Model refinements continue through all stages of the corrective action strategy, including long-term monitoring.

- There is increased reliance on monitoring to test, refine, and confirm model results and to build confidence that model results can be used in regulatory decisions.

- Institutional controls are used to restrict public access to contaminated groundwater and reduce risk to public health and the environment.

This updated strategy reflects the evolving approach to the Frenchman Flat CAI, where modeling is recognized as an uncertain tool that guides problem solving and supports regulatory decisions.

Modeling studies are designed to evaluate uncertainty and its impact on regulatory decisions, but the regulatory decision is supported by model evaluation, monitoring, and institutional controls in the $\mathrm{CADD} / \mathrm{CAP}$ and $\mathrm{CR}$ stages. 


\subsection{Conceptual Model}

\subsection{Geologic Setting}

Frenchman Flat is a closed intermontane basin located in the Basin and Range physiographic province. As is typical for much of the Basin and Range province, the geology of Frenchman Flat and vicinity is diverse and complex. The oldest rocks in the area are Paleozoic carbonate rocks that compose the highlands along the eastern and southern margins of the basin (see Plate 1). These rocks form the regional aquifer and are interpreted to underlie the entire model area. The Paleozoic rocks show intense compressional deformation in the form of overturned folds and thrust faults. This compressional deformation has been overprinted by extensive normal and strike-slip faulting associated with basin-and-range extension.

The Paleozoic rocks are unconformably overlain by Tertiary volcanic rocks and tuffaceous sedimentary rocks that compose most of the highlands along the western and northern margins of the basin (see Plate 1). The lower portion of the Tertiary section is dominated by fine-grained sedimentary and tuffaceous sedimentary rocks and zeolitic nonwelded tuffs that form a thick and extensive confining unit. The upper portion of the Tertiary section includes welded ash-flow tuffs that form important volcanic aquifers beneath the northern and central portions of the basin. The Tertiary rocks are offset and tilted by numerous basin-and-range normal and strike-slip faults.

Alluvial debris shed from the surrounding highlands during basin development buries the older Tertiary and Paleozoic rocks in much of the area. This alluvium is more than 1,220 m thick beneath the central portion of Frenchman Flat, where it forms a thick alluvial aquifer on top of the volcanic rocks. Basalt flows 8.5 million years old are intercalated within the alluvium in the northern portion of the basin. The topographically low point of the basin is occupied by the Frenchman Lake playa, which is composed of silt and clay (see Plate 1). 
The Frenchman Flat basin is best described as an east-tilted, half graben, pull-apart basin. The basin is separated from the west-tilted Yucca Flat extensional basin to the north by the French Peak accommodation zone that generally coincides with the volcanic highlands that form the northern margin of Frenchman Flat. The formation of Frenchman Flat appears to be directly related to the northeastern termination of the Rock Valley fault zone within an extensional imbricate fan (BN, 2005a). The formation of this fan structure has resulted in a series of oblique-slip faults that flare out to the north and northwest from the Rock Valley fault zone. These faults drop the basin down along the south, east, and north, forming an east-tilted, half-graben-type basin beneath the central portion of Frenchman Flat and a structural platform beneath the northern portion. A large buried east-west striking, down-on-the-south normal fault marks the northern structural margin of the basin. This fault shallows with depth, and forms a zone of detachment near the contact between Tertiary volcanic and Paleozoic carbonate rocks (BN, 2005a). The main period of basin development appears to have begun between 11.45 and 9.14 million years ago, and may continue into the present (BN, 2005a).

\subsection{Regional Groundwater Flow}

Within the NTS region, groundwater occurs in alluvial, volcanic, and carbonate rocks. Saturated alluvial deposits and Tertiary volcanic rocks are present in central and southern Yucca Flat, Frenchman Flat, and Jackass Flats on the NTS, and in the basins located throughout the flow system (Figure 3-1). The distribution and thickness of alluvial and volcanic aquifers are highly variable throughout the region. In most instances, an alluvial aquifer is confined to a basin by surrounding mountain ranges. In some basins, alluvial aquifers are discontinuous due to structural controls elevating the bottom of the alluvium above the water table. In general, alluvial and volcanic aquifers are considered depositional elements overlying the regional flow system and only influence regional flow in localized areas. The underlying lower carbonate aquifer (LCA) is the principal aquifer of the regional flow system. The LCA forms a nearly continuous aquifer across the region except where interrupted by calderas, truncated by structural controls, or penetrated by intrusive rocks.

The general direction of groundwater flow in the NTS regional flow system is from north to south and east to southwest (Figure 3-1). The direction of groundwater flow is locally influenced in areas where structural and geologic conditions have controlled the distribution and thickness of the LCA. 


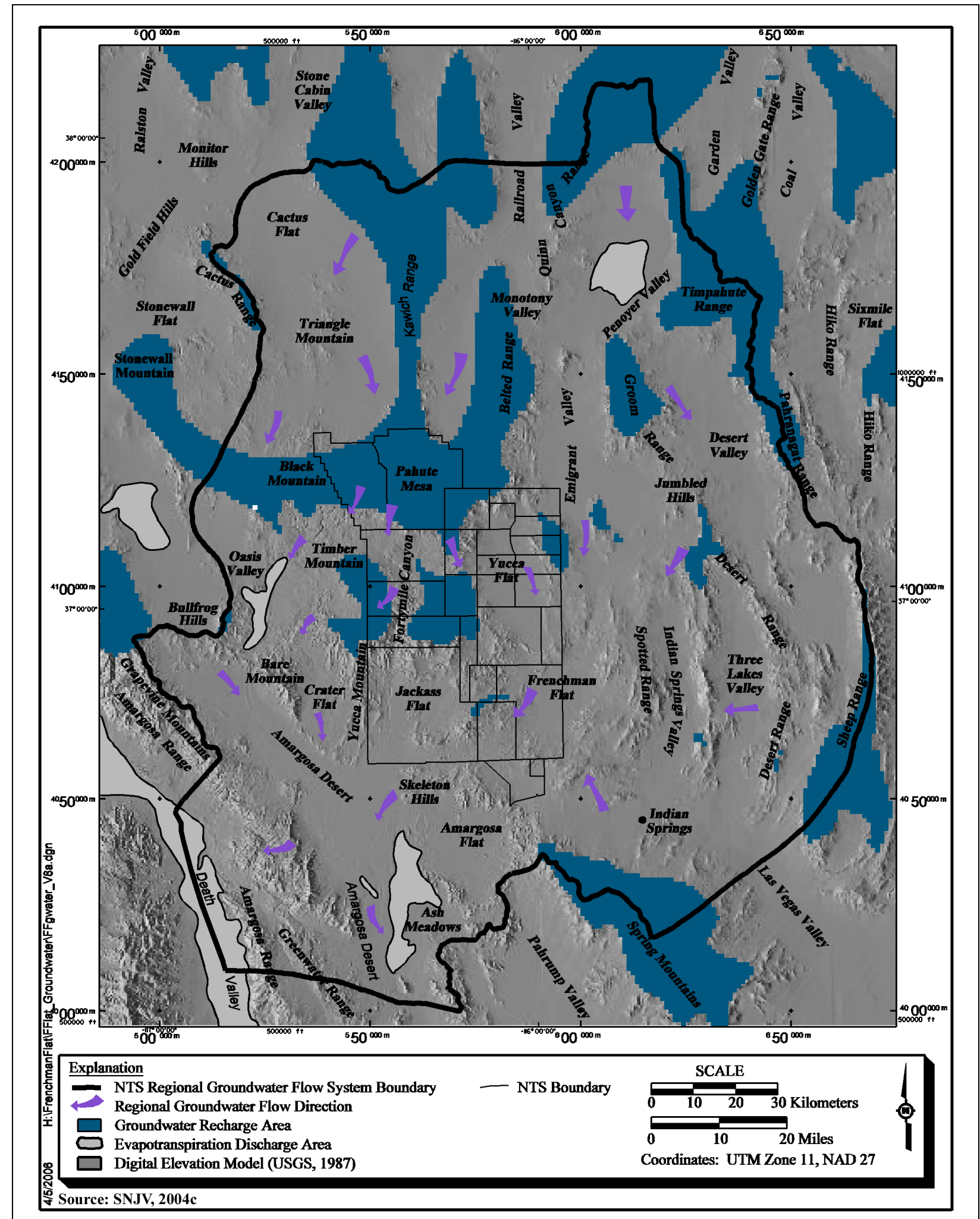

Figure 3-1

Features of the UGTA Regional Groundwater Flow System 
In some areas of the NTS regional flow system, groundwater encounters structural and geologic conditions, such as structural highs of the lower clastic confining unit (LCCU), that promote an upward flow component. The upward flow component may bring water to discharge at the surface in the form of a wet playa or springs.

Two models of the regional groundwater flow system have been developed using MODFLOW (McDonald and Harbaugh, 1988; Harbaugh et al., 2000) in support of the UGTA Subproject. The first documented (DOE/NV, 1997) is referred to as the UGTA regional model. This model was the foundation used for the majority of the Phase II CAI modeling. An updated regional model prepared by the USGS (Belcher et al., 2004) is referred to as the Death Valley Regional Flow System model, but it was not available for the entire suite of analyses needed before the construction of the groundwater flow models documented by SNJV (2004c).

\subsection{Frenchman Flat Groundwater Flow}

The data and interpretations that form the basis for conceptual and numerical models of the Frenchman Flat flow system have been developed based on hydraulic data collected intermittently for more than 50 years during various investigations (e.g., Winograd and Thordarson, 1975; Winograd and Pearson, 1976; Laczniak et al., 1996; IT, 1998 and 1999b; SNJV, 2004c, 2005b, 2006; NNES, 2010). Interpretations of new data collected during the Phase II CAI confirm many of the basic elements of the Frenchman Flat flow system first recognized as early as the 1970s. Several alternative conceptual models of the flow system were developed that focus on different directions of shallow groundwater flow but are not mutually exclusive; this section reviews the conceptual interpretations from the findings of the Phase II CAI. At the initiation of the Phase II CAI, no attempt was made to determine the likelihood of alternative conceptual models, and all conceptual models of the basin were equally considered during the initial flow model development as discussed in SNJV (2006).

Winograd and Thordarson (1975) provided the first modern description of the basic features of the Frenchman Flat flow system. They noted that hydraulic heads in the CP basin to the northwest of Frenchman Flat were approximately 113 m higher than hydraulic heads in Frenchman Flat basin, and they attributed this hydraulic discontinuity to the presence of the Cane Spring fault separating these basins. Water levels in both the alluvium and the welded tuffs within Frenchman Flat were 
determined to be several meters higher than water levels in the LCA that underlies and surrounds the basin. They concluded that groundwater in the alluvium and tuff was semiperched and could only leave the basin by draining downward to the LCA or by flowing laterally into the LCA across the basin margins. Slightly lower water levels in the alluvium at several wells near Frenchman Lake led them to suggest that a stronger hydraulic connection between the alluvium and the LCA existed near the playa, perhaps as a result of the thinning or faulting of the tuff aquitards that line the basin, and that drainage from the alluvium to the LCA was concentrated near the playa. The observed flat hydraulic gradients within Frenchman Flat, combined with data from other areas of the NTS consistent with low or moderate permeability of alluvium, support the inference (Winograd and Thordarson, 1975) that the lateral and vertical groundwater flow through the basin-filling alluvium and tuffs was relatively small.

A later conceptual model proposed by IT (1999b) suggested that semiperched groundwater in the alluvial and volcanic aquifers of Frenchman Flat was sustained by groundwater inflow from the CP basin that leaks across the Cane Spring fault (IT, 1999b). Leakage of groundwater from the CP basin into Frenchman Flat was considered to result in groundwater flow directions in Frenchman Flat that were generally northwest to southeast. This conceptual model was supported by three observations: (1) water levels in CP basin are much higher than those in the Frenchman Flat basin, (2) water levels in the alluvium are lower to the south and east of the Frenchman Lake, and (3) water levels in the northwest alluvium are higher than those observed in the central or east basin. The combination of the Winograd and Thordarson (1975) conceptual model of flow within the basin and the IT (1999b) conceptual model of flow into the basin was found to be consistent with the data during the development of the Phase II CAI flow models of the Frenchman Flat groundwater system. Thus, both conceptual models could be honored based on the Phase II CAI data.

In an effort to further evaluate the flow system after calibration of several groundwater flow models, aqueous geochemical analyses were performed (SNJV, 2006). Groundwater carbon-14 $\left({ }^{14} \mathrm{C}\right)$ data from the tuffs and alluvium in Frenchman Flat were used to calculate ages (residence times) for groundwater. The calculated dissolved inorganic carbon-14 $\left(\mathrm{DI}^{14} \mathrm{C}\right)$ ages of Frenchman Flat groundwater range in apparent age from approximately 8,500 to 29,000 years (SNJV, 2006, Figure 5-6). In general, younger groundwater is found near the low hills bordering the northern and northwestern parts of the basin, and older groundwater is found toward the basin center, reflecting the 
near absence of recharge through the alluvium in the basin even during the relatively wet conditions that existed in the late Pleistocene and early Holocene (about 10,000 years ago). The absence of groundwater $\mathrm{DI}^{14} \mathrm{C}$ ages younger than the early Holocene, even along the basin margins, is consistent with paleo-climate reconstructions based on vegetation preserved in pack-rat middens and on the ages of paleo-discharge deposits in nearby basins that indicate modern-day arid conditions were established in the NTS area by about 9,000 years ago (SNJV, 2006).

These age constraints are consistent with the Phase II groundwater model flow paths that indicate water is moving from the northern and northwestern parts of the basin and flowing toward the basin center and out of the basin center to the southeast. Inverse geochemical models were developed with the geochemical modeling code PHREEQC (Parkhurst and Appelo, 1999) to investigate the origin of groundwater at selected wells within the basin. Groundwater velocities were then calculated (based on ${ }^{14} \mathrm{C}$ ages) between pairs of wells in the alluvium that were likely to lie along the same flow path based on their relative chemical evolution. Groundwater flow velocities between the northwestern basin margin (UE-5c WW) and the center of the basin (ER-5-4) were 0.12 to 0.85 meters per year (m/yr) (SNJV, 2006) (see Figure 3-2 for well locations). North-to-south flow paths in the alluvium were between 0.19 to $0.25 \mathrm{~m} / \mathrm{yr}$ (the UE-5 PW-1 to ER-5-4 flow path) to $0.43 \mathrm{~m} / \mathrm{yr}$ (the UE-5 PW-2 to UE-5 PW-1 flow path) (SNJV, 2006). A higher groundwater velocity of $1 \mathrm{~m} / \mathrm{yr}$ was estimated for a north-to-east pathway (UE-5 PW-1 to WW-1), but this velocity is subject to greater uncertainty because it is based on an age for WW-1 groundwater estimated indirectly from its dissolved cation concentrations. An analysis of groundwater travel time for a mixture of groundwater involving components from the CP basin (Wells WW-4 and WW-4A) and the northeastern edge of the Frenchman Flat basin (UE-5c WW) indicated that groundwater velocities in the volcanic rocks were about $0.6 \mathrm{~m} / \mathrm{yr}$ (SNJV, 2006).

The low rates of groundwater movement estimated for Frenchman Flat basin are consistent with the prevailing arid conditions over the last 8,500 years and with the nearly flat water table due to limited flow rather than high flow and transmissivity (SNJV, 2006). The estimated groundwater velocities in the alluvium indicate that an advective transport distance of between about 200 to $1,000 \mathrm{~m}$ can be expected over the next 1,000 years in the alluvium (SNJV, 2006). 


\subsubsection{Vertical Head Gradients}

Although the observed groundwater elevations indicate the existence of an overall drop in water levels between the alluvium and the LCA in Frenchman Flat, Phase II CAI water-level measurements from multiple completion intervals at the ER-5-3 and ER-5-4 well clusters (Figure 3-2) provide evidence that vertical hydraulic gradients within the basin-fill units are small (SNJV, 2006).

Hydraulic heads were measured in multiple aquifer units between the alluvium and LCA in each of the three wells (ER-5-3, ER-5-3 \#2, and ER-5-3 \#3) in the ER-5-3 cluster located in the northern portion of the basin (SNJV, 2006). These water-level measurements show that vertical gradients within the upper portion of the basin-fill units are small. Thus, the measured head drop of $7 \mathrm{~m}$ between the shallow volcanic aquifer and the LCA must take place across the roughly 500-m-thick tuff confining unit that separates the LCA from the shallow tuff aquifers and corresponds to the differentiation of the semiperched system identified by Winograd and Thordarson (1975). This observation is significant because it indicates that near the northern portion of Frenchman Flat, where most of the tests were detonated, the thick confining units provide hydraulic separation between the shallow aquifers and the LCA. These thick confining units become thinner and faulted near the basin margins (away from most of the corrective action sites), as reflected in lower hydraulic head measurements in the shallow alluvium units in these areas that suggest downward drainage.

In the central portion of the Frenchman Flat basin, deeper head measurements in a welded sequence within the tuff confining unit underlying the basin-fill units at ER-5-4 \#2 show that downward drainage from the alluvium to the LCA is not only unlikely but actually prohibited. Hydraulic heads measured in the confining unit at ER-5-4 \#2 have risen to about $754 \mathrm{~m}$ amsl as of March 2004 and appear to be stabilizing at a level of approximately $755 \mathrm{~m}$ amsl (SNJV, 2004c) (Figure 3-2). Well ER-5-4 \#2 did not penetrate the LCA, but head measurements within and adjacent to the flow model area suggest that heads in the LCA near the ER-5-4 well complex would not exceed $730 \mathrm{~m}$ amsl. Therefore, the heads in the welded unit with the tuff confining unit near the center of the basin are higher than the heads in both the basin-fill units and the LCA by at least $20 \mathrm{~m}$.

Because the only known areas near Frenchman Flat with heads of $755 \mathrm{~m}$ amsl or higher are to the west in CP basin or the Wahmonie Hills, the high heads in the welded sequence within the tuff confining units at ER-5-4 \#2 must be maintained by a strong hydraulic connection between 


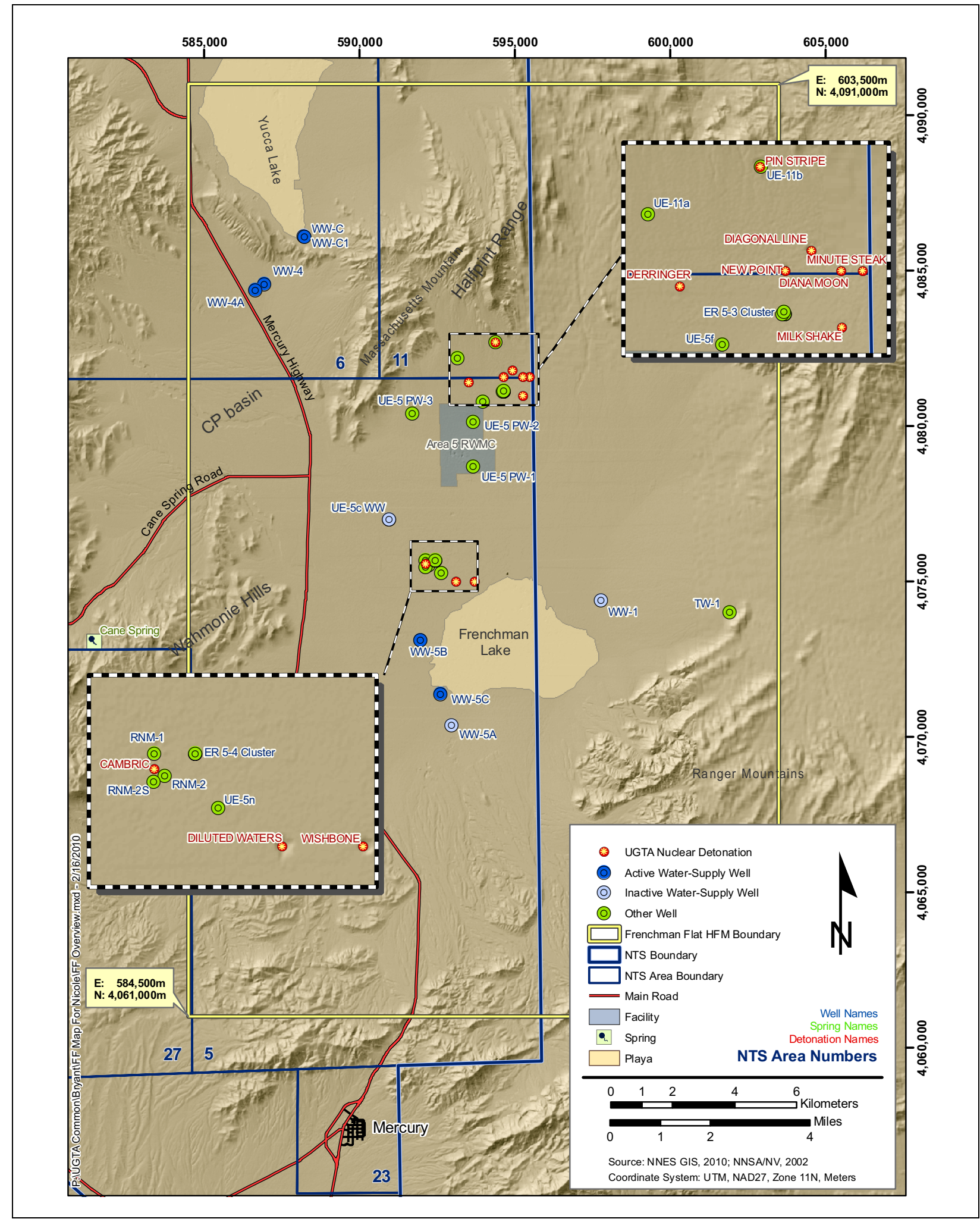

Figure 3-2

Overview of the Frenchman Flat Area Physiographic and Groundwater Features 
ER-5-4 \#2 and one of these western areas (Figure 3-2). This conceptual model is consistent with hydrogeologic cross sections through the ER-5-4 well cluster that show the tuff confining units are elevated along the western flanks of the basin allowing a connection in the Wahmonie Hills area (BN, 2005a). Multiple lines of evidence support the conclusion that the volcanic confining units beneath the alluvial-basin deposits are overpressurized in the central portion of the basin due to limited permeability in adjacent units and the resultant high heads prevent groundwater movement from the alluvium downward to the LCA.

\subsubsection{Structural Controls}

Faults and fractures in the regional carbonate aquifer (LCA) are responsible for the generally high productivity of this aquifer (Winograd and Thordarson, 1975). Near Frenchman Flat, the existence of a so-called mega channel in the LCA was suggested along the Spotted Range-Mine Mountain shear zone between Frenchman Flat and Ash Meadows (Figure 3-1) based on the presence of a potentiometric trough in this area and relatively young ${ }^{14} \mathrm{C}$ ages for the groundwater discharging from springs in Ash Meadows at the downgradient end of the trough (Winograd and Pearson, 1976). The variability in the discharge of springs at Ash Meadows is also consistent with preferential channelization of groundwater along discrete structural features, rather than diffuse, porous media flow in the LCA (Winograd and Thordarson, 1975, Figure 35). Likewise, a groundwater trough coinciding with the Yucca Flat fault suggests that groundwater in Yucca Flat drains preferentially through this fault toward CP basin and Frenchman Flat (Winograd and Thordarson, 1975; Laczniak et al., 1996). More recently, hydraulic data from an aquifer test in the LCA in Yucca Flat demonstrate a rapid hydraulic response at a monitoring well connected by a fault to the pumping well approximately 10 kilometers (km) away (SNJV, 2005a). These examples of highly channelized groundwater flow directly to the north and southwest of Frenchman Flat strongly suggest the possibility that channelization of groundwater flow along faults in the LCA may be also taking place in Frenchman Flat, where hydraulic head data are too sparse to allow the conclusive identification of similar behavior.

The alluvium in Frenchman Flat was deposited contemporaneously with basin development (BN, 2005a). The inference from mineralogical studies is that source areas for the alluvium shifted through time as structural blocks within and adjacent to the basin rose or fell relative to one another 
(Warren et al., 2002). Geologic and geophysical data strongly suggest that large basin-forming faults bound the basin on the south, east, and north. These faults are inferred to extend through the volcanic rocks and into the overlying alluvium. Based on analog studies of faults in other alluvial basins, these faults are likely to be barriers rather than conduits for groundwater flow (Rawling et al., 2001; SNJV, 2006).

\subsubsection{Precipitation and Recharge}

Precipitation in the vicinity of the NTS is strongly elevation dependent. In the vicinity of Frenchman Flat, precipitation gauges with records spanning up to 50 years show that precipitation for Frenchman Flat and CP basin areas is about 13 to 15 millimeters per year (SNJV, 2004c and 2006). The low rates of precipitation lead to estimates of recharge rates that are close to zero on the basin floor to as much as several centimeters per year in the hills bordering the basin.

Groundwater flow through the Frenchman Flat basin is believed to be driven primarily by groundwater flow from areas of higher head to the west of the basin. Hydraulic head data do not indicate large lateral or vertical gradients in the alluvium and suggest that groundwater flow is slow within the basin, a conclusion consistent with low rates of recharge and limited inflow to the basin across the Cane Spring fault inferred from the large water-level differences between the Frenchman Flat and CP basins. For example, the estimated vertical gradient in the central testing area alluvium is $3.1 \times 10^{-3} \mathrm{~m} / \mathrm{m}$ at the ER-5-4 well cluster (SNJV, 2006). Estimated rates of present-day recharge in the basin are 1 percent or less of the total flow estimated to pass through the regional groundwater system in this area, mostly through the LCA (Russell and Minor, 2002; Hevesi et al., 2003).

\subsubsection{Groundwater Discharge}

Within the vicinity of Frenchman Flat, the major source of groundwater discharge to the surface is pumping from wells. Pumping wells of interest are those pumped for more than one year (see Figure 3-2 for well locations). The pumping wells include nine NTS water-supply wells and Well RNM-2S, which was pumped for 16 years as part of the CAMBRIC RNM experiment. Of the nine water-supply wells, seven discharge from the shallow basin-fill alluvium and volcanic aquifers, and the remaining two (WW-C and WW-C1) discharge from the LCA (SNJV, 2004c). 
Based on production from the water-supply wells only, groundwater withdrawal peaked during the mid-1960s and then decreased (SNJV, 2004c). A larger peak in withdrawal occurred in the late 1980s and early 1990s. Water withdrawal via pumping declined between the early 1990s and about 2000, and has slightly increased since that time.

\subsection{Development of the Frenchman Flat Transport Conceptual Model}

The purpose of the UGTA Subproject is to assess the migration of radionuclides from the nuclear test cavities to the surrounding environment. Migration occurs when radionuclides move with groundwater flow and exit the test cavity. Various investigations of Frenchman Flat (e.g., Winograd and Thordarson, 1975; Winograd and Pearson, 1976; IT, 1999a and b; Tompson et al., 1999 and 2005; Carle et al., 2002 and 2007; SNJV, 2005b; NNES, 2010) interpret the available groundwater information with respect to flow velocities and processes of radionuclide migration. This section reviews the interpretations and resulting transport conceptual model.

\subsubsection{Underground Nuclear Test Phenomenology and Radionuclide Inventory}

Borg et al. (1976) define the general events that occur after an underground nuclear test (Figure 3-3), with the timing of events after detonation summarized by Tompson et al. (1999):

- Vaporization of rock and pore water immediately surrounding the device, and expansion of the plasma (microseconds)

- Development of a compressional shock wave that travels several hundred meters before becoming an elastic wave (100 to 500 milliseconds)

- Melting and spalling of adjacent rock from shock and heat (milliseconds)

- Enlargement of the cavity due to gas (mainly steam) expansion (milliseconds)

- Collapse of the cavity as the gases cool and the pressure drops, thus quenching the melted rock in the cavity (seconds to weeks)

- Formation of a chimney as the surrounding rock replaces the material that fell into the cavity (seconds to weeks)

Tompson et al. (1999) add another event: the elastic rebounding of the rock as the rock rebounds to its original position. The compressive tangential hoop stress when the stress in the rock is greater 


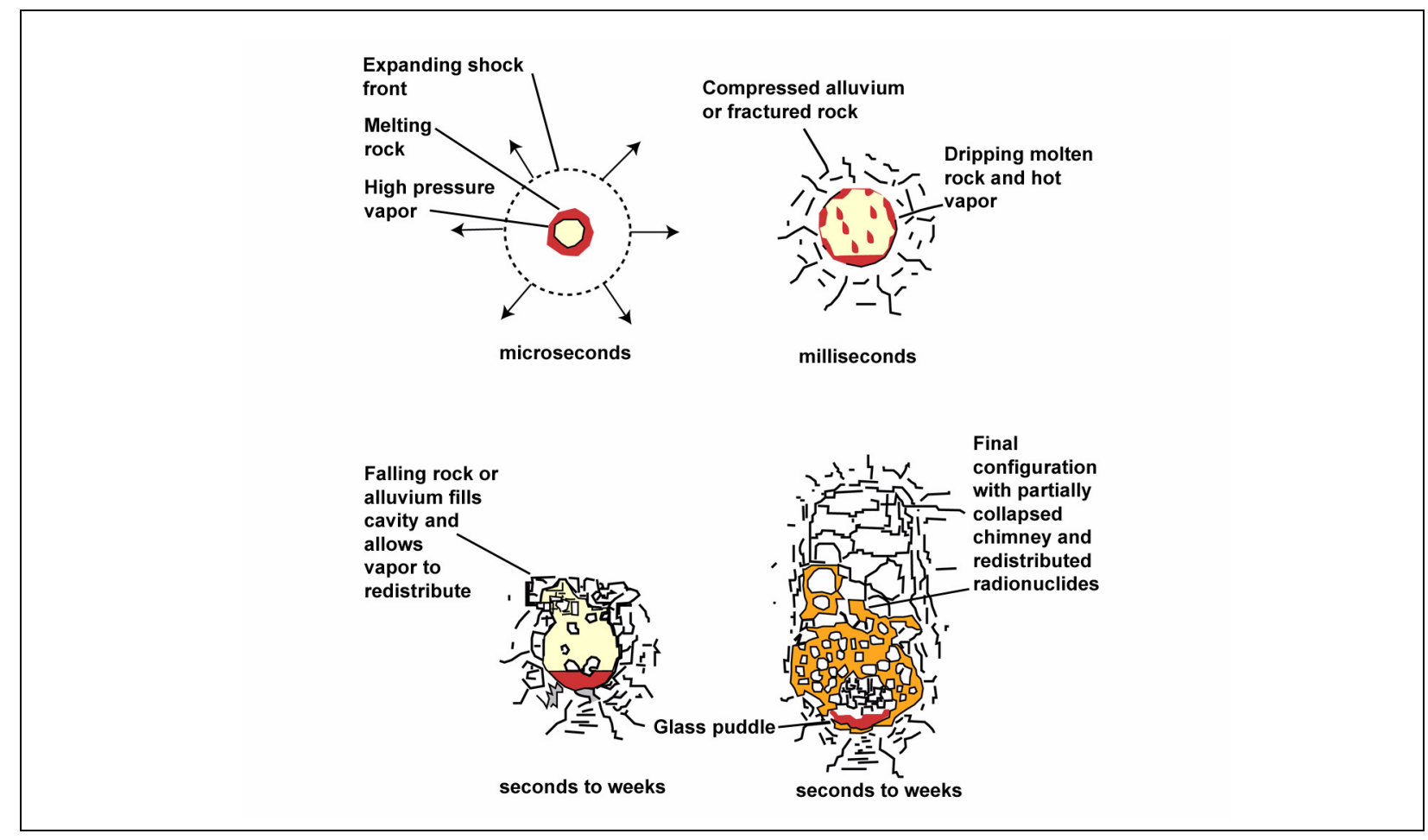

\section{Figure 3-3 \\ Conceptual Illustration Phenomenology of an Underground Nuclear Explosion in Competent Rock}

Source: Tompson et al., 1999

than the gas-phase pressure acts to close any radial fractures that might have opened during cavity expansion. Depending on the setting, any of these processes may be absent or of minor importance. However, during this relatively short time, many features are created that affect the long-term fate and transport of radionuclides. The terminology used to describe the nuclear test cavity and surrounding geologic environment is summarized in Table 3-1.

Radionuclides are heterogeneously distributed in the subsurface by the interaction of the short-term physical processes and chemical character of the radionuclides (Note: Radionuclide inventory is listed in Table 3-2). Non-volatile radionuclides (e.g., $\mathrm{Pu}, \mathrm{Am}, \mathrm{Np}$, and $\mathrm{Eu}$ ) with high boiling points will condense from gas first and be largely entrained in the cooling and condensing rock that coalesces at the bottom of the cavity as nuclear melt glass. If the collapse of the cavity occurs quickly such that the melt glass is still liquid, then rubble can be incorporated in the melt glass and the melt glass splashed around the cavity. Radionuclides with lower boiling points remain gaseous at lower temperatures, and thus have the potential to migrate further. Finally, as steam condenses in the cavity, 
Table 3-1

Terminology Used To Describe Nuclear Test Cavity and Near-field Environment

\begin{tabular}{||l|l||}
\hline \multicolumn{1}{|c|}{ Zone } & \multicolumn{1}{|c|}{ Description } \\
\hline \hline Cavity Zone & $\begin{array}{l}\text { Idealized sphere that represents the rock that has been vaporized, melted, and shocked to } \\
\text { create a void. }\end{array}$ \\
\hline Nuclear Melt Glass & $\begin{array}{l}\text { A zone at the bottom of the cavity where vaporized and melted material accumulates due to } \\
\text { gravity. This volume may also contain in-fallen rubble. }\end{array}$ \\
\hline Chimney Zones & $\begin{array}{l}\text { Idealized cylinder of rubble that falls into the collapsed cavity void, with a radius equal to the } \\
\text { cavity radius. The chimney zone may extend to the ground surface or stop before that, } \\
\text { dependent on yield of the test and the strength of the overlying rock. }\end{array}$ \\
\hline Crushed Zone & $\begin{array}{l}\text { Idealized sphere surrounding the cavity with radius 1.3 to 3 times the cavity radius, } \\
\text { representing material that mechanically failed and permanently lost porosity due to the } \\
\text { compression shock wave. }\end{array}$ \\
\hline Compressed Zone & $\begin{array}{l}\text { Idealized sphere surrounding the cavity and crushed zone with a radius of up to 20 times the } \\
\text { cavity radius. This material has permanently lost porosity due to the compression shock wave. }\end{array}$ \\
\hline Exchange Volume & $\begin{array}{l}\text { The volume of disturbed rock in which radionuclides are distributed - encompasses parts of } \\
\text { nearly all the above zones, with the exception of the compressed zone. }\end{array}$ \\
\hline
\end{tabular}

tritiated water will form that will have significant concentration of high-solubility (e.g., ${ }^{36} \mathrm{Cl}$ and ${ }^{129} \mathrm{I}$ ) radionuclides. In tests conducted below the water table, like CAMBRIC, this condensed water will mix with inflowing native groundwater to eventually fill the pore space in the cavity (Tompson et al., 1999). Approximately 10 years after the CAMBRIC test, Well RNM-1 was drilled into the test cavity; the measured distribution of tritiated water and gamma activity near and through the CAMBRIC cavity is shown in Figure 3-4. The CAMBRIC test is the only test that was conducted in saturated rocks in Frenchman Flat CAU; other tests were conducted above the water table and are mostly treated as saturated sources by projecting the source to the water table. Two tests, PIN STRIPE and MILK SHAKE, are treated differently because their exchange volumes intersect fractured volcanic rock, which, conceptually, allows more potential radionuclide migration than accounted for in the CAMBRIC conceptual model. Process models that consider both the unsaturated and saturated zones were used for source-term analysis of these two tests.

A compilation of radiologic contaminants generated during the underground nuclear tests may be found in Nevada Test Site Radionuclide Inventory, 1951-1992 (Bowen et al., 2001). The contaminant source for Frenchman Flat was reported as a total inventory for all 10 nuclear tests. The inventory was grouped in an effort to provide usable information for contaminant transport forecasts without revealing the specific details of the nuclear devices. This inventory includes tritium $\left({ }^{3} \mathrm{H}\right)$, fission 


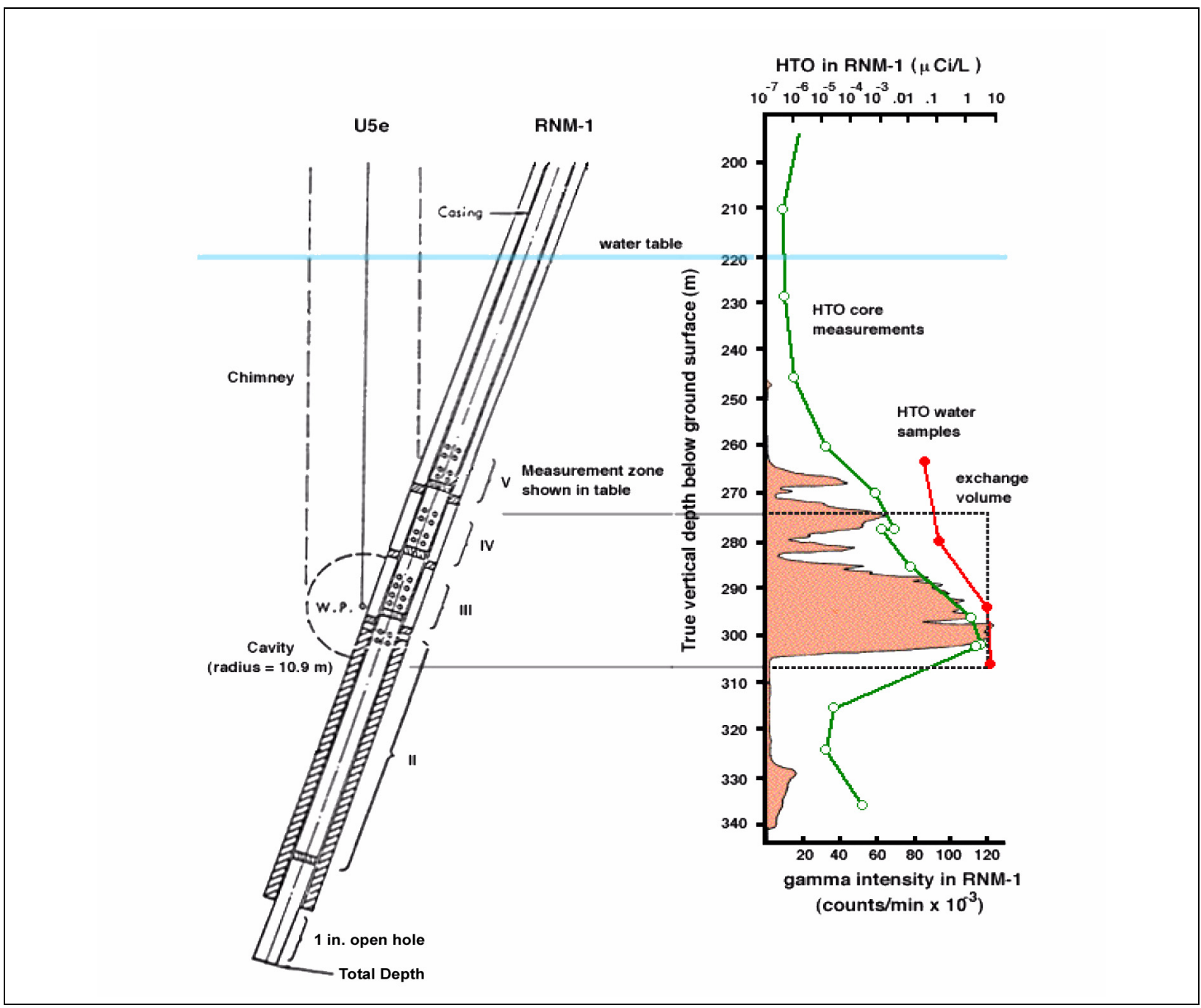

Figure 3-4

Schematic of Slanted RNM-1 Monitoring Hole, Measured Gamma Intensity Profile, and Measured Aqueous ${ }^{3} \mathrm{H}$ (HTO) Concentration Profiles

Source: Tompson et al., 1999

products, actinides, and activation products. The Frenchman Flat tests represent 0.14 percent of the total inventory at the NTS. The inventory for Frenchman Flat provided by Bowen et al. (2001) is reported in Table 3-2. The Bowen et al. (2001) inventory also provides an estimate of radioactivity remaining underground after completion of nuclear testing in 1992. Bowen et al. (2001) published an uncertainty estimate for the groups of radionuclides in the inventory (Table 3-3). The uncertainties depended on a number of factors, mostly on the source of the information. The Bowen et al. (2001) report is the most representative and comprehensive information available for unclassified contaminant transport analyses. Like many contaminated sites, the exact source information and 
Table 3-2

Radionuclide Inventory for Frenchman Flat CAU

\begin{tabular}{|c|c|c|}
\hline Radionuclide & Curies a & Atoms a \\
\hline Tritium $\left({ }^{3} \mathrm{H}\right)$ & $1.744 \times 10^{5}$ & $3.620 \times 10^{24}$ \\
\hline Carbon-14 $\left({ }^{14} \mathrm{C}\right)$ & $6.653 \times 10^{1}$ & $6.405 \times 10^{23}$ \\
\hline Aluminum-26 $\left({ }^{26} \mathrm{Al}\right)$ & $7.035 \times 10^{-3}$ & $8.413 \times 10^{21}$ \\
\hline Chlorine-36 $\left({ }^{36} \mathrm{Cl}\right)$ & $8.907 \times 10^{0}$ & $4.516 \times 10^{24}$ \\
\hline Argon-39 $\left({ }^{39} \mathrm{Ar}\right)$ & $6.166 \times 10^{0}$ & $2.794 \times 10^{21}$ \\
\hline Potassium-40 $\left({ }^{40} \mathrm{~K}\right)$ & $1.649 \times 10^{0}$ & $3.527 \times 10^{27}$ \\
\hline Calcium-41 $\left({ }^{41} \mathrm{Ca}\right)$ & $6.542 \times 10^{1}$ & $1.135 \times 10^{25}$ \\
\hline Nickel-59 ( $\left.{ }^{59} \mathrm{Ni}\right)$ & $1.634 \times 10^{0}$ & $2.092 \times 10^{23}$ \\
\hline Nickel-63 ( $\left.{ }^{63} \mathrm{Ni}\right)$ & $1.679 \times 10^{2}$ & $2.828 \times 10^{22}$ \\
\hline Krypton-85 ( $\left.{ }^{85} \mathrm{Kr}\right)$ & $1.285 \times 10^{2}$ & $2.329 \times 10^{21}$ \\
\hline Strontium-90 (90 Sr) & $1.879 \times 10^{3}$ & $9.109 \times 10^{22}$ \\
\hline Zirconium-93 $\left({ }^{93} \mathrm{Zr}\right)$ & $1.118 \times 10^{-1}$ & $2.825 \times 10^{23}$ \\
\hline Niobium-93m $\left({ }^{93 m} \mathrm{Nb}\right)$ & 0 & 0 \\
\hline Niobium-94 $\left({ }^{94} \mathrm{Nb}\right)$ & $6.968 \times 10^{-1}$ & $2.347 \times 10^{22}$ \\
\hline Technetium-99 $\left({ }^{99} \mathrm{Tc}\right)$ & $1.167 \times 10^{0}$ & $4.189 \times 10^{23}$ \\
\hline Palladium-107 (107Pd) & $1.949 \times 10^{-2}$ & $2.135 \times 10^{23}$ \\
\hline Cadmium-113m ( $\left.{ }^{113 m} \mathrm{Cd}\right)$ & $2.991 \times 10^{0}$ & $7.104 \times 10^{19}$ \\
\hline Tin-121m ( ${ }^{121 \mathrm{~m} S n)}$ & $1.646 \times 10^{1}$ & $1.525 \times 10^{21}$ \\
\hline Tin-126 ( $\left.{ }^{126} \mathrm{Sn}\right)$ & $8.193 \times 10^{-2}$ & $3.450 \times 10^{22}$ \\
\hline lodine-129 $\left({ }^{129} \mid\right)$ & $4.542 \times 10^{-3}$ & $1.201 \times 10^{23}$ \\
\hline Cesium-135 $\left({ }^{135} \mathrm{Cs}\right)$ & $1.362 \times 10^{-1}$ & $5.277 \times 10^{23}$ \\
\hline Cesium-137 ( $\left.{ }^{137} \mathrm{Cs}\right)$ & $5.045 \times 10^{3}$ & $2.555 \times 10^{23}$ \\
\hline Samarium-151 $\left({ }^{151} \mathrm{Sm}\right)$ & $2.949 \times 10^{2}$ & $4.471 \times 10^{22}$ \\
\hline Europium-150 $\left({ }^{150} \mathrm{Eu}\right)$ & $9.859 \times 10^{-3}$ & $5.979 \times 10^{17}$ \\
\hline Europium-152 (152Eu) & $7.569 \times 10^{2}$ & $1.726 \times 10^{22}$ \\
\hline Europium-154 (154Eu) & $2.622 \times 10^{2}$ & $3.796 \times 10^{21}$ \\
\hline Holmium-166m $\left({ }^{166 m \mathrm{Ho})}\right.$ & $2.024 \times 10^{0}$ & $4.092 \times 10^{21}$ \\
\hline Thorium-232 (232Th) & $1.196 \times 10^{-1}$ & $2.821 \times 10^{27}$ \\
\hline Uranium-232 ( $\left.{ }^{232 U}\right)$ & $1.027 \times 10^{-2}$ & $1.208 \times 10^{18}$ \\
\hline Uranium-233 $\left({ }^{233} \mathrm{U}\right)$ & $1.334 \times 10^{-3}$ & $3.578 \times 10^{20}$ \\
\hline Uranium-234 $\left({ }^{234} \mathrm{U}\right)$ & $2.748 \times 10^{-1}$ & $1.139 \times 10^{23}$ \\
\hline Uranium-235 $\left({ }^{235} \mathrm{U}\right)$ & $8.570 \times 10^{-3}$ & $1.016 \times 10^{25}$ \\
\hline Uranium-236 $\left({ }^{236} \mathrm{U}\right)$ & $2.995 \times 10^{-3}$ & $1.181 \times 10^{23}$ \\
\hline Uranium-238 $\left({ }^{238} \mathrm{U}\right)$ & $9.507 \times 10^{-2}$ & $7.159 \times 10^{26}$ \\
\hline Neptunium-237 ( $\left.{ }^{237} \mathrm{~Np}\right)$ & $1.379 \times 10^{-2}$ & $4.969 \times 10^{22}$ \\
\hline Plutonium-238 $\left({ }^{238} \mathrm{Pu}\right)$ & $3.232 \times 10^{2}$ & $4.775 \times 10^{22}$ \\
\hline Plutonium-239 $\left({ }^{239} \mathrm{Pu}\right)$ & $1.415 \times 10^{3}$ & $5.744 \times 10^{25}$ \\
\hline Plutonium-240 $\left.{ }^{240} \mathrm{Pu}\right)$ & $3.489 \times 10^{2}$ & $3.855 \times 10^{24}$ \\
\hline Plutonium-241 $\left({ }^{241} \mathrm{Pu}\right)$ & $4.408 \times 10^{3}$ & $1.069 \times 10^{23}$ \\
\hline Plutonium-242 $\left({ }^{242} \mathrm{Pu}\right)$ & $2.882 \times 10^{-2}$ & $1.821 \times 10^{22}$ \\
\hline Americium-241 $\left({ }^{241} \mathrm{Am}\right)$ & $5.022 \times 10^{2}$ & $3.661 \times 10^{23}$ \\
\hline Americium-243 $\left({ }^{243} \mathrm{Am}\right)$ & 0 & 0 \\
\hline Curium-244 $\left({ }^{244} \mathrm{Cm}\right)$ & 0 & 0 \\
\hline Total & $1.901 \times 10^{5}$ & $7.158 \times 10^{27}$ \\
\hline
\end{tabular}

Source: Modified from Bowen et al., 2001

a Decay corrected to September 23, 1992 (date of last underground nuclear test). 
Table 3-3

Estimated Accuracies for Groups of Radionuclides

\begin{tabular}{|c|c|c|c|c|c|c|}
\hline $\begin{array}{l}\text { Radionuclide } \\
\text { Group }^{\text {a }}\end{array}$ & Accuracy ${ }^{a}$ & $\begin{array}{l}\text { Accuracy } \\
\text { Range }\end{array}$ & Radionuclides $^{a}$ & $\begin{array}{l}\text { Lower } \\
\text { Limit }{ }^{b}\end{array}$ & $\begin{array}{l}\text { Upper } \\
\text { Limit }\end{array}$ & SD c \\
\hline Fission Products & $\sim 10$ to $30 \%$ & 0.7 to $1.3(0.6)$ & $\begin{array}{c}{ }^{85} \mathrm{Kr},{ }^{90} \mathrm{Sr},{ }^{93} \mathrm{Zr},{ }^{99} \mathrm{Tc},{ }^{107} \mathrm{Pd},{ }^{121} \mathrm{Sn}, \\
{ }^{126} \mathrm{Sn},{ }^{29},{ }^{135} \mathrm{Cs},{ }^{137} \mathrm{Cs},{ }^{151} \mathrm{Sm}\end{array}$ & 0.7 & 1.3 & 0.10 \\
\hline $\begin{array}{l}\text { Unspent Fuel } \\
\text { Materials }\end{array}$ & $\sim 20 \%$ or better & 0.8 to $1.2(0.4)$ & ${ }^{232} \mathrm{Th},{ }^{233} \mathrm{U},{ }^{234} \mathrm{U},{ }^{235} \mathrm{U},{ }^{236} \mathrm{U},{ }^{238} \mathrm{Um}$ & 0.8 & 1.2 & 0.067 \\
\hline $\begin{array}{l}\text { Fuel Activation } \\
\text { Products }\end{array}$ & $\sim 50 \%$ or better & 0.5 to $1.5(1)$ & $\begin{array}{c}{ }^{232} \mathrm{U},{ }^{237} \mathrm{~Np},{ }^{238} \mathrm{Pu},{ }^{239} \mathrm{Pu},{ }^{240} \mathrm{Pu} \\
{ }^{241} \mathrm{Am},{ }^{241} \mathrm{Pu},{ }^{242} \mathrm{Pu}\end{array}$ & 0.5 & 1.5 & 0.17 \\
\hline Residual ${ }^{3} \mathrm{H}$ & $\sim 300 \%$ or better & -2 to $4(6)$ & ${ }^{3} \mathrm{H}$ & $0^{d}$ & $2^{d}$ & 1 \\
\hline $\begin{array}{l}\text { Activation } \\
\text { Products }\end{array}$ & a factor of 10 & -9 to $11(20)$ & $\begin{array}{c}{ }^{14} \mathrm{C},{ }^{36} \mathrm{Cl},{ }^{39} \mathrm{Ar},{ }^{41} \mathrm{Ca},{ }^{59} \mathrm{Ni},{ }^{63} \mathrm{Ni}, \\
{ }^{94} \mathrm{Nb},{ }^{150} \mathrm{Eu},{ }^{152} \mathrm{Eu},{ }^{154} \mathrm{Eu},{ }^{166 m_{\mathrm{Ho}}} \mathrm{Ho}\end{array}$ & $0^{d}$ & $2^{d}$ & 3.3 \\
\hline
\end{tabular}

Source: SNJV, 2005d

a Bowen et al., 2001

b Upper and lower limits are based on maximum percent uncertainty.

c Standard deviation (SD) is taken to be the accuracy range divided by 6 (estimate falls within the range of one plus and minus three SDs).

d Lower limit truncated to be non-negative and upper limit truncated to maintain a mean of one.

initial distribution of the source in the subsurface cannot be quantified for the NTS. This leads to uncertainties in the release of contaminants to the geologic formations, but the inventory uncertainty provided in Bowen et al. (2001) and the total radionuclide inventory for the CAU provide the foundation for analysis of these uncertainties with respect to contaminant transport forecasts.

\subsubsection{Radionuclide Transport}

Forecasts of the maximum extent of groundwater contamination from a particular source are dependent upon the radionuclides present in the inventory, the distribution of the radionuclides resulting from the explosion, the release of the radionuclides from the altered environment, and the longer-term mass transfer processes that serve to redistribute the radionuclides in the subsurface.

When a nuclear detonation occurs, residual radionuclides are distributed based on their volatility, or the volatility of parent radionuclides that produce them (Borg et al., 1976). This results in radionuclides in aqueous or gaseous states, precipitated or chemically sorbed states, or incorporated in melt glass (Kersting et al., 1998). Constraints on nuclear melt-glass dissolution, and radioactive decay are required to compute the rate and extent of radionuclide migration mass transfer and transport processes that describe radionuclide interaction with water and rock. Given the time horizon of the contaminant transport forecasts (1,000 years) and the slow release of radionuclides 
that partition to the melt-glass zone, the radionuclide drivers for the contaminant boundary forecasts are very soluble radionuclides that remain in the aqueous phase after the nuclear test (e.g., $\left.{ }^{3} \mathrm{H},{ }^{14} \mathrm{C},{ }^{99} \mathrm{Tc}\right)(\mathrm{NNES}, 2010)$.

Radionuclides that partition to the nuclear melt glass tend to be longer-lived in the groundwater than radionuclides that stay in the aqueous state. As a result, the kinetics of melt-glass dissolution becomes important to the transport forecast at very long-time intervals because it governs the release of these radionuclides into the flow system after the decay of shorter-lived radionuclides (Bowen et al., 2001). Most of these melt-glass radionuclides are essentially immobile during the 1,000-year regulatory time frame for model forecasts of the contaminant boundary. The limited transport of these radionuclides away from the nuclear test cavity is expected to be generally governed by equilibrium processes (Zavarin et al., 2004). As a result, complex reaction chemistry may be simplified to a linear sorption isotherm and defined based on a distribution coefficient $\left(\mathrm{K}_{\mathrm{d}}\right)$. For transport conditions in the majority of the Frenchman Flat flow model, the simplifying assumptions were tested in the hydrologic source term (HST) model of CAMBRIC (Carle et al., 2007), which employed two modeling approaches: transient transport equations and equilibrium transport path models. These two approaches yielded comparable results of radionuclide migration.

Additionally, radionuclides undergo decay that results in decreases in the mass of contaminants within the aquifer and/or changes the contaminant species. Groundwater advection moves dissolved radionuclides by bulk motion. Direct observations of radionuclide transport in Frenchman Flat have been made from the CAMBRIC test, where the RNM experiment was conducted near the test cavity. Hoffman and Daniels (1984) noted that ${ }^{3} \mathrm{H},{ }^{85} \mathrm{Kr}$, and minute quantities of ${ }^{106} \mathrm{Ru}$ were observed in Well RNM-2S over the first six years of the RNM experiment, consistent with laboratory studies that show radionuclide sorption is sufficiently high to preclude the migration of sorbing species to RNM-2S. Carle et al. (2007) provide a synopsis of the RNM experiment observations:

- Radionuclides that were routinely observed in pumping well effluent included ${ }^{3} \mathrm{H},{ }^{36} \mathrm{Cl}$, ${ }^{85} \mathrm{Kr}$, and ${ }^{129} \mathrm{I}$.

- $\quad{ }^{106} \mathrm{Ru}$ and ${ }^{99} \mathrm{Tc}$ were sporadically observed in pumping well effluent.

- $\quad$ Recovery curves of ${ }^{3} \mathrm{H}$ and ${ }^{36} \mathrm{Cl}$ are relatively complete breakthrough curves. 
- Radionuclides that are known to sorb to aquifer materials such as ${ }^{90} \mathrm{Sr},{ }^{137} \mathrm{Cs}$, and ${ }^{238 / 239} \mathrm{Pu}$ were never positively detected above background in effluent samples.

- Colloid-facilitated contaminant transport is either extremely limited or non-existent based on ${ }^{137} \mathrm{Cs}$ and ${ }^{90} \mathrm{Sr}$ observations.

- $\quad{ }^{137} \mathrm{Cs}$ and ${ }^{90} \mathrm{Sr}$ concentrations from the drill-back hole (RNM-1) in the CAMBRIC cavity are constant during the pumping experiment, indicating a quasi-steady-state mass transfer process.

- $\quad{ }^{14} \mathrm{C}$ may have degassed or sorbed to calcite in the alluvium because insignificant quantities have reached nearby observation wells during a 40-year observation period.

- Transport of ${ }^{129} \mathrm{I}$ is similar to ${ }^{3} \mathrm{H},{ }^{99} \mathrm{Tc}$, and ${ }^{36} \mathrm{Cl}$.

- $\quad$ Observed transport of ${ }^{237} \mathrm{~Np}$ is consistent with laboratory studies, indicating that ${ }^{237} \mathrm{~Np}$ is slightly retarded in Frenchman Flat alluvium.

The results of the CAMBRIC RNM experiment confirm the conceptual model that radionuclides that do not undergo surface complexation and ion exchange reactions with aquifer materials (tracers) tend to be readily transported during pumping (Carle et al., 2007); those radionuclides that tend to sorb readily to the aquifer materials are not transported to the pumping well (Carle et al., 2007). It is anticipated that transport will be similar in an ambient flow field, where tracer radionuclides will move in the flow system at a rate equivalent to the groundwater velocity and that radionuclides that sorb onto the aquifer materials will be delayed compared to the tracers during the 1,000 -year transport simulations. 


\subsection{Modeling approach and Model Construction}

The CAI process includes the selection and regulatory approval of a numerical model to complete the contaminant boundary calculations. For the Frenchman Flat CAU, the LANL Finite Element Heat-Mass (FEHM) code (Zyvoloski et al., 1997) was selected. Over the time-scale for the contaminant boundary forecasts, the assumption of steady-state groundwater flow was judged to be an acceptable approximation. This is particularly true in northern Frenchman Flat. In central Frenchman Flat, where pumping has occurred (notably in the form of the RNM experiment) and continues today at low levels, a transient sub-CAU model was created specifically to address the short-term pumping effects - steady conditions were used for the contaminant boundary forecasts. The model construction in FEHM is based on a confined aquifer approximation in which the water table defines the top of the model domain. An estimate of the water table is developed using observed heads in wells relatively shallow in the flow system and regional model results. This approach does not include an unsaturated zone or moving water table. Relative to the saturated thickness of the rocks and the uncertainty in their properties, this is judged to be an acceptable approximation. The modeling approach relied on the use of the FEHM numerical framework and noted approximations to sequentially incorporate a series of model components used to evaluate the FFACO-required ensemble of contaminant boundaries along with estimates of uncertainty (NNSA/NV, 2001).

The model components include: (1) hydrostratigraphic framework of Frenchman Flat, (2) development of appropriate groundwater flow models, and (3) groundwater transport simulations in the CAU that include appropriate HST models. Each of the component models is summarized below.

\subsection{Hydrostratigraphic Framework Model}

The geologic model, or hydrostratigraphic framework model (HFM) (BN, 2005a), was developed as the first step in the modeling approach. The HFMs represent geologic interpretations by BN (2005a) that honor the available data. These include an HFM judged to represent the consensus or most viable 
integration of data (called BASE), and four alternative HFMs (different geologic interpretations that are mutually consistent with the available data) that were developed. The BASE HFM includes more than 70 faults and 17 HSUs (9 aquifers and 8 confining units) (see Plates 1 and 2; Table 4-1). The structural elements are typically normal faults (basin-and-range-style faults) but also include several strike-slip and older thrust faults. Only faults considered hydrologically significant, faults with long traces and/or offsets, and faults that are inferred to form significant structural boundaries were included in the model (BN, 2005a). The alternative HFMs contain all of the same HSUs, but the models differ in the structural representation of the geology (see Table 4-2).

Table 4-1

Hydrostratigraphic Units of the Frenchman Flat HFM

(Page 1 of 2)

\begin{tabular}{|c|c|}
\hline HSU (Symbol) & General Description \\
\hline $\begin{array}{l}\text { Alluvial Aquifer (AA1, AA2, AA3) } \\
\text { (this term is also used to designate a } \\
\text { hydrogeologic unit) }\end{array}$ & $\begin{array}{l}\text { Consists mainly of alluvium that fills extensional basins. Also includes } \\
\text { generally older Tertiary gravels and very thin air-fall tuffs. The AA, AA1, } \\
\text { AA2, and AA3 are equivalent hydrogeologically except for position } \\
\text { relative to other HSUs embedded within the alluvial section. }\end{array}$ \\
\hline $\begin{array}{l}\text { Playa Confining Unit } \\
\text { (PCU2T) }\end{array}$ & Clayey silt and sandy silt. Forms the Frenchman Lake playa. \\
\hline $\begin{array}{l}\text { Basalt Lava-Flow Aquifer } \\
\text { (BLFA) }\end{array}$ & $\begin{array}{l}\text { Several (possibly dissected) basalt flows are recognized in the middle of } \\
\text { the alluvial section of the northeastern Frenchman Flat. Related to other } \\
\text { basalt flows in Scarp Canyon. }\end{array}$ \\
\hline $\begin{array}{l}\text { Older Alluvial Aquifer } \\
\text { (OAA and OAA1) }\end{array}$ & $\begin{array}{l}\text { Older, denser, zeolitized alluvium recognized only in northern Frenchman } \\
\text { Flat. The OAA and OAA1 are equivalent except for position; the OAA is } \\
\text { above the BLFA, and the OAA1 is stratigraphically beneath the BLFA. }\end{array}$ \\
\hline $\begin{array}{l}\text { Older Playa Confining Unit } \\
\text { (PCU1U and PCU1L) }\end{array}$ & $\begin{array}{l}\text { Deep, subsurface playa deposits in the deepest portion of Frenchman } \\
\text { Flat. Recognized in ER-5-4 \#2 and with 3-D seismic data. The PCU1U } \\
\text { and PCU1L are similar except for position. }\end{array}$ \\
\hline $\begin{array}{l}\text { Timber Mountain Welded-Tuff Aquifer } \\
\text { (TM-WTA) }\end{array}$ & $\begin{array}{l}\text { Consists mainly of welded ash-flow tuffs of Ammonia Tanks tuff (Tma) and } \\
\text { Rainier Mesa tuff (Tmr). Unit occurs mostly in north and central } \\
\text { Frenchman Flat. Prolific aquifer when saturated. }\end{array}$ \\
\hline $\begin{array}{l}\text { Timber Mountain Lower Vitric-Tuff Aquifer } \\
\text { (TM-LVTA) }\end{array}$ & $\begin{array}{l}\text { Defined to include all unaltered (nonzeolitic) nonwelded and bedded tuffs } \\
\text { below the welded Tmr and above the level of pervasive zeolitization. The } \\
\text { presence of the welded Topopah Spring tuff (Tpt) (see Topopah Spring } \\
\text { aquifer [TSA]) complicates this general description. }\end{array}$ \\
\hline $\begin{array}{l}\text { Upper Tuff Confining Unit } \\
\text { (UTCU) }\end{array}$ & $\begin{array}{l}\text { Relatively thin TCU above the TSA. Grouped with the lower tuff confining } \\
\text { unit (LTCU) where the TSA is not present. }\end{array}$ \\
\hline $\begin{array}{l}\text { Topopah Spring Aquifer } \\
\text { (TSA) }\end{array}$ & $\begin{array}{l}\text { The welded ash-flow lithofacies of the Tpt in the Massachusetts } \\
\text { Mountain/French Peak area and north-central Frenchman Flat. }\end{array}$ \\
\hline $\begin{array}{l}\text { Lower Vitric-Tuff Aquifer } \\
\text { (LVTA) }\end{array}$ & $\begin{array}{l}\text { Relatively thin vitric-tuff aquifer (VTA) unit below the TSA. Grouped with } \\
\text { the TM-LVTA where TSA is not present. }\end{array}$ \\
\hline
\end{tabular}


Table 4-1

Hydrostratigraphic Units of the Frenchman Flat HFM

(Page 2 of 2)

\begin{tabular}{|c|c|}
\hline HSU (Symbol) & General Description \\
\hline $\begin{array}{l}\text { Lower Tuff Confining Unit } \\
\text { (LTCU and LTCU1) }\end{array}$ & $\begin{array}{l}\text { Generally includes all the zeolitic nonwelded and bedded tuffs in } \\
\text { southeastern NTS. May include all units from the base of Tmr to the top } \\
\text { of Paleozoic-age rocks. The Wahmonie formation stratigraphic interval } \\
\text { grades or interfingers laterally westward into the Wahmonie confining unit } \\
\text { (WCU). Zeolitic bedded tuffs stratigraphically below the WCU are } \\
\text { classified as the LTCU1. }\end{array}$ \\
\hline $\begin{array}{l}\text { Wahmonie Confining Unit } \\
\text { (WCU) }\end{array}$ & $\begin{array}{l}\text { Mixture of lava flows, debris flows, lahars, ash flows, and air-falls. } \\
\text { Typically zeolitic, argillic, or hydrothermally altered. Grades or interfingers } \\
\text { laterally with the LTCU. }\end{array}$ \\
\hline $\begin{array}{l}\text { Volcaniclastic Confining Unit } \\
\text { (VCU) }\end{array}$ & $\begin{array}{l}\text { Older Tertiary sedimentary rocks of variable lithologies including silt, clay, } \\
\text { limestone, gravel, and tuffaceous units. Present in southeastern half of } \\
\text { Frenchman Flat. }\end{array}$ \\
\hline $\begin{array}{l}\text { Lower Carbonate Aquifer-Thrust Plate } \\
\text { (LCA3) }\end{array}$ & $\begin{array}{l}\text { Cambrian through Devonian, mostly limestone and dolomite, rocks that } \\
\text { occur in the hanging wall of the CP thrust fault. Present only in the } \\
\text { northwest corner (CP basin) of the model area. }\end{array}$ \\
\hline $\begin{array}{l}\text { Upper Clastic Confining Unit } \\
\text { (UCCU) }\end{array}$ & $\begin{array}{l}\text { Late Devonian through Mississippian siliciclastic rocks. Present only in } \\
\text { the northwest corner (CP basin) of the model area, northwest of Cane } \\
\text { Spring fault and southwest of Topgallant fault. }\end{array}$ \\
\hline $\begin{array}{l}\text { Lower Carbonate Aquifer } \\
\text { (LCA) }\end{array}$ & $\begin{array}{l}\text { Cambrian through Devonian mostly limestone and dolomite. Regional } \\
\text { carbonate aquifer present throughout the model area. }\end{array}$ \\
\hline $\begin{array}{l}\text { Lower Clastic Confining Unit } \\
\text { (LCCU) }\end{array}$ & $\begin{array}{l}\text { Late Proterozoic through Early Cambrian siliciclastic rocks. Hydrologic } \\
\text { basement present at great depth in the model area. }\end{array}$ \\
\hline
\end{tabular}

Source: Modified from BN, 2005a

The Phase II Frenchman Flat HFM area encompasses more than 570 square kilometers in the southeastern portion of the NTS. The model area has a north-south length of $30 \mathrm{~km}$ and an east-west length of $19 \mathrm{~km}$, and includes geologic units as deep as $5 \mathrm{~km}$ below mean sea level. Figure 4-1 is an HSU surface map of the Frenchman Flat CAU model domain showing the locations of well clusters ER-5-3 and ER-5-4. The wells at both of these locations penetrated Quaternary and Tertiary alluvium to depths of $622.4 \mathrm{~m}$ and 1,120.4 m, respectively. Plate 1 shows cross sections through the BASE HFM. Plate 2 shows the HSU distribution at the water table with the surface traces of the faults within the BASE HFM.

The Phase II Frenchman Flat BASE HFM was constructed using all available drill-hole and geophysical data collected in the Frenchman Flat model area. This geologic model remains broadly consistent with the NTS hydrologic system described by Winograd and Thordarson (1975) and the 


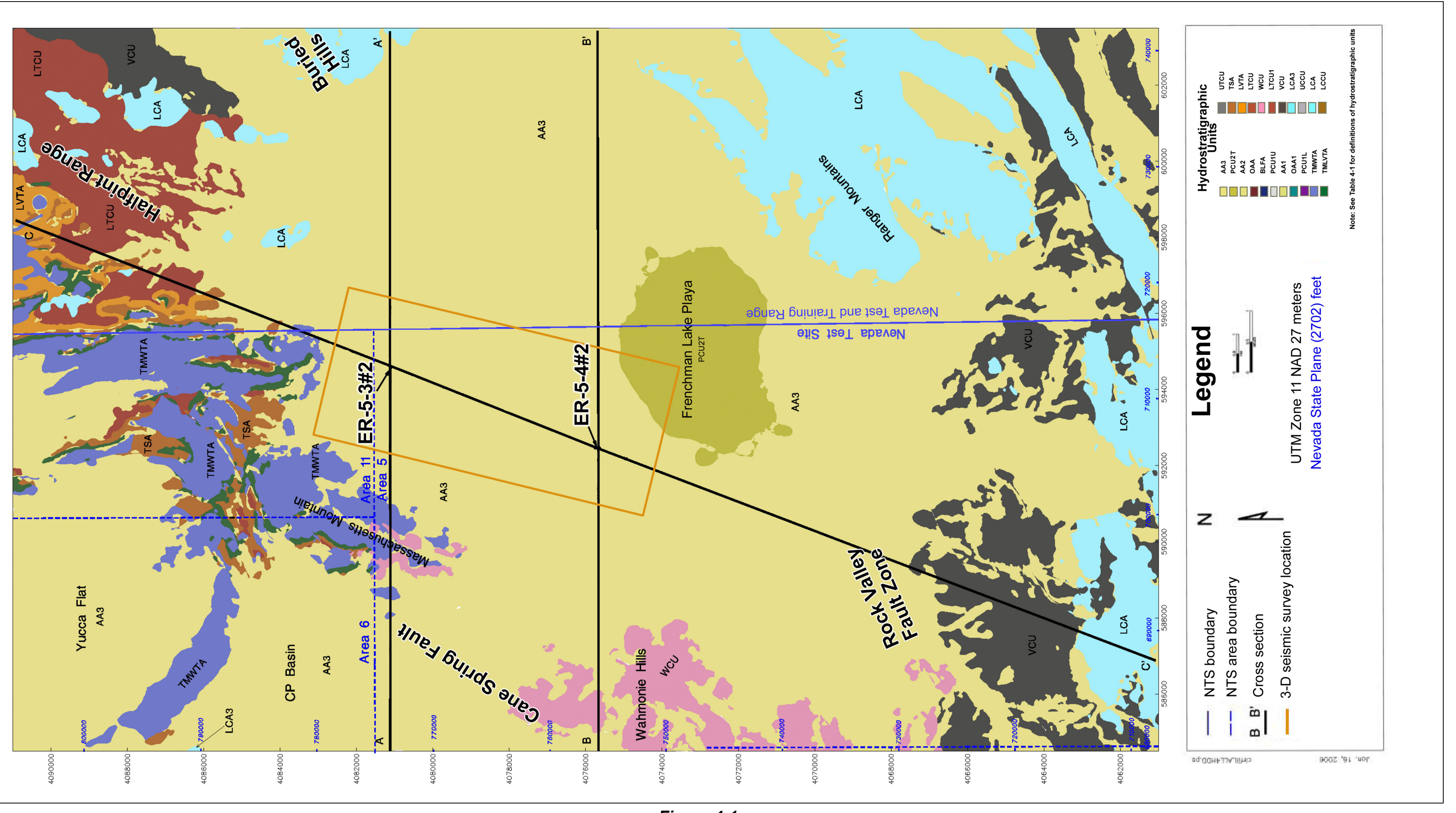

Hydrostratigraphic Unit Surface Map of the Frenchman Flat Model Area

Source: Modified from SNJV, 2006 
Phase I HFM, and consists of a thick, faulted LCA overlain by volcanic rocks that have been downfaulted and buried by alluvium (see Plate 1).

Data collected during the Phase II CAI clearly show that the basin (bottom formed by the top of pre-Tertiary rocks) is deeper than originally depicted in the Phase I HFM. In the vicinity of the underground nuclear test locations in the central portion of Frenchman Flat, the LCA is more than 1,000 $\mathrm{m}$ deeper than estimated from the data available during Phase I. In northern Frenchman Flat, near well cluster ER-5-3, the LCA is about $400 \mathrm{~m}$ deeper in the Phase II HFM (BN, 2005a).

Differences in the geologic conceptualization of the hydrostratigraphic framework that were permitted by the data and hypothesized to be important to the flow and transport models of Frenchman Flat were developed into alternative HFMs (Table 4-2). Although they differ in some of their details, the various HFMs share similarities and generally are based on consistent conceptual models for the origin, structure, and large-scale hydrogeologic system of the Frenchman Flat basin. These models were discretely incorporated in a FEHM mesh used to simulate groundwater flow and transport (SNJV, 2006). By incorporating each framework conceptualization, the structural uncertainty effects of alternative arrangements of rock units on groundwater flow and transport are evaluated. Plate 3 illustrates the changes between the BASE HFM and alternative HFMs.

Table 4-2

Summary of Alternative HFMs Considered

(Page 1 of 2)

\begin{tabular}{||c|c|l||}
\hline Alternative HFM & $\begin{array}{c}\text { Key Difference(s) } \\
\text { Compared to BASE HFM }\end{array}$ & \multicolumn{1}{c|}{$\begin{array}{c}\text { Potential Impacts } \\
\text { on Flow and Transport Model }\end{array}$} \\
\hline \hline $\begin{array}{c}\text { Basalt Lava-Flow Aquifer } \\
\text { (BLFA) }\end{array}$ & $\begin{array}{c}\text { The BLFA HSU is modeled } \\
\text { as a single continuous flow, } \\
\text { rather than three } \\
\text { separate zones. }\end{array}$ & $\begin{array}{l}\text { Located at or near the water table, which may affect flow } \\
\text { and transport of radionuclides away from underground } \\
\text { nuclear tests in the Northern Testing Area. Conceptually, } \\
\text { the BLFA is a fractured rock; thus, fracture/matrix processes } \\
\text { are acting over a larger area. This alternative primarily } \\
\text { affects the MILK SHAKE test, which overlies the BLFA. }\end{array}$ \\
\hline $\begin{array}{c}\text { Detachment Fault } \\
\text { (DETA) }\end{array}$ & $\begin{array}{c}\text { This alternative is a no } \\
\text { detachment fault model. }\end{array}$ & $\begin{array}{l}\text { In this alternative, removing the fault eliminates potential } \\
\text { hydrologic consequences of volcanic unit offsets across the } \\
\text { fault. Volcanic rocks were modeled as dipping moderately } \\
\text { southward from Area 11. }\end{array}$ \\
\hline
\end{tabular}




\section{Table 4-2 \\ Summary of Alternative HFMs Considered \\ (Page 2 of 2)}

\begin{tabular}{||c|c|l||}
\hline Alternative HFM & $\begin{array}{c}\text { Key Difference(s) } \\
\text { Compared to BASE HFM }\end{array}$ & $\begin{array}{c}\text { Potential Impacts } \\
\text { on Flow and Transport Model }\end{array}$ \\
\hline \hline $\begin{array}{c}\text { Displacement Fault } \\
\text { (Aquifer Juxtaposition) } \\
\text { (DISP) }\end{array}$ & $\begin{array}{c}\text { This alternative is concerned } \\
\text { with the locations } \\
\text { and displacement of } \\
\text { basin-forming faults. }\end{array}$ & $\begin{array}{l}\text { This alternative juxtaposes shallow aquifers against deeper } \\
\text { aquifers, allowing a hydraulic connection between volcanic } \\
\text { aquifers underlying the AA in Frenchman Flat to carbonate } \\
\text { aquifers east and south from the Rock Valley fault system. } \\
\text { Juxtaposition removes the zeolitic LTCU and WCU from a } \\
\text { potential flow path, reducing the effects of sorption. }\end{array}$ \\
$\begin{array}{c}\text { CP Thrust Fault } \\
\text { (CPBA) }\end{array}$ & $\begin{array}{c}\text { The CP basin alternative } \\
\text { extends the UCCU beneath } \\
\text { all of CP basin. }\end{array}$ & $\begin{array}{l}\text { Some uncertainty exists in the distribution of pre-Tertiary } \\
\text { basin. This alternative results in a continuous sheet of } \\
\text { UCCU beneath CP basin. No direct transport } \\
\text { consequences in terms of materials, but broadly impacts } \\
\text { the flow system. }\end{array}$ \\
\hline
\end{tabular}

Sources: BN, 2005a; SNJV, 2005b

Also see Plates 1 through 3.

\subsection{Groundwater Flow Model}

\subsubsection{Computational Mesh}

The Frenchman Flat flow model uses the FEHM modeling code (Zyvoloski et al., 1997) and a computational grid generation approach based on a balanced octree refinement of an orthogonal grid (SNJV, 2006). Octree refinement uses a recursive refinement of hexahedral blocks into eight octants by planes perpendicular to each coordinate axis. The splitting of blocks is continued, creating progressively smaller cells, until the desired refinement criteria are met. Voronoi polygons are the FEHM control volumes associated with the mesh nodes. The Frenchman Flat mesh was refined to ensure continuity of thin units, provide high node density at underground test detonations and open intervals of wells, resolve fault locations, and resolve contacts of HSUs.

\subsubsection{Material Properties}

Hydrologic properties were assigned to each node in the model based on the HSU specified in the HFM. Faults were represented by material zones after the HSUs were defined. The material properties associated with the HSU nodes remain assigned to the fault nodes pending another property assignment. The approach to parameterizing the faults was to multiply existing fault node 
properties (still derived from an HSU) by a permeability factor. Thus, the difficulty was avoided of directly assigning a fault permeability for each HSU that it crosses. Intrinsic permeability and fault permeability multipliers were treated as calibration parameters in the Frenchman Flat CAU steady-state flow model.

Analysis of hydraulic conductivity data considered three distinct datasets based on the scale of the tests. Evaluation criteria were measurement scale (aquifer scale, slug-test scale, and laboratory scale), scaling and spatial distribution, and vertical anisotropy. Site-specific permeability values for each HSU are provided in Table 4-3. Figure 4-2 shows locations where the hydraulic property data were obtained in the Frenchman Flat area. For the purposes of specifying the Frenchman Flat CAU flow model, the aquifer-scale data were inferred to be the most appropriate (SNJV, 2004c). Slug tests involve the movement of smaller volumes of water through the formation and are not as representative for the scale of the flow model parameterization.

Table 4-3

Summary of Measured Permeability for HSUs within the Frenchman Flat CAU Model Domain (Page 1 of 2)

\begin{tabular}{|c|c|c|c|c|c|c|c|}
\hline \multirow{3}{*}{ HSU } & \multirow{2}{*}{ Mean } & \multirow{2}{*}{$\begin{array}{l}\text { Standard } \\
\text { Deviation }\end{array}$} & \multirow{3}{*}{ Count } & \multirow{2}{*}{ Minimum } & \multirow{2}{*}{ Maximum } & \multicolumn{2}{|c|}{$\begin{array}{l}95 \% \text { Confidence } \\
\text { Interval Bounds }\end{array}$} \\
\hline & & & & & & Lower & Upper \\
\hline & \multicolumn{2}{|c|}{$\log _{10} k\left(m^{2}\right)$} & & \multicolumn{2}{|c|}{$\log _{10} k\left(m^{2}\right)$} & \multicolumn{2}{|c|}{$\log _{10} k\left(m^{2}\right)$} \\
\hline \multicolumn{8}{|c|}{ Aquifer-Scale Data } \\
\hline AA & -12.24 & 0.80 & 17 & -13.24 & -10.36 & -13.81 & -10.68 \\
\hline LCA & -12.15 & 1.43 & 5 & -13.53 & -9.92 & -14.95 & -9.36 \\
\hline $\begin{array}{l}\text { TM-WTA } \\
\text { TM-LVTA }\end{array}$ & -10.73 & 0.22 & 5 & -11.07 & -10.45 & -11.17 & -10.32 \\
\hline LTCU & -13.10 & $\mathrm{~N} / \mathrm{A}$ & 1 & $\mathrm{~N} / \mathrm{A}$ & $\mathrm{N} / \mathrm{A}$ & $\mathrm{N} / \mathrm{A}$ & $\mathrm{N} / \mathrm{A}$ \\
\hline \multicolumn{8}{|c|}{ Slug-Test-Scale Data } \\
\hline AA & -12.27 & $\mathrm{~N} / \mathrm{A}$ & 2 & -12.55 & -11.99 & $\mathrm{~N} / \mathrm{A}$ & $\mathrm{N} / \mathrm{A}$ \\
\hline BLFA & -12.40 & $\mathrm{~N} / \mathrm{A}$ & 1 & N/A & N/A & $\mathrm{N} / \mathrm{A}$ & N/A \\
\hline TM-WTA & -11.94 & $\mathrm{~N} / \mathrm{A}$ & 2 & -11.94 & -11.93 & $\mathrm{~N} / \mathrm{A}$ & N/A \\
\hline
\end{tabular}


Table 4-3

Summary of Measured Permeability for HSUs within the Frenchman Flat CAU Model Domain

(Page 2 of 2)

\begin{tabular}{|c|c|c|c|c|c|c|c|}
\hline \multirow{3}{*}{ HSU } & \multirow{2}{*}{ Mean } & \multirow{2}{*}{$\begin{array}{l}\text { Standard } \\
\text { Deviation }\end{array}$} & \multirow{3}{*}{ Count } & \multirow{2}{*}{ Minimum } & \multirow{2}{*}{ Maximum } & \multicolumn{2}{|c|}{$\begin{array}{l}95 \% \text { Confidence } \\
\text { Interval Bounds }\end{array}$} \\
\hline & & & & & & Lower & Upper \\
\hline & \multicolumn{2}{|c|}{$\log _{10} k\left(m^{2}\right)$} & & \multicolumn{2}{|c|}{$\log _{10} k\left(m^{2}\right)$} & \multicolumn{2}{|c|}{$\log _{10} k\left(m^{2}\right)$} \\
\hline \multicolumn{8}{|c|}{ Laboratory-Scale Data } \\
\hline AA & -12.36 & 0.73 & 50 & -14.94 & -11.32 & -13.80 & -10.93 \\
\hline TM-WTA & -12.49 & 0.76 & 11 & -13.91 & -11.57 & -13.98 & -10.99 \\
\hline LCA & -15.70 & 1.38 & 9 & -18.02 & -13.72 & -18.40 & -13.00 \\
\hline
\end{tabular}

Source: Modified from SNJV, 2004c, Table 5-1

$\mathrm{m}^{2}=$ Square meter

In addition to providing constraints on the HSU permeability, field data were evaluated to constrain the representation of anisotropy in the flow model. Little data exist on the anisotropy of volcanic and regional sedimentary HSUs; however, several studies of the Frenchman Flat alluvium provide insight into appropriate values for anisotropy in the AA.

Alluvial anisotropy results from permeability contrasts and the continuity of sedimentary layers that comprise the alluvium. Several indirect observations of alluvial anisotropy have been made and provide values ranging from 0.02 to 0.9 vertical to horizontal permeability ratio. With a range in estimated alluvial anisotropy of more than one order of magnitude, these data provided limited constraints on the model. Small-scale measurements of permeability from sediment cores collected at UE-5 PW-1 and UE-5 PW-2 (Figure 4-2) provide the most detailed data to calculate anisotropy. The vertical to horizontal permeability ratio values from these measurements range from 0.08 to 0.25. These values are similar to the SNJV (2004a) interpretation of the RNM-2S MWAT. Only one estimate of anisotropy is available for the OAA. Stoller-Navarro Joint Venture (2004b) reports a vertical to horizontal permeability ratio equal to 0.13 based on data interpretation from the ER-5-3 MWAT. On average, it is expected that as scale increases, anisotropy also increases in HSUs with pervasive layering. In the case of Frenchman Flat, sediment layers are generally not continuous (correlation lengths for saturated hydraulic conductivity is on the order of several tens of meters), likely reflecting the lobate nature of alluvial deposition and propagation of alluvial fans during 


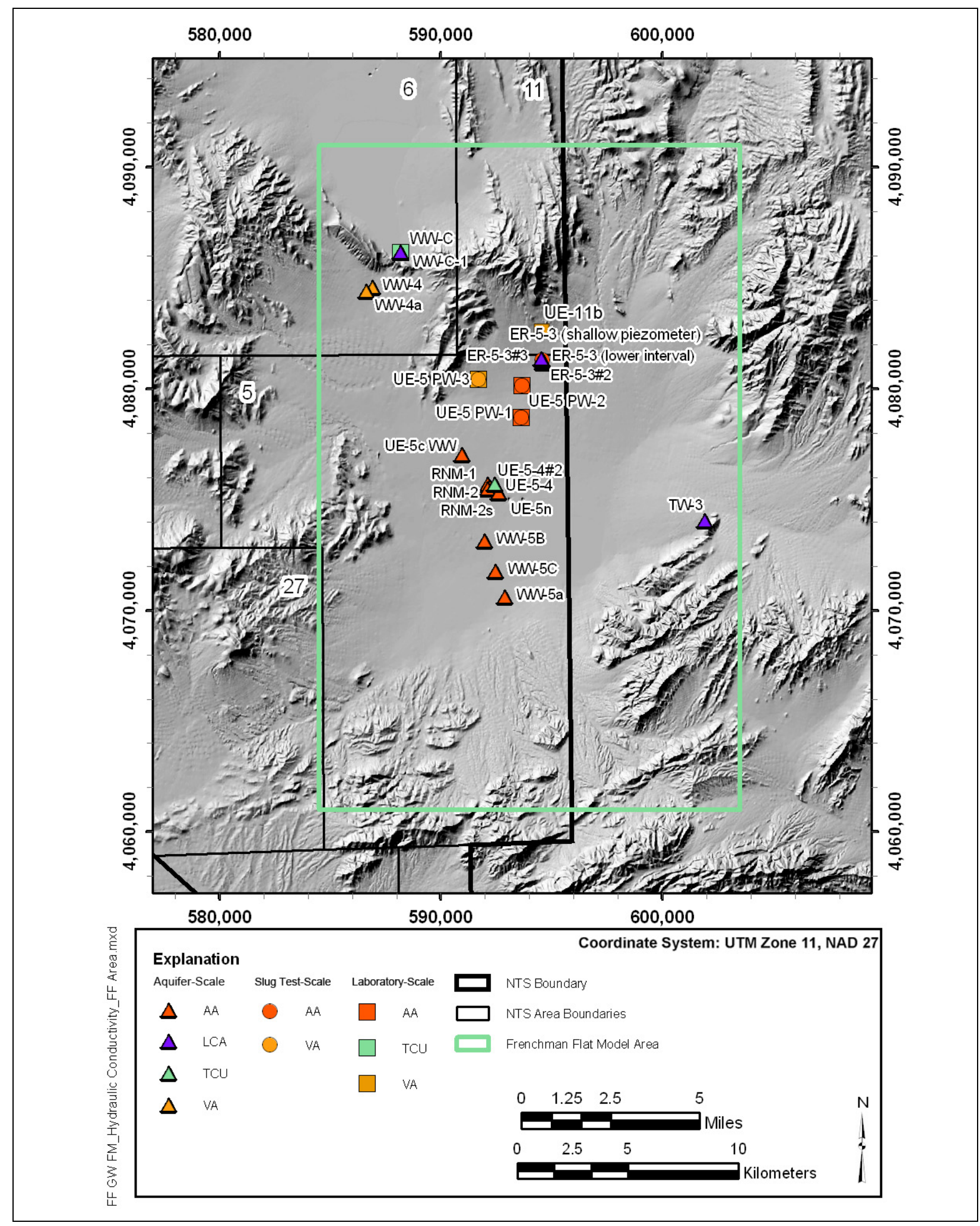

Figure 4-2

Frenchman Flat Hydraulic Property Data Locations

Source: Modified from SNJV, 2006 
development of the Frenchman Flat basin (Carle et al., 2002; Istok et al., 1994). Likewise, the LCA has been subjected to multiple tectonic events over long time intervals (hundreds of millions of years), and the local orientations and dips of these rocks can be highly variable (BN, 2005a). Consequently, there is no systematic basis for assessing the dip of these beds or in assigning anisotropy values, and no anisotropy values are assumed for this HSU. To the extent that anisotropy exists in the LCA, it is probably associated with the structural fabric of younger tectonic events associated with basin-and-range extension, and strike-slip faulting during basin formation; these effects are partly implemented in the model through the inclusion of major faults, including the Rock Valley fault system (BN, 2005a).

\subsubsection{Boundary Condition Uncertainty}

The solution of the groundwater flow equations requires specification of head and/or flow at the edges and at internal discharge points of the numerical model. This is a particularly challenging problem for the Frenchman Flat CAU model because the model boundaries do not coincide with natural hydrologic boundaries. The Frenchman Flat CAU model must account for regional inflow and outflow across all four edges and internal flow from precipitation recharge. There are no natural internal discharge locations within the Frenchman Flat CAU flow model domain.

Boundary condition uncertainty was addressed by incorporating multiple alternative approaches to assigning precipitation recharge to both the regional groundwater flow and CAU flow models (SNJV, 2004c). Calibrated regional models using specific recharge representations were used to supply the lateral boundary heads and flux targets for the CAU-scale flow model (SNJV, 2006). This approach allowed recharge uncertainty and subsequent lateral boundary condition uncertainty to propagate through the CAU flow model analysis (SNJV, 2006).

\subsubsection{Precipitation Recharge}

Recharge is implemented in the CAU model as a specified flux condition, where a given volume (mass) of water is applied to the top boundary of the model. Recharge flux is assumed to be constant over time for the duration of all simulations, but varies over the domain as a function of altitude and soil and vegetation types. Recharge is difficult to estimate in arid climates; as a result, three different methods to estimate precipitation recharge for the NTS region were incorporated into the CAU model 
development: an empirical mass-balance method and its derivatives (MME) (Maxey and Eakin, 1949), a deterministic method (USGSD) (Hevesi et al., 2003), and a chloride mass-balance method (DRIA) (Russell and Minor, 2002). The total mass flow over the Frenchman Flat model domain area for each recharge distribution is summarized in Table 4-4. The amount of recharge over the Frenchman Flat model domain is very small and does not vary significantly from one recharge dataset to another. Tyler et al. (1996) demonstrated that even during past pluvial conditions, little or no recharge occurred under the thick alluvium in Frenchman Flat in the interfluvial areas. Therefore, under the present arid conditions, no recharge is expected in the alluvial basin except possibly under arroyos or the playa. Differences among the recharge distributions are primarily manifested in the boundary heads and lateral boundary fluxes that are derived from the corresponding calibrated regional model (SNJV, 2004c).

Table 4-4

Total Recharge over the Frenchman Flat Model Area

\begin{tabular}{|c|c|c|}
\hline Recharge Model & \multicolumn{2}{c|}{ Total Mass Flow } \\
\cline { 2 - 3 } & $\mathbf{k g} / \mathbf{s}$ & $\mathbf{m m} / \mathbf{y r}$ \\
\hline \hline DRI - Chloride Mass Balance with Alluvial and Elevation Masks (DRIAE) & 4.45 & 0.246 \\
\hline DRI - Chloride Mass Balance with Alluvial Mask (DRIA) & 4.54 & 0.251 \\
\hline Original Maxey-Eakin from UGTA Regional Model (OME) & 22.79 & 1.261 \\
\hline Modified Maxey-Eakin from UGTA Regional Model (MME) & 8.63 & 0.478 \\
\hline USGS - Rainfall-Infiltration with Redistribution (USGSD) & 5.94 & 0.328 \\
\hline USGS - Rainfall-Infiltration without Redistribution (USGSND) & 5.26 & 0.291 \\
\hline USGS - Death Valley Regional Ground-Water Flow System (DVRFS) & 5.88 & 0.325 \\
\hline
\end{tabular}

Source: SNJV, 2006

$\mathrm{kg} / \mathrm{s}=$ Kilograms per second $\mathrm{mm} / \mathrm{yr}=$ Millimeters per year

\subsubsection{Inflow and Outflow (Lateral Boundary Flows and Boundary Heads)}

As noted, the Frenchman Flat CAU model boundary does not correspond to natural hydrologic boundaries. The boundary condition uncertainty was addressed by deriving sets of alternate boundary flows and associated boundary heads using multiple discrete calibrations of the UGTA regional model (DOE/NV, 1997; SNJV, 2006). Thirty models were used to represent the flow system by combining the five alternative HFMs (Section 4.1) and the first six recharge distributions on 
Table 4-4. The different HFMs reflect the effect of uncertainty in the geology. The recharge distributions represent different methods of approximating recharge for the NTS and Frenchman Flat areas. The DVRFS recharge distribution was not available at the time of SNJV (2004c) boundary flow and head analysis.

In general, groundwater is simulated in the UGTA regional model as flowing from the north and east toward the south and west through the Frenchman Flat CAU-flow model domain. This generalization remains consistent regardless of the recharge model or HFM. The lateral boundary fluxes are insensitive to changes in the HFM within the regional model, whereas the choice of recharge has a significant impact on the lateral boundary flows and heads, primarily by changing the heads and gradients along the boundaries of the models (SNJV, 2004c).

When it became available, lateral boundary flows and recharge flux estimates for the Frenchman Flat model domain were also obtained from the DVRFS model (Belcher et al., 2004). Flows are generally similar in magnitude and direction compared to the boundary flows estimated from the UGTA regional model. However, there are differences in the simulated flows across the southern and eastern boundaries between these two regional flow models. While both models simulate net inflows from the north and east into the Frenchman Flat CAU model domain, the UGTA regional model inflows from the east exceed those from the north; in contrast, the DVRFS model simulates more flow into the northern model boundary.

\subsubsection{Groundwater Discharge}

Within the Frenchman Flat area and vicinity, the only mechanism of groundwater discharge to the surface is withdrawal from the flow system by wells. Water-level measurements in wells have been recorded in Frenchman Flat since 1954. Evaluation of the water-level data by SNJV (2004c) established that groundwater levels at the site were generally in an equilibrium condition, and calibration targets were established to reflect pre-development conditions for the aquifer system. Lateral controls on groundwater flow and boundary conditions were difficult to determine at local scales within the basin using the available data. As a result, it was determined initially that a large-scale, steady-state CAU flow model would be constructed, calibrated, and evaluated for use in contaminant boundary forecasts, as described by SNJV (2006). 
Transient effects in the system, such as those influenced by water-well withdrawals and the CAMBRIC RNM experiment, were considered as potential complications in the use of a steady-state model to develop contaminant boundary forecasts because these localized changes to the flow system occur in areas near underground nuclear tests. As a result, local-scale transient models were developed of the 16-year CAMBRIC RNM experiment and water-well withdrawals in central Frenchman Flat (Carle et al., 2007; NNES, 2010). The RNM experiment generated a significant local transient effect that involved the withdrawal of water, and the extraction of radionuclides from RNM-2S and their subsequent redistribution to groundwater underneath the discharge ditch.

The small-scale model of the Central Testing Area, and specifically the CAMBRIC RNM experiment, was constructed as a submodel of the larger-scale CAU model, paralleling a more detailed model and analysis of radionuclide release and ditch recirculation conducted by LLNL as part of the HST analysis for Frenchman Flat (Carle et al., 2007). This submodel derived hydraulic boundary conditions from the parent steady-state CAU-scale model, and its development was consistent with the uncertainty analysis required by the FFACO (1996, as amended March 2010) and addendum to the Corrective Action Investigation Plan (NNSA/NV, 2001). The domain of the transient Central Testing Area model is shown in Figure 4-3.

Concerns over the effects of past, present, and future groundwater withdrawals for water supply on plume migration rates and trajectories in central Frenchman Flat prompted the development of an additional transient-flow model to address this issue. After the RNM experiment simulations, the sub-CAU model was extended to the southeast by several kilometers to encompass water-supply Wells WW-5a, WW-5b, and WW-5c, allowing the possible effects of pumping from these wells on groundwater flow paths and subsequent contaminant migration to be investigated - no impact on contaminant boundary forecasts is expected due to water withdrawals based on this analysis (NNES, 2010). Therefore, the extended sub-CAU model footprint was not used during contaminant boundary simulations.

\subsubsection{CAU-Scale Calibration Constraints}

The groundwater flow model of the Frenchman Flat CAU required a calibration dataset. This dataset includes four estimated lateral boundary flows from the regional model analysis and a set of 30 observed water-level measurements. The calibration was guided by the site-specific and regional 


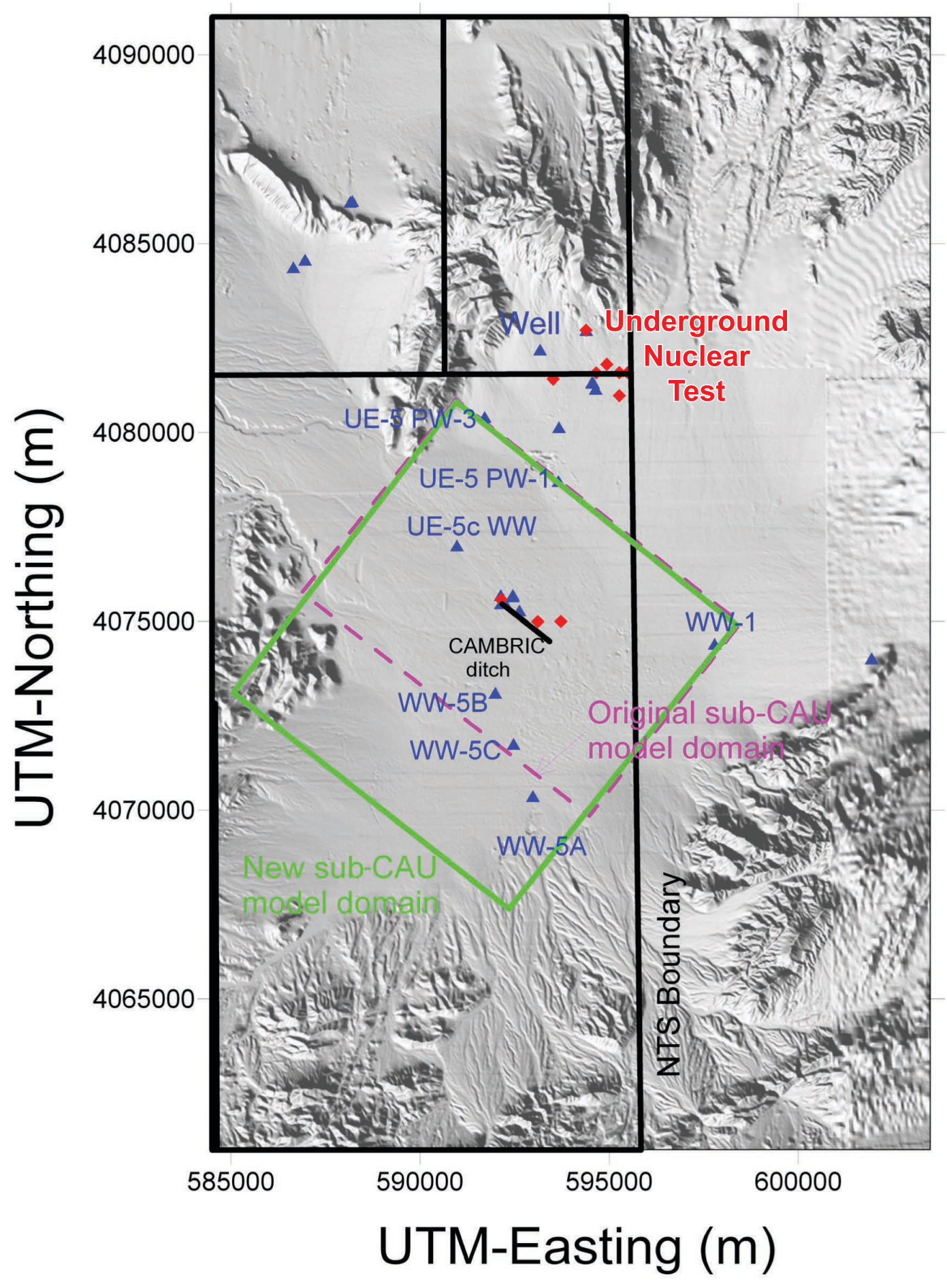

Figure 4-3

Map Showing the New and the Original Sub-CAU Model Domains along with Selected Wells

Source: NNES, 2010 
hydraulic property data and qualitative information provided by internal review by organizations participating in the UGTA Subproject and anticipated hydrostratigraphic relationships.

The mean, standard deviation, and range of the water levels for different HSUs in the Frenchman Flat basin are provided in Table 4-5. The summary does not include data for the Timber Mountain HSUs from CP basin (physically separate from Frenchman Flat), which are approximately $110 \mathrm{~m}$ higher than in Frenchman Flat. The water-level measurement from the LTCU at Well ER-5-4 \#2 is unlikely to be representative of the LTCU throughout Frenchman Flat because the water level had not yet stabilized at the time of measurement. The summary in Table 4-5 demonstrates that hydraulic heads in Frenchman Flat have limited variability within the alluvium and between the alluvium and tuff aquifers; heads within the alluvial and tuff aquifers are generally about $7 \mathrm{~m}$ higher than in the LCA. The steady-state head values are shown by hydrostratigraphic group in Figures 4-4 through 4-6.

Table 4-5

Summary of Water-Level Measurements

\begin{tabular}{|c|c|c|c|c|c||}
\hline HSU & $\begin{array}{c}\text { Number of } \\
\text { Static } \\
\text { Water-Level } \\
\text { Measurement } \\
\text { Sites }\end{array}$ & $\begin{array}{c}\text { Minimum } \\
\text { Static } \\
\text { Water-Level } \\
(\mathbf{m} \text { ams })\end{array}$ & $\begin{array}{c}\text { Average Static } \\
\text { Water-Level } \\
(\mathbf{m} \text { ams } \mathbf{)}\end{array}$ & $\begin{array}{c}\text { Maximum } \\
\text { Static } \\
\text { Water-Level } \\
(\mathbf{m} \text { ams } \mathbf{)}\end{array}$ & $\begin{array}{c}\text { Standard } \\
\text { Deviation } \\
(\mathbf{m})^{\text {a }}\end{array}$ \\
\hline \hline AA & 17 & 720.2 & 732.9 & 735.1 & 1.4 \\
\hline OAA & 1 & 733.8 & 733.9 & 734.1 & N/A \\
\hline TM-WTA ${ }^{b}$ & 4 & 733.1 & 733.7 & 734.0 & 0.2 \\
\hline TM-LVTA & 1 & 734.6 & 734.6 & 734.6 & N/A \\
\hline LTCU ${ }^{c}$ & 1 & N/A & 755 & N/A & N/A \\
\hline LCA ${ }^{d}$ & 4 & 725.1 & 726.6 & 728.1 & 1.0 \\
\hline
\end{tabular}

Source: SNJV, 2006

a Standard deviation reported by SNJV, 2004c.

${ }^{b}$ Water-level measurements at CP basin for WW-4 and WW-4A are not included in the above data because they are physically separate from the Frenchman Flat basin. These measurements (844 and $845 \mathrm{~m}$ ) are much higher than those observed within the Frenchman Flat basin.

c This water-level measurement was measured at Well ER-5-4 \#2 and may not representative of the LTCU in other parts of the Frenchman Flat basin (see text for discussion).

${ }^{\mathrm{d}}$ Three water-level measurements outside the Frenchman Flat basin are included in these data because they are consistent with the regional LCA data and with the only LCA water-level measurements $(727.1 \mathrm{~m})$ available for the Frenchman Flat basin at Well ER-5-3 \#2. 


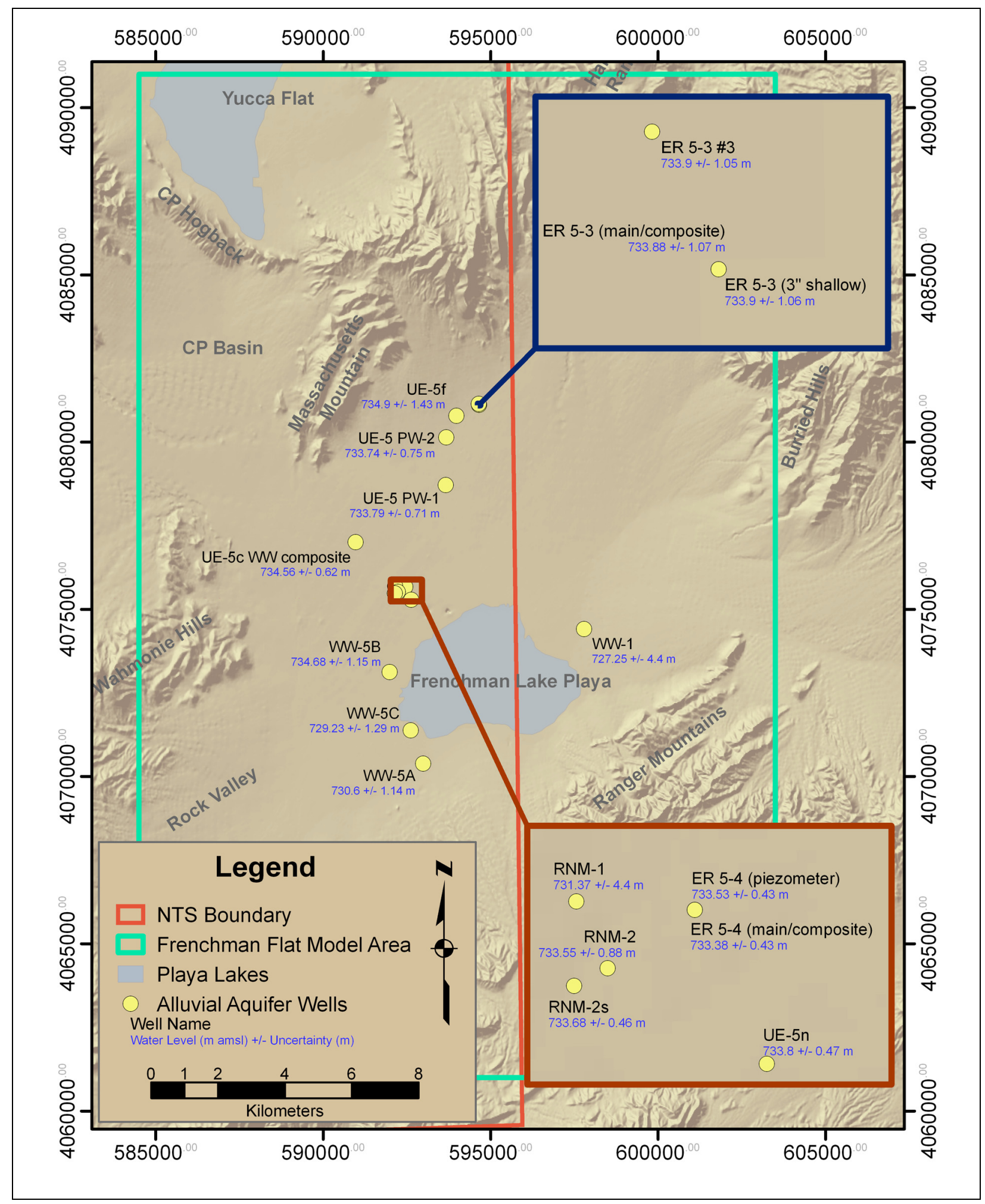

Figure 4-4

Alluvial Aquifer Well Locations and Steady-State Heads

Source: SNJV, 2006 


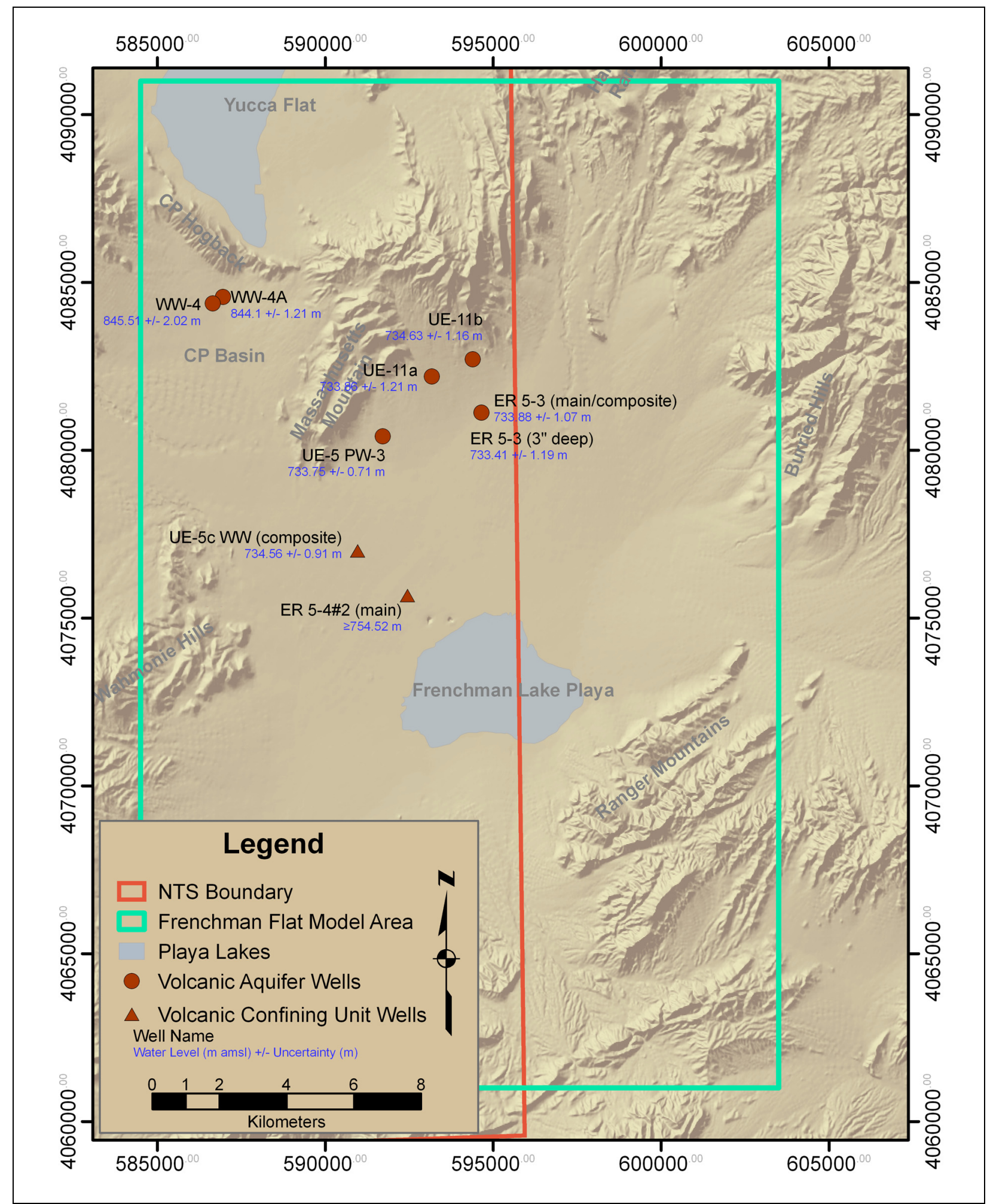

Figure 4-5

Volcanic Aquifer and Confining Unit Well Locations and Steady-State Heads Source: SNJV, 2006 


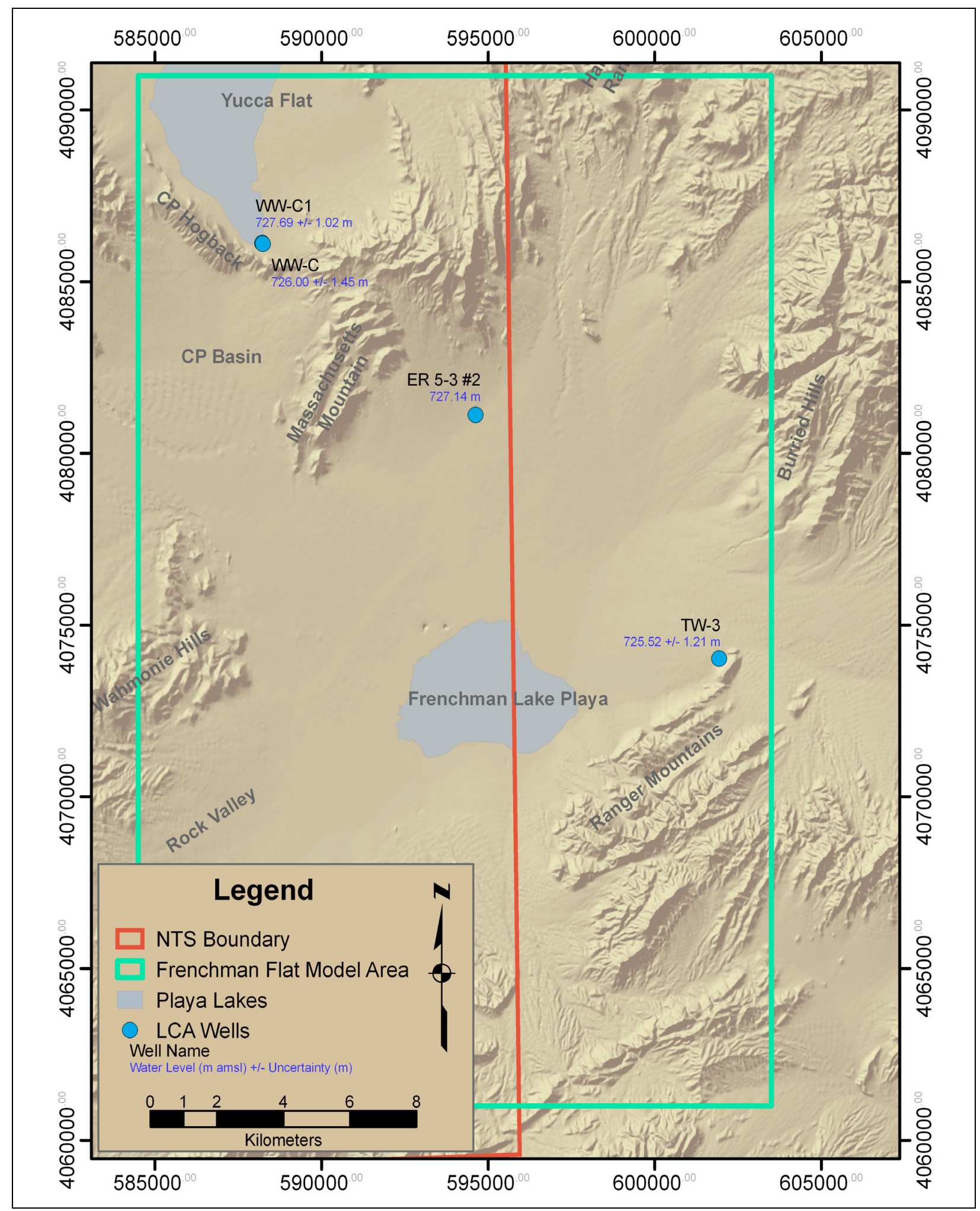

Figure 4-6

Lower Carbonate Aquifer Well Locations and Steady-State Heads

Source: SNJV, 2006 


\subsubsection{Transient Central Testing Area Calibration Constraints}

The transient model of the Central Testing Area was constrained by the following data:

- Data on the historical pumping rate from RNM-2S

- Head data at RNM-1, ER-5-4, and RNM-2S from the RNM-2S MWAT (SNJV, 2004c)

- Data on radionuclide concentration in the RNM-2S effluent

- Water-level changes at UE-5n

- Tritium breakthrough at UE-5n

\subsection{Contaminant Transport Models}

Within the context of a CAU model, the transport model is based on a collection of process submodels, often simplified, that simulate radionuclide releases into groundwater at each underground nuclear test. Uncertainty is present in all of the model components and must, according to the FFACO, be considered in developing the contaminant boundary.

\subsubsection{Contaminant Source Term for Transport Calculations}

For the Frenchman Flat CAU analysis, LLNL constructed and calibrated a detailed model of the 16-year CAMBRIC RNM experiment conducted in the saturated portion of the alluvial aquifer in central Frenchman Flat (Carle et al., 2007). This work explicitly represented HST processes in a well-characterized test cavity and exchange volume, and provided detailed insight into the groundwater flow and radionuclide transport within the alluvial aquifer and around the cavity and melt glass zones at CAMBRIC, as well as the trench and Frenchman Lake areas.

Neither sufficient data nor resources are available to support the development of detailed HST process models for all tests within the NTS; therefore, simplified source term models (SSMs) were developed to capture the important processes and uncertainties of the HST. The Frenchman Flat SSMs were developed from a steady-state process HST model that eliminated the RNM experiment groundwater withdrawals and reinfiltration (Tompson et al., 2005) from the CAMBRIC analysis. These SSMs serve as the source-release function for the DERRINGER, NEW POINT, MINUTE STEAK, DIANA MOON, DILUTED WATERS, and WISHBONE tests, all of which were conducted in the unsaturated zone (Figure 3-2). 
The hydrogeologic settings of the PIN STRIPE and MILK SHAKE tests are significantly different than the CAMBRIC test. The PIN STRIPE test was detonated in volcanic tuff (TM-LVTA), and the cavity is located entirely above the water table. A fraction of the PIN STRIPE exchange volume is located below the water table in welded tuff (TSA). The MILK SHAKE test was performed in alluvium, and the center of the test emplacement (working point) and majority of the cavity is located above the water table. The lower fraction of the MILK SHAKE cavity and exchange volume is located below the water table in basalt lava (BLFA). Because of the different rock types at the test cavities, the CAMBRIC test may not accurately represent the processes that impact the release and transport of radionuclides in the near-field environment at the PIN STRIPE and MILK SHAKE tests. The effects of underground nuclear testing on rock properties vary by rock type, and it cannot be assumed that CAMBRIC is representative of PIN STRIPE and MILK SHAKE. Further, the relative impact of the PIN STRIPE and MILK SHAKE tests on the contaminant boundary forecast is much greater than the other Frenchman Flat tests because both tests have exchange volumes that intersect low-effective porosity fractured rock aquifers at the water table (NNES, 2010).

Therefore, simplified process models focusing on the uncertainty of source release were constructed for PIN STRIPE and MILK SHAKE to supplement the abstraction developed from CAMBRIC for tests in alluvium. The conceptual approach for the SSMs only includes the most important processes of release of radionuclides from the source region. These processes are largely taken from detailed HST modeling performed by the LLNL for the NTS CAUs, including the CAMBRIC test (Tompson et al., 1999 and 2005; Carle et al., 2007); tests in Areas 2 and 3 (Maxwell et al., 2008); the HANDCAR and NASH carbonate test (Carle et al., 2008); and the CHESHIRE test on Pahute Mesa (Pawloski et al., 2001).

\subsubsection{Computational Approach}

The addendum to the Corrective Action Investigation Plan (NNSA/NV, 2001) specifies the use of FEHM (Zyvoloski et al., 1997) for groundwater flow and transport modeling and that the transport simulations will be performed with a 3-D streamline particle-tracking technique whenever possible. The FEHM code was selected based on a number of attributes or capabilities needed to satisfy the modeling objectives. The required code attributes that were defined consistently with the three modeling objectives were categorized under general, flow model, and transport model (Table 4-6). 
Table 4-6

Required Hydrologic Code Attributes ${ }^{a}$

\begin{tabular}{|c|c|c|}
\hline General Attributes & Flow Model Attributes & Transport Model Attributes \\
\hline $\begin{array}{ll}\text { - } & \text { Fully three-dimensional } \\
\text { - } & \text { Large number of nodes } \\
\text { - } 500,000 \text { or more) capability } \\
\text { - } \text { Multiple boundary } \\
\text { condition options } \\
\text { - } & \text { Transient capability } \\
\text { - } & \text { Efficient solver } \\
\text { - } & \text { Acceptable numerical accuracy } \\
\text { - } & \text { Ainimal numerical dispersion } \\
\text { - } & \text { and validation } \\
\text { Access to source code }\end{array}$ & $\begin{array}{ll}\text { - } & \text { Saturated groundwater flow } \\
\text { - } & \text { Heterogeneous and anisotropic } \\
\text { hydraulic conductivity } \\
\text { - }\end{array}$ & $\begin{array}{l}\text { - Advection, dispersion, sorption, } \\
\text { and matrix diffusion } \\
\text { - } \quad \text { Radioactive decay }\end{array}$ \\
\hline
\end{tabular}

Source: Modified from DOE/NV, 1999b

a Order of attributes does not indicate order of importance.

Streamline particle-tracking mass transport modeling techniques are available in the FEHM code and provide the numerical foundation for all steady-state transport calculations for the Frenchman Flat CAU. In this approach, advection, dispersion, matrix diffusion, sorption, and radioactive decay of dissolved chemical mass from a source is simulated with a finite distribution of (numerical) particles.

For steady-state groundwater flow, transport can be simulated quickly in the stand-alone code PlumeCalc (Robinson and Dash, 2006). PlumeCalc is a streamline-based convolution transport code that employs a convolution-based particle-tracking technique to simulate resident or flux-averaged solute concentrations in groundwater models. This approach is able to more efficiently compute transport when the flow field is steady state and processes such as sorption, matrix diffusion, and decay are mathematically linear. Under such conditions, contaminant concentrations can be calculated using the principle of superposition with multiple solute sources and numerical convolution to handle time-varying source-release functions. Because the convolution-based particle-tracking method uses particle tracking, it is able to maintain sharp fronts for advection-dominated transport problems common in groundwater modeling. PlumeCalc outputs concentration on the same model control volumes used in the particle tracking. PlumeCalc also has a feature called the virtual subgrid, where runtime local refinement can be made to compute the concentration on smaller control volumes of a given subset of the particle tracking control 
volume - the properties remain the same, but the resolution of the calculation is locally increased. Using the virtual subgrid, a local increase of 4 was used in all grid dimensions during transport simulations (NNES, 2010).

Calculations of contaminant transport for the CAMBRIC RNM experiment transient flow fields were completed using the FEHM continuum transport model for those radionuclides observed in the RNM experiment breakthrough at UE-5n. For all other radionuclide species, the steady-state flow field was used and transport calculations were completed with PlumeCalc (Robinson and Dash, 2006; described above) and the SSM aqueous-phase, source-term release functions. The continuum and SSM results were added to the streamline particle tracking results to complete the contaminant boundary calculations.

\subsubsection{Transport Parameters}

The calculation of the contaminant boundary requires many parameters, all of which are uncertain. In assigning probability distributions to capture parametric uncertainty, a few general guidelines are followed as described by Mishra (2002). In general, uniform (and log-uniform) distributions are applied to uncertain quantities where the data range can be established based on physical arguments, expert knowledge, or historical data - but little else is known about the relative likelihood of values within this range (distribution shape). Triangular (and log-triangular) distributions are appropriate for uncertain quantities where a most likely value can be established in addition to the range of possible values - but where the shape of the distribution can only be approximated. When sufficient data were available, distributions were not fitted to data using all possible distribution types; instead, the empirical cumulative distribution functions were sampled directly. This section reviews major rock groupings used when describing the required transport parameters associated with the Frenchman Flat model, and the method used for generating samples for Monte Carlo analysis as required by the Frenchman Flat Corrective Action Investigation Plan (DOE/NV, 1999a) and its addendum (NNSA/NV, 2001).

Bechtel Nevada (2005a) grouped rocks within the model area into hydrogeologic units based on lithologic character, propensity to fracture, and degree of secondary alteration. The rocks of the Frenchman Flat model area are classified as one of the following eight hydrogeologic units: playa confining unit (PCU), alluvial aquifer (AA), welded-tuff aquifer (WTA), vitric-tuff aquifer (VTA), 
lava-flow aquifer (LFA), tuff confining unit (TCU), clastic confining unit (CCU), and carbonate aquifer (CA). These units are described in more detail in BN (2005a).

Uncertain model parameters for the transport simulations including fracture porosity and aperture, matrix and effective porosity, linear distribution coefficients $\left(\mathrm{K}_{\mathrm{d}}\right)$, and matrix diffusion have assigned distributions developed that were sampled during Monte Carlo transport simulations based on individual hydrogeologic units. Fracture retardation was neglected because of limited data and information to support conceptual understanding of these processes for the Frenchman Flat rocks (NNES, 2010).

The Monte Carlo method is proposed in the Frenchman Flat Corrective Action Investigation Plan (DOE/NV, 1999a), its addendum (NNSA/NV, 2001), and modeling strategy (IT, 2001). The method is most suited for analyzing parameter uncertainty that can be described in the form of statistical distributions, or elements of a conceptual model that can be represented parametrically (e.g., sorption from none to some higher value), rather than high-level conceptual uncertainty. Conducting a Monte Carlo analysis requires many samples, or realizations, of the uncertain input transport parameters described in this section.

Parameter distributions were sampled during transport simulations using the Latin Hypercube sampling approach (McKay et al., 1979), also termed stratified sampling with replacement. This approach (Imam and Helton, 1991; Helton, 1999) gives more efficient statistical stability for complex systems. The commercially available Crystal Ball software (Decisioneering, Inc., 2005) version 7.1 was used to generate Latin Hypercube samples for input into the CAU transport model. To ensure consistency among the distribution coefficients of multiple radionuclides, many of which depend on the presence or absence of essentially the same minerals, the Spearman rank correlation coefficients were used in conjunction with the restricted-pairing approach of Iman and Conover (1982) to maintain the appropriate rank correlations in each realization (NNES, 2010).

\subsubsection{Contaminant Boundary and Uncertainty Calculations}

The final product of the Frenchman Flat CAU transport simulations is an ensemble of model-computed contaminant boundaries, determined by a 5 th percentile likelihood of exceeding Safe Drinking Water Act standards, which are subsequently used in negotiation of a compliance 
boundary for the CAU (FFACO, 1996; as amended March 2010). Under completely certain conditions, the contaminant boundary represents a dividing line that envelops the greatest areal extent (as projected onto the land surface) under which the radionuclide concentration of groundwater would exceed the relevant regulatory standards for radionuclides (defined by the State of Nevada as the Safe Drinking Water Act [CFR, 2009]) over a 1,000-year period. In reality, however, multiple components of uncertainty are present in the site characterization data and in model representations of flow and transport process, and the location of the boundary is determined probabilistically to quantitatively represent the effects of uncertainty. The compliance boundary is to be negotiated by NNSA/NSO and NDEP using the contaminant boundary results as the starting point of the negotiations (FFACO, 1996; as amended March 2010). 


\subsection{Model Results}

Groundwater flow models of the Frenchman Flat area included steady-state models designed to address conceptual model and parametric uncertainty. A synopsis of these groundwater flow models developed during the Phase II CAI is provided in Appendix C. The steady-state models were analyzed for parameter sensitivity, parameter correlations, and agreement and consistency with conceptual and corroborative data of the flow system. These models also formed the foundation for local-scale, transient models used to investigate specific perturbations to the groundwater flow system in areas with likely contaminant migration. The calibration of multiple alternative models of groundwater flow is consistent with the requirements of the FFACO (1996, as amended March 2010). For the UGTA Subproject, multiple alternative representations of groundwater flow that combine hydrostratigraphic framework and boundary condition uncertainty are combined with Monte Carlo transport simulations to capture an ensemble of contaminant boundary forecasts.

Contaminant transport models were developed at several scales. The contaminant transport analyses reflect an evolving understanding of both the flow system and the critical factors influencing contaminant migration within the Frenchman Flat CAU. Early in the Phase II CAI, LLNL generated a steady-state flow model of contaminant migration at the CAMBRIC test, which was conducted in the saturated alluvium of Frenchman Flat (Tompson et al., 2005). This model was abstracted in an effort to provide source release functions from the Frenchman Flat test cavities (SNJV, 2005d). This approach proved inadequate for tests where the contaminant source and associated exchange volume intersect fractured volcanic rocks. For these cases (PIN STRIPE and MILK SHAKE tests), separate source release models were developed to better represent the test cavities in brittle, fractured rock (NNES, 2010). Additionally, a modeling study completed by LLNL during 2007 (Carle et al., 2007) demonstrated that the transient changes to the groundwater flow field and the complex distribution of contaminants resulting from the CAMBRIC RNM experiment necessitated further transport analysis in the central portion of the Frenchman Flat basin. As a result, sub-CAU models were developed for 
the Phase II CAI contaminant boundary calculations, which included additional flow-field complexities in the Central Testing Area.

This section summarizes the primary results from the flow and transport models for the Phase II Frenchman Flat CAI.

\subsection{Steady-State Groundwater Flow}

In developing groundwater flow models of the Frenchman Flat CAU (described in detail by SNJV [2006] with supplemental analysis in NNES [2010]), a single HFM and recharge model were selected to represent a baseline case. This baseline model was then used to compare models addressing conceptual uncertainty (SNJV, 2006). The baseline model was intended to represent the most integrated understanding of the flow system at the initiation of flow model development and calibration. The steady-state groundwater flow model using the BASE HFM in conjunction with a water-balance model of infiltration and recharge model (designated the USGSD model; Hevesi et al., 2003) was selected as the baseline model (designated the BASE-USGSD flow model). The boundary conditions were taken from the regional model by interpolating hydraulic heads produced with the regional model (SNJV, 2004c) onto the lateral boundaries of the BASE-USGSD model. The net groundwater fluxes calculated by the regional model along the planes coinciding with the lateral boundaries of the BASE-USGSD flow model were used along with 30 hydraulic head measurements to calibrate the model (Figure 3-2).

Calibration of the BASE-USGSD flow model was accomplished through a combination of automated parameter estimation using parameter estimation software (PEST) (Doherty, 2008) and manual adjustments to the model parameters guided by iterative sensitivity analyses. Automated parameter estimation was successful in matching boundary fluxes but was less successful in matching hydraulic heads within the flow model area. Typically, manual adjustments to the model parameters were required to obtain a set of simulated heads consistent with the uncertainty of the measured hydraulic heads. Simulated heads generally matched the measured heads to within the uncertainty limits estimated for the measurements except at wells in the LCA near the northern boundary of the model (WW-C and WW-C1, Figure 5-1). Poorer calibration to these LCA observations may be the result of proximity to the uncertain boundary conditions or may be related to local structures within Yucca Flat basin that are not well represented in the Frenchman Flat model. Permeability within the model 


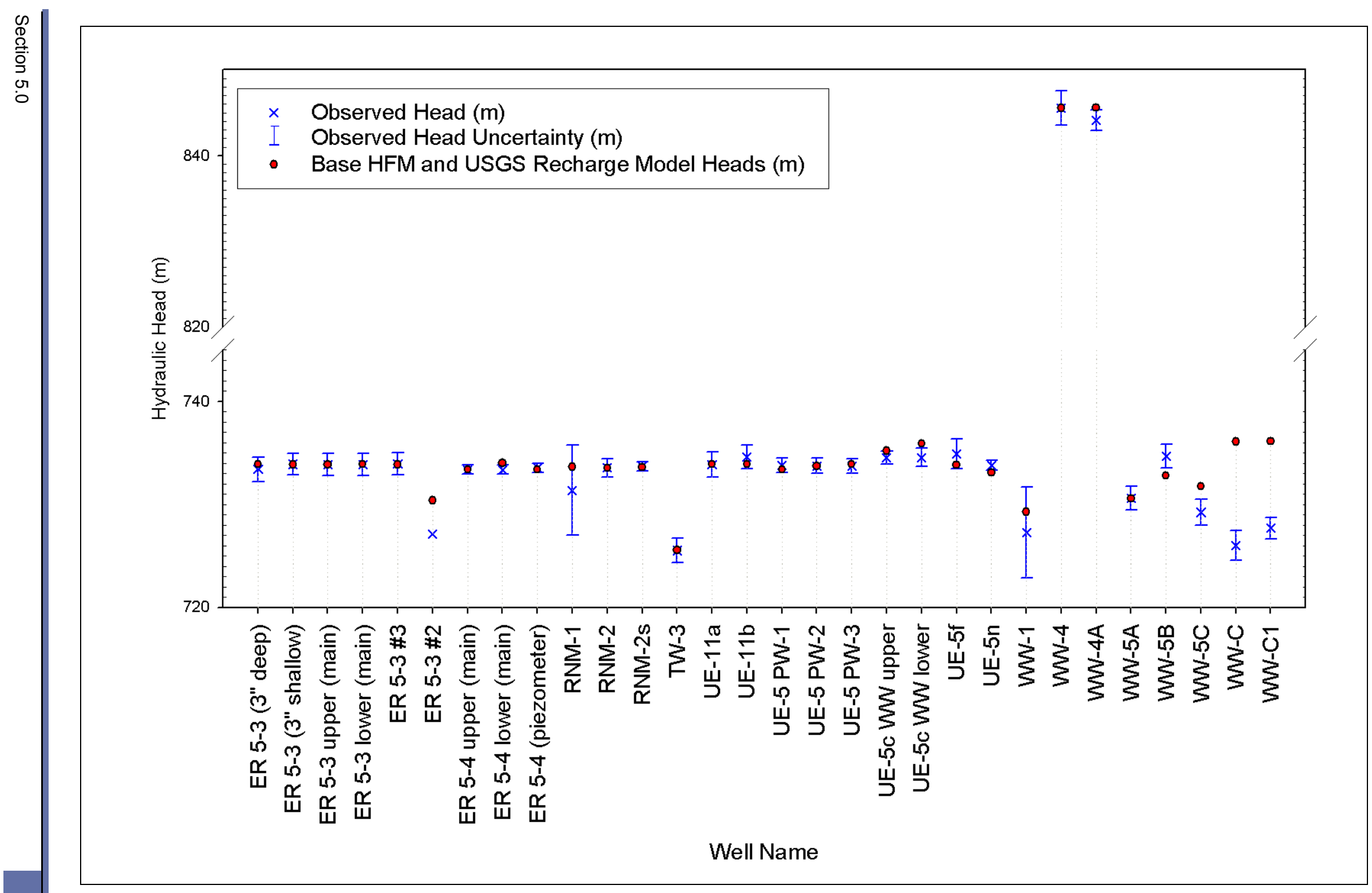


varied among the HSUs and as a function both of depth and parameter assignment to each unit. Permeability modification factors were then applied to the faults during calibration. Appendix C provides summary statistics for each calibrated flow model.

The simulated heads in the AA matched the head data with a high degree of accuracy, and correctly simulated the near-absence of both lateral (Figure 5-2) and vertical gradients within the AA indicated by the data. A comparison of measured heads at the ER-5-3 and ER-5-4 well complexes with a vertical profile of simulated heads produced with the BASE-USGSD flow model indicated that both measured and modeled vertical head gradients are virtually non-existent between the alluvium and the underlying volcanic aquifers. Therefore, there seems to be very little potential for downward flow in the alluvium, despite the overall drop in heads between the alluvium and the carbonate aquifer. The data and the model results indicate that most of the head loss between the alluvium and the carbonate aquifer occurs across the thick confining units, like the LTCU, that are present beneath the basin (see Plate 1).

The permeabilities estimated during calibration of the BASE-USGSD flow model were compared to the data from Frenchman Flat supplemented with analog data from the NTS region. The match between the estimated and measured permeabilities is reasonable in most cases (SNJV, 2006; NNES, 2010). For some HSUs, such as the AA and the LTCU, the estimated permeabilities were skewed toward the lower end of the observed data range. Alternative calibrations with somewhat improved matches to specific permeability data were achieved in alternative models addressing parameterization or conceptual model uncertainty (see Appendix C; SNJV, 2006; NNES, 2010).

The final permeability fields associated with the calibrated models reflect differences among the permeabilities estimated for the different HSUs, the effect of decay in permeability with increasing depth, and the effects of permeability changes associated with faults (Figure 5-3). The permeability fields that result from the superposition of these effects can be very complex in some areas, particularly in the Northern Testing Area, where groundwater flow bifurcates due to structural control and HSU continuity, with flow north of a detachment fault (see Plate 2, Fault ID Number 36) flowing east or northeast, and groundwater to the south of the detachment fault flowing predominantly south or southeast. 


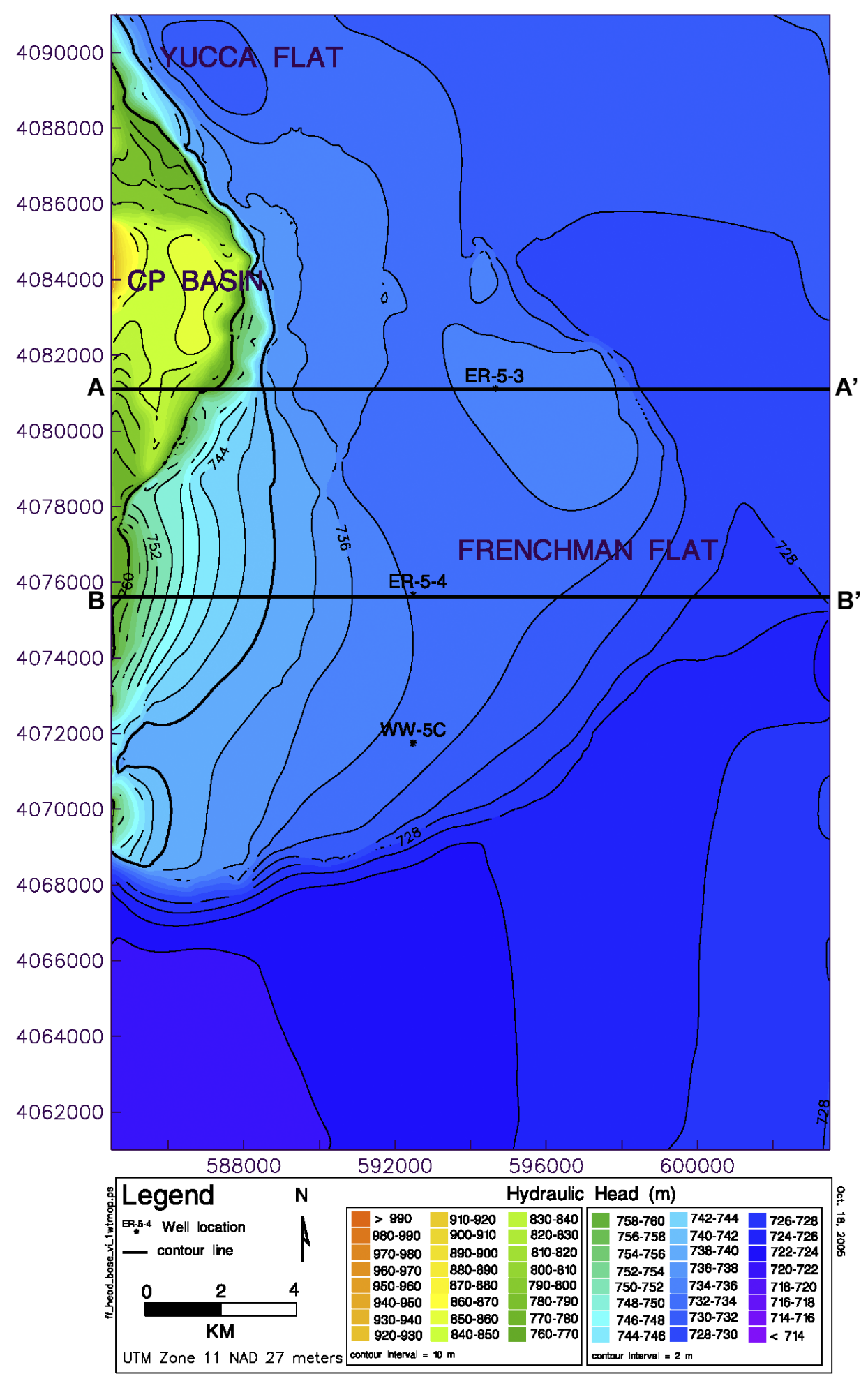

Figure 5-2

Water-Table Contours for the Calibrated BASE-USGSD Model

Source: SNJV, 2006 


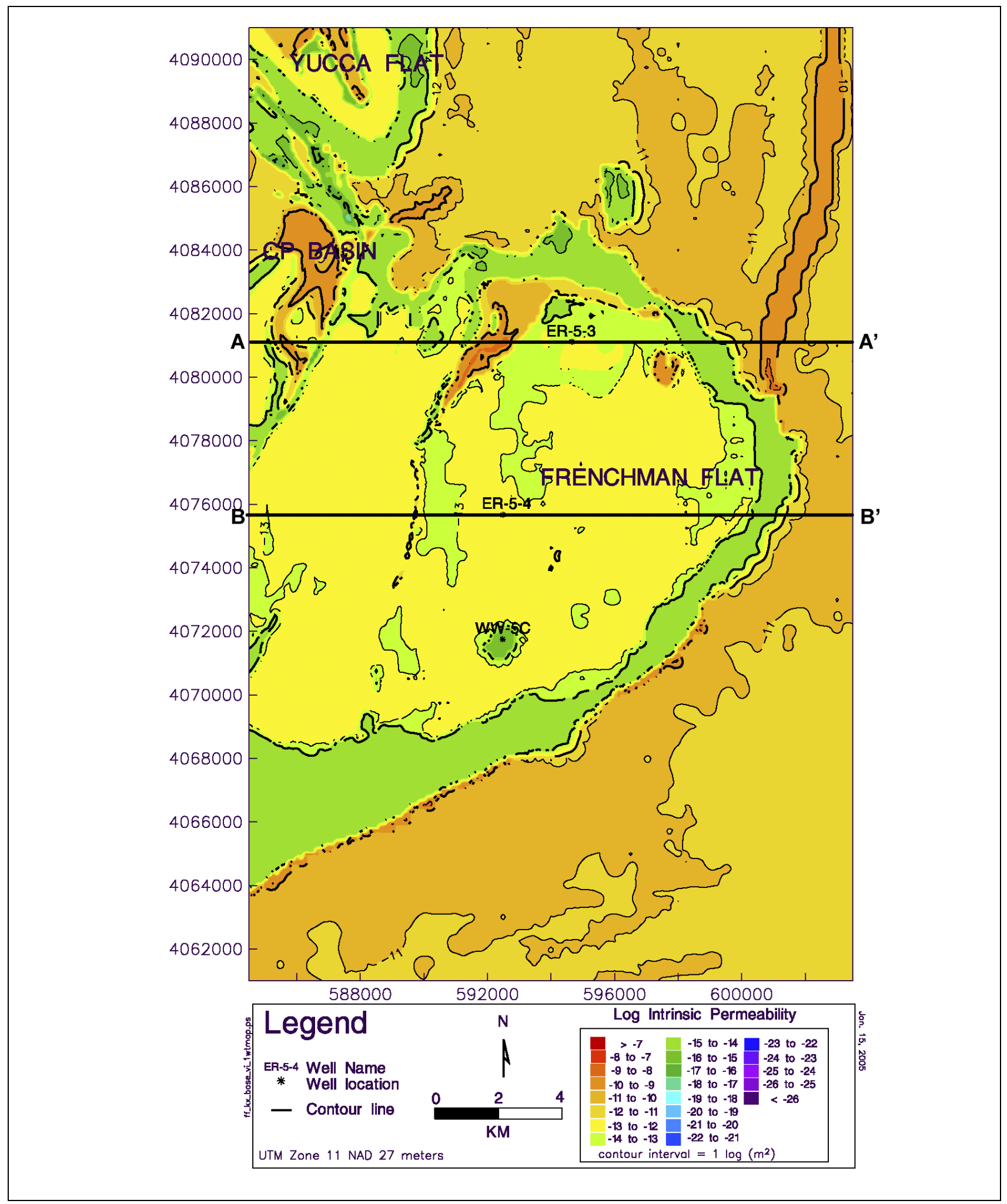

Figure 5-3

Calibrated Intrinsic Permeability at the Water Table for the BASE-USGSD Model

Source: SNJV, 2006 


\subsubsection{HFM Uncertainty}

Steady-state groundwater flow models were used to assess conceptual model uncertainty in interpreted aspects of the Frenchman Flat hydrostratigraphy (i.e., structural uncertainty). Each of the HFMs included 17 HSUs, of which 9 were aquifers and 8 were confining units, and more than 70 faults were included based on their potential hydrologic significance (BN, 2005a). Each HFM was used in conjunction with the lateral and recharge boundary conditions taken from a water-balance model of infiltration and recharge model (designated the USGSD model) to produce a calibrated model of the Frenchman Flat flow system (see Appendix C; SNJV, 2006; NNES, 2010).

Independently calibrated models for the BASE-USGSD and CPBA-USGSD models provide generally similar fits for boundary fluxes and simulated heads, with the exception of measured heads in southern Yucca Flat and CP basin, where the heads are better simulated by the BASE-USGSD model (see Appendix C). The attempts to calibrate the DISP-USGSD model show that a completely open connection between the alluvium and the LCA is unrealistic, but decreasing the fault permeability multipliers through the Tertiary volcanics allows for a good simulation of water-level observations. The BLFA-USGSD and DETA-USGSD model alternatives were calibrated using the parameters estimated during calibration of the BASE-USGSD model, thus indicating that observed water levels used as calibration constraints were not sensitive to these structural changes within the HFM.

All of the models built to address HFM uncertainty show similar flow fields in the testing areas compared to the BASE-USGSD and, by extension, with the conceptual model foundation provided by Winograd and Thordarson (1975) of the Frenchman Flat groundwater system. Flow fields in the testing areas were compared for the alternative models using particle tracks that originated at each of the test-cavity corrective action sites. The largest differences are in the paths starting in the vicinity of PIN STRIPE and MILK SHAKE. The flow paths at PIN STRIPE are very sensitive to the direction and magnitude of flow within a narrow band of fractured volcanic rock along the northern edge of the basin, and the flow paths at MILK SHAKE are sensitive to the local distribution and hydraulic properties of basaltic volcanic rocks. Therefore, the BLFA alternative HFM produced different flow pathways from the MILK SHAKE test cavity. However, the calibrated permeability of the BLFA HSU in all of the HFMs was not constrained by the observed water levels. 


\subsubsection{Boundary Condition Uncertainty}

The two HFMs that are most distinctly different based on calibration with the USGSD boundary conditions (BASE HFM and CPBA alternative HFM) were combined with the DRIA-, MME-, and DVRFS-recharge maps and boundary heads (Table 4-4) to investigate the effects of conceptual model uncertainty resulting from variations in boundary conditions. Because areal recharge provides limited water flux into the top of the Frenchman Flat CAU flow model domain (SNJV, 2006), differences among the boundary heads assignments and boundary flux targets dominated the effects of boundary condition uncertainty on the flow field.

Results for the BASE HFM and CPBA alternative HFM using the MME boundary conditions and original UGTA regional model (DOE, 1997) (BASE-MME and CPBA-MME) are most similar to the BASE-USGSD model and provided the best overall match to the hydraulic head calibration data (see Appendix C).

Results using the DVRFS (Belcher et al., 2004) regional model-derived boundary conditions using the BASE HFM and CPBA alternative HFM (BASE-DVRFS, CPBA-DVRFS), however, are the most dissimilar to the BASE-USGSD model. Although the models calibrated with the DVRFS boundary conditions provided as good a fit as other models to the hydraulic head at the observations within the basin-fill units and the boundary flows, the simulated head in LCA for both models was higher than heads measured in the overlying alluvium and tuffs. This indicates an upward head gradient between the alluvium and LCA, contrary both to the hydraulic head data and the conceptual understanding of the Frenchman Flat CAU flow system.

Among the six models used to evaluate boundary condition components of the conceptual model uncertainty, the models broadly provide similar flow fields based on particle tracks originating at the test-location corrective action sites. Differences among the models were apparent in the direction of flow in the Northern Testing Area, where flow trajectories ranged from southeast to nearly due south. The flow field along the northern edge of the basin in the fractured volcanic rocks was eastward. The Central Testing Area showed considerably less variability in the calibrated flow fields based on the particle track analysis; this is likely due to the thickness of the alluvial deposits and the distance of this testing area from high heads in the adjoining CP basin. 
During interim model evaluation activities, an alternative approach to boundary head assignment and an alternative approach to recharge assignment were identified and used to evaluate the BASE-USGSD model. The boundary head modification approach was to limit changes to boundary heads to specific HSUs along the western edge of the model in the vicinity of CP basin (BASE-USGSD with alternative boundary conditions; see SNJV, 2006). The second model addressed the assignment of recharge in the upland area, north of the saturated alluvial basin (NHA-USGSD, discussed further in this section; see NNES, 2010).

Results (not shown) from the BASE-USGSD with alternative boundary conditions model demonstrate that flow paths are similar to those generated during the boundary condition uncertainty analysis using alternative recharge distributions, boundary heads, and boundary flows. To improve the model simulation of observed heads in the LCA, a hydraulic connection in the volcanic units of CP basin and Frenchman Flat basin was established to route the water from areas of higher head (CP basin) into the basin-fill material of Frenchman Flat basin. Advective particle tracks for this alternative show a strong eastern component of flow in the Northern Testing Area. Particle trajectories in the Central Testing Area were very similar to those observed in other calibrated flow models. The general orientation of flow paths appears to be within the range of the other calibrated flow models that were used to evaluate conceptual model uncertainty (structural or boundary condition).

North of the Frenchman Flat alluvial basin, the Massachusetts Mountain and the Halfpint Range are upland areas with surface outcrops of highly fractured and faulted volcanic rocks including the TM-WTA, TM-LVTA, TSA, LTCU, and LVTA HSUs (Table 4-1). All of the recharge models used in the boundary condition uncertainty analyses have appreciable higher recharge in these upland areas compared to other areas of the model domain (SNJV, 2006, Figures 2-2 though 2-10). However, when the mesh for the groundwater flow model was constructed, the volcanic rocks above the water table were completely eliminated from this portion of the model domain because these units were not likely to be saturated based on the interpretation of the water table before model construction. As a result, recharge is supplied directly to the LCA in these portions of the model (SNJV, 2004c, Figure 2-3). An alternative conceptual model of recharge is that water infiltrating in this upland area travels laterally as saturated, unsaturated, or perched water through the conductive volcanic rocks at the northern edge of the alluvial basin rather than direct vertical flow from the ground surface to the 
LCA through a series of permeable rocks underlain by lower-permeability volcanic rocks. The result is a small but potentially important (because overall flow system flow rates are low) source of recharge applied to the northern edge of the alluvial basin. This small adjustment in the recharge distribution has potentially important consequences to the direction and magnitude of flow and subsequent contaminant transport in the Northern Testing Area. The alternative model calibrated using this approach to recharge assignment is referred to as the Northern Hydrologic Alternative ("NHA") (NNES, 2010).

Parallel to the above-described changes in the recharge application, there was a change in the UGTA Subproject strategy during 2008 (FFACO, 1996; as amended March 2010). The revised strategy recognizes the importance of using all available data, particularly data key to constraining groundwater velocity, and discards the concept of model validation consistent with the scientific literature (Oreskes et al., 1994). This shift in strategy allowed geochemical data (Section 3.3) to be used directly during model development and calibration. Therefore, in addition to the observed heads and computed fluxes from the regional groundwater model used in all of the previous calibrations of the Frenchman Flat CAU model (SNJV, 2006; NNES, 2010), the direction and the velocity of flow computed between the well pairs developed by geochemical age relationships were used as two additional observation datasets. Because the direction and velocity of flow computed from the geochemistry are dependent on the location of the well pairs, the inferred direction and magnitude of flow reflect the net flow trajectory and velocity between sampling wells.

The simulated hydraulic heads for the calibrated "NHA" model are shown in Figure 5-4 for the water table. Notable changes in the "NHA" model for the water table are in the vicinity of CP basin, where the boundary heads within CP basin are lower than in many previous calibrations while maintaining the good match to WW-4 and WW-4a and result in a smaller gradient across the Cane Spring fault. The decrease in gradient across the fault results in lower heads along the eastern edge of the alluvial basin. Similarly, heads in the LCA along the eastern margin of the basin are lower than the previously described Frenchman Flat CAU flow models. These simulated lower heads are prominent along the trace of the Rock Valley fault system (Figure 3-1). 


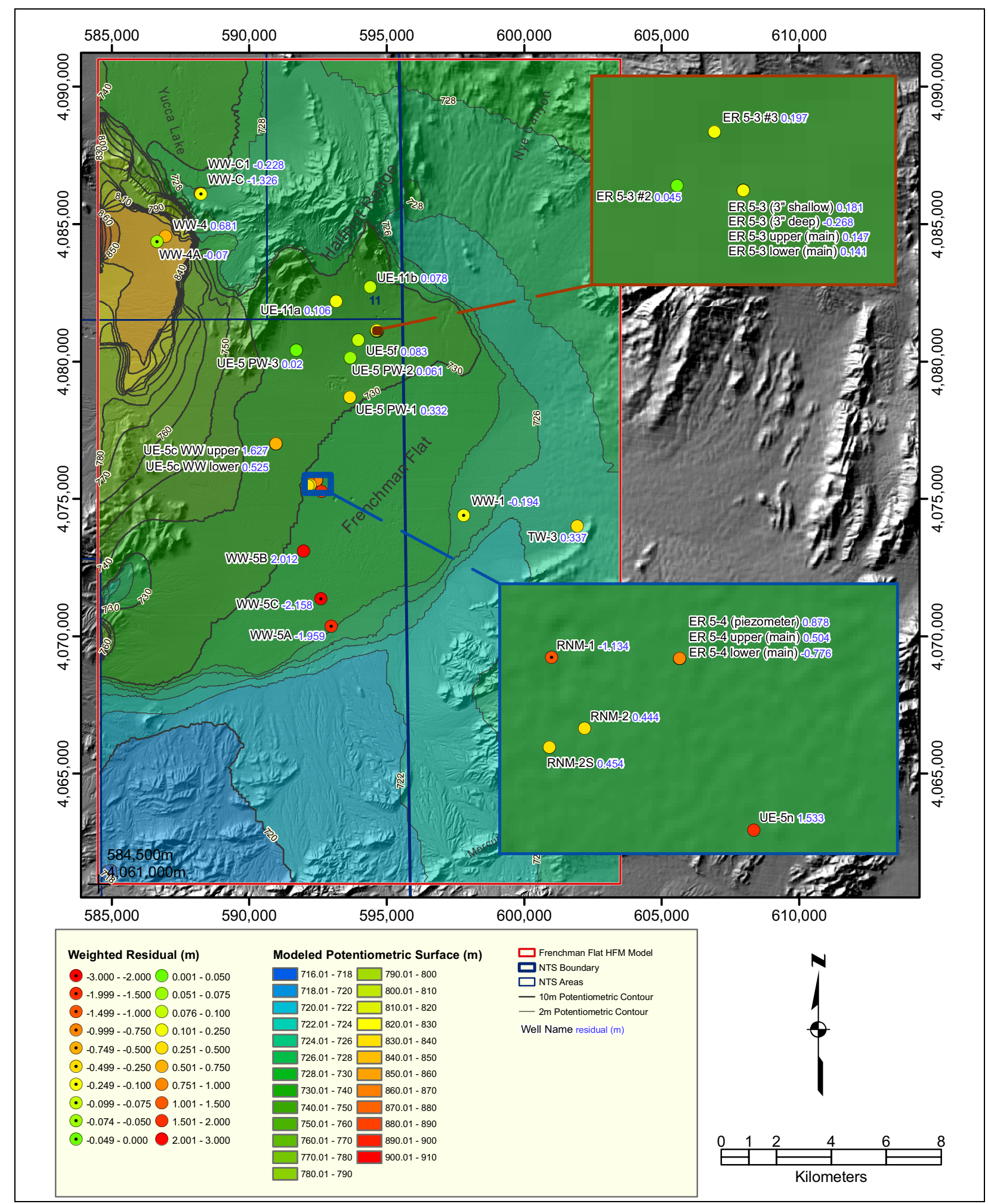

Figure 5-4

Water-Table Contours and Spatial Distribution of Weighted Residuals for the "NHA" Model

Source: NNES, 2010 


\subsubsection{Flow Model Parameter Assignment Uncertainty}

Due to the complexity of the Frenchman Flat flow model (more than 100 adjustable parameters) and the limitations of the data to constrain model parameter selection, multiple alternative parameterization techniques were used for the groundwater flow model. The focus of the alternative model development was to influence the velocity and direction of groundwater flow in the areas with underground nuclear tests. To do this, a series of 14 models was developed to investigate the process of permeability depth decay and the addition of prior information to constrain the range in flow model outcomes (NNES, 2010).

A review of the literature demonstrates that depth decay in permeability has been recognized for decades by investigators in many geologic environments and has also been routinely adopted in groundwater modeling studies (SNJV, 2006). For the Frenchman Flat CAU flow model, depth decay was applied to all alluvial, volcanic, and carbonate units. Sufficient site-specific data to evaluate depth decay in permeability do not exist for HSUs other than the AA and OAA. Because supporting site data are limited, testing the use of permeability depth decay on the flow model results was an important evaluation. The following models were developed (SNJV, 2006; NNES, 2010): (1) no permeability depth decay in the AA and OAA, (2) a minimum value imposed on the permeability of HSUs to constrain projected values at depth within a range of values supported by data, (3) a model limiting the depth-decay-induced anisotropy to the intended value of element-by-element anisotropy, and (4) no permeability depth decay in alluvium and volcanic aquifers and confining units.

In all cases, the flow models testing the application of permeability depth decay result in calibration statistics, matches to observed permeability values, and flow directions in the vicinity of the underground tests within the range of other calibrated models of the flow system. Because of the thickness of the alluvium and volcanic aquifers, the added process of permeability depth decay does not appear to limit connectivity to the regional groundwater flow system as long as the head gradient between the shallower units and the LCA is maintained. 


\subsubsection{Flow Model Uncertainty Summary}

The purpose of the flow model uncertainty analysis was not to identify a best predictor flow model, or to quantify a likelihood function for model acceptance of any particular flow model among the suite of possibilities. Instead, the purpose was to develop a reasonable range of possible flow models that would be considered for further analysis in the transport simulations and that could be used to develop forecasts of the contaminant boundary. These different flow models assess a range of possible HFMs, boundary conditions, and assumptions about the presence or lack of permeability depth decay in the alluvium and volcanic aquifers. Despite the variation provided by each of these conceptual models, generally the flow pathways originating at the test-cavity corrective action sites were very similar. Variability existed in the Northern Testing Area as a result of adjustments to the flux of water across the Cane Spring fault. Flow directions in the Central Testing Area were very consistent, and changes investigated through these uncertainty analyses did not provide a significant influence on the calculated flow fields.

\subsubsection{Selection and Evaluation of Models Using Corroborative Data}

While some groundwater flow models calibrate more acceptably than others using statistical measures of goodness of fit, it is infeasible to determine with certainty which of the models developed for Frenchman Flat are most representative of the physical system. Indeed, Beven (2002) observes that most environmental modeling problems are underdetermined with respect to the available data, and that non-identifiability and non-uniqueness are the inevitable result. Furthermore, the National Research Council (2007) notes that errors in prediction are frequently caused by a poor choice of conceptual model and that a good calibration does not mean that the correct conceptual model is represented; the right answer (if calibration is the sole purpose of modeling, which it is not for the UGTA Subproject) can be obtained for the wrong reason.

To further assess the flow model results, the aqueous geochemical age analyses (Section 3.3; SNJV, 2006, Section 8.0) were used to independently evaluate the flow paths generated by the Phase II Frenchman Flat flow models - only the "NHA" model used these data explicitly for calibration via identifiability, linear uncertainty, and nonlinear uncertainty analyses (NNES, 2010). Identifiability analysis showed that the alluvium, LCA, and volcanic confining units were informed by the calibration data, which is consistent with key controls in the conceptual model (NNES, 2010). 
However, the identifiability statistic does not address the degree that the calibration data inform the prediction of interest. Uncertainty associated with predictions may be high, even if the model is “calibrated" (Moore and Doherty, 2005). The linear predictive uncertainty analysis approach in PEST (Doherty, 2008) allowed for an assessment of the effects of each item of calibration data on model predictions. Because of the computational burden required for complete transport simulations, a surrogate measure of transport - the flow (kilograms per second) through each of the nuclear-test cavities (or their approximation) - was used instead of the prediction of interest (radionuclide transport). Analysis of the calibration data influence on the surrogate predictive measure clearly shows that hydraulic head alone is insufficient to significantly inform the prediction of interest - an unsurprising result. Additionally, the regional model flows used to condition the boundary fluxes at the edges of the model are also not particularly informative because they pertain largely to the LCA, which is separated from the alluvial basin by thick volcanic confining units. If prediction of the flow in the LCA was important to the flow through the nuclear test cavities, these data would be of direct value. The relatively high identifiability provided by the boundary flow data to the LCA model parameters did not help to reduce the surrogate prediction uncertainty. Adding the geochemically estimated velocity and inferred directions, even with their associated uncertainty, provides a direct constraint on groundwater velocity, which is directly related to radionuclide migration (NNES, 2010).

Based on the results from the linear uncertainty analysis, the geochemistry data provide considerable information to constrain the simulated cavity flows. In an effort to better understand the range in transport predictions that could be expected within the Frenchman Flat CAU, the geochemistry data were added as additional observation datasets to each calibrated flow model. The objective function for the flow velocity and angle of groundwater movement were recorded for each of the five geochemistry well pairs based on the weight assigned during calibration of the "NHA" model. No effort was made to recalibrate previous models using the new geochemistry information. The geochemistry portion of the model objective functions calculated for each model is shown in Figure 5-5. The "NHA" model has the best fit to both the velocity and angle observations; this is an expected result because the geochemistry data were used to constrain the "NHA" model calibration.

Overall, the calculated flow velocity is more consistent with the geochemistry data than the flow direction for the models calibrated without the geochemistry data (Figure 5-5; also see Figures 5-6 through 5-10). The best fit to the geochemistry velocity data is the CPBA-DRIA model. The 


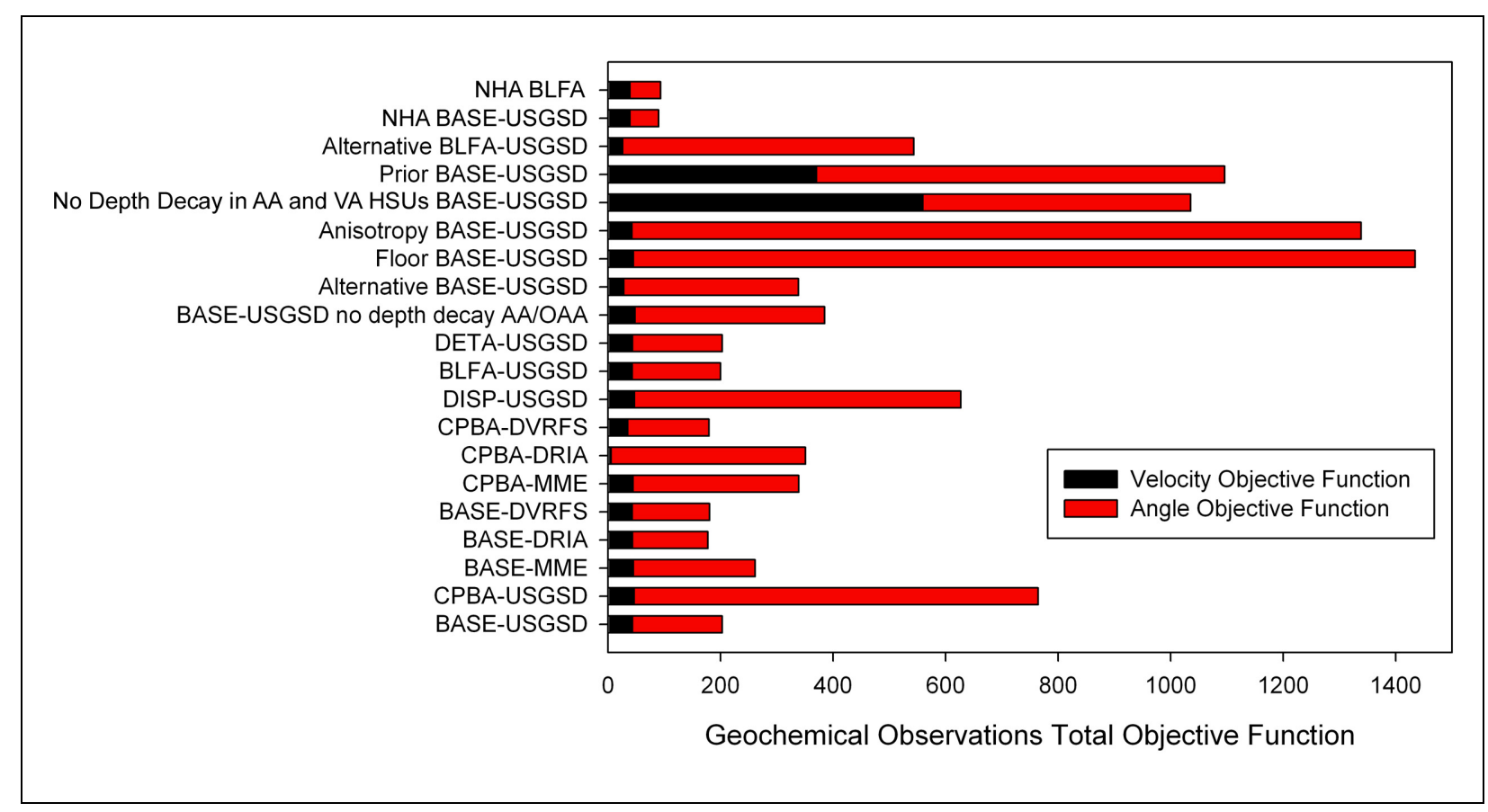

Figure 5-5

Model Objective Functions Based on Geochemistry Velocity and Flow Angle Observations

Source: NNES, 2010

Note: "Alternative" is an abbreviation for a model with alternative boundary conditions. See Appendix C for a complete description for each model.

BASE-USGSD with alternative boundary conditions and derivative models are reasonably consistent with the geochemistry-based flow velocity. The velocities interpreted from the geochemical data are generally expected to be higher because these data likely represent integrated recharge during past wetter pluvial climates, whereas the models calibrated with head observations reflect drier conditions associated with the current inter-pluvial period. Hydraulic heads are expected to equilibrate more rapidly with changing climate than the geochemistry, which requires actual replacement of the pore water rather than pressure equilibration (NNES, 2010, Appendix F). This interpretation of the flow system is used to help guide the identification of outlier flow models that may not be useful for transport (NNES, 2010). Generally, the match of the models to the velocity component of the geochemistry objective function does not appear to depend on either the recharge model or the HFM.

None of the models calibrated without the geochemistry information provides optimal matches to the orientation of flow determined by the geochemical age relationships. This could be due, in part, to the limited number of well pairs with suitable geochemical data and the overall north-south alignment 
of the wells. Also, the orientation of flow determined with the geochemical analysis identifies plausible alternative directions in certain cases, so that it is not possible for the flow models to be in simultaneous agreement with each of the alternatives. For example, SNJV (2006) identifies a south-southwesterly flow path from UE-5 PW-1 to ER-5-4 and a southeasterly flow path from UE-5 PW-1 to WW-1 as possible alternatives. Models that simultaneously attempt to match both of these constraints would inevitably have some calculated error in the flow trajectories because the data provide conflicting flow trajectories. The geochemistry portion of the objective function provides information about the goodness of each model fit to the geochemistry data, but may offer limited insight into the variability among the models and the predicted flow pathways.

The evaluation of model flow fields with supporting geochemical information demonstrates that many of the models have similar performance characteristics (predictive capability) and indicates that some models may be able to serve as proxies for others. To further understand the range of flow model results and which models provided similar performance, the concept of "calibration null space" was considered (NNES, 2010). Moore and Doherty (2005) show that the calibration process can be viewed as subdividing parameter space into two separate subspaces: calibration null space and calibration solution space. Parameter combinations lying within the calibration null space are not informed by the calibration process, while parameters lying within the calibration solution space are informed by the calibration dataset. The nonlinear interaction of flow model parameters within the calibration null space was assessed to capture the parametric uncertainty that allows calibration-insensitive parameters to produce alternative flow fields that may influence transport forecasts. The technique used to produce the flow model realizations of the Frenchman Flat model is the null-space Monte Carlo method available in PEST, version 11 (Doherty, 2008).

One hundred realizations of the BASE-USGSD with alternative boundary conditions flow model described in SNJV (2006) and the "NHA" model (NNES, 2010) were generated using the null-space Monte Carlo method, which samples the parametric uncertainty of the flow model parameters. The water flow through the test cavities was calculated for each simulation as was the simulated velocity and orientation of flow for each geochemical well pair (recall only the "NHA" model incorporated these data as a constraint; NNES, 2010). 
The scatter of the null-space Monte Carlo realizations for the BASE-USGSD with alternative boundary conditions and the "NHA" (NHA BASE-USGSD) models versus the calibration data for the geochemical data is shown in Figures 5-6 through 5-10. These data, much more so than hydraulic head and boundary flux, constrain the potential uncertainty in plume forecasts because they assess the range of possible transport model predictions via groundwater trajectory and velocity. The scatter in the null-space Monte Carlo realizations of the BASE-USGSD model with alternative boundary conditions and "NHA" model coincides with many of predictions by the discrete models used to test boundary conditions, HFM, and parameterization approaches. Most of the cases that do not coincide with null-space Monte Carlo realizations completed for the selected models are also judged to be in generally poor agreement with the corroborative geochemical data and of questionable utility (e.g., "prior," "anisotropy," and "no depth decay in AA and VA HSUs").

The cavity flow results from the null-space Monte Carlo realizations and the individually calibrated flow models were further evaluated to understand the completeness with which the flow fields generated using the null-space Monte Carlo technique were able to represent the cavity flows for all of the individually calibrated flow models. Three representative tests (NEW POINT, PIN STRIPE, and CAMBRIC) were selected for surrogate analysis. NEW POINT was selected as a representative test above the water table in the alluvium in the northern part of the Frenchman Flat CAU.

PIN STRIPE was selected as a representative test below the water table in the volcanic aquifer in the northern part of the Frenchman Flat CAU. CAMBRIC was selected as a representative test below the water table in the alluvium in the central part of the Frenchman Flat CAU. The linear uncertainty analysis for these tests also showed modest benefit, no benefit, and the most benefit from using the geochemical data, respectively. Liquid cavity flow, the surrogate prediction measure, was summarized by grouping the results by HFM. All the results using the BASE HFM are considered as one distribution, and the results from all other HFMs are considered another distribution. There are not enough results from different HFMs to construct a distribution of cavity flow for each alternative HFM. In addition, the distribution of cavity flows from the null-space Monte Carlo realizations is also shown to test the hypothesis that the variation in HFM is more important to uncertainty than parameter uncertainty within an HFM. 


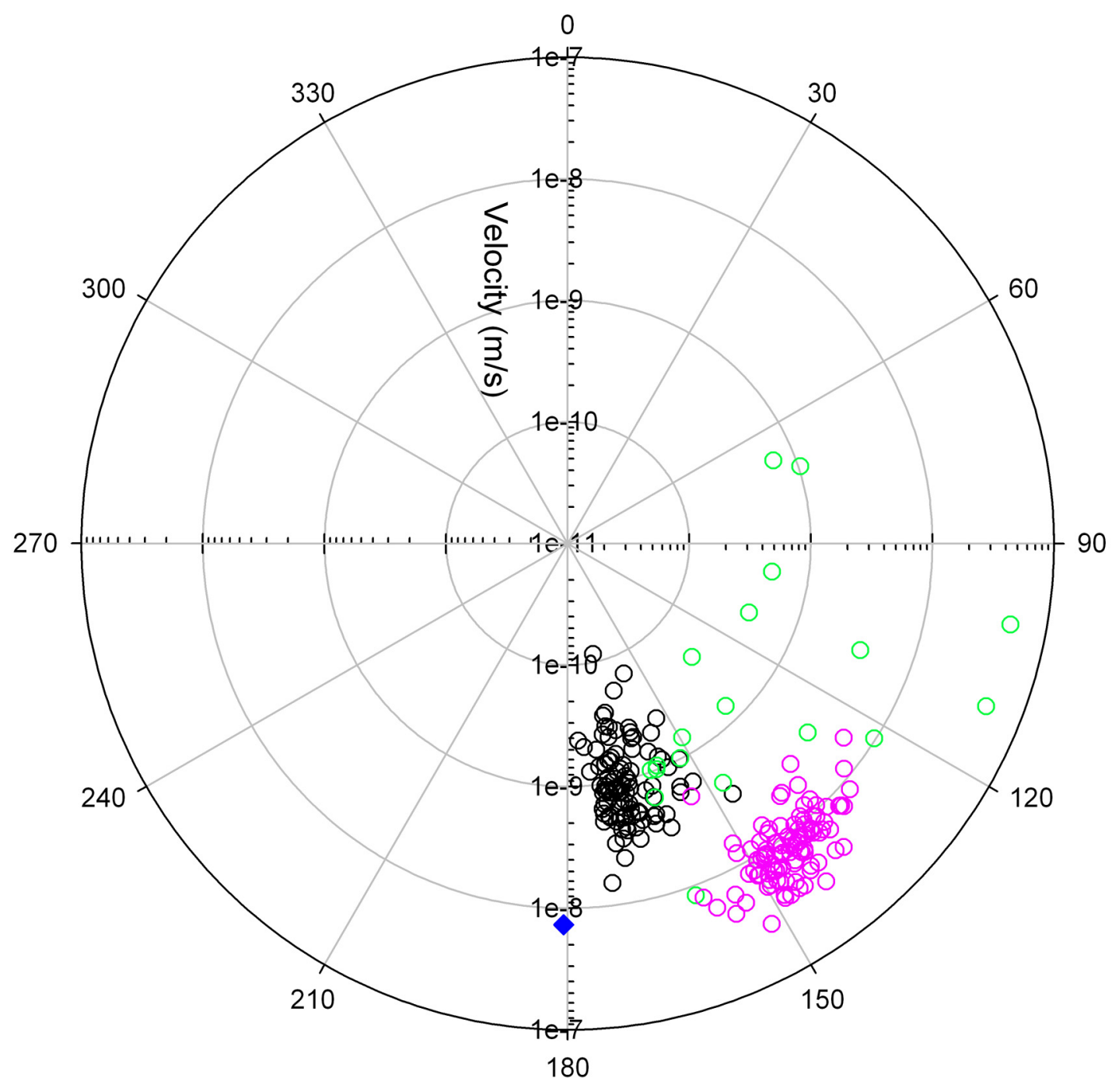

- NHA NSMC Calibrated Models

- Geochemistry Data

- Discrete Calibrated Models

- BASE-USGSD with Alternative Boundary Conditions NSMC Calibrated Models

Figure 5-6

Null-Space Monte Carlo (NSMC) and Discrete Model Comparison to Flow Velocity and Direction from Well UE-5 PW-2 to UE-5 PW-1

Source: NNES, 2010 


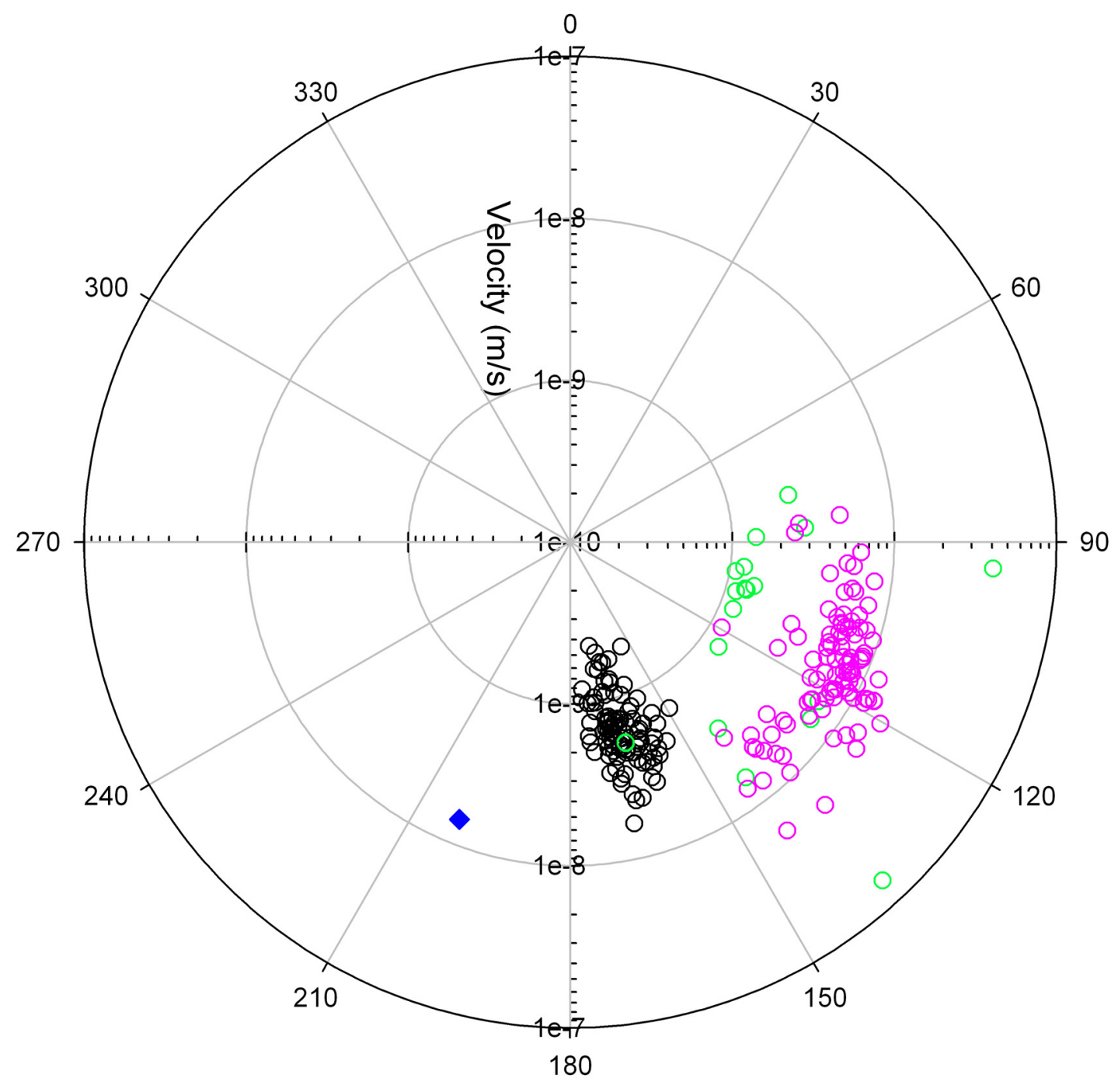

O NHA NSMC Calibrated Models

- Geochemistry Data

- Discrete Calibrated Models

- BASE-USGSD with Alternative Boundary Conditions NSMC Calibrated Models

Figure 5-7

Null-Space Monte Carlo (NSMC) and Discrete Model Comparison to Flow Velocity and Direction from Well UE-5 PW-1 to ER 5-4

Source: NNES, 2010 


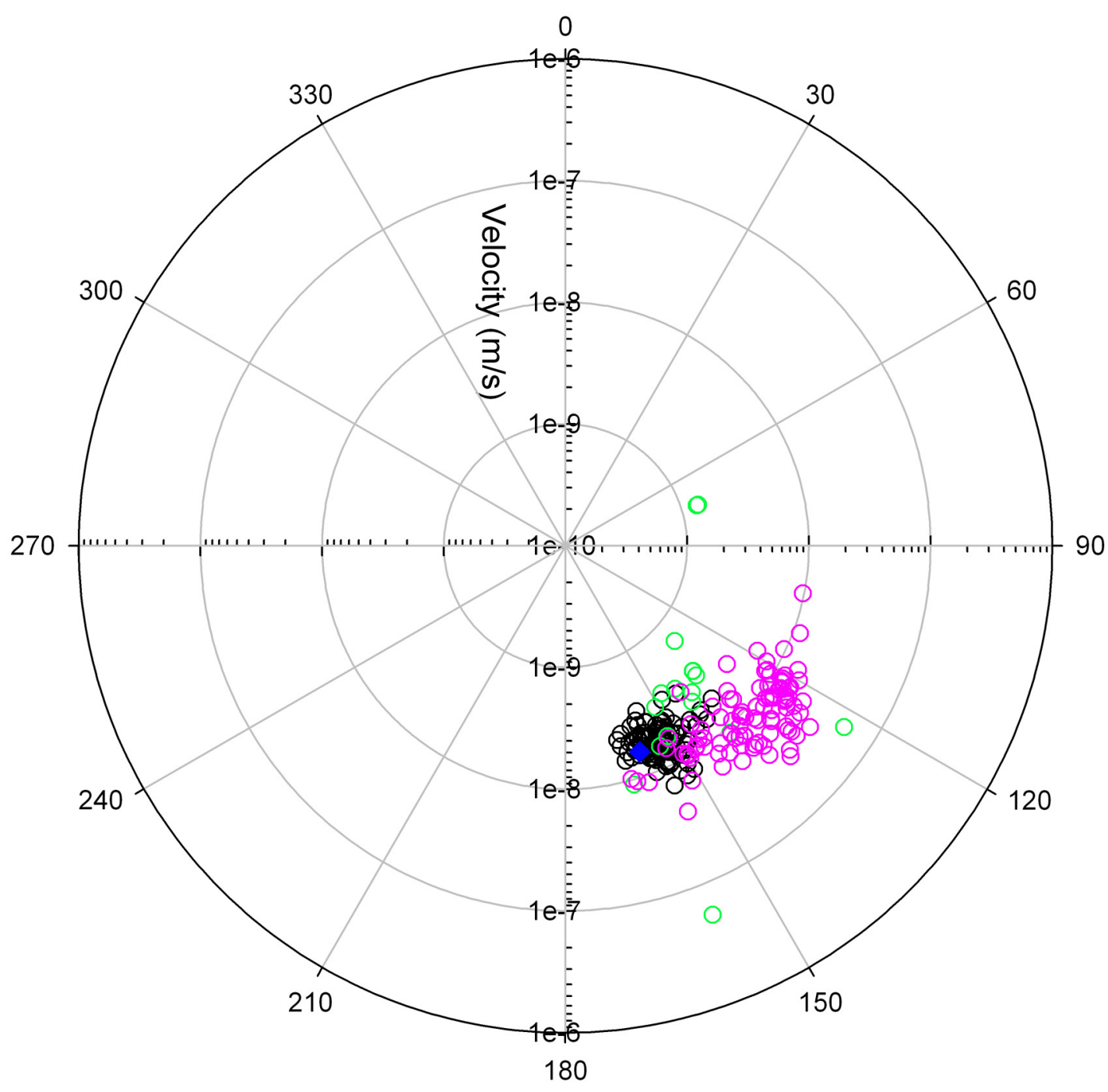

- NHA NSMC Calibrated Models

- Geochemistry Data

- Discrete Calibrated Models

- BASE-USGSD with Alternative Boundary Conditions NSMC Calibrated Models

Figure 5-8

Null-Space Monte Carlo (NSMC) and Discrete Model Comparison to Flow Velocity and Direction from WW-5b to WW-5c

Source: NNES, 2010 


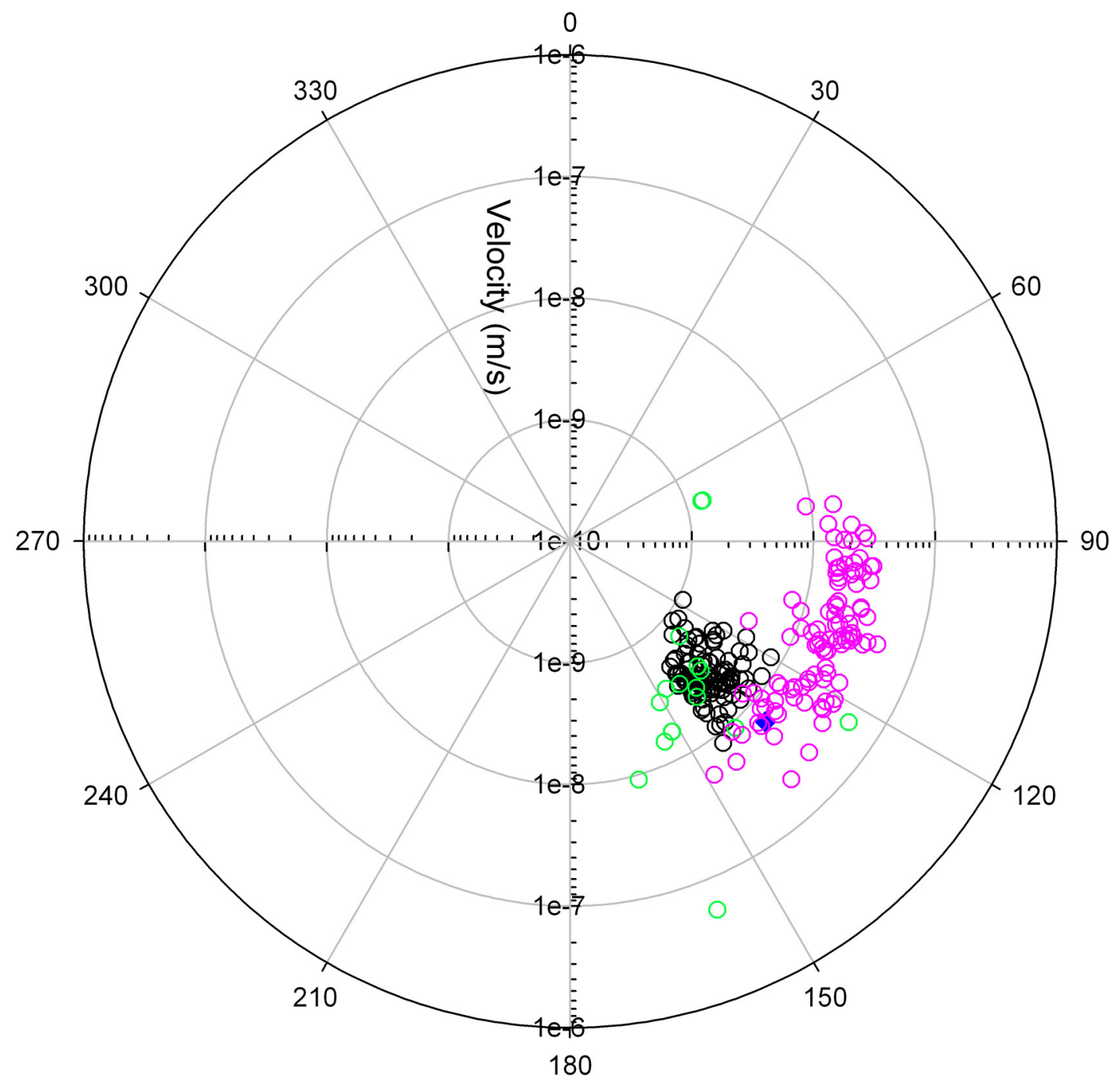

NHA NSMC Calibrated Models

- Geochemistry Data

- Discrete Calibrated Models

- BASE-USGSD with Alternative Boundary Conditions NSMC Calibrated Models

Figure 5-9

Null-Space Monte Carlo (NSMC) and Discrete Model Comparison to Flow Velocity and Direction from Well UE-5c to ER 5-4

Source: NNES, 2010 


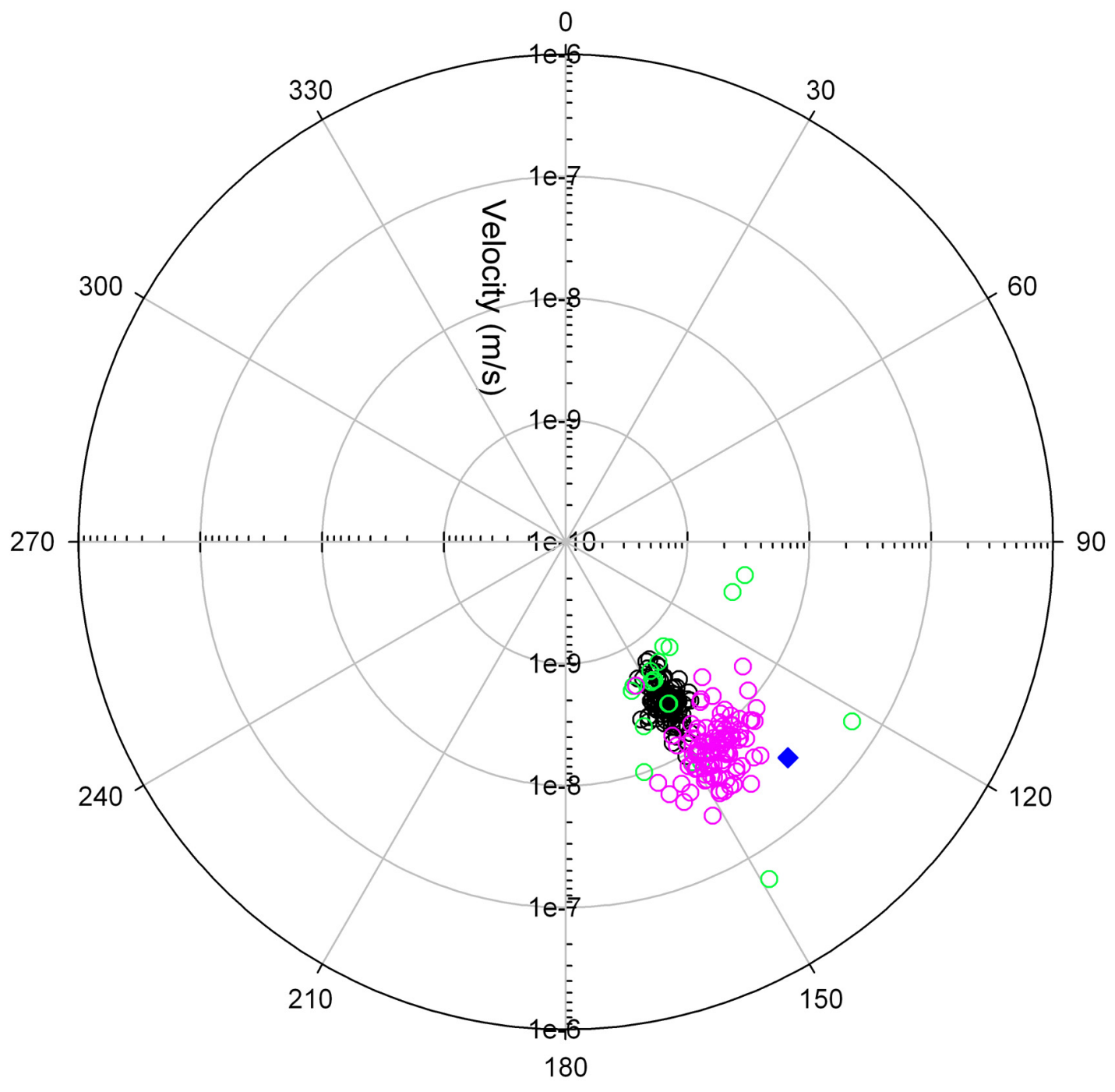

O NHA NSMC Calibrated Models

- Geochemistry Data

- Discrete Calibrated Models

- BASE-USGSD with Alternative Boundary Conditions NSMC Calibrated Models

Figure 5-10

Null-Space Monte Carlo (NSMC) and Discrete Model Comparison to Flow Velocity and Direction from Well UE-5 PW-1 to WW-1

Source: NNES, 2010 
Liquid cavity flows for CAMBRIC, NEW POINT, and PIN STRIPE are shown in Figures 5-11 through 5-13. A few observations can readily be made:

- The alternative model (i.e., not the BASE HFM) cavity flows are generally encompassed within the null-space Monte Carlo limits of the "NHA" and BASE-USGSD with alternative boundary condition models.

- The "NHA" empirical distributions are tighter than those for the BASE-USGSD with alternative boundary condition model, reflecting the additional value of the geochemistry data and incorporation of conceptually based parameter constraints for null-space Monte Carlo calculations.

- Most of the BASE models cavity flows are encompassed by the null-space Monte Carlo limits of the two tested models. The two large values at CAMBRIC (Figure 5-12) are associated with the "prior" and "no depth in AA and VA HSUs" models, which are nearly uniformly in poor agreement with the velocity data (Figure 5-5) and should not be considered valid estimates of uncertainty.

Based on these flow model evaluations and corroborative data analyses, the BASE-USGSD with alternative boundary conditions and the "NHA" models were selected for contaminant boundary forecasts when steady-state groundwater flow was applicable. These models reasonably captured the range of possible transport (as estimated by the cavity flow rate surrogate). Additionally, because the structural representation in the BLFA alternative HFM was believed to have potentially significant influence on the contaminant boundary, and the observation data used to calibrate the model was not sensitive to the changes introduced in the BLFA alternative HFM, the estimated parameter sets for the BASE-USGSD with alternative boundary conditions and the "NHA" models were substituted into the BLFA alternative HFM to provide two additional flow models that were used for contaminant boundary forecasts. Similarly, two sets of null-space Monte Carlo results that addressed parametric uncertainty in the BASE-USGSD with alternative boundary conditions and "NHA" models were used for contaminant boundary forecasts when steady-state groundwater flow was applicable. 


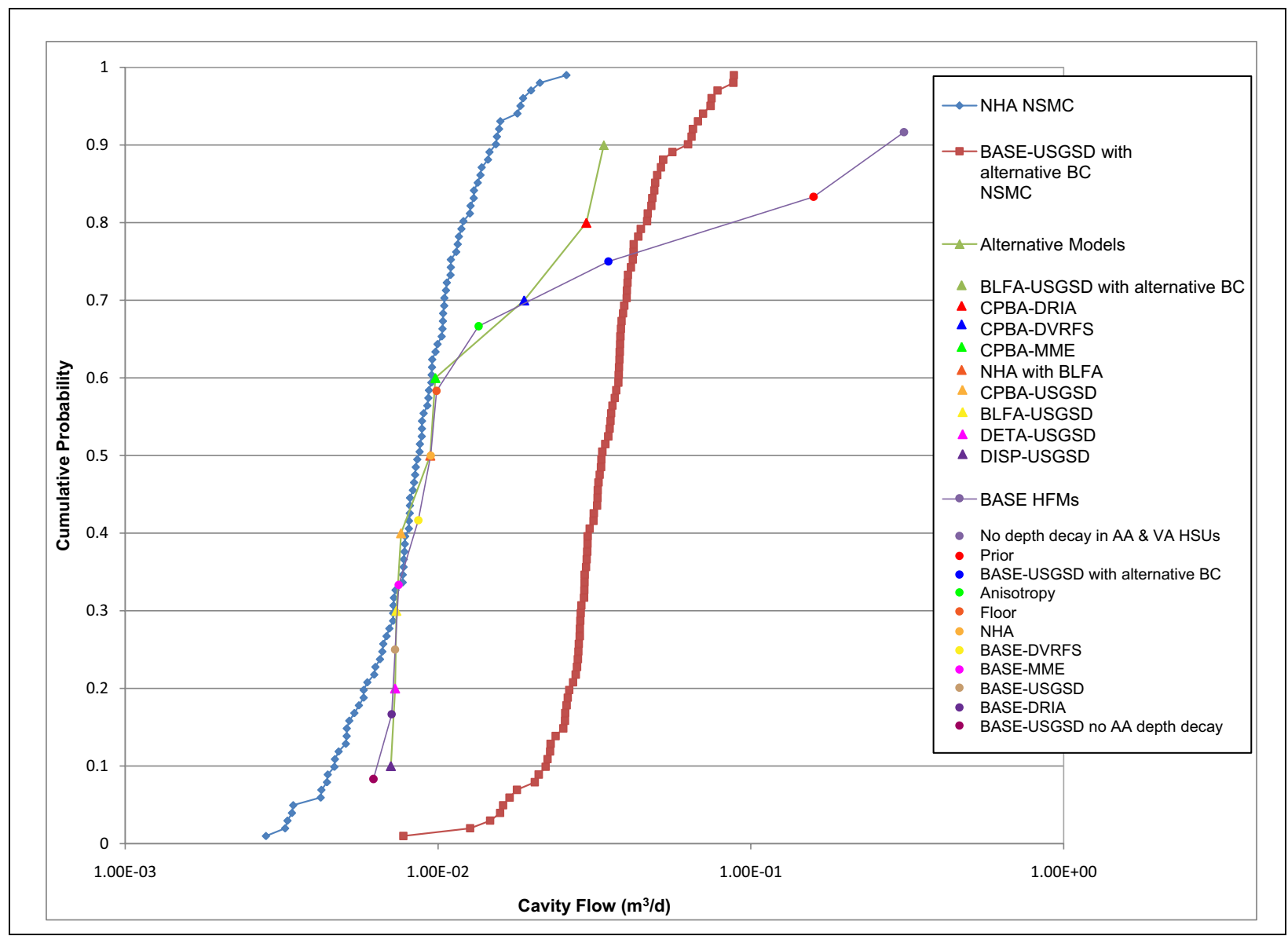

Figure 5-11

Cumulative Probability Plot for CAMBRIC Cavity Flux for All Flow Models

Source: NNES, 2010

\subsection{Transient Groundwater Flow (Central Testing Area Sub-CAU Model)}

Four calibrated steady-state groundwater models were selected as the foundation for further development of the Central Testing Area transient groundwater flow model of the RNM experiment (SNJV, 2006). These are:

- BASE-USGSD with alternative boundary conditions

- BASE-USGSD with no depth decay in AA and OAA permeability

- DISP-USGSD alternative

- CPBA-USGSD alternative

These models were selected to span a range of assumptions regarding the presence and strength of depth decay in the permeability of the AA. The BASE-USGSD with alternative boundary conditions sub-CAU model assumed a depth-decay coefficient of $1.93 \times 10^{-3} \mathrm{~m}^{-1}$. The BASE-USGSD without 


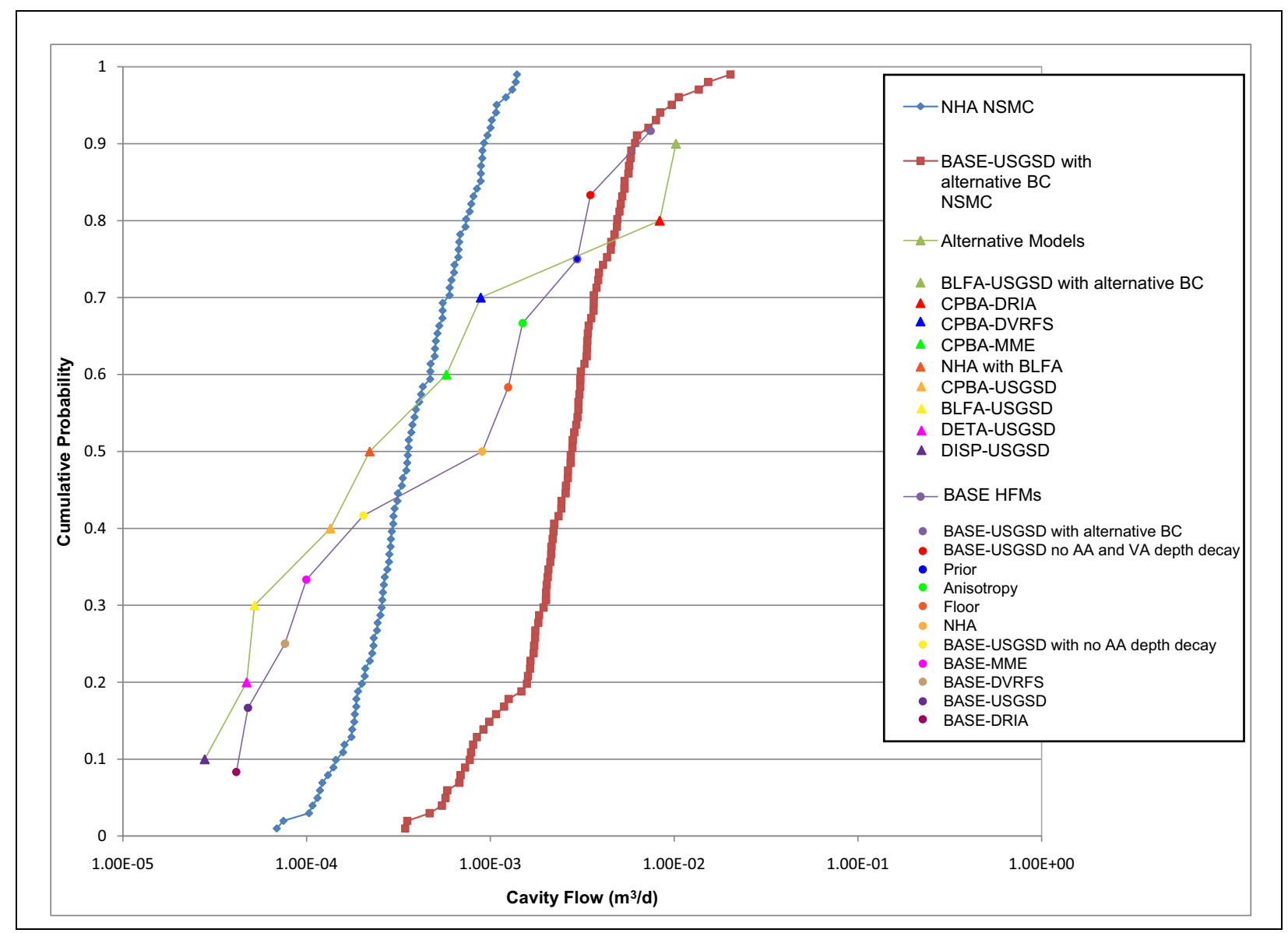

Figure 5-12

Cumulative Probability Plot for NEWPOINT Cavity Flux for All Flow Models

Source: NNES, 2010

AA/OAA depth decay, by definition, assumed no depth decay in the permeability of the AA or OAA. The DISP-USGSD and CPBA-USGSD alternatives both assumed that permeability depth decay in the AA, OAA, and playa sediments occurred with a depth-decay coefficient equal to $5.63 \times 10^{-3} \mathrm{~m}^{-1}$. Additionally, the DISP-USGSD model was included because it was the only alternative HFM with structural changes to the Central Testing Area.

Each of these models was calibrated to the RNM-2S multiple well aquifer test (SNJV, 2004a and b) (Figure 5-14). Calibration data included measurements taken at five-day intervals from observation Wells RNM-2, RNM-1, ER-5-4 (piezometer), and ER-5-4 (Upper) during the drawdown phase of the RNM-2S MWAT. 


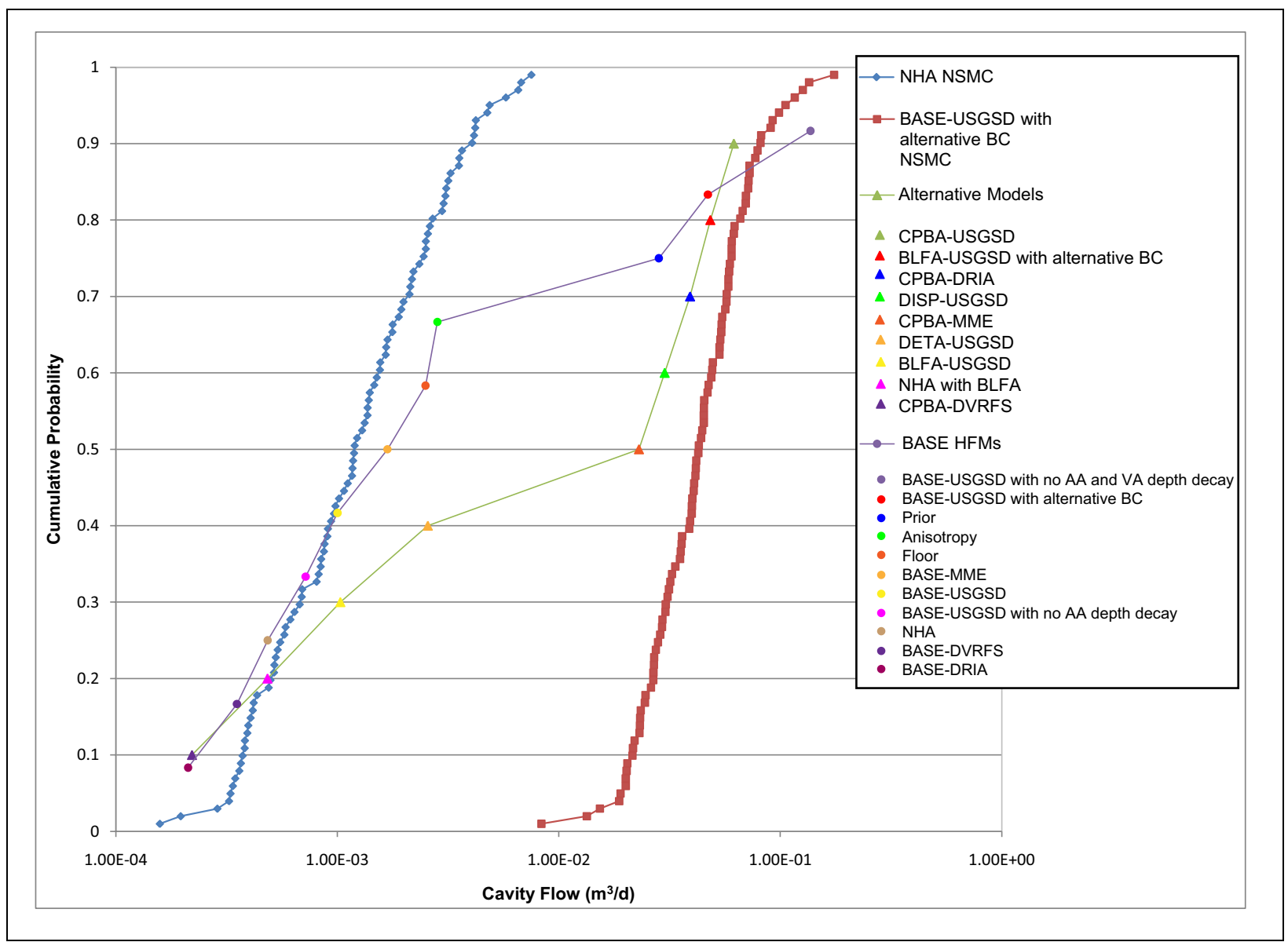

Figure 5-13

Cumulative Probability Plot for PIN STRIPE Cavity Flux for All Flow Models

Source: NNES, 2010

In all cases except the BASE-USGSD with alternative boundary conditions model, the sub-CAU models have one to two orders-of-magnitude-higher alluvial aquifer permeability than the steady-state CAU scale models from which they took their boundary conditions. For the BASE-USGSD with alternative boundary conditions model, the sub-CAU model has a permeability that is about three times higher than the corresponding CAU model. Because head gradients along the boundaries of the sub-CAU models are fixed by the heads in the parent CAU models, these permeability increases will result in flows through the sub-CAU models that will be proportionately higher than those through the corresponding volumes of the CAU models. The fluxes modeled in the sub-CAU model, which are based on permeability estimated from the MWAT data, are more reliable than the permeability and fluxes determined in the parent CAU models because they are constrained at the model scale by the known pumping withdrawals during the MWAT, whereas there are no 
a)

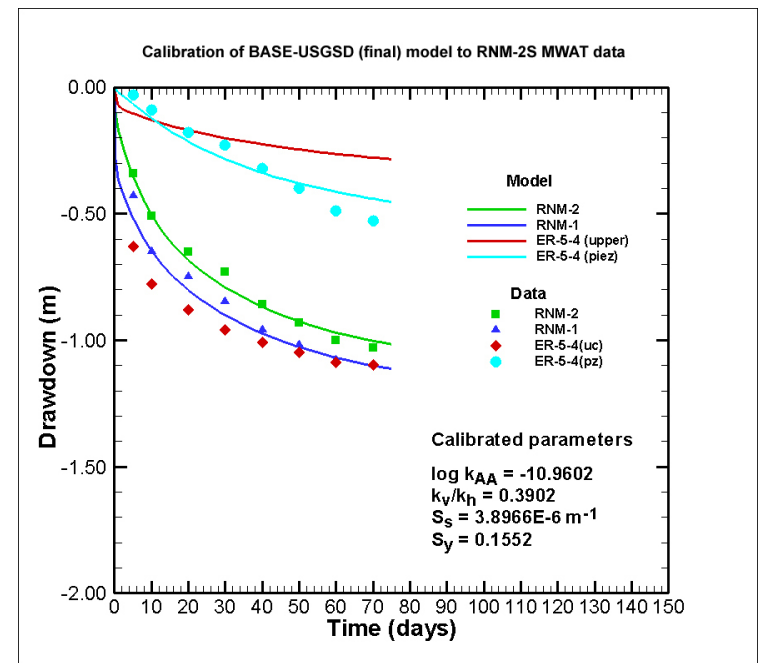

c)

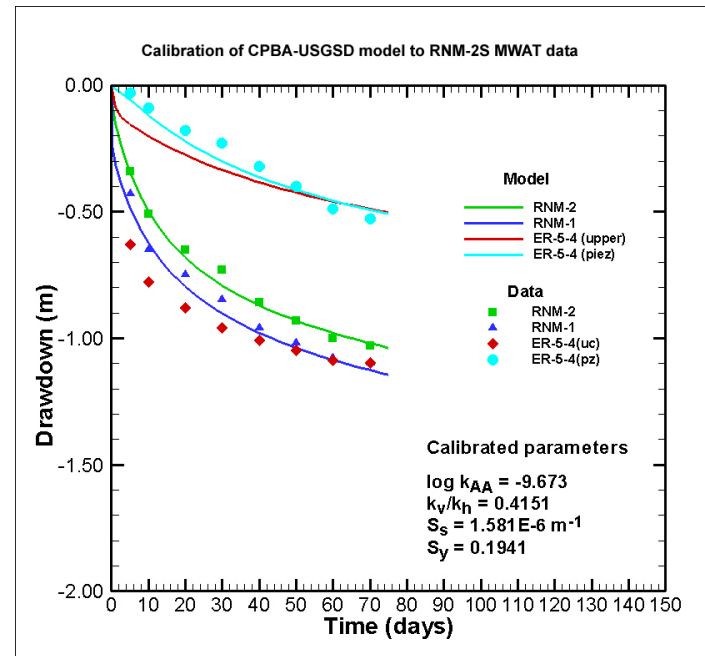

b)

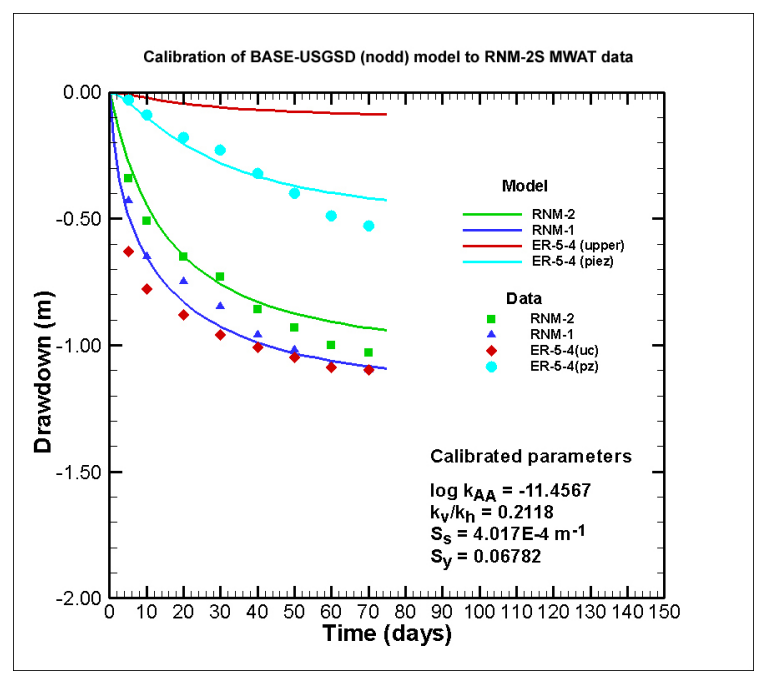

d)

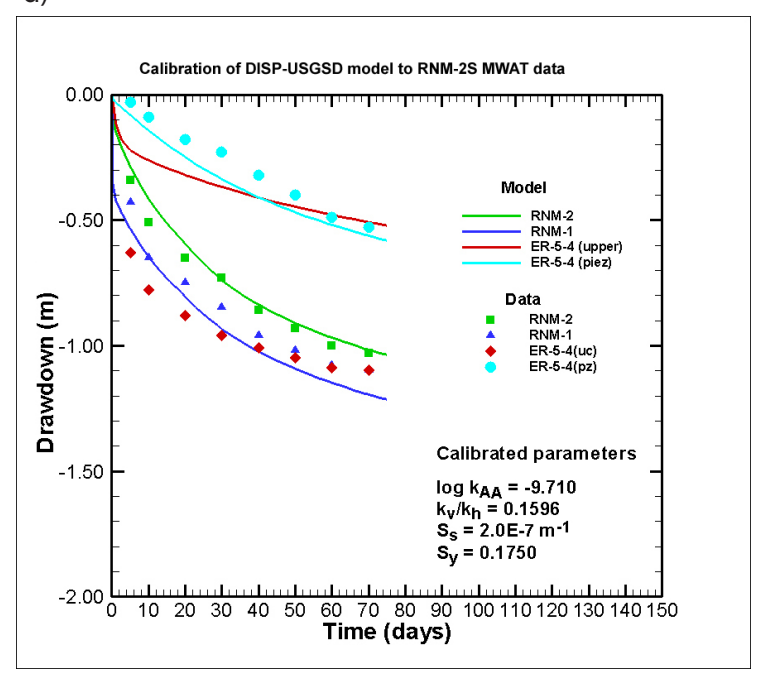

Figure 5-14

Results of RNM-2S MWAT Calibration (a) BASE-USGSD Alternative, (b) BASE-USGSD with no AA/OAA Depth Decay, (c) CPBA-USGSD, and (d) DISP-USGSD Models 
observed groundwater fluxes to constrain the permeability in the steady-state CAU model. For this reason, and for reasons of conservatism, the higher permeability estimated from the MWAT data is used for the alluvial aquifer permeability and simulations of the RNM experiment and other contaminant forecasts.

\subsection{Transport Model}

The final product of the Frenchman Flat CAU transport model is the contaminant boundary forecasts used to initiate negotiations of the CAU compliance boundary (FFACO, 1996; as amended March 2010). A subset of Frenchman Flat CAU and sub-CAU models was selected for these calculations in an effort to provide a reasonable range of forecasts without the computation time required for all model combinations (NNES, 2010). Independent models were used to evaluate UGTA sites in the Northern Testing Area and the Central Testing Area. Calculations of the contaminant boundary for the Northern Testing Area were completed for the (1) BASE-USGSD with alternative boundary conditions model, (2) the "NHA" model, (3) null-space Monte Carlo versions of these models, and (4) each of these sets of calibrated model parameters with the BLFA alternative HFM (recall that the alternative geology represented in the BLFA HFM was not constrained by the calibration dataset). For the Central Testing Area, the contaminant boundary calculations were completed for calibrated sub-CAU models derived from the BASE-USGSD model with alternative boundary conditions, DISP-USGSD, and BASE-USGSD with no depth decay in the AA or OAA parent CAU models. This section reviews the results from the hydrologic source term models that provide the mass flux to the transport models, reviews the method used to compute the boundary, and shows the boundaries (derived from Monte Carlo analysis) for the selected models.

\subsubsection{Hydrologic Source Term Models}

Hydrologic source term models have been developed that include detailed processes (Tompson et al., 1999 and 2005; Carle et al., 2007), simplified processes (NNES, 2010), and abstracted processes (SNJV, 2005d; NNES, 2010). This section reviews the results from these approaches.

\subsubsection{Steady-State CAMBRIC Hydrologic Source Term}

In support of the Phase II CAI, the steady-state flow analysis of the CAMBRIC test (Tompson et al., 2005) was performed to help develop a general release models for the CAMBRIC test under ambient 
groundwater conditions without the influence of the CAMBRIC RNM experiment. The LLNL CAMBRIC test source term study developed a conceptual model of the test cavity and release processes. The model provided concentrations of radionuclides in and away from the CAMBRIC test cavity, taking into account processes that include solute speciation, the rate of dissolution of melt glass, residual test heat, radionuclide desorption from the exchange volume, and radionuclide precipitation and adsorption by minerals in the alluvium.

\subsubsection{Transient CAMBRIC Hydrologic Source Term}

Carle et al. (2007) conducted an analysis of various transient effects at CAMBRIC test including residual test heat and the RNM experiment. From 1976 to 1991, groundwater was pumped from Well RNM-2S located $91 \mathrm{~m}$ from the CAMBRIC test working point at 300 to 600 gallons per minute, and breakthrough of ${ }^{3} \mathrm{H}$ and other radionuclides was observed (Figure 5-15) at RNM-2S and at Well UE-5n. The pumping drew many mobile radionuclides out of the cavity. Carle et al. (2007) estimated that more than 70 percent of mobile radionuclides were flushed out of the cavity and captured by RNM-2S during the experiment. The RNM-2S discharge went into the nearby drainage ditch and then down to the Frenchman Lake impoundment areas, infiltrating into the unsaturated zone and creating a dispersed source of radionuclides at the water table.

Based on simulation results, relevant radionuclides that form the ditch source include ${ }^{3} \mathrm{H},{ }^{14} \mathrm{C},{ }^{36} \mathrm{Cl}$, ${ }^{129} \mathrm{I}$, and ${ }^{99} \mathrm{Tc}$. Two noble gases $\left({ }^{39} \mathrm{Ar}\right.$ and $\left.{ }^{85} \mathrm{Kr}\right)$ are predicted to be present, but subsequent degassing to the atmosphere is likely to minimize their impact during ditch infiltration (e.g., Guell and Hunt, 2003). Simulation results (using the Nonisothermal Unsaturated-Saturated Flow and Transport [NUFT] model [Nitao, 1998]) are in good agreement with observed breakthrough of these nonsorbing radionuclides at RNM-2S (Figure 5-16; note that time is represented as time since the CAMBRIC detonation).

The LLNL HST analysis (Tompson et al., 2005; Carle et al., 2007) did not use the CAU HFM, and the uncertainty and sensitivity analysis approach set out in the addendum to the Corrective Action Investigation Plan (NNSA/NV, 2001). Thus, it was decided in fiscal year 2007 to create a sub-CAU model that would focus on the ditch and resulting plume, and ignore much of the local near-test detail incorporated in the HST model by using the measured radionuclide concentrations at the wellhead of RNM-2S just before discharge to the ditch as the source term (NNES, 2010). 


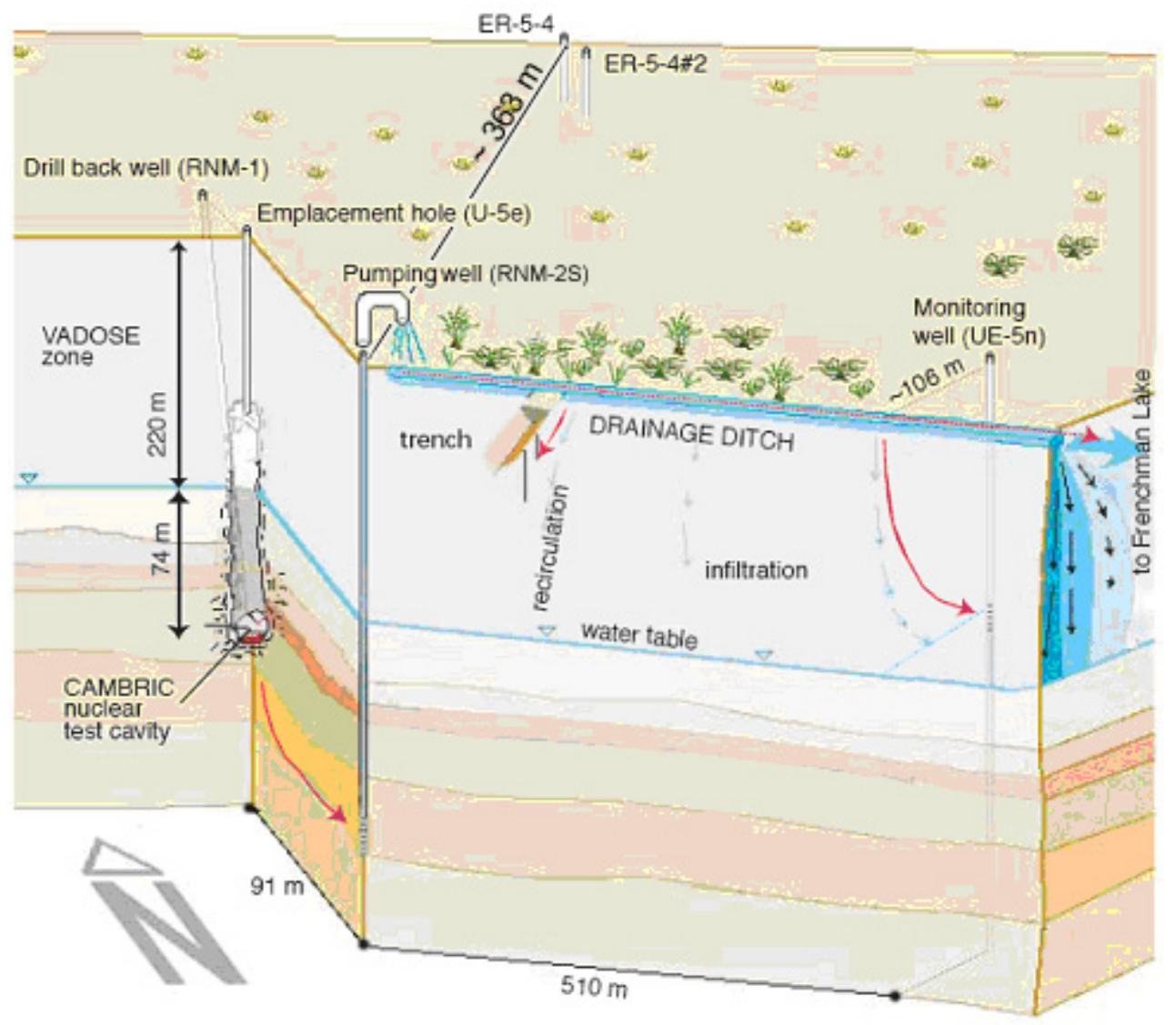

Note: Known ${ }^{3} \mathrm{H}$ pathways are shown in red.

\section{Figure 5-15}

Schematic of the CAMBRIC Test Area in Frenchman Flat at the NTS

Schematic shows the test emplacement hole (U-5e); cavity and collapsed chimney; pumping well RNM-2S; draining ditch; lysimeter trench; and monitoring wells UE-5n, ER-5-4, and ER-5-4 \#2.

Source: Modified from Carle et al., 2007

Of the four transient groundwater flow models that were calibrated to the RNM-2S MWAT data (Section 5.2), only three were carried forward in this phase of the flow and transport simulations (NNES, 2010). The CPBA-USGSD model exhibited numerical instability that resulted in prohibitively long computation times and could not be used for the 50- or 1,000-year transport runs. For the three models carried forward, the transport forecast results were nearly identical.

The simulated head responses at UE-5n (Figure 5-17; note that time is represented as time since the CAMBRIC detonation) are complex and reflect several events: (1) the onset of pumping from 


\section{Tritium Breakthrough at RNM-2S}

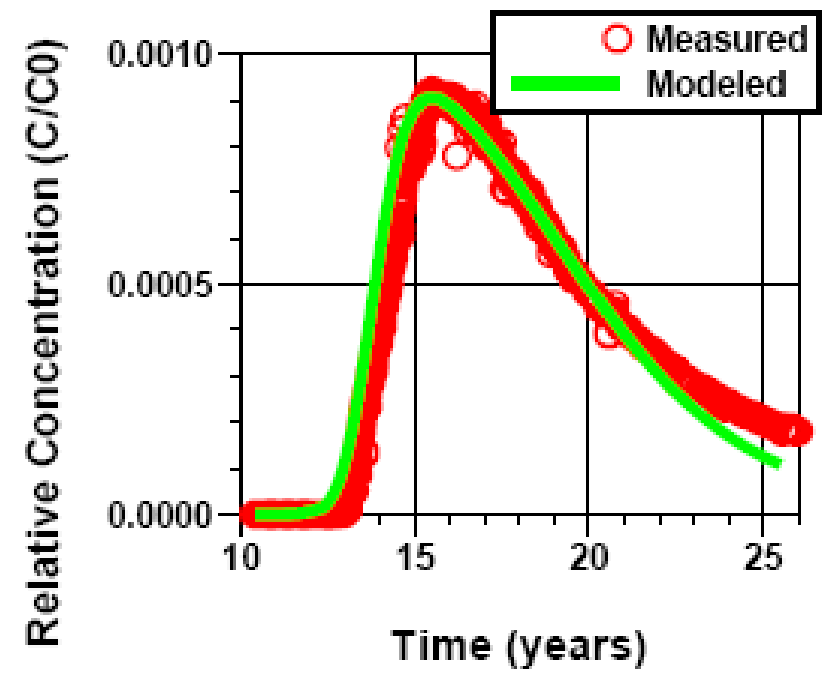

Figure 5-16

Calibration of NUFT Model Alluvial Layer Hydraulic Properties to Tracer Breakthrough (Green Line) to Measured Decay-Corrected ${ }^{3} \mathrm{H}$ Breakthrough Data (Red Circles) at RNM-2S Pumping Well during the RNM Experiment

Source: Carle et al., 2007

RNM-2S at 300 gallons per minute after 10.4 years, (2) the doubling of the pumping rate at RNM-2S to 600 gallons per minute at 12.3 years, (3) the arrival of recharge beneath the CAMBRIC ditch at about 16.7 years, and (4) the cessation of RNM-2S pumping at 25.5 years; note that all times in these figures refer to the number of years after the CAMBRIC detonation (May 14, 1965). The steep rise in simulated water levels at UE-5n after roughly 25.5 years reflects the mounding that takes place beneath the ditch once pumping from RNM-2S had stopped. Each of the three models accurately reproduces the measured peak water table rise of about $0.7 \mathrm{~m}$ at UE-5n at about 26.8 years, as well as the gradual recession and return to ambient heads by the end of the 50 -year simulation period (May 14, 2015).

The simulated ${ }^{3} \mathrm{H}$ breakthrough for the sub-CAU model derived from the BASE-USGSD with alternative boundary conditions model is compared to the measured ${ }^{3} \mathrm{H}$ activity of groundwater at UE-5n in Figure 5-17. The simulated ${ }^{3} \mathrm{H}$ breakthrough for each of the three models occurs roughly 2,000 days (5.5 years) before the measured breakthrough and overpredicts measured peak ${ }^{3} \mathrm{H}$ concentrations by a factor of about 2 in the BASE-USGSD with alternative boundary conditions and 
a)

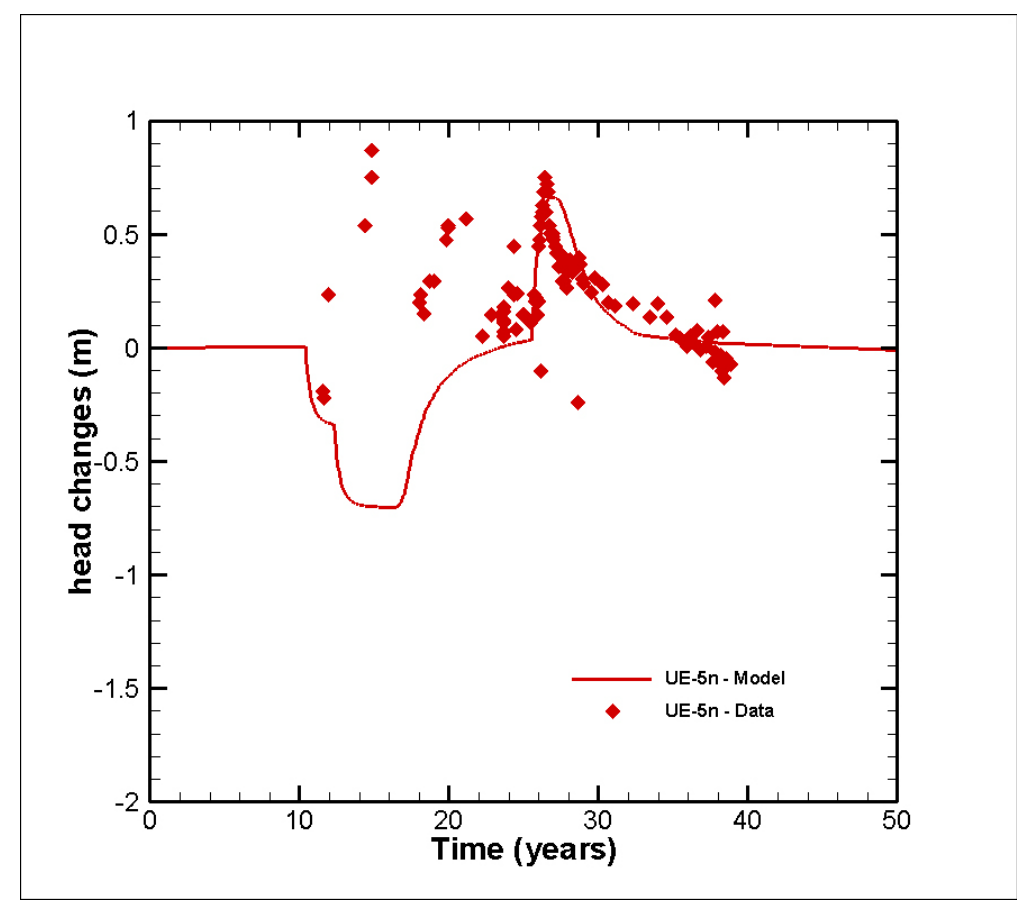

b)

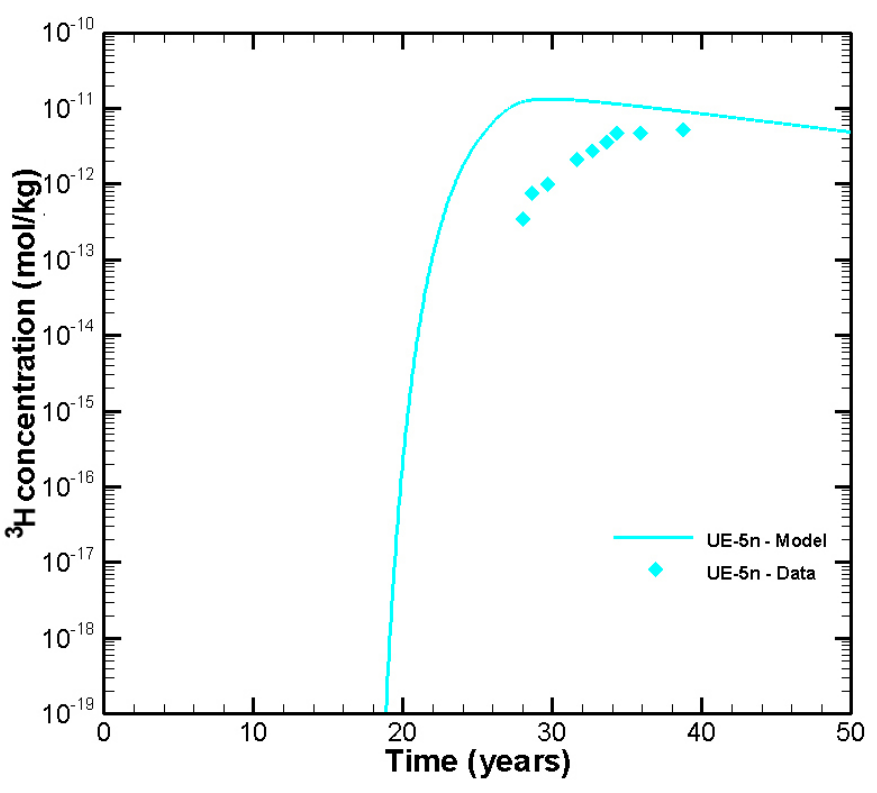

Figure 5-17

Comparison of the BASE-USGSD with Alternative Boundary Conditions Model Results to the UE-5n Data (a) Hydraulic Heads and (b) ${ }^{3} \mathrm{H}$ Concentrations

Source: NNES, 2010 
no depth-decay models, and by a factor of 3 to 4 in the DISP-USGSD model. The early arrival and relatively high peak concentrations of ${ }^{3} \mathrm{H}$ in the simulations may be the consequence of several assumptions underlying the development of the ${ }^{3} \mathrm{H}$ input function for the ditch and playa recharge: (1) unsaturated-zone travel times are 3.3 years, (2) no additional dispersion of the RNM-2S ${ }^{3} \mathrm{H}$ source occurs in the unsaturated zone, (3) all of the water pumped from RNM-2S recharges the water table, with 56 percent of the pumped water recharging beneath the ditch, and (4) recharge enters the saturated zone along a 20-m-wide band centered around the ditch. Longer residences times in the unsaturated zone, more dispersion in the unsaturated zone, or lower recharge rates beneath the ditch because of evapotranspiration (or more flow down the ditch to the playa) are each model changes that would have the expected effect of either lowering the peak concentrations or delaying the simulated peak ${ }^{3} \mathrm{H}$ arrival at UE-5n. However, rather than explore the effects of all these assumptions, the simulated early arrival and high peak ${ }^{3} \mathrm{H}$ concentrations at UE-5n were accepted as providing a reasonable upper bound on the magnitude, rate, and extent of likely radionuclide contamination arising from the CAMBRIC RNM experiment source. In each of the three sub-CAU models, the input concentrations of other mobile radionuclides beneath the ditch were estimated from a tracer whose concentration was scaled to reflect the relative abundance of each radionuclide in the CAMBRIC inventory (NNES, 2010).

The hydraulic head changes relative to steady-state condition and ${ }^{3} \mathrm{H}$ concentrations were simulated with the BASE-USGSD with alternative boundary conditions model for a 50-year period following detonation of the CAMBRIC test. The results at 37.3 years after detonation (Figures 5-18a and 5-18b) show that by mid-2002, hydraulic heads had returned to within centimeters of their long-term steady-state values and that the ${ }^{3} \mathrm{H}$ plume had spread laterally away from the ditch and the impoundment area of the playa. The simulated head changes have completely dissipated, and steady-state flow conditions have been re-established by the end of the 50-year period ending in 2015. A similar duration for the hydraulic transients associated with the CAMBRIC RNM experiment was estimated by Carle et al. (2007). In contrast to the HST model results, which showed that ${ }^{3} \mathrm{H}$ transport is dominantly to the northeast after 50 years (Carle et al., 2007, Figure 5-55), the transient model constructed with boundary conditions from the BASE-USGSD with alternative boundary conditions model results suggests that ${ }^{3} \mathrm{H}$ is symmetrically distributed around the ditch after 50 years. 


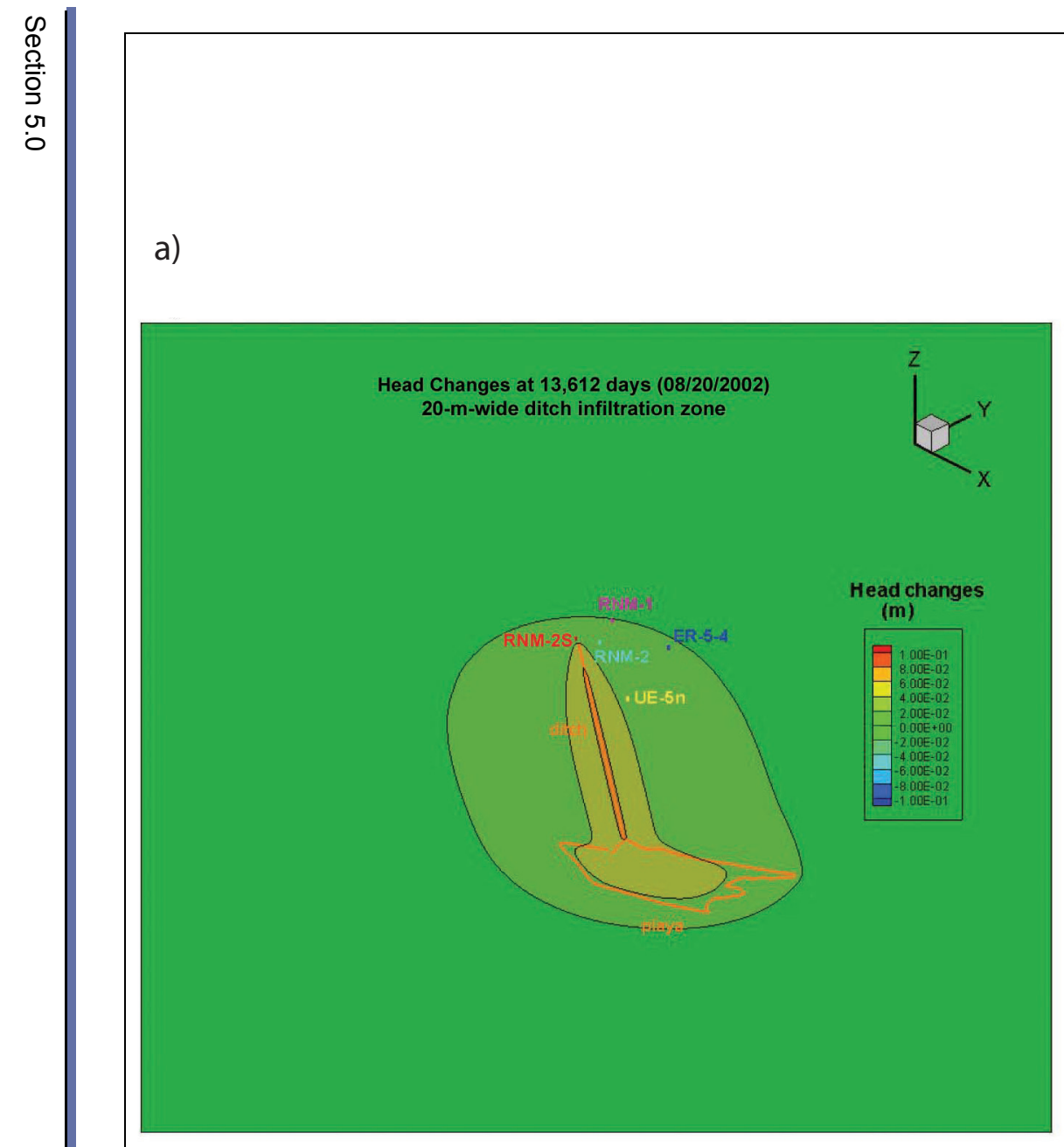

b)

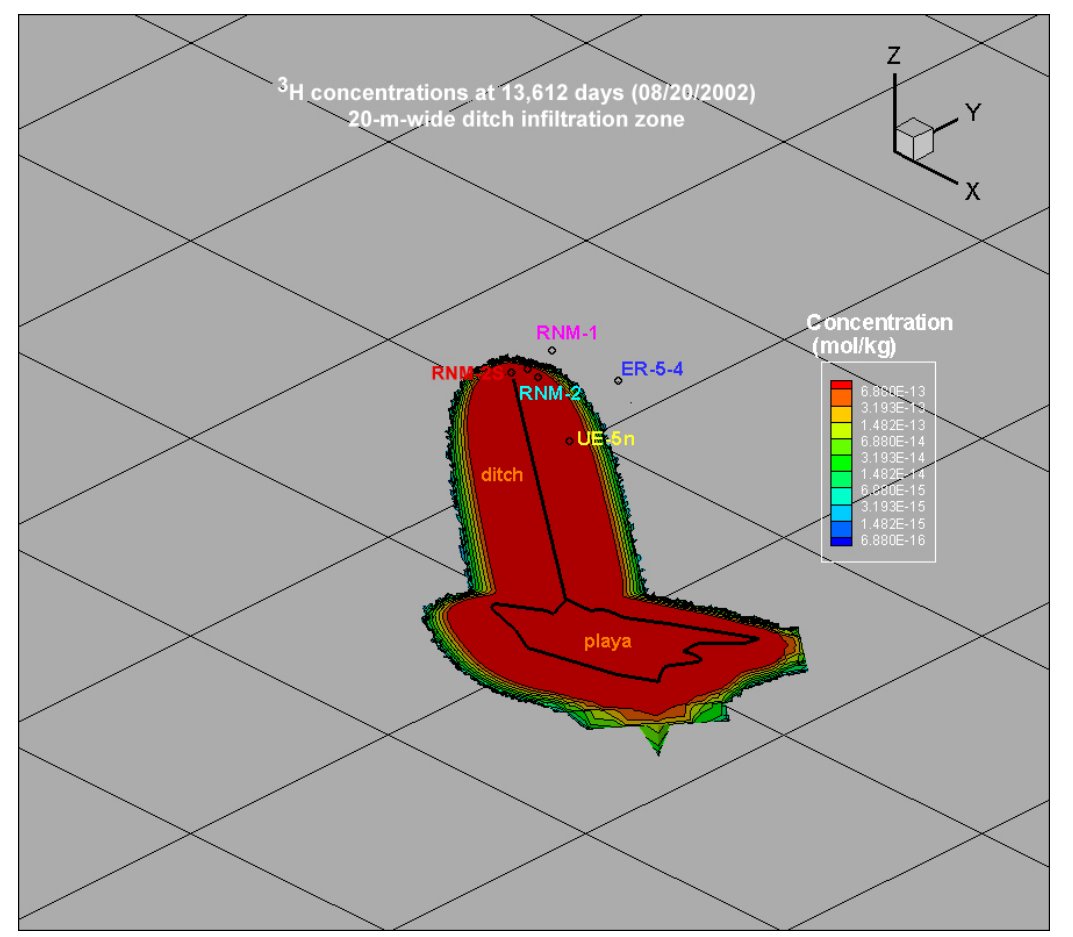

Figure 5-18

BASE-USGSD Alternative Model Results: (a) Head Changes and (b) ${ }^{3} \mathrm{H}$ Concentrations after 13,612 days $(08 / 20 / 2002)$

Source: NNES, 2010 


\subsubsection{Simplified Source Term Models}

To create models with appropriate site-specific parameters for the underground nuclear tests conducted in Frenchman Flat, an abstraction to the steady-state CAMBRIC HST

(Tompson et al., 2005) was constructed. This allowed the abstraction model to be conditioned to a complex process model before site-specific parameters for other tests were substituted into the simplified model. The abstraction of CAMBRIC, along with a comparison of the CAMBRIC HST model (Tompson et al., 2005) and the SSM, is described in SNJV (2005d). The process of model abstraction is defined as "a methodology for reducing the complexity of a simulation model while maintaining the validity of the simulation results with respect to the question that the simulation is being used to address" (Pachepsky et al., 2006). Model abstraction reduces the complexity of the system to be simulated to its essential components and processes (SNJV, 2005d; Tompson et al., 2005). A variety of packages are available for this purpose, and the GoldSim software (GoldSim, 2006) was selected due to its use in the DOE complex.

The GoldSim abstraction was created with the contaminant transport module and the software's built-in probabilistic framework. The test and immediate environment (the scale of the HST model) is represented using mixing cells and transport pipes for the cavity, compressed or crushed zones, nuclear melt glass zone, and undisturbed material (see SNJV [2005d] for complete description). The SSM for CAMBRIC captures the important hydrological and chemical processes probabilistically so that the range of output from the SSM represents the range of output from the CAMBRIC HST model. The CAMBRIC SSM is then modified by applying test-specific parameters including the test cavity geometry, size of the exchange volume, groundwater flow, inventory, porosities, nuclear melt-glass dissolution parameters, and linear distribution coefficients from the local geologic setting for tests without process-based HST models (SNJV, 2005d; NNES, 2010). Example SSM calculations for DIANA MOON are shown in Figure 5-19. A key limitation in this approach is the degree that the CAMBRIC results can be assumed to represent other tests.

\subsubsection{Simplified Process Models}

The Frenchman Flat SSMs were developed from the steady-state process HST model results from the CAMBRIC test, which was detonated in alluvium below the water table. However, the 


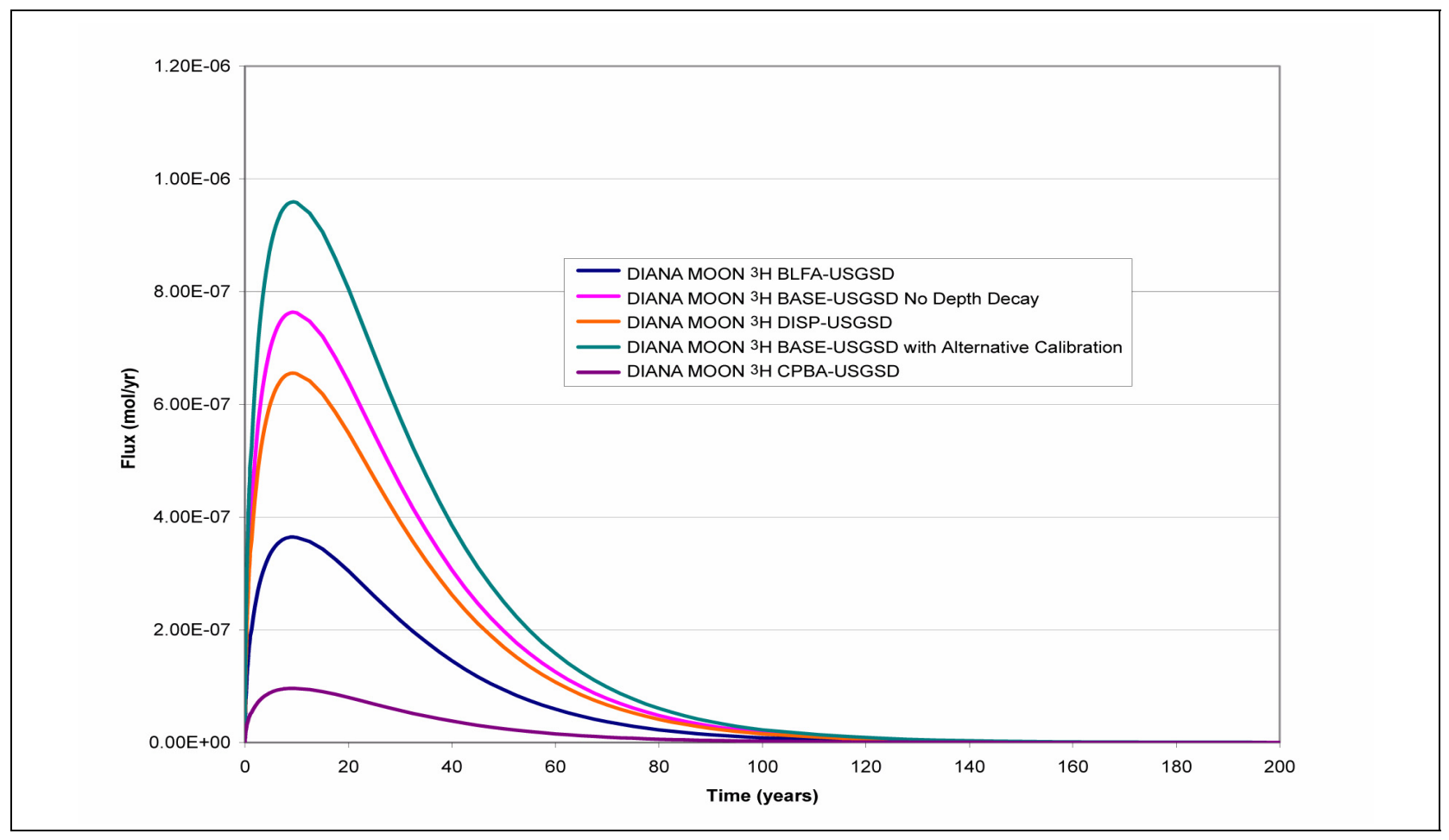

\section{Figure 5-19}

Median Source Term for the BASE-USGSD No Depth Decay, BASE-USGSD with Alternative Calibration, CPBA-USGSD, and DISP-USGSD Flow Models for the DIANA MOON SSM

Source: NNES, 2010

hydrogeologic settings of the PIN STRIPE and MILK SHAKE tests are significantly different than the CAMBRIC test (Section 4.3.1).

Review of the literature on rock property alteration in the shock wave crushed zone from underground nuclear testing shows that the geology at PIN STRIPE and MILK SHAKE is sufficiently different from the CAMBRIC test to warrant an alternative conceptual model (Johnson et al., 1958; IAEA, 1998; Pawloski, 1999). In ductile alluvium and vitric tuff, porosity and permeability are reduced in the crushed zone after test detonation; however, in hard brittle rock, the permeability and porosity is unchanged or enhanced compared to the unaffected rock mass. Simplified (relative to the LLNL HST model) process models for PIN STRIPE and MILK SHAKE were constructed that accounted for unsaturated flow including aqueous radionuclide and ${ }^{3} \mathrm{H}$ and ${ }^{14} \mathrm{C}$ gas-phase transport in the vadose zone (to more realistically represent transfer to the saturated zone), and the uncertainty in shock-altered materials (NNES, 2010). 


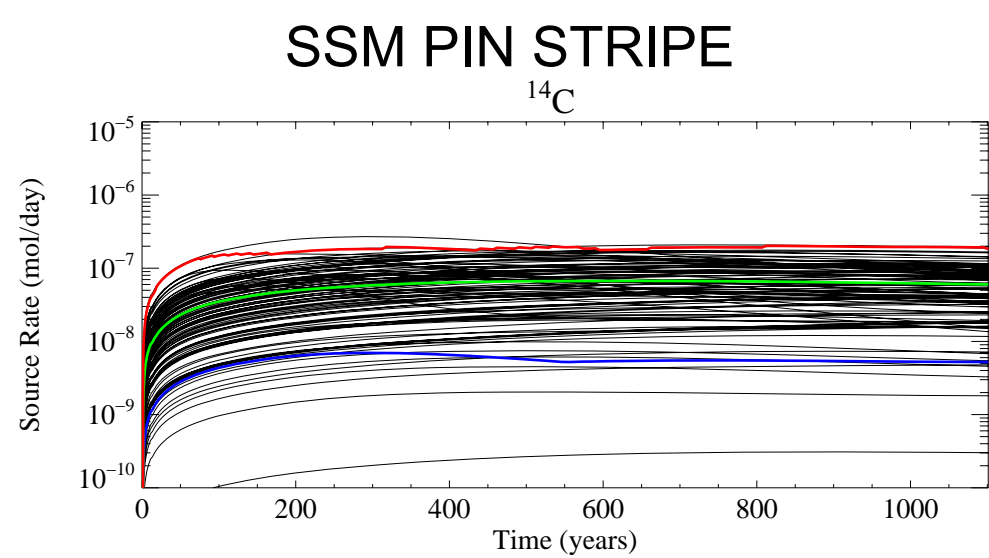

Process Model PIN STRIPE

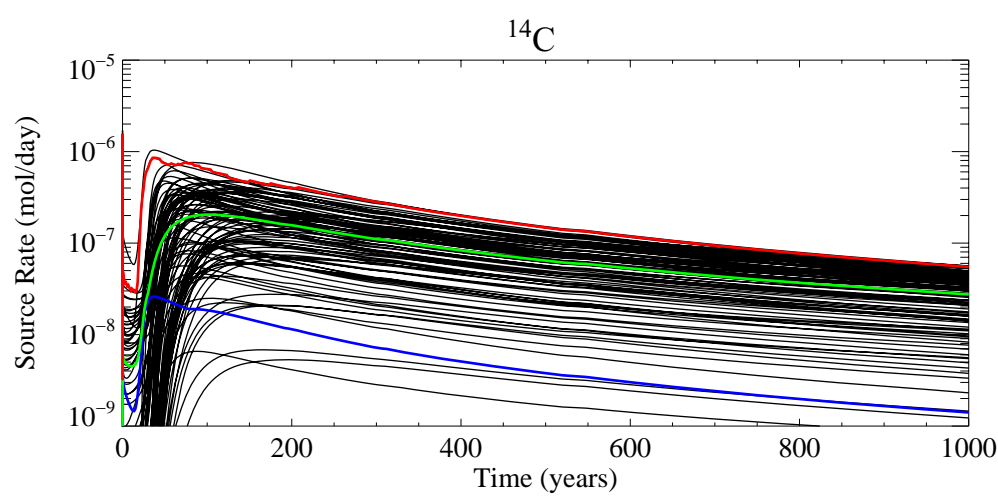

SSM MILK SHAKE

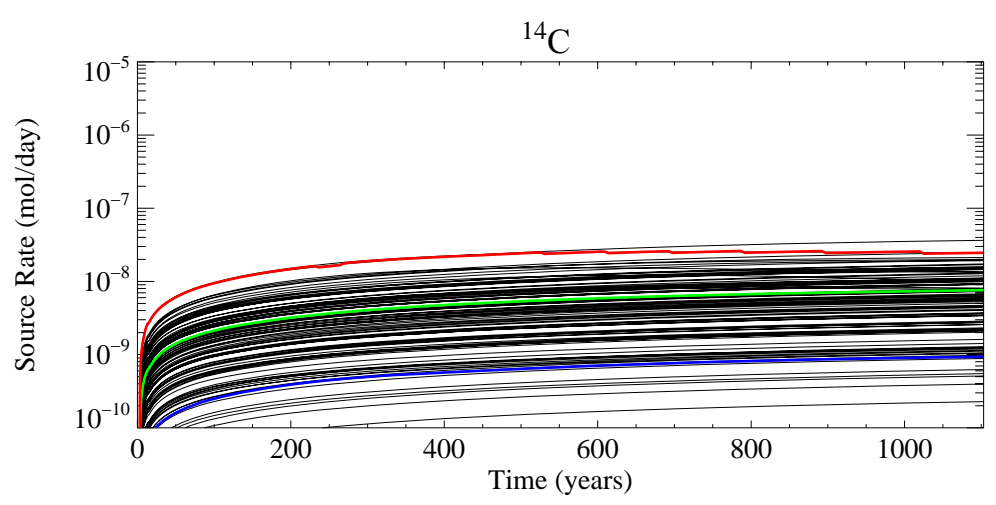

Process Model MILK SHAKE

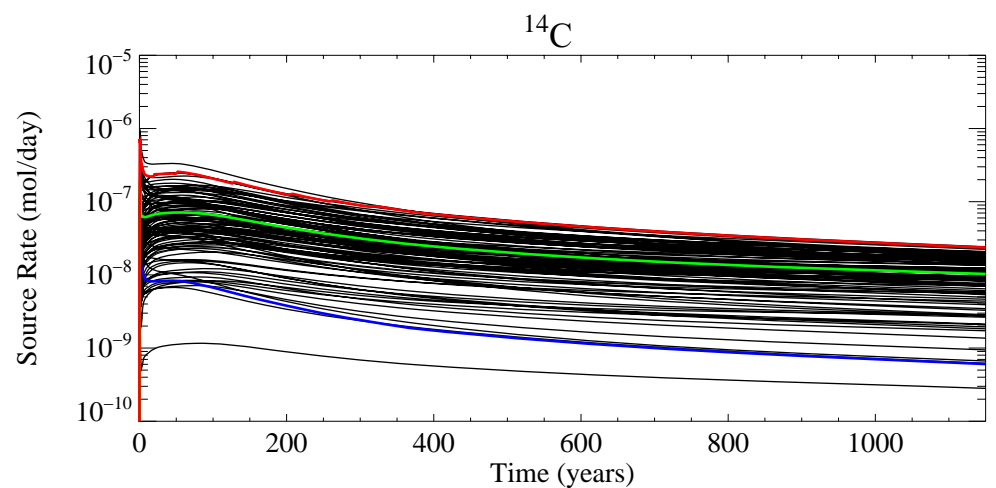

ndividual Realization

$5^{\text {th }}$ Percentile

Mean

95 ${ }^{\text {th }}$ Percentile 
Differences between the SSM and simplified process model do not appreciably affect contaminant boundary estimates. Although the magnitude of the SSM and simplified process model breakthrough are similar (i.e., within an order of magnitude), the character of the breakthrough is very different. Figure 5-20 illustrates the ${ }^{14} \mathrm{C}$ breakthrough for the process models and SSMs for the PIN STRIPE and MILK SHAKE tests. The process model breakthrough has a very high amplitude initial breakthrough resulting from the fraction of the exchange volume below the water table and in fractured rock quickly moving away from the source area. The general character of the long-term breakthrough is also different. The process model breakthrough increases quickly and declines approximately an order of magnitude over 1,000 years. The SSM breakthrough slowly increases during the first 100 years and remains constant through the remainder of the simulation period, reflecting the lower permeability of the compressed zone in this conceptual model.

\subsubsection{Contaminant Boundary}

The contaminant boundary is defined by a 5th percentile likelihood of exceeding the Safe Drinking Water Act (FFACO, 1996; as amended March 2010). For the Frenchman Flat CAI, this regulatory description is interpreted as the region where there is a 95 percent certainty that contaminants do not exceed Safe Drinking Water Act regulatory standards (CFR, 2009). That is, the area outside the contaminant boundary has only a 5 percent or less chance of being contaminated during the next 1,000 years. To compute these probabilities, Monte Carlo simulation is used to compute the cumulative distribution function of exceeding the Safe Drinking Water Act. The Safe Drinking Water Act has three categories of radionuclides, as shown in Table 5-1. Table 5-2 shows the activity to dose conversion factors for beta emitters that correspond to the Safe Drinking Water Act standards. If one or more of the categories of maximum contaminant levels is exceeded in the model simulations, then the regulatory standard is exceeded.

Each of the Safe Drinking Water Act regulatory limits is tested follows:

- For the alpha-emitting radionuclides (e.g., ${ }^{237} \mathrm{~Np}$ and ${ }^{241 / 243} \mathrm{Am}$ ), the sum of the activity concentrations (i.e., the molar concentration from the transport model simulation converted via the radionuclide specific activity) of alpha-emitting radionuclides is calculated and compared to the 15-picocuries-per-liter standard. If a fluid parcel exceeds the 15-picocuries-per-liter standard, then the maximum contaminant level for this fluid parcel is violated. 
Table 5-1

Radionuclide Regulatory Groups

\begin{tabular}{||c|c|c||}
\hline Regulatory Group & Bowen et al. (2001) Radionuclide & Maximum Contaminant Level \\
\hline \hline Beta/Photon Emitter & $\begin{array}{c}{ }^{3} \mathrm{H},{ }^{14} \mathrm{C},{ }^{26} \mathrm{Al},{ }^{36} \mathrm{Cl},{ }^{39} \mathrm{Ar},{ }^{40} \mathrm{~K},{ }^{41} \mathrm{Ca},{ }^{113 \mathrm{~m}} \mathrm{Cd}{ }^{59 / 63} \mathrm{Ni},{ }^{85} \mathrm{Kr},{ }^{90} \mathrm{Sr}, \\
{ }^{93} \mathrm{Zr},{ }^{93 \mathrm{~m} / 94} \mathrm{Nb},{ }^{99} \mathrm{Tc},{ }^{107} \mathrm{Pd},{ }^{121 \mathrm{~m} / 126} \mathrm{Sn},{ }^{129},{ }^{135 / 137} \mathrm{Cs},{ }^{241} \mathrm{Pu},\end{array}$ & 4 millirem per year \\
\hline Gross Alpha Particles & ${ }^{150 / 152 / 154} \mathrm{Eu},{ }^{151} \mathrm{Sm},{ }^{166} \mathrm{Ho}$ & 15 picocuries per liter \\
\hline$U$ & All lsotopes & 30 micrograms per liter \\
\hline
\end{tabular}

Source: NNES, 2010

Table 5-2

Activity Concentrations Equal to 4-Millirem-per-Year Dose (Page 1 of 2)

\begin{tabular}{|c|c|}
\hline Nuclide & Picocuries per Liter \\
\hline${ }^{3} \mathrm{H}$ & 20,000 \\
\hline${ }^{14} \mathrm{C}$ & 2,000 \\
\hline${ }^{26} \mathrm{Al}$ & Low Inventory - omitted \\
\hline${ }^{36} \mathrm{Cl}$ & 700 \\
\hline${ }^{39} \mathrm{Ar}$ & No SDWA activity to dose factor \\
\hline${ }^{40} \mathrm{~K}$ & Naturally abundant - omitted \\
\hline${ }^{41} \mathrm{Ca}$ & No SDWA activity to dose factor \\
\hline${ }^{113 \mathrm{~m}} \mathrm{Cd}$ & No SDWA activity to dose factor \\
\hline $59 / 63 \mathrm{Ni}$ & 50 \\
\hline${ }^{85} \mathrm{Kr}$ & No SDWA activity to dose factor \\
\hline${ }^{90} \mathrm{Sr}$ & 8 \\
\hline${ }^{93} \mathrm{Zr}$ & 2,000 \\
\hline $93 \mathrm{~m} N b$ & Low Inventory - omitted \\
\hline${ }^{94} \mathrm{Nb}$ & No SDWA activity to dose factor \\
\hline${ }^{99} \mathrm{Tc}$ & 900 \\
\hline${ }^{107} \mathrm{Pd}$ & No SDWA activity to dose factor \\
\hline $121 \mathrm{~m} / 126 \mathrm{Sn}$ & No SDWA activity to dose factor \\
\hline 129 & 1 \\
\hline${ }^{135 / 137} \mathrm{Cs}$ & 200 \\
\hline${ }^{241} \mathrm{Pu}$ & 300 \\
\hline
\end{tabular}


Table 5-2

Activity Concentrations Equal to 4-Millirem-per-Year Dose

(Page 2 of 2)

\begin{tabular}{|c|c|}
\hline Nuclide & Picocuries per Liter \\
\hline \hline${ }^{150 / 152 / 154} \mathrm{Eu}$ & 200 \\
\hline${ }^{151} \mathrm{Sm}$ & 1,000 \\
\hline${ }^{166} \mathrm{Ho}$ & No SDWA activity to dose factor \\
\hline
\end{tabular}

Source: EPA, 2002b

SDWA = Safe Drinking Water Act

- For the beta- and photon-emitting radionuclides (e.g., ${ }^{3} \mathrm{H},{ }^{90} \mathrm{Sr},{ }^{129} \mathrm{I}$, and ${ }^{135 / 137} \mathrm{Cs}$ ), a

"sum-of-the-fractions" procedure is executed (EPA, 2002a). Using the molar concentration of simulated beta- and photon-emitting radionuclides, which are converted into an activity concentration, an annual dose equivalent of 4 millirem per year is computed using EPA published factors (EPA, 2001) by dividing each radionuclide-specific activity concentration value by the activity concentration equivalent to the annual dose equivalent of 4 millirem per year for that particular radionuclide. This fraction represents the contribution of a radionuclide to the maximum allowable 4-millirem-per-year limit for each beta and photon emitter present. These fractions are then summed for all beta and photon emitters at each location in the model. If the sum exceeds unity, then the location exceeds the maximum contaminant level.

- For $U$ isotopes, the sum of mass concentrations of $U$ isotopes (i.e., micrograms per liter) present at each location is calculated. If the sum of mass concentrations exceeds the 30-micrograms-per-liter standard for $\mathrm{U}$, then the maximum contaminant level is violated.

After a series of test calculations, a further simplification was made for the contaminant boundary forecasts for MILK SHAKE and PIN STRIPE and all null-space Monte Carlo simulations. In these cases, only ${ }^{14} \mathrm{C},{ }^{36} \mathrm{Cl},{ }^{3} \mathrm{H},{ }^{129} \mathrm{I}$, and ${ }^{99} \mathrm{Tc}$ were included in the integrated transport simulations. These five beta emitters make up 92 percent of the source-term inventory based on activity (Bowen et al., 2001) and control the contaminant boundary based on all transport analyses of the Frenchman Flat CAU (NNES, 2010). As a group, these species are the most mobile within the source-term inventory and generally have short half-lives, which lead to high activity values during the 1,000-year simulations (NNES, 2010).

For the Northern Testing Area, transport calculations were done based on the steady-state flow field and the streamline-based convolution method embedded in PLUMECALC (Robinson and Dash, 
2006). For the Central Testing Area, transport calculations were done with a combination of transient and steady-state flow fields and different transport models. The finite-element continuum method as implemented in FEHM was used for the transient flow fields in the Central Testing Area resulting from the CAMBRIC RNM experiment. The finite-element continuum method was only used for those radionuclides observed in the RNM experiment breakthrough at UE-5n. For all other radionuclide species, the steady-state flow field was used and transport calculations were completed with PlumeCalc (Robinson and Dash, 2006; also described above) and the GoldSim source term release functions (GoldSim, 2006). The continuum source term model results were added to the streamline particle tracking results to complete the contaminant boundary calculations.

The contaminant boundary calculation applied to all Monte Carlo transport realizations are as follows:

- Read the transport model concentrations at the output times.

- Convert molar concentration output to activity concentration for alpha-, beta- and photon-emitting radionuclides. Compute dose, fraction per radionuclide, and then sum of fractions for beta- and photon-emitting nuclides. For $\mathrm{U}$, the molar concentration is converted to the micrograms-per-liter mass concentration.

- For each time and at each model element, test whether any of the Safe Drinking Water Act regulatory standards (EPA, 2002a) are exceeded.

- If the standard is exceeded for the realization, add 1 to the exceedance count for that location at that time.

- Compute the number of counts divided by the total number of realizations. If a value of 0.05 or higher is obtained, the element is within the contaminant boundary.

The results from the contaminant boundary calculation are illustrated in two ways: time-cumulative probability maps and time-specific probability maps (NNES, 2010). Both show the probability of exceeding the Safe Drinking Water Act standard (EPA, 2002a), the exceedance count divided by the number of realizations, as described above. The time-specific probability maps show this value at a given time, while the time-cumulative probability maps show the maximum of this value at any time over the 1,000-year simulations. The time-cumulative maps are defined as a contaminant boundary, while the time-specific maps are used to understand the evolution of the contaminant boundary from the underlying physical process of groundwater flow and transport. 


\subsubsection{Northern Testing Area}

One thousand transport model realizations were conducted for each of the four flow models selected for transport analysis (BASE-USGSD with alternative boundary conditions, "NHA," and each of these calibrated parameter sets with the BLFA alternative HFM). One thousand realizations were used based on computational time and the expectation that this would be a reasonable number of realizations to calculate the 5th percentile likelihood of exceedance of the Safe Drinking Water Act standards at each node. This assumption was tested during sensitivity analyses, where changes to the exceedance volume were determined with 2,000 and 5,000 transport simulations, demonstrating that there was no difference in the exceedance volume calculation. The impact of dispersivity was also discretely tested by using values lower and higher than that determined from analyses of the CAMBRIC RNM experiment. Ten transport realizations were run for each of the 100 BASE-USGSD with alternative boundary conditions null-space Monte Carlo flow fields and 1 for each of the "NHA" null space flow fields, respectively, totaling 1,000 and 100 transport realizations. The detailed results and a sensitivity analysis to identify important parameters are described in the transport analysis (NNES, 2010).

Overall, the contaminant boundary results show that transport in the Northern Testing Area is predominantly horizontal with a maximum boundary thickness of $60 \mathrm{~m}$. Table 5-3 summarizes the contaminant boundary maximum lateral distance, width, and depth of the boundary from each test. The HSUs encountered by the contaminant boundary are also shown. Figure 5-21 shows a composite of the contaminant boundaries at the element center for the Northern Testing Area. There are two general categories of contaminant boundaries: (1) small boundaries associated with sites where the test cavity and transport are in the alluvial aquifer, and (2) larger boundaries where the test cavities and/or transport are in fractured volcanic rock. The direction of transport is generally similar in all modeled cases with some variability for the MILK SHAKE plume, whereas simulated travel distance is more variable for the PIN STRIPE and MILK SHAKE tests (Figure 5-21).

The PIN STRIPE forecast contaminant plume is mainly confined to a narrow east-west trending area east of the PIN STRIPE test location and between the regions of larger fault offsets in the accommodation zone to the north and the detachment fault to the south. The TSA along the path of the model-forecast plume is represented in the HFM as a continuous unit not disrupted by faulting. This representation, however, is uncertain because of alluvial cover, and ambiguous geophysical data 
Table 5-3

Saturated Zone Dimensions of Contaminant Boundary for Each Source

\begin{tabular}{|c|c|c|c|c||}
\hline Test & $\begin{array}{c}\text { Maximum Lateral } \\
\text { Distance } \\
(\mathbf{m})\end{array}$ & $\begin{array}{c}\text { Maximum } \\
\text { Width } \\
\mathbf{( m )}\end{array}$ & $\begin{array}{c}\text { Maximum } \\
\text { Depth } \\
\mathbf{( m )}\end{array}$ & $\begin{array}{c}\text { Intersected } \\
\text { HSUs }\end{array}$ \\
\hline \hline DERRINGER & 500 & 200 & 5 & OAA, BLFA \\
\hline DIAGONAL LINE & 220 & 200 & 35 & BLFA, OAA \\
\hline DIANA MOON & 150 & 190 & 30 & BLFA, OAA \\
\hline MILK SHAKE & 1,650 & 625 & 60 & OAA, BLFA \\
\hline MINUTE STEAK & 140 & 190 & 35 & OAA \\
\hline NEW POINT & 180 & 175 & 20 & OAA \\
\hline PIN STRIPE & 1,610 & 350 & 15 & TSA, LTCU, TM-VTA, OAA \\
\hline CAMBRIC & 25 & 25 & 30 & AA \\
\hline DILUTED WATERS & 160 & 120 & 45 & AA \\
\hline WISHBONE & 180 & 130 & 30 & AA \\
\hline CAMBRIC Ditch & 2,860 & 110 & 110 & AA \\
\hline
\end{tabular}

Source: NNES, 2010

throughout the area. The current HFM representation assumes continuity of thin HSUs along the flow path. The continuity of the TSA, however, could vary from continuous to significantly disrupted by one or more poorly characterized faults within this structurally complex transitional zone.

Although regional structural trends suggest that large offset faults may not cross-cut the path of the PIN STRIPE forecast contaminant plume, the saturated TSA is relatively thin along the plume path (e.g., approximately $30 \mathrm{~m}$ [100 feet (ft)] at UE-11b), and thus susceptible to offset and/or structural disruption across undocumented buried faults with more moderate throws (i.e., greater than $30 \mathrm{~m}$ $[100 \mathrm{ft}])$. Offset of the TSA is likely to juxtapose the unit against alluvial deposits, vitric-tuff aquifer units, or volcanic confining units, all of which are expected to have significantly lower permeability than the TSA and reduce the length of the PIN STRIPE contaminant boundary. Local-scale models of this fractured rock pathway using alternative geologic interpretations were completed (NNES, 2010, Appendix D). The results of these models demonstrate that the assumed lateral continuity of this thin stratigraphic interval in the HFMs indeed produces the largest extent of contaminant boundary. However, because of the complexity of the hydrogeologic setting in this portion of the model domain, hydrologic continuity of the TSA cannot be discounted. 


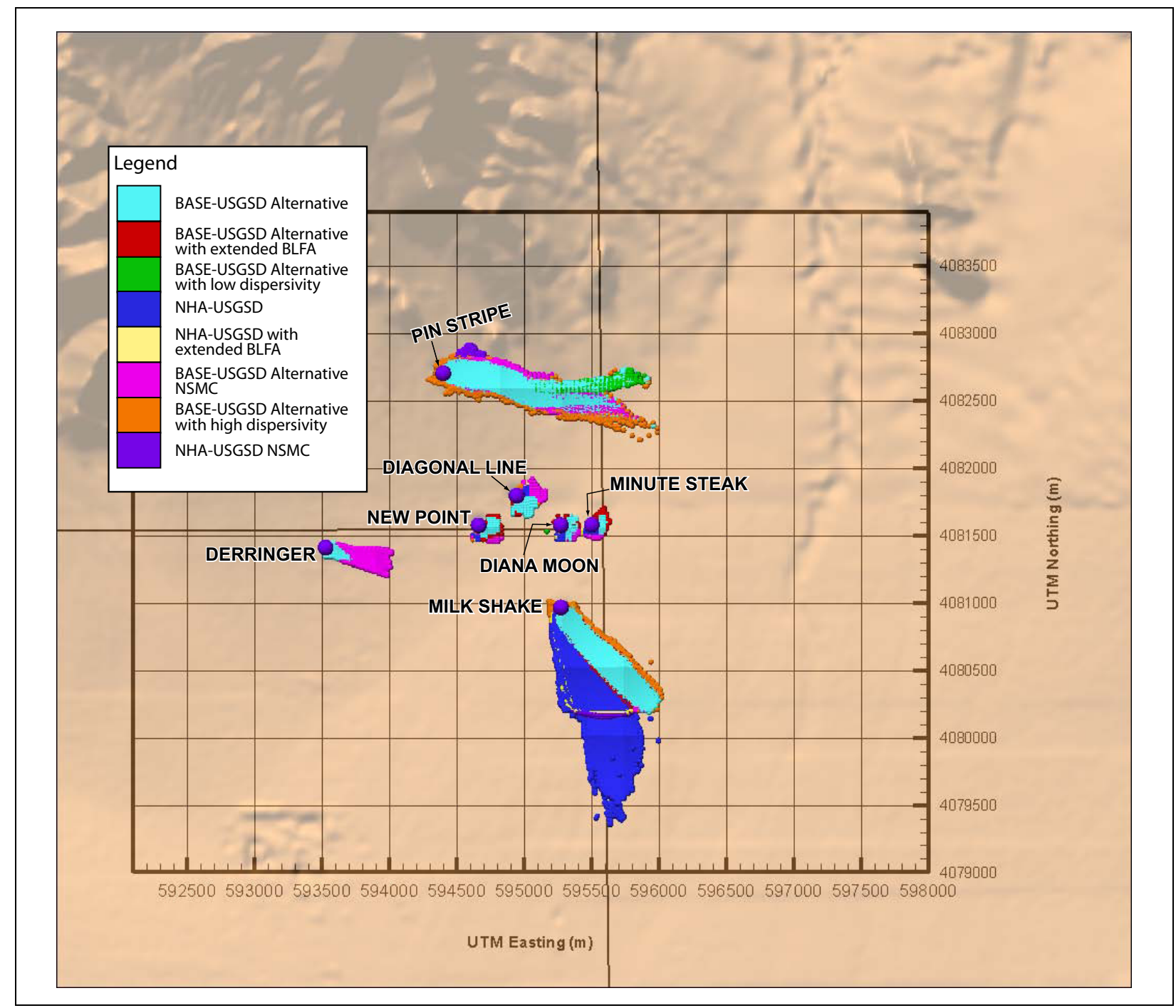

\section{Figure 5-21 \\ Northern Testing Area Composite of All Northern Testing Area Transport Models Time-Cumulative Contaminant Boundary \\ Source: NNES, 2010}

\subsubsection{Central Testing Area}

Transport calculations including Monte Carlo simulations sampling uncertain transport parameters were conducted for the three transient sub-CAU models calibrated to the CAMBRIC RNM experimental data. Because of lengthy model run times, only 100 realizations of transport parameter combinations were executed for each flow model. The sampled parameters include porosity and the infiltration rate from the ditch into which the RNM-2S flow was discharged. The transport porosity values were sampled from a uniform distribution ranging from 0.20 to 0.46 , and the ditch infiltration 
rates were simultaneously sampled from a uniform distribution ranging from 0.75 to 1.0 as a fraction of the measured RNM-2S flow rate.

Following the transport simulations, model output for each of the realizations was post-processed to convert the calculated concentrations of ${ }^{3} \mathrm{H}$ and a conservative tracer into concentrations for other mobile radionuclides of interest. This was necessary because not all of the radionuclides believed to have broken through at the pumping well, RNM-2S, were measured during the RNM experiment and hence it was necessary to estimate their concentrations indirectly using the relative abundance of these radionuclides in the estimated CAMBRIC inventory and radionuclide-specific radioactive decay constants.

Steady-state flow simulations were then conducted to extract the cavity flows for use in the SSM. The SSM was used to compute the CAMBRIC nuclear melt glass source (it is assumed, based on RNM-2S data, that the other nuclides were pumped out of the cavity), and the entire WISHBONE and DILUTED WATERS contaminant source. These sources were analyzed in the steady-state flow field with 100 PlumeCalc realizations using Monte Carlo Latin Hypercube sampling of transport parameters. The probabilistic contaminant boundary was then calculated by adding the Safe Drinking Water Act exceedance from the combined transient and steady-state transport simulations.

For the Central Testing Area, the groundwater flow model uncertainty addressed through variations in parameterization and HFM caused very little change in the forecast contaminant boundary (Figure 5-22). This result reflects the constraints imposed on the flow system and subsequent transport forecasts by the addition of data from the RNM-2S multiple well aquifer test and the observed contaminant breakthrough at UE-5n from the CAMBRIC RNM experiment. The contaminant boundary in the Central Testing Area is clearly dominated by the source associated with the ditch infiltration, which also causes more vertical flow than was seen in the Northern Testing Area. Because the contaminant boundary in the Central Testing Area is defined by short-lived ${ }^{3} \mathrm{H}$ (half-life 12.3 years), the contaminant boundary forecast stabilizes and shrinks over the near term, so that by 2065 even ${ }^{3} \mathrm{H}$ concentrations fall below the Safe Drinking Water Act standard (EPA, 2002a). 


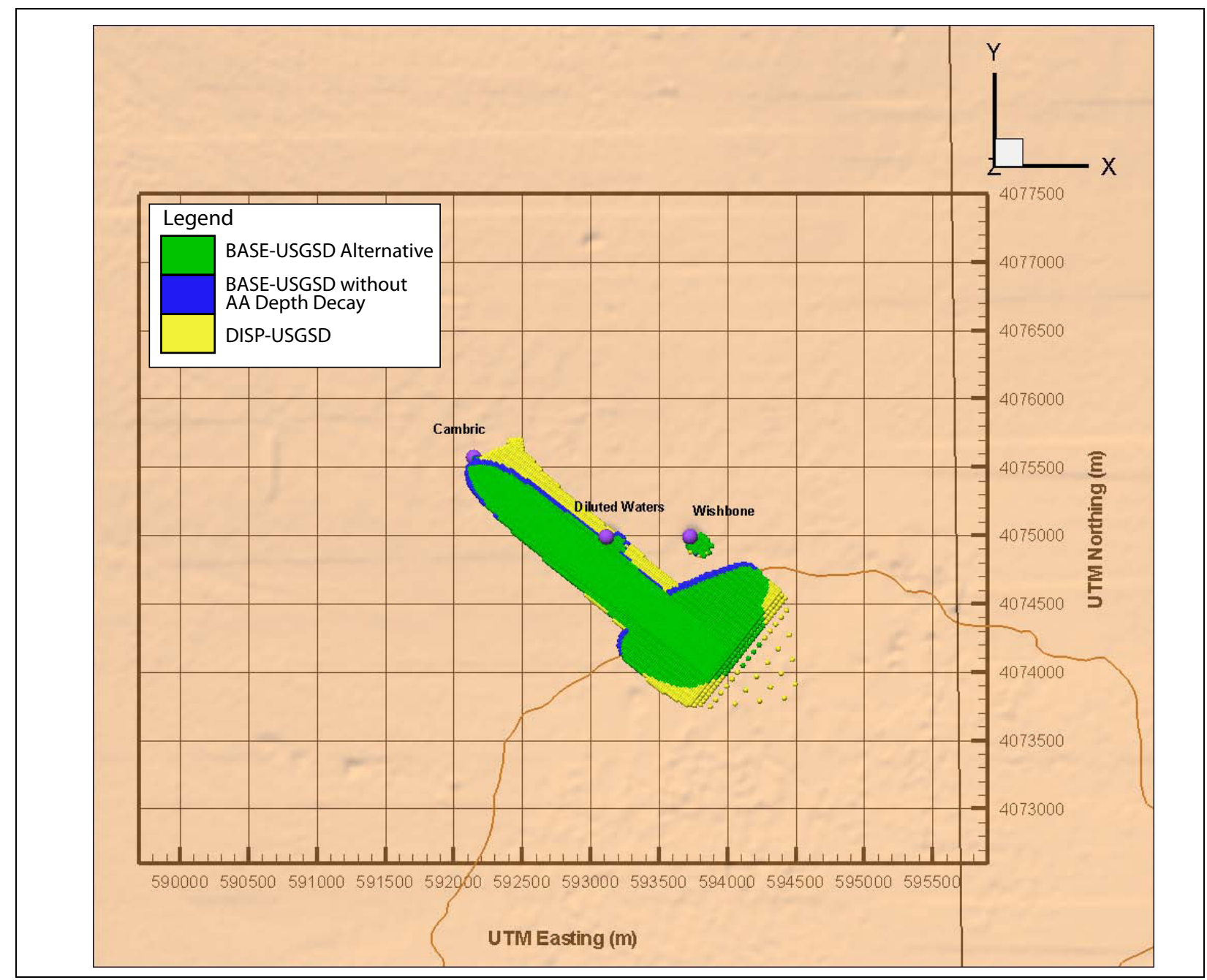

Figure 5-22

Central Testing Area Composite of All Central Testing Area Transport Models Time-Cumulative Contaminant Boundary

Source: NNES, 2010

\subsubsection{Transport Model Uncertainty and Sensitivity}

Multiple approaches were used to interpret and quantify the sensitivity of uncertain model parameters on the forecast contaminant boundary (NNES, 2010). Two of these methods are contingency tables and classification trees. Contingency table analysis checks for non-random patterns of association, monotonic and non-monotonic. This method searches for patterns that exist across the range of modeled outcomes. Classification-tree analysis searches for parameter values that lead to the extreme upper and lower ends of the model outcome range. Associations between radionuclide sources 
inhibited the ability of the contingency table and classification-tree analyses to determine their individual sensitivity.

The sensitivity analysis examined the influence of the related parameters on the transport model results as represented by tests in the OAA (DERRINGER, DIAGONAL LINE, DIANA MOON, MINUTE STEAK, and NEW POINT); MILK SHAKE; and PIN STRIPE tests. The uncertainty is largely dominated by the source release parameters. The amount of contaminated groundwater for the five OAA tests can be completely reproduced with only the five beta emitters included in the MILK SHAKE and PIN STRIPE simulations, supporting the exclusion of the other species. For the five OAA and PIN STRIPE tests, in decreasing order of impact on the contaminant boundary, the major contributing species were ${ }^{3} \mathrm{H},{ }^{14} \mathrm{C},{ }^{36} \mathrm{Cl},{ }^{129} \mathrm{I}$, and ${ }^{99} \mathrm{Tc}$. MILK SHAKE has the same ranking with the reverse order of ${ }^{14} \mathrm{C}$ and ${ }^{3} \mathrm{H}$. 


\subsection{Conclusions}

Appendix VI of the FFACO (1996, as amended March 2010), the UGTA strategy agreed to by NDEP and NNSA/NSO, requires that a groundwater flow and contaminant transport model be used to forecast an ensemble of contaminant boundaries. These contaminant boundaries will be used by NDEP and NNSA/NSO to negotiate a compliance boundary, plan a monitoring program, and identify institutional controls. The process adopted at the present CAI stage of model evaluation for the Frenchman Flat CAU contaminant boundary forecasts is to develop and implement a range of models that reasonably account for the conceptual and boundary-condition uncertainty as well as parameter uncertainty affecting the direction and extent of contaminant migration from the 11 corrective action sites within the Frenchman Flat CAU. To accomplish this strategy, a 3-D, finite-element, steady-state groundwater flow and contaminant transport model was constructed based on the requirements outlined in the Addendum to Revision 1 of the Corrective Action Investigation Plan for Corrective Action Unit 98: Frenchman Flat, Nevada Test Site, Nevada (NNSA/NV, 2001). Additional local-scale models were also developed to address specific variations to the flow field that were important to contaminant boundary calculations.

At the current CAI stage, NDEP and NNSA/NSO must reach a joint decision that the model is acceptable. Model acceptability is determined by evaluating whether there is sufficient confidence in the model results to proceed to the Corrective Action Decision Document/Corrective Action Plan stage where NDEP and NNSA/NSO negotiate a preliminary Frenchman Flat CAU compliance boundary. If the model is acceptable, the design and implementation of monitoring activities begins to evaluate the conceptual model and results of the forecast contaminant boundary. As noted in the FFACO (1996, as amended March 2010), the level of confidence of the acceptability of the model is expected to be enhanced based on the iterative model evaluations, which incorporate new monitoring data. Another component of the model evaluation is the external peer review, which assists in gaining confidence in the model. 
Data collection and analyses in support of the Phase II CAI for Frenchman Flat have demonstrated that flow within the Frenchman Flat basin-fill units is consistent with the conceptual model that was first put forth by Winograd and Thordarson (1975). Additional data have served to refine details and relationships among the components of the flow system, but have not resulted in substantive changes to the principal interpretation of flow processes. For example, ${ }^{14} \mathrm{C}$ age dating of groundwater showed that groundwater ages in Frenchman Flat ranged from approximately 8,500 to 29,000 years, with younger groundwater found near the borders of the basin and older water found near the basin center. Groundwater velocities ranging from 0.1 to $1 \mathrm{~m} / \mathrm{yr}$ were estimated using these geochemical analyses (SNJV, 2006). The geochemically derived velocities, in concert with additional characterization data, are in agreement with the concept that flat hydraulic gradients within the alluvium are due to limited flow rather than high permeability. Additionally, the distribution of groundwater age in the basin indicates that groundwater flow is generally to the south-southeast. This is consistent with the conceptual model that vertical and horizontal leakage from the basin occurs in the vicinity of Frenchman Lake, and along the southeastern basin margin where the confining units thin and the shallow heads are more easily affected by the low heads throughout the Rock Valley fault system. Rapid migration of radionuclides past the eastern edge of the NTS and out of the Frenchman Flat physiographic basin is therefore unlikely and not consistent with either geochemical age and velocity information, or the contaminant transport predictions from the corrective action sites.

Data collected during the Phase II CAI was integrated into the flow and transport models, which considered uncertainty in geological structure, boundary conditions, conceptual model, and parameters. Evaluation of these models produced generally consistent contaminant boundary forecasts. A total of 20 steady-state flow models were constructed and calibrated. The two models with the greatest consistency with the data constraints were further analyzed to generate 100 realizations of each model using null-space Monte Carlo analysis. This suite of models provided both the variation in the groundwater flux through the nuclear test cavities and the flow fields necessary for contaminant transport calculations. In addition, a suite of transient models was calibrated for the Central Testing Area to the CAMBRIC RNM experiment and the RNM-2S multiple-well aquifer test. Once conditioned to the larger-scale flow field and the local data, these transient models all provided very similar directions and magnitudes of groundwater flow in the Central Testing Area. 
Adding the additional data constraint provided by the geochemistry analysis resulted in a model with good overall calibration metrics, and flow paths that were consistent with the conceptual model of the Frenchman Flat basin developed by Winograd and Thordarson (1975) and observations of groundwater ages. This also provided a means to reduce transport prediction uncertainty by directly incorporating data that relate to the forecast of interest as a calibration metric. Additionally, a model calibration that honors specific head, flux, velocity, and flow-direction data - and that provides results consistent with the conceptual model and qualitative observations of the flow system and rock properties - provides confidence that this is a reasonable representation of the flow system for Frenchman Flat.

In summary, the flow models used to forecast the range and uncertainty in the contaminant boundaries for the Frenchman Flat CAU simulate a reasonable range of possible results and are expected to continue to evolve through the life cycle of the regulatory decisions required in the UGTA strategy documented in the FFACO (1996, as amended March 2010). This evolution is expected to be informed by iterative model evaluations that include the results of monitoring new and existing wells during the Corrective Action Decision Document/Corrective Action Plan and Closure Report phases of the UGTA strategy.

The regulatory criteria for the contaminant boundaries are based on the Safe Drinking Water Act (CFR, 2009) and 1,000-year forecasts of contaminant transport. Given the nature of the contamination at Frenchman Flat and the low groundwater velocities, the boundary forecasts are driven by a small group of radionuclides that mobilize rapidly from the test cavity and are transported with the ambient groundwater flow system. These radionuclides are highly radioactive (among those in the Bowen et al. [2001] inventory), resulting in substantial contributions to the contaminant boundary. Observations from the CAMBRIC RNM experiment provided direct field observations of this process and provide confidence that this subset of species is indeed the primary concern for contaminant transport within the specified regulatory framework for the Frenchman Flat CAU. This information also serves to substantially reduce the uncertainty of the boundary forecast resulting from the simplifications to complex chemical processes that govern reactive transport.

The contaminant boundaries are controlled by the source term and will be limited to the area directly around a test in the absence of flow. As a result, the processes controlling fast-releasing radionuclides 
into the flow system end up changing the contaminant boundary forecasts. Because CAMBRIC is the only test in Frenchman Flat located below the water table, substantial approximations have been made in estimating the hydrologic source terms for the other tests based on the CAMBRIC HST. The main limitation is that water from the water table is assumed to pass through the exchange volumes, even though the exchange volumes are mostly above the water table. This assumption may cause the source term availability to the saturated system to be greatly overstated and is likely the reason why the tests whose HSTs are generated by the GoldSim-based SSM (which assumes the exchange volumes are saturated, when they are not) continue to grow in the Northern Testing Area through the entire regulatory period of 1,000 years. Although this assumption was addressed for highly mobile radionuclides for the tests conducted in fractured rock, forecasts for MILK SHAKE also show this behavior because more of its exchange volume is below the water table than PIN STRIPE's.

Contaminant boundary calculations were completed using a range of groundwater flow fields that bounded the uncertainty apparent in discrete model calibrations (which included varying HFM, boundary condition, and parameterization approaches; and incorporated transport parametric uncertainty). However, even with this effort, there is no guarantee that conditions in the subsurface will match any of the tested models. The National Research Council (2007) suggests that no model will ever be perfect and account for every aspect of reality. The EPA (2009) recognizes this limitation of models and their usefulness in aiding decision making, and advocates evaluation of a model for its sufficiency to serve as the basis for a decision. In the UGTA strategy (FFACO, 1996; as amended March 2010), the initial round of drilling in the monitoring phase is for model evaluation - to test key uncertainties and assess the forecasts. These additional observations are crucial in refining understanding at key locations. Therefore, the current model will serve as a foundation for long-term model acceptability activities that will be achieved through the UGTA process. 


\subsection{REFERENCES}

Arteaga, F.E., C.S. Savard, M.E. Johnson, and J.C. Stone. 1991. Hydrogeologic Data from Selected Wells and Test Holes in and Adjacent to the Nevada Test Site, Nye County, Nevada, through 1986, USGS-OFR 87-356. Boulder, CO: U.S. Geological Survey.

BN, see Bechtel Nevada.

Bechtel Nevada. 2005a. A Hydrostratigraphic Framework Model and Alternatives for the Groundwater Flow and Contaminant Transport Model of Corrective Action Unit 98: Frenchman Flat, Clark, Lincoln and Nye Counties, Nevada, DOE/NV/11718--1064. Las Vegas, NV.

Bechtel Nevada. 2005b. Site Characterization and Monitoring Data from Area 5 Pilot Wells, Nevada Test Site, Nye County, Nevada, DOE/NV/11718--1067. Las Vegas, NV.

Belcher, W.R., J.B. Blainey, F.A. D’Agnese, C.C. Faunt, M.C. Hill, R.J. Laczniak, G.M. O’Brien, C.J. Potter, H.M. Putnam, C.A. San Juan, and D.S. Sweetkind. 2004. Death Valley Regional Ground-Water Flow System, Nevada and California-Hydrogeologic Framework and Transient Ground-Water Flow Model, Scientific Investigations Report 2004-5205. U.S. Geological Survey. Prepared for the U.S. Department of Energy, National Nuclear Security Administration Nevada Site Office.

Beven, K.J. 2002. "Towards a Coherent Philosophy for Modelling the Environment." In Proceedings of the Royal Society of London, Series A, Vol. 458.

Blout, D.O., W.S. Birchfiel, D.P. Hammermeister, and K.A. Zukosky. 1995. Site Characterization Data from the Area 5 Science Boreholes, Nevada Test Site, Nye County, Nevada, DOE/NV 11432--170. Las Vegas, NV: Reynolds Electrical \& Engineering Co., Inc.

Borg, I.Y., R. Stone, H.B. Levy, and L.D. Ramspott. 1976. Information Pertinent to the Migration of Radionuclides in Groundwater at the Nevada Test Site. Part 1: Review and Analysis of Existing Information, UCRL-52078, Pt. 1. Livermore, CA: Lawrence Livermore National Laboratory.

Bowen, S.M., D.L. Finnegan, J.L. Thompson, C.M. Miller, P.L. Baca, L.F. Olivas, C.G. Geoffrion, D.K. Smith, W. Goishi, B.K. Esser, J.W. Meadows, N. Namboodiri, and J.F. Wild. 2001. Nevada Test Site Radionuclide Inventory, 1951-1992, LA-13859-MS. Los Alamos, NM: Los Alamos National Laboratory. 
Bright, D.J., S.A. Watkins, and B.A. Lisle. 2001. Analysis of Water Levels in the Frenchman Flat Area, Nevada Test Site, Water-Resources Investigations Report 00-4272. Denver, CO:

U.S. Geological Survey.

Bryant, E.A. 1992. The Cambric Migration Experiment - A Summary Report, LA12335-MS.

Los Alamos, NM: Los Alamos National Laboratory.

Buddemeier, R.W. 1988. Hydrology and Radionuclide Migration Program 1985-1986 Progress Report, UCRL-53779. Livermore, CA: Lawrence Livermore National Laboratory.

Buddemeier, R.W., and J.R. Hunt. 1988. “Transport of Colloidal Contaminants in Groundwater: Radionuclide Migration at the Nevada Test Site." In Applied Geochemistry, Vol. 3: 535-548. London, England: Pergamon Press.

Byers, F.M., Jr., and C.H. Miller. 1966. Geologic and Geophysical Log of the Ue5k Exploratory Hole, Frenchman Flat, Nevada Test Site, Technical Letter NTS-164. U.S. Geological Survey.

CFR, see Code of Federal Regulations.

Carle S.F., M. Zavarin, and G.A. Pawloski. 2002. Geostatistical Analysis of Spatial Variability of Mineral Abundance and $K_{d}$ in Frenchman Flat, NTS, Alluvium, UCRL-ID-150200.

Livermore, CA: Lawrence Livermore National Laboratory.

Carle, S.F., R.M. Maxwell, G.A. Pawloski, D.E. Shumaker, A.F.B. Tompson, and M. Zavarin. 2007. Evaluation of the Transient Hydrologic Source Term for the Cambric Underground Nuclear Test at Frenchman Flat, Nevada Test Site, UCRL-TR-226916. Livermore, CA: Lawrence Livermore National Laboratory.

Carle, S.F., M. Zavarin, Y. Sun, and G.A. Pawloski. 2008. Written communication. Subject: Evaluation of Hydrologic Source Term Processes for Underground Nuclear Tests in Yucca Flat, Nevada Test Site: Carbonate Tests, LLNL-TR-403485. Livermore, CA: Lawrence Livermore National Laboratory.

Carr, W.J., G.D. Bath, D.L. Healey, and R.M. Hazlewood. 1975. Geology of Northern Frenchman Flat, Nevada Test Site, USGS-474-216. Denver, CO: U.S. Geological Survey.

Chapman, J.B., R.L. Hershey, and B.F. Lyles. 1995. Groundwater Velocities at the Nevada Test Site: Carbon 14-Carbon-Based Estimates, Publication No. 45135. Las Vegas, NV: Desert Research Institute, Water Resources Center.

Code of Federal Regulations. 1996. Title 40 CFR Part 300.430, "Remedial Investigation/Feasibility Study and Selection of Remedy." Washington, DC: U.S. Government Printing Office.

Code of Federal Regulations. 2009. Title 40 CFR Part 141, "National Primary Drinking Water Regulations." Washington, DC: U.S. Government Printing Office. 
DOE, see U.S. Department of Energy.

DOE/NV, see U.S. Department of Energy, Nevada Operations Office.

Daniels, W.R., comp. 1981. Laboratory and Field Studies Related to the Radionuclide Migration Project (October 1, 1979 - September 30, 1980), LA-8670-PR. Los Alamos, NM: Los Alamos National Laboratory.

Daniels, W.R., comp. 1982. Laboratory and Field Studies Related to the Radionuclide Migration Project (October 1, 1980 - September 30, 1981), LA-9192-PR. Los Alamos, NM: Los Alamos National Laboratory.

Daniels, W.R., comp. 1983. Laboratory and Field Studies Related to the Radionuclide Migration Project (October 1, 1981 - September 30, 1982), LA-9691-PR. Los Alamos, NM: Los Alamos National Laboratory.

Daniels, W.R., and J.L. Thompson comps. and eds. 1984. Laboratory and Field Studies Related to the Radionuclide Migration Project (October 1, 1982 - September 30, 1983, LA-10121-PR. Los Alamos, NM: Los Alamos National Laboratory.

Decisioneering, Inc. 2005. Crystal Ball User Manual, Version 7.1. Denver, CO.

Dixon, G.L., W.J. Carr, A.T. Fernald, and F.M. Byers, Jr. 1965. Geologic Report on Drill Hole Ue11b, Nevada Test Site, USGS-NTS-157, Technical Letter. Denver, CO:

U.S. Geological Survey.

Dixon, G.L., W.J. Carr, and W.P. Williams. 1967. Geologic and Geophysical Log of Drill Hole Ue5i, Nevada Test Site, USGS-NTS-186, Technical Letter. Denver, CO: U.S. Geological Survey.

Doherty, J. 2008. PEST: Model-Independent Parameter Estimation, User's Manual, Version 11. Watermark Numerical Computing: Brisbane, Australia.

Drellack, Jr., S.L. 1995. Selected Stratigraphic Data for Drill Holes Located in Frenchman Flat, Nevada Test Site, TSD:DGP:111:95. Las Vegas, NV: Raytheon Services Nevada.

EPA, see U.S. Environmental Protection Agency.

Eakin, T.E., G.B. Maxey, T.W. Robinson, J.C. Fredericks and O.J. Loeltz. 1951. "Contributions to the Hydrology of Eastern Nevada." In Water Resources Bulletin, No. 12. Carson City, NV: State of Nevada, Office of the State Engineer/U.S. Geological Survey.

FFACO, see Federal Facility Agreement and Consent Order.

Federal Facility Agreement and Consent Order. 1996. Agreed to by the State of Nevada, the U.S. Department of Energy, and the U.S. Department of Defense. 
Federal Facility Agreement and Consent Order. 1996 (as amended March 2010). Agreed to by the State of Nevada; U.S. Department of Energy, Environmental Management; U.S. Department of Defense; and U.S. Department of Energy, Legacy Management.

Fernald, A.T., G.L. Dixon, W.J. Carr, and F.M. Byers, Jr. 1965. Geologic Report on Drill Hole Uella, Nevada Test Site, USGS - NTS-160, Technical Letter. Denver, CO:

U.S. Geological Survey.

Finnegan, D.L., and J.L. Thompson. 2002. Laboratory and Field Studies Related to Radionuclide Migration at the Nevada Test Site in Support of the Underground Test Area and Hydrologic Resources Management Projects, LA-13919-MS. Los Alamos, NM: Los Alamos National Laboratory.

GoldSim, see GoldSim Technology Group, LLC.

GoldSim Technology Group, LLC. 2006. User’s Guide: GoldSim Graphical Simulation Environment, Version 9.5. Issaquah, WA.

Grauch, V.J.S., and M.R. Hudson. 1995. Preliminary Analysis of Major Structures and Lithologic Boundaries for the Frenchman Flat Model Area. Denver, CO: U.S. Geological Survey.

Guell, M.A., and J.R. Hunt. 2003. "Groundwater Transport of Tritium and Krypton-85 from a Nuclear Detonation Cavity." In Water Resources Research, Vol 39 (7), doi:10.1029/2001WR001249.

Harbaugh, A.W., E.R. Banta, M.C. Hill, and M.G. McDonald. 2000. MODFLOW-2000, the U.S. Geological Survey Modular Ground-Water Model -- User Guide to Modularization Concepts and the Ground-Water Flow Process, Open-File Report 00-92. Reston, VA: U.S. Geological Survey.

Helton, J.C. 1999. "Uncertainty and Sensitivity Analysis in Performance Assessment for the Waste Isolation Pilot Plant." In Computer Physics Communications, Vol. 117, no. 1-2, pp. 156-180.

Hershey, R.L., J.M. Thomas, T.P. Rose, J.B. Paces, I.M. Farnham and F.C. Benedict, Jr. 2005. Evaluation of Groundwater Movement in the Frenchman Flat CAU Using Geochemical and Isotopic Analysis, DOE/NV/13609-36, Publication No. 45207. Prepared for the U.S. Department of Energy, National Nuclear Security Administration Nevada Site Office. Las Vegas, NV: Desert Research Institute.

Hevesi, J.A., A.L. Flint, and L.E. Flint. 2003. Simulation of Net Infiltration and Potential Recharge Using a Distributed Parameter Watershed Model for the Death Valley Region, Nevada and California, Water-Resources Investigations Report 03-4090. Sacramento, CA:

U.S. Geological Survey. 
Hoffman, D.C., and W.R. Daniels. 1984. "Assessment of the Potential for Radionuclide Migration from a Nuclear Explosion Cavity." In Groundwater Contamination, pp. 139-146.

Washington, DC: National Academy Press.

Hoffman, D.C., R. Stone, and W.W. Dudley, Jr. 1977. Radioactivity in the Underground Environment of the Cambric Nuclear Explosion at the Nevada Test Site, LA-6877-MS. Los Alamos, NM: Los Alamos Scientific Laboratory.

Howard, N. 1976. Site Characteristic Summary for U5b and U5e Projected from Ue5n, AGTG 76-25. Livermore, CA: Lawrence Livermore National Laboratory.

IAEA, see International Atomic Energy Agency.

IT, see IT Corporation.

Iman, R.L., and W.J. Conover. 1982. “A Distribution-Free Approach to Inducing Rank Correlation Among Input Variables.” In Communications in Statistics, Vol. B11(3): 311-334.

Iman, R.L., and J.C. Helton. 1991. “The Repeatability of Uncertainty and Sensitivity Analyses for Complex Probabilistic Risk Assessments.” In Risk Analysis, Vol. 11, no. 4, pp. 591-606.

International Atomic Energy Agency. 1998. The Radiological Situation at the Atolls of Mururoa and Fangataufa, Technical Report, Volume 3: Inventory of Radionuclides Underground at the Atolls, IAEA-MFTR-3. In "Proceedings of an IAEA Conference, Vienna, 30 June - 3 July." Vienna, Austria.

Istok, J.D., D.O. Blout, L. Barker, K.R. Johnejack, and D.P. Hammermeister. 1994. "Spatial Variability in Alluvium Properties at a Low-Level Nuclear Waste Site." In Soil Scientists Society of America, Vol. 58: 1040-1051.

IT Corporation. 1996a. Groundwater Flow Model Documentation Package (Phase I Data Analysis Documentation, Volume VI), ITLV/10972-181. Prepared for the U.S. Department of Energy, Nevada Operations Office. Las Vegas, NV.

IT Corporation. 1996b. Groundwater Recharge and Discharge Data Documentation Package (Phase I Data Analysis Documentation, Volume III), ITLV/10972-181. Prepared for the U.S. Department of Energy, Nevada Operations Office. Las Vegas, NV.

IT Corporation. 1996c. Hydrologic Parameter Data Documentation Package (Phase I Data Analysis Documentation, Volume IV), ITLV/10972-181. Prepared for the U.S. Department of Energy, Nevada Operations Office. Las Vegas, NV.

IT Corporation. 1996d. Potentiometric Data Documentation Package (Phase I - Data Analysis Documentation, Volume II), ITLV/10972-181. Prepared for the U.S. Department of Energy, Nevada Operations Office. Las Vegas, NV. 
IT Corporation. 1996e. Regional Geologic Model Documentation Package (Phase I Data Analysis Documentation, Volume I, Parts 1 and 2), ITLV/10972-181. Prepared for the U.S. Department of Energy, Nevada Operations Office. Las Vegas, NV.

IT Corporation. 1997a. Risk Assessment Documentation Package (Phase I Data Analysis Documentation, Volume VIII). Prepared for U.S. Department of Energy, Nevada Operations Office. Las Vegas, NV.

IT Corporation. 1997b. Value of Information Analysis Corrective Action Unit No. 98 for Frenchman Flat, ITLV/10972-192. Las Vegas, NV.

IT Corporation. 1998. Underground Test Area Subproject, Corrective Action Unit 98: Frenchman Flat Data Analysis Task, Volume I - Hydrostratigraphic Model Documentation Package, ITLV/13052-044. Las Vegas, NV.

IT Corporation. 1999a. External Peer Review Group Report on Frenchman Flat Data Analysis and Modeling Task, Underground Test Area Project, ITLV/13052--077. Las Vegas, NV.

IT Corporation. 1999b. Underground Test Area Project Corrective Action Unit 98: Frenchman Flat, Vol. II - Groundwater Data Documentation Package, Rev. 0, DOE/NV/13052-044-V2. Las Vegas, NV.

IT Corporation. 2000. Lessons Learned from the Frenchman Flat Corrective Action Groundwater Flow and Radionuclide Transport Model, ITLV/13052--121. Las Vegas, NV.

IT Corporation. 2001. Modeling Approach for Corrective Action Unit 98, Frenchman Flat, ITLV/13052--141. Prepared for the U.S. Department of Energy, National Nuclear Security Administration Nevada Operations Office. Las Vegas, NV.

Johnson, G.W., G.T. Pelsor, R.G. Preston, and C.E. Violet. 1958. The Underground Nuclear Detonation of September 19, 1957, Rainier, Operation Plumbbob, UCRL-5124. Livermore, CA: University of California Radiation Laboratory, Livermore Site.

Kersting, A.B., D.W. Efurd, D.L. Finnegan, D.J. Rokop, D.K. Smith, and J.L. Thompson. 1998. "Migration of Plutonium in Groundwater at the Nevada Test Site." In Hydrologic Resources Management Program and Underground Test Area Operable Unit FY 1997 Progress Report, UCRL-ID-130792. Livermore, CA: Lawrence Livermore National Laboratory.

Laczniak, R.J., J.C. Cole, D.A. Sawyer, and D.A. Trudeau. 1996. Summary of Hydrogeologic Controls on the Movement of Groundwater at the Nevada Test Site, Nye County, Nevada. U.S. Geological Survey, Water-Resources Investigations Report 96-4109. Carson City, NV.

Marsh, K.V., ed. 1991. Hydrology and Radionuclide Migration Program, 1987 Progress Report, UCRL-53779-87. Livermore, CA: Lawrence Livermore National Laboratory. 
Marsh, K.V., ed. 1992. Hydrology and Radionuclide Migration Program, 1988 Progress Report, UCRL-53779-88. Livermore, CA: Lawrence Livermore National Laboratory.

Maxey, G.B., and T.E. Eakin. 1949. "Groundwater in White River Valley, White Pine, Nye and Lincoln Counties, Nevada." In Water Resources Bulletin No. 8. Carson City, NV: State of Nevada, Office of the State Engineer.

Maxwell, R.M., R.L. Detwiler, Q. Hu, A.F.B. Tompson, S. Kollet, and S.K. Roberts. 2008. Written communication. Subject: Evaluation of Hydrologic Source Term Processes for Underground Nuclear Tests in Yucca Flat, Nevada Test Site: Saturated. Livermore, CA: Lawrence Livermore National Laboratory.

McDonald, M.G., and A.W. Harbaugh. 1988. "A Modular Three-Dimensional, Finite Difference Ground-Water Flow Model.” In U.S. Geological Survey Techniques of Water Resources Investigations, Book 6, Chapter A1.

McKay, M.D., W.J. Conover, and R.J. Beckman. 1979. "A Comparison of Three Methods for Selecting Values of Input Variables in the Analysis of Output from a Computer Code." In Technometrics, 21(3), pp. 239-245.

Meyer, G.L., and R.A. Young. 1962. Summary of Hydraulic Data and Abridged Log for Ground-Water Test Well 3, Frenchman Flat, Nevada Test Site, Nevada, USGS NTS-30, Technical Letter. Denver, CO: U.S. Geological Survey.

Miller, C.H., G.L. Dixon, W.J. Carr, and F.M. Byers, Jr. 1967. Geologic and Geophysical Logs of Exploratory Hole Ue-11c, Nevada Test Site, USGS NTS-190, Technical Letter. Denver, CO: U.S. Geological Survey.

Mishra, S. 2002. Assigning Probability Distributions to Input Parameters of Performance Assessment Models, TR-02-11. INTERA Inc.

Moore, C., and J. Doherty. 2005. "Role of the Calibration Process in Reducing Model Predictive Error." In Water Resources Research, Vol. 41, W05020, doi:10.1029/2004WR003501.

NNES, see Navarro Nevada Environmental Services, LLC.

NNES GIS, see Navarro Nevada Environmental Services Geographic Information Systems.

NNSA/NV, see U.S. Department of Energy, National Nuclear Security Administration Nevada Operations Office.

NRC, see National Research Council.

National Research Council. 2007. Models in Environmental Regulatory Decision Making. Washington, DC: National Academy Press. 
Navarro Nevada Environmental Services, LLC. 2010. Phase II Transport Model of Corrective Action Unit 98: Frenchman Flat, Nevada Test Site, Nye County, Nevada, Rev.1, N-I/28091--004, S-N/99205--122. Las Vegas, NV.

Navarro Nevada Environmental Services Geographic Information Systems. 2010. ESRI ArcGIS Software.

Nitao, J. 1998. Reference Manual for the NUFT Flow and Transport Code, Version 2.0, UCRL-MA-130651. Livermore, CA: Lawrence Livermore National Laboratory.

Oreskes, N., K. Shrader-Frechette, and K. Belitz. 1994. "Verification, Validation, and Confirmation of Numerical Models in the Earth Science." In Science 263, 641-646.

Pachepsky, Y.A., A.K. Guber, M.T. Van Genuchten, T.J. Nicholson, R.E. Cady, J. Simunek, and M.G. Schaap. 2006. Model Abstraction Techniques for Soil-Water Flow and Transport, NUREG/CR-6884. Prepared for U.S. Nuclear Regulatory Commission. Washington, DC.

Papelis, C., and W. Um. 2003. Evaluation of Cesium, Strontium, and Lead Sorption, Desorption, and Diffusion in Volcanic Tuffs from Frenchman Flat, Nevada Test Site: Macroscopic and Spectroscopic Investigations, DOE/NV/13609-18; DRI Publication No. 45189. Las Vegas, NV.

Parkhurst, D.L., and C.A.J. Appelo. 1999. User's Guide to PHREEQC - A Computer Program for Speciation, Batch-Reaction, One-Dimensional Transport, and Inverse Geochemical Calculations, Version 2. Water-Resources Investigations Report 99-4259. Denver, CO: U.S. Geological Survey.

Pawloski, G.A. 1999. Development of Phenomenological Models of Underground Nuclear Tests on Pahute Mesa, Nevada Test Site--BENHAM and TYBO, UCRL-ID-136003. Livermore, CA: Lawrence Livermore National Laboratory.

Pawloski, G.A., A.F.B. Tompson, and S.F. Carle. 2001. Evaluation of the Hydrologic Source Term from Underground Nuclear Tests on Pahute Mesa at the Nevada Test Site: CHESHIRE Test, UCRL-ID-147023. Livermore, CA: Lawrence Livermore National Laboratory.

Phelps, G.A., and S.E. Graham. 2002. Preliminary Gravity Inversion Model of Frenchman Flat Basin, Nevada Test Site, Nevada. U.S. Geological Survey Open-File Report 02-363.

Ponce, D.A., R.N. Harris, and H.W. Oliver. 1988. Isostatic Gravity Map of the Nevada Test Site and Vicinity, Nevada. U.S. Geological Survey Open File Report 88-664, scale: 1:100,000.

Poole, F.G. 1964. Geology of the Frenchman Flat Quadrangle, Nye, Lincoln, and Clark Counties, Nevada, USGS NTS-73, Technical Letter. Denver, CO: U.S. Geological Survey.

Poole, F.G. 1965. Geologic Map of the Frenchman Flat Quadrangle, Nye, Lincoln, and Clark Counties, Nevada, U.S. Geological Survey Geologic Quadrangle Map GC-456, scale 1:24,000. 
Prather, T.L. 1965. Preliminary Summary of Lithologic and Hydrologic Data from the UE5f Exploratory Drill Hole, Frenchman Flat, Nevada Test Site, Technical Letter: NTS-133. Denver, CO: U.S. Geological Survey.

Ramspott, L.D., and R.D. McArthur. 1977. Results of the Exploratory Drill Hole Ue5n, Frenchman Flat, Nevada Test Site, UCID-17392. Livermore, CA: Lawrence Livermore National Laboratory.

Rawling, G.C., L.B. Goodwin, and J.L. Wilson. 2001. "Internal Architecture, Permeability Structure, and Hydrologic Significance of Contrasting Fault-Zone Types." In Geology, Vol. 29, No. 1, pp. 43-46.

Reynolds Electrical \& Engineering Co., Inc. 1994. Site Characterization and Monitoring Data from Area 5 Pilot Wells, Nevada Test Site, Nye County, Nevada, DOE/NV-11432-74. Las Vegas, NV.

Robinson, B.A., and Z.V. Dash. 2006. Written communication. Subject: User's Guide for the PLUMECALC Application, Version 2.2. Los Alamos, NM: Los Alamos National Laboratory.

Russell, C.E., and T. Minor. 2002. Reconnaissance Estimates of Recharge Based on an Elevation-Dependent Chloride Mass-Balance Approach, DOE/NV/11508-37, Publication No. 45164. Prepared for the U.S. Department of Energy, National Nuclear Security Administration Nevada Operations Office. Las Vegas, NV: Desert Research Institute.

SNJV, see Stoller-Navarro Joint Venture.

Sinnock, S. 1982. Geology of the Nevada Test Site and Nearby Areas, Southern Nevada, SAND82-2207. Albuquerque, NM: Sandia National Laboratories.

Stewart, J.H., and J.E. Carlson. 1978. Geologic Map of Nevada. Scale 1:500,000. Reston, VA: U.S. Geological Survey.

Stoller-Navarro Joint Venture. 2004a. Integrated Analysis Report for Single- and Multiple-Well Aquifer Testing at Frenchman Flat Well Cluster RNM-2s, Nevada Test Site, Nevada, S-N/99205-029. Las Vegas, NV.

Stoller-Navarro Joint Venture. 2004b. Interpretation of Hydraulic Test and Multiple-Well Aquifer Test Data at Frenchman Flat Well Cluster ER-5-3, S-N/99205--028. Prepared for the U.S. Department of Energy, National Nuclear Security Administration Nevada Site Office. Las Vegas, NV.

Stoller-Navarro Joint Venture. 2004c. Phase II Hydrologic Data for the Groundwater Flow and Contamination Transport Model of CAU Unit 98: Frenchman Flat, Nye County, Nevada, S-N/99205-032. Las Vegas, NV. 
Stoller-Navarro Joint Venture. 2005a. Analysis of Hydraulic Responses from the ER-6-1 Multiple-Well Aquifer Test, Yucca Flat FY 2004 Testing Program, Nevada Test Site, Nye County, Nevada, Rev. 0, S-N/99205--051. Las Vegas, NV.

Stoller-Navarro Joint Venture. 2005b. Phase II Contaminant Transport Parameters for the Groundwater Flow and Contaminant Transport Model of Corrective Action Unit 98: Frenchman Flat, Nye County, Nevada, S-N/99205--043. Prepared for the U.S. Department of Energy. Las Vegas, NV.

Stoller-Navarro Joint Venture. 2005c. Letter Report: Analysis of Hydraulic Conductivity and Fracture Porosity in ER-5-3\#2 and ER-5-4\#2 Based on Fracture Data from Borehole Image Logs with Implications for the Tuff Confining Unit Flow Framework, Nevada Test Site, Nevada. August. Las Vegas, NV.

Stoller-Navarro Joint Venture. 2005d. Unclassified Source Term and Radionuclide Data for Corrective Action Unit 98: Frenchman Flat Nevada Test Site, Nevada, S-N/99205--058. Las Vegas, NV.

Stoller-Navarro Joint Venture. 2005e. Underground Test Area Fracture Analysis Report for Frenchman Flat Well Clusters ER-5-3 and ER-5-4, Nevada Test Site, Nevada, S-N/99205--060. Las Vegas, NV.

Stoller-Navarro Joint Venture. 2006. Phase II Groundwater Flow Model of Corrective Action Unit 98: Frenchman Flat, Nevada Test Site, Nye County, Nevada, S-N/99205--074. Las Vegas, NV.

Stoller-Navarro Joint Venture. 2007. Addendum to the Phase II Groundwater Flow Model of Corrective Action Unit 98: Frenchman Flat, Nevada Test Site, Nye County, Nevada, Rev. 0. May. Las Vegas, NV.

Thompson, J.L. 1991. Laboratory and Field Studies Related to the Hydrology/Radionuclide Migration Project (October 1, 1989 - September 30, 1990), LA-12100-PR. Los Alamos, NM: Los Alamos National Laboratory.

Tompson, A.F.B., C.J. Bruton, and G.A. Pawloski eds. 1999. Evaluation of the Hydrologic Source Term from Underground Nuclear Tests in Frenchman Flat at the Nevada Test Site: The CAMBRIC Test, UCRL-ID-132300. Prepared for the U.S. Department of Energy, Nevada Operations Office. Livermore, CA: Lawrence Livermore National Laboratory.

Tompson, A.F.B., M. Zavarin, C.J. Bruton, and G.A. Pawloski. 2004. Methods for Calculating a Simplified Hydrologic Source Term for Frenchman Flat: Sensitivity Studies of Radionuclide Transport Away from Underground Nuclear Tests, UCRL-TR-201817. Livermore, CA: Lawrence Livermore National Laboratory. 
Tompson, A.F.B., S.F. Carle, R.M. Maxwell, G. Pawloski, and M. Zavarin. 2005. Evaluation of the Non-Transient Hydrologic Source Term from the CAMBRIC Underground Nuclear Test in Frenchman Flat, Nevada Test Site, UCRL-TR-217191. Livermore, CA: Lawrence Livermore National Laboratory.

Travis, B.J., H.E. Nuttall, S.W. Hodson, and R.S. Rundberg. 1983. "Section B: Transport of Tritium from the Cambric Cavity Region to RNM-2S: Modeling." In Laboratory and Field Studies Related to the Hydrology/Radionuclide Migration Project (October 1, 1981 -September 30, 1982), LA-9691-PR, 9-20, Progress Report. Edited by W.R. Daniels. Los Alamos, NM: Los Alamos National Laboratory.

Tyler, S.W., J.B. Chapman, S.H. Conrad, D.P. Hammermeister, D.O. Blout, J.J. Miller, M.J. Sully, and J.M. Ginanni. 1996. "Soil-Water Flux in the Southern Great Basin, United States: Temporal and Spatial Variations Over the Last 120,000 Years." In Water Resources Research, v. 32: 1481-1499.

USGS, see U.S. Geological Survey.

U.S. Department of Energy. 1997. Focused Evaluation of Selected Remedial Alternatives for the Underground Test Area, DOE/NV-456 UC-700.

U.S. Department of Energy, National Nuclear Security Administration Nevada Operations Office. 2001. Addendum to Revision 1 of the Corrective Action Investigation Plan for Corrective Action Unit 98: Frenchman Flat, Nevada Test Site, Nevada, Rev. 1, DOE/NV--478 REV. 1-ADD. Las Vegas, NV.

U.S. Department of Energy, National Nuclear Security Administration Nevada Operations Office. 2002. Nevada Test Site Orthophoto Site Atlas, DOE/NV/11718--604. Aerial photos acquired Summer 1998. Prepared by Bechtel Nevada. Las Vegas, NV.

U.S. Department of Energy, Nevada Operations Office. 1994. Nevada Environmental Restoration Project Management Plan, Rev. 0. Las Vegas, NV.

U.S. Department of Energy, Nevada Operations Office. 1996. Final Environmental Impact Statement for the Nevada Test Site and Off-Site Locations in the State of Nevada, DOE/EIS 0243. Las Vegas, NV.

U.S. Department of Energy, Nevada Operations Office. 1997. Regional Groundwater Flow and Tritium Transport Modeling and Risk Assessment of the Underground Test Area, Nevada Test Site, Nevada, DOE/NV--477, UC-700. Las Vegas, NV.

U.S. Department of Energy, Nevada Operations Office. 1999a. Corrective Action Investigation Plan for Corrective Action Unit 98: Frenchman Flat, Nevada Test Site, Nevada, DOE/NV--478, Rev. 1. Las Vegas, NV. 
U.S. Department of Energy, Nevada Operations Office. 1999b. Corrective Action Investigation Plan for Corrective Action Units 101 and 102: Central and Western Pahute Mesa, Nevada Test Site, Nevada, DOE/NV--516, Rev. 1. Las Vegas, NV.

U.S. Department of Energy, Nevada Operations Office. 2000. United States Nuclear Tests, July 1945 through September 1992, DOE/NV--209-REV 15. Las Vegas, NV.

U.S. Environmental Protection Agency. 1994. Remediation Technologies, Screening Matrix and Reference Guide, EPA/542/B-94/013. Washington, DC.

U.S. Environmental Protection Agency. 2001. Use of Uranium Drinking Water Standards under 40 CFR 141 and 40 CFR 192 as Remediation Goals for Groundwater at CERCLA Sites, Directive No. 9283.1-14.

U.S. Environmental Protection Agency. 2002a. "National Primary Drinking Water Regulations; Radionuclides; Final Rule," 7 December. In Federal Register, Vol. 19, No. 236.

U.S. Environmental Protection Agency. 2002b. Radionuclides in Drinking Water: A Small Compliance Guide, EPA 815R02001. February. Washington, DC: Office of Ground Water and Drinking Water.

U.S. Environmental Protection Agency. 2009. Guidance on the Development, Evaluation, and Application of Environmental Models, EPA/100/K-09/003. Washington, DC.

U.S. Geological Survey. 1987. U.S. Geological Data Digital Elevation Models: U.S. Geological Survey, National Mapping Program Technical Instructions Data User’s Guide 5. Reston, VA.

Wahl, R.R., D.A. Sawyer, S.A. Minor, M.D. Carr, J.C. Cole, W.C. Swadley, R.J. Laczniak, R.G. Warren, K.S. Green, and C.M. Engle. 1997. Digital Geologic Map of the Nevada Test Site Area, Nevada, USGS Open-File Report 97-140. Denver, CO: U.S. Geological Survey.

Warren, R.G., F.C. Benedict Jr., T.P. Rose, D.K. Smith, S.J. Chipera, E.C. Kluk, and K.M. Raven. 2002. Alluvial Layering and Distribution of Reactive Phases within Drill Holes ER5/4 and UE5N of Frenchman Flat, LA-UR-02-6206. Los Alamos, NM: Los Alamos National Laboratory.

Winograd, I.J., and W. Thordarson. 1975. Hydrogeologic and Hydrochemical Framework, South-Central Great Basin, Nevada-California, with Special Reference to the Nevada Test Site. U.S. Geological Survey Professional Paper 712-C.

Winograd, I.J., and F.J. Pearson. 1976. "Major Carbon 14 Anomaly in a Regional Carbonate Aquifer: Possible Evidence for Megascale Channeling, South Central Great Basin." In Water Resources Research, Vol. 12(6): 1125-1142. 
Zavarin M., S.F. Carle, and R.M. Maxwell. 2004. Upscaling Radionuclide Retardation Linking the Surface Complexation and Ion Exchange Mechanistic Approach to a Linear $K_{d}$ Approach, UCRL-TR-214713. Livermore, CA: Lawrence Livermore National Laboratory.

Zyvoloski, G.A., B.A. Robinson, Z.V. Dash, and I.L. Trease. 1997. User's Manual for the FEHM Application - A Finite-Element Heat- and Mass-Transfer Code, LA-13306-M. Los Alamos, NM: Los Alamos National Laboratory. 


\section{Appendix A \\ Phase II CAl Approach to Key Issues of Concern from Phase I External Peer Review}


Table A.1-1

\section{Phase II CAI Approach to Key Phase I Concerns}

(Page 1 of 4)

\begin{tabular}{|c|c|}
\hline $\begin{array}{c}\text { Key Issues of Concern: External Peer } \\
\text { Review Comment from Phase I CAI } \\
\text { (IT, 1999) }\end{array}$ & Approach during Phase II CAI \\
\hline Inadequate data to define HFM & $\begin{array}{l}\text { - Five new boreholes in two clusters. One is near the test in the northern portion of the basin; the second is } \\
\text { near the Central Testing Area as recommended by the Phase I peer review. } \\
\text { - Particularly enhanced by 3-D seismic reflection survey that covered both the Northern and Central } \\
\text { Testing Areas. } \\
\text { - More detailed incorporation of site-specific data through the use of EarthVision. } \\
\text { - Development of detailed fault model. } \\
\text { - Additional definition of hydrostratigraphic units taking advantage of new borehole data and information } \\
\text { from Yucca Flat. }\end{array}$ \\
\hline $\begin{array}{l}\text { Inadequate data to support groundwater flow } \\
\text { modeling: groundwater flow directions, rates } \\
\text { and travel times in source areas }\end{array}$ & $\begin{array}{l}\text { - Two interference aquifer tests. } \\
\text { - Age dating and major ion chemistry used to constrain groundwater direction and velocities. } \\
\text { - More detailed analysis of groundwater elevations to understand uncertainties in measured values. } \\
\text { - Local-scale model of Central Testing Area calibrated to RNM-2S and CAMBRIC RNM experiment. } \\
\text { - Use of multiple recharge models and boundary heads and fluxes. } \\
\text { - Development of an alternative conceptualization of recharge along northern portion of basin } \\
\text { ("NHA" model). } \\
\text { - Incorporation of null-space Monte Carlo techniques to include parametric influences. }\end{array}$ \\
\hline $\begin{array}{l}\text { Inadequate data to define contaminant source } \\
\text { terms: site-specific validity, influence of } \\
\text { vadose zone }\end{array}$ & $\begin{array}{l}\text { - More detailed process models of CAMBRIC for HST analysis. } \\
\text { - Development of two simplified process models for tests in fractured rocks. } \\
\text { - Source term abstraction included site-specific flux as calculated by CAU flow models. } \\
\text { - Calibration to the CAMBRIC RNM experiment data, allowing for additional transport constraints. } \\
\text { - More complete documentation of CAU source term and associated uncertainty provided by } \\
\text { Bowen et al. (2001). }\end{array}$ \\
\hline
\end{tabular}


Table A.1-1

Phase II CAI Approach to Key Phase I Concerns

(Page 2 of 4)

\begin{tabular}{|c|c|}
\hline $\begin{array}{c}\text { Key Issues of Concern: External Peer } \\
\text { Review Comment from Phase I CAI } \\
\text { (IT, 1999) }\end{array}$ & Approach during Phase II CAI \\
\hline $\begin{array}{l}\text { Inadequate data to support advective } \\
\text { contaminant transport modeling: } \\
\text { specific comments about effective porosity } \\
\text { and retardation coefficients }\end{array}$ & $\begin{array}{l}\text { - Effective porosity data explicitly transferred from other sites. } \\
\text { - Use of geochemical age dates to understand appropriate advective velocities through shallow basin. } \\
\text { - Use of mechanistic model to calculate } \mathrm{K}_{\mathrm{d}} \text { terms based on site-specific information. } \\
\text { - More detailed analysis of mass release processes from test cavities. } \\
\text { - Calibration to RNM experiment radionuclide breakthrough data at RNM-2S and UE-5n. }\end{array}$ \\
\hline $\begin{array}{l}\text { Inadequate data to characterize and predict } \\
\text { contaminant concentrations: } \\
\text { initial concentrations are only estimates, } \\
\text { no information about presence or absence } \\
\text { of contaminants }\end{array}$ & $\begin{array}{l}\text { - New data collection at ER-5-4 and ER-5-3. } \\
\text { - Consistent use of Bowen et al. (2001) for inventory, which is a sum of the classified inventory. } \\
\text { - Uncertainty documented in Bowen inventory considered during CAU model analyses. } \\
\text { - Continued monitoring and analysis of radionuclide concentrations at UE-5n. } \\
\text { - Use of RNM-2S observations to help further constrain the uncertainties associated with the forecast of the } \\
\text { contaminant boundary. } \\
\text { - Only a subset of species is pertinent to the transport problem given the regulatory criteria. Focus on these } \\
\text { species for uncertainty calculations. } \\
\text { - Adjustment to the UGTA strategy to acknowledge that model evaluation includes sampling and monitoring } \\
\text { in key areas to build model confidence. }\end{array}$ \\
\hline $\begin{array}{l}\text { Inappropriate scales of models: } \\
\text { especially related to discrete fault features }\end{array}$ & $\begin{array}{l}\text { - Incorporation of many faults within the CAU model area. } \\
\text { - Development of sub-CAU model. } \\
\text { - Discrete uncertainty analyses of flow models. }\end{array}$ \\
\hline Cumbersome linkages between models & $\begin{array}{l}\text { - Eliminated the "joint calibration" approach that required iterative calibration of regional model boundary } \\
\text { conditions with every change in CAU-scale model. } \\
\text { - Used boundary heads from regional system to constrain CAU model. } \\
\text { - Used boundary flows from regional model as model targets. } \\
\text { - Testing of alternative conceptual model of recharge application ("NHA" model). } \\
\text { - Development of small-scale models that used information from larger models, but allowed site-specific } \\
\text { information to dominate analyses. }\end{array}$ \\
\hline
\end{tabular}


Table A.1-1

Phase II CAI Approach to Key Phase I Concerns

(Page 3 of 4)

\begin{tabular}{|c|c|}
\hline $\begin{array}{l}\text { Key Issues of Concern: External Peer } \\
\text { Review Comment from Phase I CAI } \\
\text { (IT, 1999) }\end{array}$ & Approach during Phase II CAI \\
\hline Need for local scale modeling & $\begin{array}{l}\text { - Development of sub-CAU model. } \\
\text { - Development of total system model to investigate PIN STRIPE alternative conceptualizations } \\
\text { (NNES, 2010, Appendix D). } \\
\text { - Local grid refinement to increase resolution in key areas. } \\
\text { - Simplified process models of test cavities in fractured rock. }\end{array}$ \\
\hline $\begin{array}{l}\text { Calculation errors related to the size of } \\
\text { grid blocks }\end{array}$ & $\begin{array}{l}\text { - Smaller grid blocks. } \\
\text { - Adaptive gridding using finite-element mesh. } \\
\text { - Virtual sub-grid for transport calculations. }\end{array}$ \\
\hline $\begin{array}{l}\text { Nonunique flow model calibrations: } \\
\text { evaluate key model assumptions, incorporation } \\
\text { of chemical and isotopic data }\end{array}$ & $\begin{array}{l}\text { - Many realizations of the "calibrated" flow model. } \\
\text { - Different conceptual models for assignment of flow model parameters tested. } \\
\text { - Geochemical evaluation of groundwater directions and velocities. } \\
\text { - Change in UGTA strategy: Clearly state that uniqueness is not the goal; instead, focus on ensemble of } \\
\text { forecasts that represent a reasonable range of plausible conditions and conceptual understanding. Use } \\
\text { monitoring and institutional controls. }\end{array}$ \\
\hline $\begin{array}{l}\text { Absent calibration/verification of the mass } \\
\text { transport model }\end{array}$ & $\begin{array}{l}\text { - Sub-CAU model calibration to observed transport from the CAMBRIC RNM experiment. } \\
\text { - Geochemical evaluation. }\end{array}$ \\
\hline Lack of consistency in mass transport data & $\begin{array}{l}\text { - Use of Bowen et al. (2001) inventory. } \\
\text { - Use of } \mathrm{K}_{\mathrm{d}} \text { model based on extrapolated surface complexation and ion exchange models for source term } \\
\text { and CAU calculations, allowed for full acknowledgement of correlated parameters. }\end{array}$ \\
\hline
\end{tabular}


Table A.1-1

Phase II CAI Approach to Key Phase I Concerns

(Page 4 of 4)

\begin{tabular}{|c|c|}
\hline $\begin{array}{l}\text { Key Issues of Concern: External Peer } \\
\text { Review Comment from Phase I CAI } \\
\text { (IT, 1999) }\end{array}$ & Approach during Phase II CAI \\
\hline $\begin{array}{l}\text { Uncertainties in the conceptual model: } \\
\text { essentially only one conceptual model } \\
\text { was explored. }\end{array}$ & $\begin{array}{l}\text { - Many combinations of HFM and recharge models were incorporated in flow model calibration. } \\
\text { - Included high-end recharge values and possible linkages between alluvium and LCA. } \\
\text { - Uncorporated multiple representations of critical discrete features (faults). } \\
\text { data, but may influence flow directions or velocities. } \\
\text { - Allowed data to guide interpretation of conceptual models. } \\
\text { - Used model evaluation techniques to understand model consistency with corroborative data. } \\
\text { - Developed multiple conceptual representations of PIN STRIPE flow path using an abstraction model. } \\
\text { - Incorporated simplified process models of nuclide release that accounted for conceptual uncertainty } \\
\text { related to geologic media. }\end{array}$ \\
\hline $\begin{array}{l}\text { Model complexity impediment, sources of } \\
\text { uncertainty that need to be evaluated: source } \\
\text { term, dispersivity, distribution coefficients, } \\
\text { recharge/boundary fluxes }\end{array}$ & $\begin{array}{l}\text { - Removed CAU model-regional model coupling. } \\
\text { - Probability distributions developed and sampled for source term and distribution coefficients. } \\
\text { - Multiple values of dispersivity and fluxes incorporated into model. } \\
\text { - Used null-space Monte Carlo techniques to take advantage of model complexities by addressing } \\
\text { uncertainty that is not sensitive to observations. } \\
\text { - Created simplified or smaller-scale models to test particular uncertainties as they were identified } \\
\text { (e.g., groundwater withdrawals from water wells near Frenchman Lake). }\end{array}$ \\
\hline $\begin{array}{l}\text { Ill-determined parameter variation: variability of } \\
\text { many of the parameters is limited and } \\
\text { documentation provides little basis for } \\
\text { prescribing parameter ranges. }\end{array}$ & $\begin{array}{l}\text { - Extensive documentation of parameter values and development of robust empirical cumulative distribution } \\
\text { functions for CAU model. } \\
\text { - Null-space Monte Carlo analysis allows parameters to vary commensurate with their uncertainty. } \\
\text { - Perturbation analyses. }\end{array}$ \\
\hline Inappropriateness of spatial variability analysis & - Eliminated spatial variability analysis in the CAU model. \\
\hline Calibration discrepancy in uncertainty analysis & - Calibrated all models that were used for uncertainty analysis. \\
\hline $\begin{array}{l}\text { Exclusion of radionuclides with classified } \\
\text { source term }\end{array}$ & $\begin{array}{l}\text { - Complete listing of CAU inventory and associated uncertainty from Bowen et al. (2001). This inventory is } \\
\text { derived from classified sources. }\end{array}$ \\
\hline
\end{tabular}




\section{A.2.0 ReFERENCES}

Bowen, S.M., D.L. Finnegan, J.L. Thompson, C.M. Miller, P.L. Baca, L.F. Olivas, C.G. Geoffrion, D.K. Smith, W. Goishi, B.K. Esser, J.W. Meadows, N. Namboodiri, and J.F. Wild. 2001. Nevada Test Site Radionuclide Inventory, 1951-1992, LA-13859-MS. Los Alamos, NM: Los Alamos National Laboratory.

IT, see IT Corporation.

IT Corporation. 1999. External Peer Review Group Report on Frenchman Flat Data Analysis and Modeling Task, Underground Test Area Project, ITLV/13052--077. Las Vegas, NV.

NNES, see Navarro Nevada Environmental Services, LLC.

Navarro Nevada Environmental Services, LLC. 2010. Phase II Transport Model of Corrective Action Unit 98: Frenchman Flat, Nevada Test Site, Nye County, Nevada, Rev.1, N-I/28091--004, S-N/99205--122. Las Vegas, NV. 
Appendix B

Reference Synopsis 
Table B.1-1

Frenchman Flat CAIP and Phase II Document UGTA References

(Page 1 of 17)

\begin{tabular}{|c|c|c|c|}
\hline Author & Year & Report & Select Descriptions of Content \\
\hline Barnes et al. & 1982 & $\begin{array}{l}\text { Geology and Tectonic Maps of the Mercury Quadrangle, } \\
\text { Nye and Clark Counties, Nevada }\end{array}$ & \\
\hline Bechtel Nevada & 1998 & $\begin{array}{l}\text { Hydrologic Characterization of the Unsaturated Zone at the } \\
\text { Area } 3 \text { Radioactive Waste Management Site }\end{array}$ & \\
\hline Bechtel Nevada & 2004 & Completion Report for Well Cluster ER-5-3 & \\
\hline Bechtel Nevada & 2004 & Completion Report for Well Cluster ER-5-4 & \\
\hline Bechtel Nevada & 2005 & $\begin{array}{l}\text { A Hydrostratigraphic Framework Model and Alternatives for } \\
\text { the Groundwater Flow and Contaminant Transport Model of } \\
\text { Corrective Action Unit 98: Frenchman Flat, Clark, Lincoln } \\
\text { and Nye Counties, Nevada }\end{array}$ & $\begin{array}{l}\text { The HFM for groundwater flow and transport } \\
\text { modeling of Frenchman Flat Phase II }\end{array}$ \\
\hline Bechtel Nevada & 2005 & $\begin{array}{l}\text { Site Characterization and Monitoring Data from Area } 5 \\
\text { Pilot Wells, Nevada Test Site, Nye County, Nevada }\end{array}$ & \\
\hline Bechtel Nevada & 2006 & $\begin{array}{l}\text { A Hydrostratigraphic Model and Alternatives for the } \\
\text { Groundwater Flow and Contaminant Transport Model of } \\
\text { Corrective Action Unit 97: Yucca Flat-Climax Mine, } \\
\text { Lincoln and Nye Counties, Nevada }\end{array}$ & \\
\hline Beiriger & 1977 & X-ray Analysis of 36 Samples from Ue $5 n$ & \\
\hline Belcher et al. & 2001 & $\begin{array}{l}\text { Hydraulic-Property Estimates for Use With a Transient } \\
\text { Ground-Water Flow Model for the Death Valley Regional } \\
\text { Ground-Water Flow System, Nevada and California }\end{array}$ & \\
\hline Belcher et al. & 2004 & $\begin{array}{l}\text { Death Valley Regional Ground-Water Flow System, Nevada } \\
\text { and California-Hydrogeologic Framework and Transient } \\
\text { Ground-Water Flow Model }\end{array}$ & $\begin{array}{l}\text { The U.S. Geological Survey regional model that } \\
\text { superseded the UGTA (IT) regional model }\end{array}$ \\
\hline Benedict et al. & 2003 & Geochemistry Technical Basis Document & $\begin{array}{l}\text { The general UGTA technical approach for } \\
\text { geochemical data analysis }\end{array}$ \\
\hline
\end{tabular}


Table B.1-1

Frenchman Flat CAIP and Phase II Document UGTA References

(Page 2 of 17)

\begin{tabular}{|c|c|c|c|}
\hline Author & Year & Report & Select Descriptions of Content \\
\hline Berger & 1992 & $\begin{array}{l}\text { Lithologic Properties of Carbonate-Rock Aquifers at Five Test } \\
\text { Wells in the Coyote Spring Valley Area, Southern Nevada, as } \\
\text { Determined from Geophysical Logs }\end{array}$ & \\
\hline Blout & 1995 & $\begin{array}{l}\text { Site Characterization Data from the Area } 5 \text { Science } \\
\text { Boreholes, Nevada Test Site, Nye County, Nevada }\end{array}$ & \\
\hline Boardman & 1967 & $\begin{array}{l}\text { Results of an Exploration into the Top of the } \\
\text { Piledriver Chimney }\end{array}$ & $\begin{array}{l}\text { Data used to develop conceptual models of } \\
\text { shock-altered rock properties }\end{array}$ \\
\hline Borg & 1971 & $\begin{array}{l}\text { Some Shock Effects in Granodiorite to } 270 \text { kbar at the } \\
\text { Piledriver Site }\end{array}$ & $\begin{array}{l}\text { Data used to develop conceptual models of } \\
\text { shock-altered rock properties }\end{array}$ \\
\hline Borg & 1973 & $\begin{array}{l}\text { Comparison of Shock Effects in Granitic Rock Recovered } \\
\text { From the Monique Event, Algeria, and the Piledriver Event, } \\
\text { Nevada Test Site }\end{array}$ & $\begin{array}{l}\text { Data used to develop conceptual models of } \\
\text { shock-altered rock properties }\end{array}$ \\
\hline Borg et al. & 1976 & $\begin{array}{l}\text { Information Pertinent to the Migration of Radionuclides in } \\
\text { Groundwater at the Nevada Test Site. Part 1: Review and } \\
\text { Analysis of Existing Information }\end{array}$ & $\begin{array}{l}\text { An early overview of groundwater transport } \\
\text { of radionuclides }\end{array}$ \\
\hline Bowen et al. & 2001 & Nevada Test Site Radionuclide Inventory, 1951-1992 & $\begin{array}{l}\text { The unclassified NTS inventory and associated } \\
\text { uncertainty factors }\end{array}$ \\
\hline Bright et al. & 2001 & $\begin{array}{l}\text { Analysis of Water Levels in the Frenchman Flat Area, Nevada } \\
\text { Test Site }\end{array}$ & \\
\hline Butkovich and Lewis & 1973 & $\begin{array}{l}\text { Aids for Estimating Effects of Underground } \\
\text { Nuclear Explosions }\end{array}$ & \\
\hline Byers and Miller & 1966 & $\begin{array}{l}\text { Geologic and Geophysical Log of the Ue5k Exploratory Hole, } \\
\text { Frenchman Flat, Nevada Test Site }\end{array}$ & \\
\hline Carle et al. & 2002 & $\begin{array}{l}\text { Geostatistical Analysis of Spatial Variability of Mineral } \\
\text { Abundance and } K_{d} \text { in Frenchman Flat, NTS, Alluvium }\end{array}$ & $\begin{array}{l}\text { Assessment of spatial continuity of minerals } \\
\text { controlling radionuclide sorption in Frenchman } \\
\text { Flat alluvium }\end{array}$ \\
\hline
\end{tabular}


Table B.1-1

Frenchman Flat CAIP and Phase II Document UGTA References

(Page 3 of 17)

\begin{tabular}{|c|c|c|c|}
\hline Author & Year & Report & Select Descriptions of Content \\
\hline Carle et al. & 2007 & $\begin{array}{l}\text { Evaluation of the Transient Hydrologic Source Term for the } \\
\text { Cambric Underground Nuclear Test at Frenchman Flat, } \\
\text { Nevada Test Site }\end{array}$ & \\
\hline Carle et al. & 2008 & $\begin{array}{l}\text { Written communication. Subject: Evaluation of Hydrologic } \\
\text { Source Term Processes for Underground Nuclear Tests in } \\
\text { Yucca Flat, Nevada Test Site: Carbonate Tests }\end{array}$ & \\
\hline Carr et al. & 1975 & Geology of Northern Frenchman Flat, Nevada Test Site & $\begin{array}{l}\text { Magnetometer transects that help define the } \\
\text { areal extent of the basalt flow in Northern } \\
\text { Frenchman Flat }\end{array}$ \\
\hline Carroll & 1981 & $\begin{array}{l}\text { "Seismic Velocity and Postshot Properties in and } \\
\text { near Chimneys." In Proceedings of the Monterey } \\
\text { Containment Symposium }\end{array}$ & $\begin{array}{l}\text { Geophysical data analysis that suggests shock } \\
\text { alteration near underground nuclear tests }\end{array}$ \\
\hline Case et al. & 1984 & $\begin{array}{l}\text { Site Characterization in Connection with the Low-Level } \\
\text { Defense Waste Management Site in Area } 5 \text { of the Nevada } \\
\text { Test Site, Nye County, Nevada - Final Report }\end{array}$ & \\
\hline Cole & 1997 & $\begin{array}{l}\text { Major Structural Controls on the Distribution of Pre-Tertiary } \\
\text { Rocks, Nevada Test Site Vicinity, Southern Nevada }\end{array}$ & \\
\hline Cole and Cashman & 1999 & $\begin{array}{l}\text { Structural Relationships of Pre-Tertiary Rocks in the Nevada } \\
\text { Test Site Region, Southern Nevada }\end{array}$ & \\
\hline Daniels and Tompson & 2003 & $\begin{array}{l}\text { Technical Basis for Also Using Health-Risk Assessment } \\
\text { To Establish Contaminant Boundaries for Corrective Action } \\
\text { Units (CAUs) of the Underground Test Area (UGTA) at the } \\
\text { Nevada Test Site (NTS) }\end{array}$ & $\begin{array}{l}\text { The method for computing the contaminant } \\
\text { boundary is described, and how to use broader } \\
\text { risk approaches other than that summarized in the } \\
\text { Safe Drinking Water Act }\end{array}$ \\
\hline Dixon et al. & 1965 & Geologic Report on Drill Hole Ue11b, Nevada Test Site & \\
\hline Dixon et al. & 1967 & $\begin{array}{l}\text { Geologic and Geophysical Log of Drill Hole Ue } 5 i \text {, } \\
\text { Nevada Test Site }\end{array}$ & \\
\hline Drellack & 1997 & $\begin{array}{l}\text { Selected Stratigraphic Data for Drill Holes Located in } \\
\text { Frenchman Flat, Nevada Test Site }\end{array}$ & \\
\hline
\end{tabular}


Table B.1-1

Frenchman Flat CAIP and Phase II Document UGTA References

(Page 4 of 17)

\begin{tabular}{|c|c|c|c|}
\hline Author & Year & Report & Select Descriptions of Content \\
\hline Drellack et al. & 1997 & $\begin{array}{l}\text { Analysis of Fractures in Volcanic Cores from Pahute Mesa, } \\
\text { Nevada Test Site }\end{array}$ & \\
\hline Faunt & 1998 & $\begin{array}{l}\text { Effects of Faulting on Groundwater Movement in the Death } \\
\text { Valley Region, Nevada and California }\end{array}$ & \\
\hline $\begin{array}{l}\text { Federal Facility Agreement } \\
\text { and Consent Order }\end{array}$ & $\begin{array}{l}1996 \\
\text { (as amended } \\
\text { March 2010) }\end{array}$ & Federal Facility Agreement and Consent Order, Appendix VI & \\
\hline Fernald et al. & 1965 & Geologic Report on Drill Hole Ue11a, Nevada Test Site & \\
\hline Fiero et al. & 1974 & $\begin{array}{l}\text { Use of Hydrochemistry for Interpreting Ground-Water Flow } \\
\text { Systems in Central Nevada }\end{array}$ & \\
\hline Flint et al. & 1996 & $\begin{array}{l}\text { Physical and Hydrologic Properties of Rock Outcrop Samples } \\
\text { at Yucca Mountain, Nevada }\end{array}$ & \\
\hline Forester et al. & 1999 & $\begin{array}{l}\text { The Climatic and Hydrologic History of Southern Nevada } \\
\text { During the Late Quaternary }\end{array}$ & \\
\hline George & 1997 & Unstructured 3D Grid Toolbox for Modeling and Simulation & \\
\hline Gillespie et al. & 1996 & Nevada Test Site Water-Supply Wells & \\
\hline Grasso & 2003 & $\begin{array}{l}\text { Geologic Surface Effects of Underground Nuclear Testing, } \\
\text { Buckboard Mesa, Climax Stock, Dome Mountain, Frenchman } \\
\text { Flat, Rainier/Aqueduct Mesa, and Shoshone Mountain, } \\
\text { Nevada Test Site, Nevada }\end{array}$ & \\
\hline Grauch and Hudson & 1995 & $\begin{array}{l}\text { Preliminary Analysis of Major Structures and Lithologic } \\
\text { Boundaries for the Frenchman Flat Model Area }\end{array}$ & Phase I geologic model for Frenchman Flat \\
\hline Healey & 1965 & $\begin{array}{l}\text { An Evaluation of Northeastern Frenchman Flat Based on } \\
\text { Gravity Data }\end{array}$ & \\
\hline Healey et al. & 1967 & $\begin{array}{l}\text { Proposed Ue } 5 m \text { Test Area, Southwest Frenchman Flat, } \\
\text { Nevada Test Site }\end{array}$ & \\
\hline
\end{tabular}


Table B.1-1

Frenchman Flat CAIP and Phase II Document UGTA References

(Page 5 of 17)

\begin{tabular}{|c|c|c|c|}
\hline Author & Year & Report & Select Descriptions of Content \\
\hline Healey et al. & 1987 & $\begin{array}{l}\text { Complete Bouguer Gravity Map of the Nevada Test Site and } \\
\text { Vicinity, Nevada }\end{array}$ & \\
\hline Hershey and Acheampong & 1997 & $\begin{array}{l}\text { Estimation of Groundwater Velocities from Yucca Flat } \\
\text { to the Amargosa Desert Using Geochemistry and } \\
\text { Environmental Isotopes }\end{array}$ & \\
\hline Hershey et al. & 2001 & $\begin{array}{l}\text { Geochemically Calibrated Discrete-State Cell Model of the } \\
\text { Frenchman Flat Hydrographic Area }\end{array}$ & \\
\hline Hershey et al. & 2005 & $\begin{array}{l}\text { Evaluation of Groundwater Movement in the Frenchman Flat } \\
\text { CAU Using Geochemical and Isotopic Analysis }\end{array}$ & \\
\hline Hevesi et al. & 2003 & $\begin{array}{l}\text { Simulation of Net Infiltration and Potential Recharge Using a } \\
\text { Distributed Parameter Watershed Model for the Death Valley } \\
\text { Region, Nevada and California }\end{array}$ & \\
\hline Hinrichs & 1968 & $\begin{array}{l}\text { Geologic Map of the Camp Desert Rock Quadrangle, } \\
\text { Nye County, Nevada }\end{array}$ & \\
\hline Hinrichs and McKay & 1965 & $\begin{array}{l}\text { Geologic Map of the Plutonium Valley Quadrangle, } \\
\text { Nye and Lincoln Counties, Nevada }\end{array}$ & \\
\hline Hockett and French & 1998 & Evaluation of Recharge Potential at Crater U5a (WISHBONE) & \\
\hline Hockett and Gillespie & 1996 & $\begin{array}{l}\text { Preliminary Evaluation of Recharge Potential at Subsidence } \\
\text { Crater U5A in Frenchman Flat, Nevada Test Site }\end{array}$ & \\
\hline Hoffman et al. & 1977 & $\begin{array}{l}\text { Radioactivity in the Underground Environment of the Cambric } \\
\text { Nuclear Explosion at the Nevada Test Site }\end{array}$ & \\
\hline Hokett and French & 1998 & Evaluation of Recharge Potential at Crater U5a (WISHBONE) & \\
\hline Howard & 1976 & $\begin{array}{l}\text { Site Characteristic Summary for U5b and U5e } \\
\text { Projected from Ue } 5 n\end{array}$ & \\
\hline Hudson & 1997 & $\begin{array}{l}\text { Structural Geology of the French Peak Accommodation Zone, } \\
\text { Nevada Test Site, Southwestern Nevada }\end{array}$ & \\
\hline
\end{tabular}


Table B.1-1

Frenchman Flat CAIP and Phase II Document UGTA References

(Page 6 of 17)

\begin{tabular}{|c|c|c|c|}
\hline Author & Year & Report & Select Descriptions of Content \\
\hline $\begin{array}{l}\text { International Atomic Energy } \\
\text { Agency }\end{array}$ & 1998 & $\begin{array}{l}\text { The Radiological Situation at the Atolls of Mururoa and } \\
\text { Fangataufa, Technical Report, Volume 3: Inventory of } \\
\text { Radionuclides Underground at the Atolls }\end{array}$ & \\
\hline Istok et al. & 1994 & $\begin{array}{l}\text { "Spatial Variability in Alluvium Properties at a Low-Level } \\
\text { Nuclear Waste Site." In Soil Scientists Society of America }\end{array}$ & \\
\hline IT Corporation & 1996 & $\begin{array}{l}\text { Groundwater Flow Model Documentation Package } \\
\text { (Phase I Data Analysis Documentation, Volume VI) }\end{array}$ & \\
\hline IT Corporation & 1996 & $\begin{array}{l}\text { Groundwater Recharge and Discharge Data Documentation } \\
\text { Package (Phase I Data Analysis Documentation, Volume III) }\end{array}$ & \\
\hline IT Corporation & 1996 & $\begin{array}{l}\text { Hydrologic Parameter Data Documentation Package } \\
\text { (Phase I Data Analysis Documentation, Volume IV) }\end{array}$ & \\
\hline IT Corporation & 1996 & $\begin{array}{l}\text { Potentiometric Data Documentation Package } \\
\text { (Phase I - Data Analysis Documentation, Volume II) }\end{array}$ & \\
\hline IT Corporation & 1996 & $\begin{array}{l}\text { Regional Geologic Model Documentation Package (Phase I } \\
\text { Data Analysis Documentation, Volume I, Parts } 1 \text { and 2) }\end{array}$ & \\
\hline IT Corporation & 1996 & $\begin{array}{l}\text { Transport Parameter and Source Term Data Documentation } \\
\text { Package (Phase 1, Data Analysis Documentation, Volume V) }\end{array}$ & \\
\hline IT Corporation & 1996 & $\begin{array}{l}\text { Tritium Transport Model Documentation Package } \\
\text { (Phase } 1 \text { Data Analysis Documentation, Volume VII) }\end{array}$ & \\
\hline IT Corporation & 1996 & $\begin{array}{l}\text { Wells ER-6-1 and ER-6-2 Core Fracture Analyses and } \\
\text { Geophysical Log Comparisons }\end{array}$ & \\
\hline IT Corporation & 1997 & $\begin{array}{l}\text { Risk Assessment Documentation Package (Phase I Data } \\
\text { Analysis Documentation, Volume VIII) }\end{array}$ & \\
\hline IT Corporation & 1997 & $\begin{array}{l}\text { Value of Information Analysis Corrective Action Unit No. } 98 \\
\text { for Frenchman Flat }\end{array}$ & \\
\hline
\end{tabular}


Table B.1-1

Frenchman Flat CAIP and Phase II Document UGTA References

(Page 7 of 17)

\begin{tabular}{|c|c|c|c|}
\hline Author & Year & Report & Select Descriptions of Content \\
\hline IT Corporation & 1998 & $\begin{array}{l}\text { Corrective Action Unit Modeling Approach } \\
\text { for the Underground Test Area, Nevada Test Site, } \\
\text { Nye County, Nevada }\end{array}$ & \\
\hline IT Corporation & 1998 & $\begin{array}{l}\text { Report and Analysis of the BULLION } \\
\text { Forced-Gradient Experiment }\end{array}$ & \\
\hline IT Corporation & 1998 & $\begin{array}{l}\text { Summary of Micrographic Analysis of Fracture Coating } \\
\text { Phases on Drill Cores from Pahute Mesa, Nevada Test Site }\end{array}$ & \\
\hline IT Corporation & 1998 & $\begin{array}{l}\text { Underground Test Area Subproject, Corrective Action Unit 98: } \\
\text { Frenchman Flat Data Analysis Task, Volume I - } \\
\text { Hydrostratigraphic Model Documentation Package }\end{array}$ & \\
\hline IT Corporation & 1999 & $\begin{array}{l}\text { External Peer Review Group Report on Frenchman Flat Data } \\
\text { Analysis and Modeling Task, Underground Test Area Project }\end{array}$ & \\
\hline IT Corporation & 1999 & $\begin{array}{l}\text { Underground Test Area Project Corrective Action Unit 98: } \\
\text { Frenchman Flat, Vol. II - Groundwater Data } \\
\text { Documentation Package }\end{array}$ & \\
\hline IT Corporation & 2000 & $\begin{array}{l}\text { Frenchman Flat Hydrogeologic Investigation Wells Drilling } \\
\text { and Completion Criteria }\end{array}$ & \\
\hline IT Corporation & 2000 & $\begin{array}{l}\text { Lessons Learned from the Frenchman Flat Corrective Action } \\
\text { Groundwater Flow and Radionuclide Transport Model }\end{array}$ & \\
\hline IT Corporation & 2001 & $\begin{array}{l}\text { Addendum to the Frenchman Flat Hydrogeologic } \\
\text { Investigation Wells Drilling and Completion Criteria }\end{array}$ & \\
\hline IT Corporation & 2002 & $\begin{array}{l}\text { Integrated Data Report for the Multiple-Well Aquifer Test at } \\
\text { Frenchman Flat Well Cluster ER-5-3 }\end{array}$ & \\
\hline IT Corporation & 2003 & $\begin{array}{l}\text { Written communication. Subject: Frenchman Flat ER-5-4 \#2 } \\
\text { Well Data Report }\end{array}$ & \\
\hline
\end{tabular}


Table B.1-1

Frenchman Flat CAIP and Phase II Document UGTA References

(Page 8 of 17)

\begin{tabular}{|c|c|c|c|}
\hline Author & Year & Report & Select Descriptions of Content \\
\hline Johnson & 1968 & $\begin{array}{l}\text { U.S. Geological Survey Tracer Study, Amargosa Desert, Nye } \\
\text { County, Nevada. Part I: Exploratory Drilling, Tracer Well } \\
\text { Construction and Testing, and Preliminary Findings }\end{array}$ & \\
\hline Johnson et al. & 1958 & $\begin{array}{l}\text { The Underground Nuclear Detonation of September 19, } \\
\text { 1957, Rainier, Operation Plumbbob }\end{array}$ & Early observations of shock altered rock properties \\
\hline Jones & 1982 & $\begin{array}{l}\text { Mineralogy of Fine Grained Alluvium from Borehole U11G, } \\
\text { Expl. 1, Northern Frenchman Flat Area, Nevada Test Site }\end{array}$ & \\
\hline Kersting and Reimus & 2003 & $\begin{array}{l}\text { Colloid-Facilitated Transport of Low-Solubility Radionuclides: } \\
\text { A Field, Experimental, and Modeling Investigation }\end{array}$ & \\
\hline Kersting et al. & 2003 & Radionuclide Decay and In-growth Technical Basis Document & \\
\hline Kirchoff-Stein et al. & 1989 & $\begin{array}{l}\text { Preliminary Aeromagnetic Map of the Nevada Test Site } \\
\text { and Vicinity, Nevada }\end{array}$ & \\
\hline Kwicklis et al. & 1998 & $\begin{array}{l}\text { Numerical Simulation of Air- and Water-flow Experiments } \\
\text { in a Block of Variably Saturated, Fractured Tuff from Yucca } \\
\text { Mountain, Nevada }\end{array}$ & \\
\hline Laczniak et al. & 1996 & $\begin{array}{l}\text { Summary of Hydrogeologic Controls on the Movement of } \\
\text { Groundwater at the Nevada Test Site, Nye County, Nevada }\end{array}$ & \\
\hline Laczniak et al. & 1999 & $\begin{array}{l}\text { Digital Geologic Map of the Nevada Test Site and Vicinity, } \\
\text { Nye, Lincoln, and Clark Counties, Nevada, and } \\
\text { Inyo County, California }\end{array}$ & \\
\hline Laczniak et al. & 1999 & $\begin{array}{l}\text { Estimates of Ground-Water Discharge as Determined from } \\
\text { Measurements of Evapotranspiration, Ash Meadows Area, } \\
\text { Nye County, Nevada }\end{array}$ & \\
\hline Laczniak et al. & 2001 & $\begin{array}{l}\text { Ground-Water Discharge as Determined from Estimates of } \\
\text { Evapotranspiration, Death Valley Regional Flow System, } \\
\text { Nevada and California }\end{array}$ & \\
\hline
\end{tabular}


Table B.1-1

Frenchman Flat CAIP and Phase II Document UGTA References

(Page 9 of 17)

\begin{tabular}{|c|c|c|c|}
\hline Author & Year & Report & Select Descriptions of Content \\
\hline $\begin{array}{l}\text { Lawrence Livermore National } \\
\text { Laboratory }\end{array}$ & 1999 & $\begin{array}{l}\text { Evaluation of the Hydrologic Source Term from Underground } \\
\text { Nuclear Tests in Frenchman Flat at the Nevada Test Site: } \\
\text { The CAMBRIC Test }\end{array}$ & The Phase I CAMBRIC hydrologic source term \\
\hline Mehta et al. & 1964 & $\begin{array}{l}\text { Changes in Physical Properties of Rocks in the Vicinity of an } \\
\text { Underground Nuclear Explosion }\end{array}$ & $\begin{array}{l}\text { Laboratory experiments relating to shock alteration } \\
\text { of rock properties }\end{array}$ \\
\hline Meyer and Young & 1962 & $\begin{array}{l}\text { Summary of Hydraulic Data and Abridged Log for } \\
\text { Ground-Water Test Well 3, Frenchman Flat, } \\
\text { Nevada Test Site, Nevada }\end{array}$ & \\
\hline Miller and Healey & 1986 & Gravity Interpretation of Frenchman Flat and Vicinity, NTS & \\
\hline Miller et al. & 1967 & $\begin{array}{l}\text { Geologic and Geophysical Logs of Exploratory Hole Ue-11c, } \\
\text { Nevada Test Site }\end{array}$ & \\
\hline Nimz and Thompson & 1992 & Underground Radionuclide Migration at the Nevada Test Site & \\
\hline Oberlander & 2001 & $\begin{array}{l}\text { Letter Report: Hydraulic Conductivity Profile with Depth for } \\
\text { Monitor Wells ER-5-3, ER-5-3 \#2, and ER-5-4 }\end{array}$ & \\
\hline Oberlander & 2003 & Hydraulic Conductivity Profile with Depth for Well ER-5-4 \#2 & \\
\hline Papelis and Um & 2003 & $\begin{array}{l}\text { Evaluation of Cesium, Strontium, and Lead Sorption, } \\
\text { Desorption, and Diffusion in Volcanic Tuffs from } \\
\text { Frenchman Flat, Nevada Test Site: Macroscopic and } \\
\text { Spectroscopic Investigations }\end{array}$ & \\
\hline Pawloski & 1999 & $\begin{array}{l}\text { Development of Phenomenological Models of Underground } \\
\text { Nuclear Tests on Pahute Mesa, Nevada Test Site--BENHAM } \\
\text { and TYBO }\end{array}$ & $\begin{array}{l}\text { Description of effects of these two underground } \\
\text { nuclear tests }\end{array}$ \\
\hline Pawloski et al. & 2001 & $\begin{array}{l}\text { Evaluation of the Hydrologic Source Term from Underground } \\
\text { Nuclear Tests on Pahute Mesa at the Nevada Test Site: } \\
\text { CHESHIRE Test }\end{array}$ & $\begin{array}{l}\text { The hydrologic source term from CHESHIRE - } \\
\text { used to help conceptualize PIN STRIPE and } \\
\text { MILK SHAKE }\end{array}$ \\
\hline Phelps and Graham & 2002 & $\begin{array}{l}\text { Preliminary Gravity Inversion Model of Frenchman Flat Basin, } \\
\text { Nevada Test Site, Nevada }\end{array}$ & \\
\hline
\end{tabular}


Table B.1-1

Frenchman Flat CAIP and Phase II Document UGTA References

(Page 10 of 17)

\begin{tabular}{|c|c|c|c|}
\hline Author & Year & Report & Select Descriptions of Content \\
\hline Phelps et al. & 1999 & $\begin{array}{l}\text { Thickness of Cenozoic Deposits of Yucca Flat Inferred from } \\
\text { Gravity Data, Nevada Test Site, Nevada }\end{array}$ & \\
\hline Phelps et al. & 2005 & $\begin{array}{l}\text { A Preliminary Investigation of the Structure of Southern } \\
\text { Yucca Flat, Massachusetts Mountain, and CP Basin, Nevada } \\
\text { Test Site, Nevada, Based on Geophysical Modeling }\end{array}$ & \\
\hline Ponce & 1997 & Gravity Data of Nevada & \\
\hline Ponce & 1999 & $\begin{array}{l}\text { Digital Aeromagnetic Map of the Nevada Test Site Area, } \\
\text { Nye, Lincoln, and Clark Counties, Nevada } \\
\text { and Inyo County, California }\end{array}$ & \\
\hline Ponce et al. & 1999 & $\begin{array}{l}\text { Digital Isostatic Gravity Map of the Nevada Test Site Area, } \\
\text { Nye, Lincoln, and Clark Counties, Nevada } \\
\text { and Inyo County, California }\end{array}$ & \\
\hline Poole & 1965 & $\begin{array}{l}\text { Geologic Map of the Frenchman Flat Quadrangle, } \\
\text { Nye, Lincoln, and Clark Counties, Nevada }\end{array}$ & \\
\hline Poole et al. & 1961 & $\begin{array}{l}\text { Eleana Formation of Nevada Test Site and Vicinity, } \\
\text { Nye County, Nevada }\end{array}$ & \\
\hline Poole et al. & 1963 & $\begin{array}{l}\text { Geology of a Strip Between Cane Spring Road and } \\
\text { Mara Wash, Nevada Test Site }\end{array}$ & \\
\hline Poole et al. & 1965 & $\begin{array}{l}\text { Geologic Map of the Cane Spring Quadrangle, } \\
\text { Nye County, Nevada }\end{array}$ & \\
\hline Prather & 1965 & $\begin{array}{l}\text { Preliminary Summary of Lithologic and Hydrologic Data } \\
\text { from the UE5f Exploratory Drill Hole, Frenchman Flat, } \\
\text { Nevada Test Site }\end{array}$ & \\
\hline Prothro and Drellack & 1997 & $\begin{array}{l}\text { Review and Reconnaissance of the Hydrogeology of } \\
\text { Tertiary Sedimentary Rocks in the Vicinity of Frenchman Flat, } \\
\text { Nevada Test Site }\end{array}$ & \\
\hline Ramspott and McArthur & 1977 & $\begin{array}{l}\text { Results of the Exploratory Drill Hole Ue } 5 n \text {, Frenchman Flat, } \\
\text { Nevada Test Site }\end{array}$ & \\
\hline
\end{tabular}


Table B.1-1

Frenchman Flat CAIP and Phase II Document UGTA References

(Page 11 of 17)

\begin{tabular}{|c|c|c|c|}
\hline Author & Year & Report & Select Descriptions of Content \\
\hline Reimus et al. & 2001 & $\begin{array}{l}\text { FY2001 Progress Report on Colloid-Facilitated Plutonium } \\
\text { Transport in Fractured Rocks from Pahute Mesa, } \\
\text { Nevada Test Site }\end{array}$ & \\
\hline Reimus et al. & 2002 & $\begin{array}{l}\text { "Chapter } 7 \text { - Colloid-Facilitated Plutonium Fracture Transport } \\
\text { Experiments." In Colloid-Facilitated Transport of } \\
\text { Low-Solubility Radionuclides: A Field, Experimental, and } \\
\text { Modeling Investigation }\end{array}$ & \\
\hline Reimus et al. & 2002 & $\begin{array}{l}\text { Diffusive and Advective Transport of }{ }^{3} \mathrm{H},{ }^{14} \mathrm{C} \text {, and }{ }^{99} \mathrm{Tc} \\
\text { in Saturated, Fractured Volcanic Rocks from } \\
\text { Pahute Mesa, Nevada }\end{array}$ & \\
\hline Reimus et al. & 2006 & $\begin{array}{l}\text { Colloid Characteristics and Radionuclide Associations with } \\
\text { Colloids in Near-Field Waters at the Nevada Test Site } \\
\text { (FY2005 Progress Report) }\end{array}$ & \\
\hline Reiner & 2002 & Aquifer-Test Report for WW-4A, Area 6, Nevada Test Site & \\
\hline Reiner & 2003 & Aquifer-Test Report for WW-5C, Area 5, Nevada Test Site & \\
\hline Reiner et al. & 1995 & $\begin{array}{l}\text { Ground-Water Data for the Nevada Test Site and Selected } \\
\text { Other Areas in South-Central Nevada, 1992-1993 }\end{array}$ & \\
\hline $\begin{array}{l}\text { Reynolds Electrical \& } \\
\text { Engineering Co., Inc. }\end{array}$ & 1993 & $\begin{array}{l}\text { Hydrogeologic Data for Existing Excavations at the Area } 5 \\
\text { Radioactive Waste Management Site, Nevada Test Site, } \\
\text { Nye County, Nevada }\end{array}$ & \\
\hline $\begin{array}{l}\text { Reynolds Electrical \& } \\
\text { Engineering Co., Inc. }\end{array}$ & 1993 & $\begin{array}{l}\text { Hydrogeologic Data for Science Trench Boreholes at the Area } \\
5 \text { Radioactive Waste Management Site, Nevada Test Site, } \\
\text { Nye County, Nevada }\end{array}$ & \\
\hline $\begin{array}{l}\text { Reynolds Electrical \& } \\
\text { Engineering Co., Inc. }\end{array}$ & 1994 & $\begin{array}{l}\text { Site Characterization and Monitoring Data from Area } 5 \\
\text { Pilot Wells, Nevada Test Site, Nye County, Nevada }\end{array}$ & \\
\hline Rose & 2003 & Isotopic Analyses: Environmental Monitoring Well ER-5-3 & \\
\hline Rose & 2003 & Isotopic Analyses: Environmental Monitoring Well ER-5-3\#2 & \\
\hline
\end{tabular}


Table B.1-1

Frenchman Flat CAIP and Phase II Document UGTA References

(Page 12 of 17)

\begin{tabular}{|c|c|c|c|}
\hline Author & Year & Report & Select Descriptions of Content \\
\hline Rose & 2003 & Isotopic Analyses: Environmental Monitoring Well ER-5-4 & \\
\hline Rose & 2003 & Isotopic Analyses: Environmental Monitoring Well ER-5-4\#2 & \\
\hline Rose et al. & 2000 & $\begin{array}{l}\text { "Lithologic, Mineralogic, and Petrographic Characterization of } \\
\text { Alluvium from the U-1a 102C and 102D Drifts of the U-1a } \\
\text { Tunnel Complex, Nevada Test Site." In Hydrologic } \\
\text { Resources Management Program and Underground Test } \\
\text { Area FY } 1999 \text { Progress Report }\end{array}$ & \\
\hline Rose et al. & 2002 & $\begin{array}{l}\text { Geochemical Data Analysis and Interpretation of the Pahute } \\
\text { Mesa - Oasis Valley Groundwater Flow System, Nye County, } \\
\text { Nevada }\end{array}$ & \\
\hline Rose et al. & 2003 & $\begin{array}{l}\text { Hydrologic Resources Management Program and } \\
\text { Underground Test Area Project FY2001-2002 } \\
\text { Progress Report }\end{array}$ & \\
\hline Rose et al. & 2004 & $\begin{array}{l}\text { Hydrologic Resources Management Program and } \\
\text { Underground Test Area Project FY2003 Progress Report }\end{array}$ & \\
\hline Ross and Wheatcraft & 1999 & $\begin{array}{l}\text { A Two-Dimensional Simulation and Tritium Transport in the } \\
\text { Vadose Zone at the Nevada Test Site }\end{array}$ & \\
\hline Russell and Minor & 2002 & $\begin{array}{l}\text { Reconnaissance Estimates of Recharge Based on an } \\
\text { Elevation-dependent Chloride Mass-balance Approach }\end{array}$ & \\
\hline Shott et al. & 1995 & $\begin{array}{l}\text { Performance Assessment for the Area } 5 \text { Radioactive Waste } \\
\text { Management Site at the Nevada Test Site, } \\
\text { Nye County, Nevada }\end{array}$ & \\
\hline Slate et al. & 1999 & $\begin{array}{l}\text { Digital Geologic Map of the Nevada Test Site and Vicinity, } \\
\text { Nye, Lincoln, and Clark Counties, Nevada, } \\
\text { and Inyo County, California }\end{array}$ & \\
\hline Stoller-Navarro Joint Venture & 2004 & $\begin{array}{l}\text { Integrated Analysis Report for Single and Multiple-Well } \\
\text { Aquifer Testing at Frenchman Flat Well Cluster RNM-2s, } \\
\text { Nevada Test Site, Nevada }\end{array}$ & \\
\hline
\end{tabular}


Table B.1-1

Frenchman Flat CAIP and Phase II Document UGTA References

(Page 13 of 17)

\begin{tabular}{|c|c|c|c|}
\hline Author & Year & Report & Select Descriptions of Content \\
\hline Stoller-Navarro Joint Venture & 2004 & $\begin{array}{l}\text { Interpretation of Hydraulic Test and Multiple-Well Aquifer Test } \\
\text { Data at Frenchman Flat Well Cluster ER-5-3 }\end{array}$ & \\
\hline Stoller-Navarro Joint Venture & 2004 & $\begin{array}{l}\text { Phase II Hydrologic Data for the Groundwater Flow and } \\
\text { Contamination Transport Model of CAU Unit 98: Frenchman } \\
\text { Flat, Nye County, Nevada }\end{array}$ & \\
\hline Stoller-Navarro Joint Venture & 2004 & $\begin{array}{l}\text { The Role of Dispersion in Radionuclide Transport-Data and } \\
\text { Modeling Requirements }\end{array}$ & \\
\hline Stoller-Navarro Joint Venture & 2004 & $\begin{array}{l}\text { Transferability of Data Related to the Underground Test Area } \\
\text { Project, Nevada Test Site, Nye County, Nevada }\end{array}$ & \\
\hline Stoller-Navarro Joint Venture & 2004 & $\begin{array}{l}\text { Written communication. Subject: Interpretation of Hydraulic } \\
\text { Test and Multiple-Well Aquifer Test Data at Frenchman Flat } \\
\text { Well Cluster ER-5-3 }\end{array}$ & \\
\hline Stoller-Navarro Joint Venture & 2005 & $\begin{array}{l}\text { Analysis of Hydraulic Responses from the ER-6-1 } \\
\text { Multiple-Well Aquifer Test, Yucca Flat FY } 2004 \text { Testing } \\
\text { Program, Nevada Test Site, Nye County, Nevada }\end{array}$ & \\
\hline Stoller-Navarro Joint Venture & 2005 & $\begin{array}{l}\text { Analysis of Well ER-6-2 Testing, Yucca Flat FY } 2004 \text { Testing } \\
\text { Program, Nevada Test Site, Nye County, Nevada }\end{array}$ & \\
\hline Stoller-Navarro Joint Venture & 2005 & $\begin{array}{l}\text { Geochem05.mdb and A User's Guide to the Comprehensive } \\
\text { Water Quality Database for Groundwater in the Vicinity of the } \\
\text { Nevada Test Site }\end{array}$ & \\
\hline Stoller-Navarro Joint Venture & 2005 & $\begin{array}{l}\text { Phase II Contaminant Transport Parameters for the } \\
\text { Groundwater Flow and Contaminant Transport Model } \\
\text { of Corrective Action Unit 98: Frenchman Flat, } \\
\text { Nye County, Nevada }\end{array}$ & \\
\hline Stoller-Navarro Joint Venture & 2005 & $\begin{array}{l}\text { Unclassified Source Term and Radionuclide Data for } \\
\text { Corrective Action Unit 98: Frenchman Flat } \\
\text { Nevada Test Site, Nevada }\end{array}$ & \\
\hline
\end{tabular}


Table B.1-1

Frenchman Flat CAIP and Phase II Document UGTA References

(Page 14 of 17)

\begin{tabular}{|c|c|c|c|}
\hline Author & Year & Report & Select Descriptions of Content \\
\hline Stoller-Navarro Joint Venture & 2005 & $\begin{array}{l}\text { Underground Test Area Fracture Analysis Report for } \\
\text { Frenchman Flat Well Clusters ER-5-3 and ER-5-4, } \\
\text { Nevada Test Site, Nevada }\end{array}$ & \\
\hline Stoller-Navarro Joint Venture & 2005 & $\begin{array}{l}\text { Written communication. Subject: Unclassified Source Term } \\
\text { and Radionuclide Data for Corrective Action Unit 98: } \\
\text { Frenchman Flat, Nevada }\end{array}$ & \\
\hline Stoller-Navarro Joint Venture & 2006 & $\begin{array}{l}\text { Digital Orthophoto of the CAMBRIC Site 1994, } \\
\text { Nevada Test Site }\end{array}$ & \\
\hline Stoller-Navarro Joint Venture & 2006 & $\begin{array}{l}\text { Phase II Groundwater Flow Model of Corrective Action Unit } \\
\text { 98: Frenchman Flat, Nevada Test Site, Nye County, Nevada }\end{array}$ & \\
\hline Stoller-Navarro Joint Venture & 2006 & $\begin{array}{l}\text { Well ER-6-1 Tracer Test Analysis: Yucca Flat, } \\
\text { Nevada Test Site, Nye County, Nevada }\end{array}$ & \\
\hline Thomas et al. & 2002 & $\begin{array}{l}\text { Geochemical and Isotopic Interpretations of Groundwater } \\
\text { Flow in the Oasis Valley Flow System, Southern Nevada }\end{array}$ & \\
\hline Thompson & 1995 & $\begin{array}{l}\text { Radionuclide Distribution in a Nuclear Test Cavity: } \\
\text { The Baseball Event }\end{array}$ & \\
\hline Tompson et al. & 1999 & $\begin{array}{l}\text { Evaluation of the Hydrologic Source Term from the } \\
\text { Underground Nuclear Tests in Frenchman Flat and the } \\
\text { Nevada Test Site: The CAMBRIC Test }\end{array}$ & \\
\hline Tompson et al. & 2002 & $\begin{array}{l}\text { Analysis of Radionuclide Migration through a 200-m Vadose } \\
\text { Zone following a 16-Year Infiltration Event }\end{array}$ & \\
\hline Tompson et al. & 2003 & $\begin{array}{l}\text { Radionuclide Decay and In-Growth Technical } \\
\text { Basis Document }\end{array}$ & \\
\hline Tompson et al. & 2004 & $\begin{array}{l}\text { Methods for Calculating a Simplified Hydrologic Source Term } \\
\text { for Frenchman Flat Sensitivity Studies of Radionuclide } \\
\text { Transport Away from Underground Nuclear Tests }\end{array}$ & $\begin{array}{l}\text { An approach, not used, for computing simplified } \\
\text { source terms }\end{array}$ \\
\hline
\end{tabular}


Table B.1-1

Frenchman Flat CAIP and Phase II Document UGTA References

(Page 15 of 17)

\begin{tabular}{|c|c|c|c|}
\hline Author & Year & Report & Select Descriptions of Content \\
\hline Tompson et al. & 2005 & $\begin{array}{l}\text { Evaluation of the Non-Transient Hydrologic Source Term from } \\
\text { the CAMBRIC Underground Nuclear Test in Frenchman Flat, } \\
\text { Nevada Test Site }\end{array}$ & $\begin{array}{l}\text { Steady state CAMBRIC hydrologic source } \\
\text { term used to develop initial simplified source } \\
\text { model abstractions }\end{array}$ \\
\hline Tonkin and Doherty & 2009 & $\begin{array}{l}\text { "Calibration-Constrained Monte Carlo Analysis of Highly } \\
\text { Parameterized Models Using Subspace Techniques." } \\
\text { In Water Resources Research }\end{array}$ & \\
\hline Triay et al. & 1997 & $\begin{array}{l}\text { Summary and Synthesis Report on Radionuclide Retardation } \\
\text { for the Yucca Mountain Site Characterization Project }\end{array}$ & \\
\hline $\begin{array}{l}\text { TRW Environmental Safety } \\
\text { Systems, Inc. }\end{array}$ & 2000 & Unsaturated Zone Flow and Transport Process Model Report & \\
\hline $\begin{array}{l}\text { U.S. Department of Energy, } \\
\text { National Nuclear Security } \\
\text { Administration Nevada } \\
\text { Operations Office }\end{array}$ & 2001 & $\begin{array}{l}\text { Addendum to Revision } 1 \text { of the Corrective Action } \\
\text { Investigation Plan for Corrective Action Unit 98: Frenchman } \\
\text { Flat, Nevada Test Site, Nevada }\end{array}$ & \\
\hline $\begin{array}{l}\text { U.S. Department of Energy, } \\
\text { National Nuclear Security } \\
\text { Administration Nevada Site } \\
\text { Office }\end{array}$ & 2005 & Well Completion Report for Well Cluster ER-5-3 & \\
\hline $\begin{array}{l}\text { U.S. Department of Energy, } \\
\text { National Nuclear Security } \\
\text { Administration Nevada Site } \\
\text { Office }\end{array}$ & 2005 & Well Completion Report for Well Cluster ER-5-4 & \\
\hline $\begin{array}{l}\text { U.S. Department of Energy, } \\
\text { Nevada Operations Office }\end{array}$ & 1997 & $\begin{array}{l}\text { Regional Groundwater Flow and Tritium Transport Modeling } \\
\text { and Risk Assessment of the Underground Test Area, Nevada } \\
\text { Test Site, Nevada }\end{array}$ & \\
\hline $\begin{array}{l}\text { U.S. Department of Energy, } \\
\text { Nevada Operations Office }\end{array}$ & 1997 & $\begin{array}{l}\text { Shaft and Tunnel Nuclear Detonations at the Nevada } \\
\text { Test Site: Development of a Primary Database for the } \\
\text { Estimation of Potential Interactions with the Regional } \\
\text { Groundwater System }\end{array}$ & \\
\hline
\end{tabular}


Table B.1-1

Frenchman Flat CAIP and Phase II Document UGTA References

(Page 16 of 17)

\begin{tabular}{|c|c|c|c|}
\hline Author & Year & Report & Select Descriptions of Content \\
\hline $\begin{array}{l}\text { U.S. Department of Energy, } \\
\text { Nevada Operations Office }\end{array}$ & 1999 & $\begin{array}{l}\text { Corrective Action Investigation Plan for Corrective Action } \\
\text { Unit 98: Frenchman Flat, Nevada Test Site, Nevada }\end{array}$ & \\
\hline $\begin{array}{l}\text { U.S. Department of Energy, } \\
\text { Nevada Operations Office }\end{array}$ & 2000 & $\begin{array}{l}\text { Addendum to the Corrective Action Investigation Plan } \\
\text { for Corrective Action Unit 98: Frenchman Flat, } \\
\text { Nevada Test Site, Nevada }\end{array}$ & \\
\hline $\begin{array}{l}\text { U.S. Department of Energy, } \\
\text { Nevada Operations Office }\end{array}$ & 2000 & $\begin{array}{l}\text { United States Nuclear Tests, July } 1945 \text { through } \\
\text { September } 1992\end{array}$ & \\
\hline $\begin{array}{l}\text { U.S. Department of Energy, } \\
\text { Office of Civilian Radioactive } \\
\text { Waste Management, Office } \\
\text { of Repository Development }\end{array}$ & 2001 & $\begin{array}{l}\text { Unsaturated Zone and Saturated Zone Transport } \\
\text { Properties (U0100) }\end{array}$ & \\
\hline U.S. Geological Survey & 2007 & $\begin{array}{l}\text { Mercury Core Library \& Data Center; } \\
\text { Rock-Property Database }\end{array}$ & \\
\hline Viani & 2006 & $\begin{array}{l}\text { Compilation of Partition Coefficients }\left(K_{d}\right) \text { Applicable to } \\
\text { Modeling Transport in the Basalt Lava Flow Aquifer } \\
\text { Hydrostratigraphic Unit }\end{array}$ & \\
\hline Warren et al. & 2002 & $\begin{array}{l}\text { Alluvial Layering and Distribution of Reactive Phases within } \\
\text { Drill Holes ER5/4 and UE5N of Frenchman Flat }\end{array}$ & \\
\hline Warren et al. & 2003 & $\begin{array}{l}\text { A Petrographic, Geochemical and Geophysical Database, } \\
\text { and Stratigraphic Framework for the Southwestern Nevada } \\
\text { Volcanic Field }\end{array}$ & \\
\hline Winograd and Thordarson & 1975 & $\begin{array}{l}\text { Hydrogeologic and Hydrochemical Framework, South-Central } \\
\text { Great Basin, Nevada-California, with Special Reference to } \\
\text { the Nevada Test Site }\end{array}$ & \\
\hline Wolfsberg et al. & 2002 & $\begin{array}{l}\text { TYBO/BENHAM Model Analysis of Groundwater Flow and } \\
\text { Radionuclide Migration from Underground Nuclear Tests in } \\
\text { Southwestern Pahute Mesa, NTS }\end{array}$ & \\
\hline Young & 1972 & $\begin{array}{l}\text { Water Supply for the Nuclear Rocket Development Station at } \\
\text { the U.S. Atomic Energy Commission's Nevada Test Site }\end{array}$ & \\
\hline
\end{tabular}


Table B.1-1

Frenchman Flat CAIP and Phase II Document UGTA References

(Page 17 of 17)

\begin{tabular}{|c|c|c|c|}
\hline Author & Year & Report & Select Descriptions of Content \\
\hline Zavarin and Bruton & 2004 & $\begin{array}{l}\text { A Non-Electrostatic Surface Complexation Approach to } \\
\text { Modeling Radionuclide Migration at the Nevada Test Site: } \\
\text { I. Iron Oxides and Calcite }\end{array}$ & \\
\hline Zavarin and Bruton & 2004 & $\begin{array}{l}\text { A Non-Electrostatic Surface Complexation Approach to } \\
\text { Modeling Radionuclide Migration at the Nevada Test Site: } \\
\text { II. Aluminosilicates }\end{array}$ & \\
\hline Zavarin et al. & 2002 & $\begin{array}{l}\text { Validating Mechanistic Sorption Model Parameters and } \\
\text { Processes for Reactive Transport in Alluvium }\end{array}$ & \\
\hline Zavarin et al. & 2004 & $\begin{array}{l}\text { High-Temperature Studies of Glass Dissolution Rates Close } \\
\text { to Saturation }\end{array}$ & \\
\hline Zavarin et al. & 2004 & $\begin{array}{l}\text { Nuclear Melt Glass Dissolution and Secondary Mineral } \\
\text { Precipitation at } 40 \text { to } 200 \mathrm{C}\end{array}$ & \\
\hline Zavarin et al. & 2004 & $\begin{array}{l}\text { Upscaling Radionuclide Retardation - Linking the Surface } \\
\text { Complexation and lon Exchange Mechanistic Approach to a } \\
\text { Linear } K_{d} \text { Approach }\end{array}$ & \\
\hline
\end{tabular}




\section{B.2.0 REFERENCES}

Barnes, H., E.B. Ekren, C.L. Rodgers, and D.C. Hedlund. 1982. Geology and Tectonic Maps of the Mercury Quadrangle, Nye and Clark Counties, Nevada. U.S. Geological Survey, Miscellaneous Geologic Investigations Series Map I-1197, scale 1:24,000.

Bechtel Nevada. 1998. Hydrologic Characterization of the Unsaturated Zone at the Area 3 Radioactive Waste Management Site, DOE/NV/11718-210. Las Vegas, NV.

Bechtel Nevada. 2004a. Completion Report for Well Cluster ER-5-3. Las Vegas, NV.

Bechtel Nevada. 2004b. Completion Report for Well Cluster ER-5-4. Las Vegas, NV.

Bechtel Nevada. 2005a. A Hydrostratigraphic Framework Model and Alternatives for the Groundwater Flow and Contaminant Transport Model of Corrective Action Unit 98: Frenchman Flat, Clark, Lincoln and Nye Counties, Nevada, DOE/NV/11718--1064. Las Vegas, NV.

Bechtel Nevada. 2005b. Site Characterization and Monitoring Data from Area 5 Pilot Wells, Nevada Test Site, Nye County, Nevada, DOE/NV/11718--1067. Las Vegas, NV.

Bechtel Nevada. 2006. A Hydrostratigraphic Model and Alternatives for the Groundwater Flow and Contaminant Transport Model of Corrective Action Unit 97: Yucca Flat-Climax Mine, Lincoln and Nye Counties, Nevada, DOE/NV/11718--1119. Las Vegas, NV.

Beiriger, W. 1977. X-ray Analysis of 36 Samples from Ue5n. Livermore, CA: Lawrence Livermore National Laboratory.

Belcher, W.R., P.E. Elliot, and A.L. Geldon. 2001. Hydraulic-Property Estimates for Use With a Transient Ground-Water Flow Model for the Death Valley Regional Ground-Water Flow System, Nevada and California, USGS Water-Resources Investigations Report 2001-4210, 28 p.

Belcher, W.R., J.B. Blainey, F.A. D’Agnese, C.C. Faunt, M.C. Hill, R.J. Laczniak, G.M. O’Brien, C.J. Potter, H.M. Putnam, C.A. San Juan, and D.S. Sweetkind. 2004. Death Valley Regional Ground-Water Flow System, Nevada and California-Hydrogeologic Framework and Transient Ground-Water Flow Model, Scientific Investigations Report 2004-5205. U.S. Geological Survey. Prepared for the U.S. Department of Energy, National Nuclear Security Administration Nevada Site Office. 
Benedict, Jr. F.C., T.P. Rose, J.M. Thomas, R. Waddell, and R. Jacobson. 2003. Geochemistry Technical Basis Document, Report Publication No. 45205, DOE/NV/13609-34. Prepared for the U.S. Department of Energy, National Nuclear Security Administration Nevada Site Office. Las Vegas, NV: Desert Research Institute.

Berger, D.L. 1992. Lithologic Properties of Carbonate-Rock Aquifers at Five Test Wells in the Coyote Spring Valley Area, Southern Nevada, as Determined from Geophysical Logs, USGS-WRIR-91-4167. Prepared in cooperation with the State of Nevada, the Las Vegas Valley Water District, and the U.S Bureau of Reclamation. Carson City, NV: U.S. Geological Survey.

Blout, D.O., W.S. Birchfiel, D.P. Hammermeister, and K.A. Zukosky. 1995. Site Characterization Data from the Area 5 Science Boreholes, Nevada Test Site, Nye County, Nevada, DOE/NV 11432--170. Las Vegas, NV: Reynolds Electrical \& Engineering Co., Inc.

Boardman, C.R. 1967. Results of an Exploration into the Top of the Piledriver Chimney, UCRL-50385. Livermore, CA: Lawrence Livermore National Laboratory.

Borg, I.Y. 1971. Some Shock Effects in Granodiorite to 270 kbar at the Piledriver Site, UCRL-73377 Rev. 1. Livermore, CA: Lawrence Livermore National Laboratory.

Borg, I.Y. 1973. Comparison of Shock Effects in Granitic Rock Recovered From the Monique Event, Algeria, and the Piledriver Event, Nevada Test Site, UCRL-51349. Livermore, CA: Lawrence Livermore National Laboratory.

Borg, I.Y., R. Stone, H.B. Levy and L.D. Ramspott. 1976. Information Pertinent to the Migration of Radionuclides in Groundwater at the Nevada Test Site. Part 1: Review and Analysis of Existing Information, UCRL-52078, Pt. 1. Livermore, CA: Lawrence Livermore National Laboratory.

Bowen, S.M., D.L. Finnegan, J.L. Thompson, C.M. Miller, P.L. Baca, L.F. Olivas, C.G. Geoffrion, D.K. Smith, W. Goishi, B.K. Esser, J.W. Meadows, N. Namboodiri, and J.F. Wild. 2001. Nevada Test Site Radionuclide Inventory, 1951-1992, LA-13959-MS. Los Alamos, NM: Los Alamos National Laboratory.

Bright, D.J., S.A. Watkins, and B.A. Lisle. 2001. Analysis of Water Levels in the Frenchman Flat Area, Nevada Test Site, Water-Resources Investigations Report 00-4272. Denver, CO: U.S. Geological Survey.

Butkovich, T.R., and A.E. Lewis. 1973. Aids for Estimating Effects of Underground Nuclear Explosions, UCRL-50929 (Rev. 1). Livermore, CA: Lawrence Livermore National Laboratory.

Byers, F.M., Jr., and C.H. Miller. 1966. Geologic and Geophysical Log of the Ue5k Exploratory Hole, Frenchman Flat, Nevada Test Site, Technical Letter NTS-164. U.S. Geological Survey. 
Carle, S.F., M. Zavarin, and G.A. Pawloski. 2002. Geostatistical Analysis of Spatial Variability of Mineral Abundance and $K_{d}$ in Frenchman Flat, NTS, Alluvium, UCRL-ID-150200. Livermore, CA: Lawrence Livermore National Laboratory.

Carle, S.F., R.M. Maxwell, G.A. Pawloski, D.E. Shumaker, A.F.B. Tompson, and M. Zavarin. 2007. Evaluation of the Transient Hydrologic Source Term for the Cambric Underground Nuclear Test at Frenchman Flat, Nevada Test Site, UCRL-TR-226916. Livermore, CA: Lawrence Livermore National Laboratory.

Carle, S.F., M. Zavarin, Y. Sun, and G.A. Pawloski. 2008. Written communication. Subject: Evaluation of Hydrologic Source Term Processes for Underground Nuclear Tests in Yucca Flat, Nevada Test Site: Carbonate Tests, LLNL-TR-403485. Livermore, CA: Lawrence Livermore National Laboratory.

Carr, W.J., G.D. Bath, D.L. Healey, and R.M. Hazlewood. 1975. Geology of Northern Frenchman Flat, Nevada Test Site. U.S. Geological Survey Report, USGS-474-216. Denver, CO: U.S. Geological Survey.

Carroll, R.D. 1981. "Seismic Velocity and Postshot Properties in and near Chimneys." In Proceedings of the Monterey Containment Symposium, LA-9211-C, Vol. 1. Los Alamos, NM: Los Alamos National Laboratory.

Case, C. M., J. Davis, R. French, and S. Racker. 1984. Site Characterization in Connection with the Low-Level Defense Waste Management Site in Area 5 of the Nevada Test Site, Nye County, Nevada - Final Report, DOE/NV/10162-13. Las Vegas, NV: Desert Research Institute.

Cole, J.C. 1997. Major Structural Controls on the Distribution of Pre-Tertiary Rocks, Nevada Test Site Vicinity, Southern Nevada, U.S. Geological Survey Open-File Report 97-533. Denver, CO: U.S. Geological Survey.

Cole, J.C., and P.H. Cashman. 1999. Structural Relationships of Pre-Tertiary Rocks in the Nevada Test Site Region, Southern Nevada, U.S. Geological Survey Professional Paper 1607.

Daniels, J.I., and A.F.B. Tompson. 2003. Technical Basis for Also Using Health-Risk Assessment To Establish Contaminant Boundaries for Corrective Action Units (CAUs) of the Underground Test Area (UGTA) at the Nevada Test Site (NTS), URCL-TR-201702. Livermore, CA: Lawrence Livermore National Laboratory.

Dixon, G.L., W.J. Carr, A.T. Fernald, and F.M. Byers, Jr. 1965. Geologic Report on Drill Hole Uellb, Nevada Test Site, USGS-NTS-157, Technical Letter. Denver, CO: U.S. Geological Survey.

Dixon, G.L., W.J. Carr, and W.P. Williams. 1967. Geologic and Geophysical Log of Drill Hole Ue5i, Nevada Test Site, USGS-NTS-186, Technical Letter. Denver, CO: U.S. Geological Survey. 
Drellack, S.L., Jr. 1997. Selected Stratigraphic Data for Drill Holes Located in Frenchman Flat, Nevada Test Site, Rev. 1, DOE/NV/11718--077. Las Vegas, NV: Bechtel Nevada.

Drellack, Jr. S.L., L.B. Prothro, K.E. Roberson, B.A. Schier, and E.H. Price. 1997. Analysis of Fractures in Volcanic Cores from Pahute Mesa, Nevada Test Site, DOE/NV/11718-160. Prepared for the U.S. Department of Energy, Nevada Operations Office. Las Vegas, NV: Bechtel Nevada.

Faunt, C. 1998. Effects of Faulting on Groundwater Movement in the Death Valley Region, Nevada and California, U.S. Geological Survey Water Resources Investigations Report 95-4132. Denver, CO: U.S. Geological Survey.

Federal Facility Agreement and Consent Order. 1996 (as amended March 2010). Agreed to by the State of Nevada; U.S. Department of Energy, Environmental Management; U.S. Department of Defense; and U.S. Department of Energy, Legacy Management.

Fernald, A.T., G.L. Dixon, W.J. Carr, and F.M. Byers, Jr. 1965. Geologic Report on Drill Hole Uella, Nevada Test Site, USGS - NTS-160, Technical Letter. Denver, CO: U.S. Geological Survey.

Fiero, G.W., Jr., J.R. Illian, G.A. Dinwiddie, and L.J. Schroder. 1974. Use of Hydrochemistry for Interpreting Ground-Water Flow Systems in Central Nevada, USGS-474-178. Lakewood, CO: U.S. Geological Survey.

Flint, L.E., A.L. Flint, C.A. Rautman, and J.D. Istok. 1996. Physical and Hydrologic Properties of Rock Outcrop Samples at Yucca Mountain, Nevada, USGS Open-File Report 95-280. Denver, CO.

Forester, R.M., J.P. Bradbury, C. Carter, A.B. Elvidge-Tuma, M.L. Hemphill, S.C. Lundstrom, S.A. Mahan, B.D. Marshall, L.A. Neymark, J.B. Paces, S.E. Sharpe, J.F. Whelan, and P.E. Wigand. 1999. The Climatic and Hydrologic History of Southern Nevada During the Late Quaternary, Open File Report 98-635. Denver, CO: U.S. Geological Survey.

George, D. 1997. Unstructured 3D Grid Toolbox for Modeling and Simulation, LA-UR-97-3052. Los Alamos, NM: Los Alamos National Laboratory.

Gillespie, D., D. Donithan, and P. Seaber. 1996. Nevada Test Site Water-Supply Wells, Publication No: 45138. Las Vegas, NV: Desert Research Institute.

Grasso, D.N. 2003. Geologic Surface Effects of Underground Nuclear Testing, Buckboard Mesa, Climax Stock, Dome Mountain, Frenchman Flat, Rainier/Aqueduct Mesa, and Shoshone Mountain, Nevada Test Site, Nevada, USGS Open File Report 03-125.

Grauch, V.J.S., and M.R. Hudson. 1995. Preliminary Analysis of Major Structures and Lithologic Boundaries for the Frenchman Flat Model Area. Denver, CO: U.S. Geological Survey. 
Healey, D.L. 1965. An Evaluation of Northeastern Frenchman Flat Based on Gravity Data, U.S. Geological Survey Technical Letter NTS-158.

Healey, D.L., M.A. Pistrang, and H. Barnes. 1967. Proposed Ue5m Test Area, Southwest Frenchman Flat, Nevada Test Site, U.S. Geological Survey Technical Letter NTS-189.

Healey, D.L., R.N. Harris, D.A. Ponce, and H.W. Oliver. 1987. Complete Bouguer Gravity Map of the Nevada Test Site and Vicinity, Nevada, U.S. Geological Survey Open-File Report 87-506, scale: $1: 100,000$.

Hershey, R.L., and S.Y. Acheampong. 1997. Estimation of Groundwater Velocities from Yucca Flat to the Amargosa Desert Using Geochemistry and Environmental Isotopes, Publication No. 45157. Las Vegas, NV: Desert Research Institute.

Hershey, R.L., O. Dahan, S.C. Calhoun, and R. Jacobson. 2001. Geochemically Calibrated Discrete-State Cell Model of the Frenchman Flat Hydrographic Area. Reno, NV: Desert Research Institute.

Hershey, R.L., J.M. Thomas, T.P. Rose, J.B. Paces, I.M. Farnham, and F.C. Benedict, Jr. 2005. Evaluation of Groundwater Movement in the Frenchman Flat CAU Using Geochemical and Isotopic Analysis, DOE/NV/13609-36, Publication No. 45207. Prepared for the U.S. Department of Energy, National Nuclear Security Administration Nevada Site Office. Las Vegas, NV: Desert Research Institute.

Hevesi, J.A., A.L. Flint, and L.E. Flint. 2003. Simulation of Net Infiltration and Potential Recharge Using a Distributed Parameter Watershed Model for the Death Valley Region, Nevada and California, Water-Resources Investigations Report 03-4090. Sacramento, CA: U.S. Geological Survey.

Hinrichs, E.N. 1968. Geologic Map of the Camp Desert Rock Quadrangle, Nye County, Nevada. U.S. Geological Survey Quadrangle Map G-726, scale 1:24,000.

Hinrichs, E.N., and E.J. McKay. 1965. Geologic Map of the Plutonium Valley Quadrangle, Nye and Lincoln Counties, Nevada, U.S. Geological Survey Geologic Quadrangle Map 384, scale 1:24,000. Denver, CO: U.S. Geological Survey.

Hockett, S.L. and R.H. French. 1998. Evaluation of Recharge Potential at Crater U5a (WISHBONE), DOE/NV/11508-32, Publ. \#45160. Las Vegas, NV: Desert Research Institute, Water Resources Center.

Hockett, S.L., and D.R. Gillespie. 1996. Preliminary Evaluation of Recharge Potential at Subsidence Crater U5A in Frenchman Flat, Nevada Test Site, DOE/NV/11508-15, Publication No: 45147. Las Vegas, NV: Desert Research Institute. 
Hoffman, D.C., R. Stone, and W.W. Dudley, Jr. 1977. Radioactivity in the Underground Environment of the Cambric Nuclear Explosion at the Nevada Test Site, LA-6877-MS. Los Alamos, NM: Los Alamos Scientific Laboratory.

Hokett, S.L., and R.H. French. 1998. Evaluation of Recharge Potential at Crater U5a (WISHBONE), DOE/NV/11508-32, Publ. No. 45160. Las Vegas, NV: Desert Research Institute.

Howard, N. 1976. Site Characteristic Summary for U5b and U5e Projected from Ue5n, AGTG 76-25. Livermore, CA: Lawrence Livermore National Laboratory.

Hudson, M.R. 1997. Structural Geology of the French Peak Accommodation Zone, Nevada Test Site, Southwestern Nevada. U.S. Geological Survey Open File Report 97-56.

International Atomic Energy Agency. 1998. The Radiological Situation at the Atolls of Mururoa and Fangataufa, Technical Report, Volume 3: Inventory of Radionuclides Underground at the Atolls, IAEA-MFTR-3. In "Proceedings of an IAEA Conference, Vienna, 30 June - 3 July." Vienna, Austria.

Istok, J.D., D.O. Blout, L. Barker, K.R. Johnejack, and D.P. Hammermeister. 1994. "Spatial Variability in Alluvium Properties at a Low-Level Nuclear Waste Site." In Soil Scientists Society of America, Vol. 58: 1040-1051.

IT Corporation. 1996a. Groundwater Flow Model Documentation Package (Phase I Data Analysis Documentation, Volume VI), ITLV/10972-181. Prepared for the U.S. Department of Energy, Nevada Operations Office. Las Vegas, NV.

IT Corporation. 1996b. Groundwater Recharge and Discharge Data Documentation Package (Phase I Data Analysis Documentation, Volume III), ITLV/10972-181. Prepared for the U.S. Department of Energy, Nevada Operations Office. Las Vegas, NV.

IT Corporation. 1996c. Hydrologic Parameter Data Documentation Package (Phase I Data Analysis Documentation, Volume IV), ITLV/10972-181. Prepared for the U.S. Department of Energy, Nevada Operations Office. Las Vegas, NV.

IT Corporation. 1996d. Potentiometric Data Documentation Package (Phase I - Data Analysis Documentation, Volume II), ITLV/10972-181. Prepared for the U.S. Department of Energy, Nevada Operations Office. Las Vegas, NV.

IT Corporation. 1996e. Regional Geologic Model Documentation Package (Phase I Data Analysis Documentation, Volume I, Parts 1 and 2), ITLV/10972-181. Prepared for the U.S. Department of Energy, Nevada Operations Office. Las Vegas, NV. 
IT Corporation. 1996f. Transport Parameter and Source Term Data Documentation Package (Phase 1, Data Analysis Documentation, Volume V). Prepared for the U.S. Department of Energy, Nevada Operations Office. Las Vegas, NV.

IT Corporation. 1996g. Tritium Transport Model Documentation Package (Phase 1 Data Analysis Documentation, Volume VII). Prepared for the U.S. Department of Energy, Nevada Operations Office. Las Vegas, NV.

IT Corporation. 1996h. Wells ER-6-1 and ER-6-2 Core Fracture Analyses and Geophysical Log Comparisons, ITLV/10972-171. Las Vegas, NV.

IT Corporation. 1997a. Risk Assessment Documentation Package (Phase I Data Analysis Documentation, Volume VIII). Prepared for U.S. Department of Energy, Nevada Operations Office. Las Vegas, NV.

IT Corporation. 1997b. Value of Information Analysis Corrective Action Unit No. 98 for Frenchman Flat, ITLV/10972-192. Las Vegas, NV.

IT Corporation. 1998a. Corrective Action Unit Modeling Approach for the Underground Test Area, Nevada Test Site, Nye County, Nevada, DOE/NV/13052-501. Las Vegas, NV.

IT Corporation. 1998b. Report and Analysis of the BULLION Forced-Gradient Experiment, ITLV/13052-042. Las Vegas, NV.

IT Corporation. 1998c. Summary of Micrographic Analysis of Fracture Coating Phases on Drill Cores from Pahute Mesa, Nevada Test Site, DOE/NV13052--050. Prepared for the U.S. Department of Energy. Las Vegas, NV.

IT Corporation. 1998d. Underground Test Area Subproject, Corrective Action Unit 98: Frenchman Flat Data Analysis Task, Volume I - Hydrostratigraphic Model Documentation Package, ITLV/13052-044. Las Vegas, NV.

IT Corporation. 1999a. External Peer Review Group Report on Frenchman Flat Data Analysis and Modeling Task, Underground Test Area Project, ITLV/13052--077. Las Vegas, NV.

IT Corporation. 1999b. Underground Test Area Project Corrective Action Unit 98: Frenchman Flat, Vol. II - Groundwater Data Documentation Package, Rev. 0, DOE/NV/13052-044-V2.

Las Vegas, NV.

IT Corporation. 2000a. Frenchman Flat Hydrogeologic Investigation Wells Drilling and Completion Criteria, ITLV/13052--094. Las Vegas, NV.

IT Corporation. 2000b. Lessons Learned from the Frenchman Flat Corrective Action Groundwater Flow and Radionuclide Transport Model, ITLV/13052--121. Las Vegas, NV. 
IT Corporation. 2001. Addendum to the Frenchman Flat Hydrogeologic Investigation Wells Drilling and Completion Criteria, ITLV/13052-094-Rev. 1-ADD. Prepared for the U.S. Department of Energy, National Nuclear Security Administration Nevada Operations Office. Las Vegas, NV.

IT Corporation. 2002. Integrated Data Report for the Multiple-Well Aquifer Test at Frenchman Flat Well Cluster ER-5-3. Las Vegas, NV.

IT Corporation. 2003. Written communication. Subject: Frenchman Flat ER-5-4 \#2 Well Data Report, Rev. 0. Las Vegas, NV.

Johnson, R.H. 1968. U.S. Geological Survey Tracer Study, Amargosa Desert, Nye County, Nevada. Part I: Exploratory Drilling, Tracer Well Construction and Testing, and Preliminary Findings, USGS Open-File Report. Washington, DC: U.S. Geological Survey.

Johnson, G.W., G.T. Pelsor, R.G. Preston, and C.E. Violet. 1958. The Underground Nuclear Detonation of September 19, 1957, Rainier, Operation Plumbbob, UCRL-5124. Livermore, CA: University of California Radiation Laboratory, Livermore Site.

Jones, B.F. 1982. Mineralogy of Fine Grained Alluvium from Borehole U11G, Expl. 1, Northern Frenchman Flat Area, Nevada Test Site, USGS-OFR-82-765. Denver, CO: U.S. Geological Survey, U.S. Department of Energy, Nevada Operations Office.

Kersting, A.B., and P.W. Reimus. 2003. Colloid-Facilitated Transport of Low-Solubility Radionuclides: A Field, Experimental, and Modeling Investigation, UCRL-ID-149688. Livermore, CA: Lawrence Livermore National Laboratory and Los Alamos, NM: Los Alamos National Laboratory.

Kersting, A.B., D.L. Finnegan, A.F.B. Tompson, B.K. Esser, D.K. Smith, M. Zavarin, C.J. Bruton, and G.A. Pawloski. 2003. Radionuclide Decay and In-growth Technical Basis Document, UCRL-ID-153798. Livermore, CA: Lawrence Livermore National Laboratory.

Kirchoff-Stein, K.S., D.A. Ponce, and B.A. Chuchel. 1989. Preliminary Aeromagnetic Map of the Nevada Test Site and Vicinity, Nevada. U.S. Geological Survey Open File Report 89-446, scale: $1: 100,000$.

Kwicklis, E.M., F. Thamir, R.W. Healy, and D. Hampson. 1998. Numerical Simulation of Air-and Water-flow Experiments in a Block of Variably Saturated, Fractured Tuff from Yucca Mountain, Nevada, USGS Water-Resource Investigations Report 97-4274. Denver, CO.

Laczniak, R.J., J.C. Cole, D.A. Sawyer, and D.A. Trudeau. 1996. Summary of Hydrogeologic Controls on the Movement of Groundwater at the Nevada Test Site, Nye County, Nevada. U.S. Geological Survey, Water-Resources Investigations Report 96-4109. Carson City, NV. 
Laczniak, C.M. Menges, J.C. Yount, and A.S. Jayko. 1999a. Digital Geologic Map of the Nevada Test Site and Vicinity, Nye, Lincoln, and Clark Counties, Nevada, and Inyo County, California, USGS-OFR-99-554-A. Denver, CO: U.S. Geological Survey.

Laczniak, R.J., G.A. DeMeo, S.R. Reiner, J.L. Smith, and W.E. Nylund. 1999b. Estimates of Ground-Water Discharge as Determined from Measurements of Evapotranspiration, Ash Meadows Area, Nye County, Nevada, Water-Resources Investigations Report 99-4079. Carson City, NV: U.S. Geological Survey.

Laczniak, R.J., J.L. Smith, P.E. Elliott, G.A. DeMeo, M.A. Chatigny, and G. Roemer. 2001. Ground-Water Discharge as Determined from Estimates of Evapotranspiration, Death Valley Regional Flow System, Nevada and California, Water-Resources Investigations Report 01-4195. Carson City, NV: U.S. Geological Survey.

Lawrence Livermore National Laboratory. 1999. Evaluation of the Hydrologic Source Term from Underground Nuclear Tests in Frenchman Flat at the Nevada Test Site: The CAMBRIC Test, UCRL-ID-132300. Livermore, CA.

Mehta, M.M., V.S. Gupta, and W.H. Somerton. 1964. Changes in Physical Properties of Rocks in the Vicinity of an Underground Nuclear Explosion, UCRL-13105. Livermore, CA: Lawrence Livermore National Laboratory.

Meyer, G.L., and R.A. Young. 1962. Summary of Hydraulic Data and Abridged Log for Ground-Water Test Well 3, Frenchman Flat, Nevada Test Site, Nevada, USGS NTS-30, Technical Letter. Denver, CO: U.S. Geological Survey.

Miller, C.H., and D.L. Healey. 1986. Gravity Interpretation of Frenchman Flat and Vicinity, NTS. U.S. Geological Survey Open File Report 86-211.

Miller, C.H., G.L. Dixon, W.J. Carr, and F.M. Byers, Jr. 1967. Geologic and Geophysical Logs of Exploratory Hole Ue-11c, Nevada Test Site, USGS NTS-190, Technical Letter. Denver, CO: U.S. Geological Survey.

Nimz, G.J., and J.L. Thompson. 1992. Underground Radionuclide Migration at the Nevada Test Site, DOE/NV-346. Las Vegas, NV: Reynolds Electrical \& Engineering Co., Inc.

Oberlander, P.L. 2001. Letter Report: Hydraulic Conductivity Profile with Depth for Monitor Wells ER-5-3, ER-5-3 \#2, and ER-5-4. Reno, NV: Desert Research Institute.

Oberlander, P.L. 2003. Hydraulic Conductivity Profile with Depth for Well ER-5-4 \#2. Las Vegas, NV: Desert Research Institute.

Papelis, C., and W. Um. 2003. Evaluation of Cesium, Strontium, and Lead Sorption, Desorption, and Diffusion in Volcanic Tuffs from Frenchman Flat, Nevada Test Site: Macroscopic and Spectroscopic Investigations, DOE/NV/13609-18; DRI Publication No. 45189. Las Vegas, NV. 
Pawloski, G.A. 1999. Development of Phenomenological Models of Underground Nuclear Tests on Pahute Mesa, Nevada Test Site--BENHAM and TYBO, UCRL-ID-136003. Livermore, CA: Lawrence Livermore National Laboratory.

Pawloski, G.A., A.F.B. Tompson, and S.F. Carle. 2001. Evaluation of the Hydrologic Source Term from Underground Nuclear Tests on Pahute Mesa at the Nevada Test Site: CHESHIRE Test, UCRL-ID-147023. Livermore, CA: Lawrence Livermore National Laboratory.

Phelps, G.A., and S.E. Graham. 2002. Preliminary Gravity Inversion Model of Frenchman Flat Basin, Nevada Test Site, Nevada, U.S. Geological Survey Open-File Report 02-363.

Phelps, G.A., V.E. Langenheim, and R.C. Jachens. 1999. Thickness of Cenozoic Deposits of Yucca Flat Inferred from Gravity Data, Nevada Test Site, Nevada, USGS-OFR-99-0310.

Menlo Park, CA: U.S. Geological Survey.

Phelps, G.A., L. Justet, B.C. Moring, and C.W. Roberts. 2005. A Preliminary Investigation of the Structure of Southern Yucca Flat, Massachusetts Mountain, and CP Basin, Nevada Test Site, Nevada, Based on Geophysical Modeling, U.S. Geological Survey Open-File Report (in press).

Ponce, D.A. 1997. Gravity Data of Nevada, DDS-0042, CD-ROM. Denver, CO: U.S. Geological Survey.

Ponce, D.A. 1999. Digital Aeromagnetic Map of the Nevada Test Site Area, Nye, Lincoln, and Clark Counties, Nevada and Inyo County, California, U.S. Geological Survey Open File Report 99-55413, CD-ROM, scale 1:100,000.

Ponce, D.A., E.A. Mankinen, J.G. Davidson, R.L. Morin, and R.J. Blakely. 1999. Digital Isostatic Gravity Map of the Nevada Test Site Area, Nye, Lincoln, and Clark Counties, Nevada and Inyo County, California, U.S. Geological Survey Open File Report 99-554c, CD-ROM, scale 1:100,000.

Poole, F.G. 1965. Geologic Map of the Frenchman Flat Quadrangle, Nye, Lincoln, and Clark Counties, Nevada, U.S. Geological Survey Geologic Quadrangle Map GC-456, scale 1:24,000.

Poole, F.G., F.N. Houser, and P.P. Orkild. 1961. Eleana Formation of Nevada Test Site and Vicinity, Nye County, Nevada, U.S. Geological Survey Professional Paper 424-D, pp. D104-D111.

Poole, F.G., R.E. Davis, and J.R. Ege, and D.L. Hoover. 1963. Geology of a Strip Between Cane Spring Road and Mara Wash, Nevada Test Site, U.S. Geological Survey Technical Letter NTS-52.

Poole, F.G., D.P. Elston, and W.J. Carr. 1965. Geologic Map of the Cane Spring Quadrangle, Nye County, Nevada, U.S. Geological Survey Geologic Quadrangle Map GQ-455, scale 1:24,000. 
Prather, T.L. 1965. Preliminary Summary of Lithologic and Hydrologic Data from the UE5f Exploratory Drill Hole, Frenchman Flat, Nevada Test Site, Technical Letter: NTS-133. Denver, CO: U.S. Geological Survey.

Prothro, L.B., and S.L. Drellack, Jr. 1997. Review and Reconnaissance of the Hydrogeology of Tertiary Sedimentary Rocks in the Vicinity of Frenchman Flat, Nevada Test Site, DOE/NV/11718-155. Las Vegas, NV: Bechtel Nevada.

Ramspott, L.D., and R.D. McArthur. 1977. Results of the Exploratory Drill Hole Ue5n, Frenchman Flat, Nevada Test Site, UCID-17392. Livermore, CA: Lawrence Livermore National Laboratory.

Reimus, P.W., S.D. Ware, N. Lu, A. Abdel-Fattah, K.S. Kung, and M.P. Neu. 2001. FY2001 Progress Report on Colloid-Facilitated Plutonium Transport in Fractured Rocks from Pahute Mesa, Nevada Test Site, ERD.011004.0001. Los Alamos, NM: Los Alamos National Laboratory.

Reimus, P.W., S.D. Ware, N. Lu, K.S. Kung, A. Abdel-Fattah, I. Anghel, M.P. Neu, and S.D. Reilly. 2002a. "Chapter 7 - Colloid-Facilitated Plutonium Fracture Transport Experiments." In Colloid-Facilitated Transport of Low-Solubility Radionuclides: A Field, Experimental, and Modeling Investigation, UCRL-ID-149688. Livermore, CA: Lawrence Livermore National Laboratory and Los Alamos, NM: Los Alamos National Laboratory.

Reimus, P.W., S.D. Ware, F.C. Benedict, R.G. Warren, A. Humphrey, A. Adams, B. Wilson, and D. Gonzales. 2002b. Diffusive and Advective Transport of ${ }^{3} \mathrm{H},{ }^{14} \mathrm{C}$, and ${ }^{99} \mathrm{Tc}$ in Saturated, Fractured Volcanic Rocks from Pahute Mesa, Nevada, LA-13891-MS. Los Alamos, NM: Los Alamos National Laboratory.

Reimus P.W., M. Murrell, A. Abdel-Fattah, E. Garcia, D. Norman, S. Goldstein, A. Nunn, R. Gritzo, and B. Martinez. 2006. Colloid Characteristics and Radionuclide Associations with Colloids in Near-Field Waters at the Nevada Test Site (FY2005 Progress Report), LA-UR-05-8612. Los Alamos, NM: Los Alamos National Laboratory.

Reiner, S. 2002. Aquifer-Test Report for WW-4A, Area 6, Nevada Test Site. Carson City, NV: U.S. Geological Survey.

Reiner, S. 2003. Aquifer-Test Report for WW-5C, Area 5, Nevada Test Site. Carson City, NV: U.S. Geological Survey.

Reiner, S.R., G.L. Locke, and L.S. Robie. 1995. Ground-Water Data for the Nevada Test Site and Selected Other Areas in South-Central Nevada, 1992-1993, USGS Open File Report 95-160. Denver, CO: U.S. Geological Survey.

Reynolds Electrical \& Engineering Co., Inc. 1993a. Hydrogeologic Data for Existing Excavations at the Area 5 Radioactive Waste Management Site, Nevada Test Site, Nye County, Nevada, DOE/NV/11432-40, UC 721. Las Vegas, NV. 
Reynolds Electrical \& Engineering Co., Inc. 1993b. Hydrogeologic Data for Science Trench Boreholes at the Area 5 Radioactive Waste Management Site, Nevada Test Site, Nye County, Nevada, DE-AC08-94-NV11432, UC 721. Las Vegas, NV.

Reynolds Electrical \& Engineering Co., Inc. 1994. Site Characterization and Monitoring Data from Area 5 Pilot Wells, Nevada Test Site, Nye County, Nevada, DOE/NV-11432-74. Las Vegas, NV.

Rose, T. 2003a. Isotopic Analyses: Environmental Monitoring Well ER-5-3. Livermore, CA: Lawrence Livermore National Laboratory.

Rose, T. 2003b. Isotopic Analyses: Environmental Monitoring Well ER-5-3\#2. Livermore, CA: Lawrence Livermore National Laboratory.

Rose, T. 2003c. Isotopic Analyses: Environmental Monitoring Well ER-5-4. Livermore, CA: Lawrence Livermore National Laboratory.

Rose, T. 2003d. Isotopic Analyses: Environmental Monitoring Well ER-5-4\#2. Livermore, CA: Lawrence Livermore National Laboratory.

Rose, T.P., D.K. Smith, and J.K. Werner, Jr. 2000. "Lithologic, Mineralogic, and Petrographic Characterization of Alluvium from the U-1a 102C and 102D Drifts of the U-1a Tunnel Complex, Nevada Test Site." In Hydrologic Resources Management Program and Underground Test Area FY 1999 Progress Report, UCRL-ID-139226, 77-110. D.K. Smith and G.F. Eaton eds. Livermore, CA: Lawrence Livermore National Laboratory.

Rose, T.P., F.C. Benedict, J.M Thomas, W.S. Sicke, R.L. Hershey, J.B. Paces, I.M. Farnham, and Z.E. Peterman. 2002. Geochemical Data Analysis and Interpretation of the Pahute Mesa - Oasis Valley Groundwater Flow System, Nye County, Nevada. Lawrence Livermore National Laboratory.

Rose, T.P., G.F. Eaton, and A.B. Kersting eds. 2003. Hydrologic Resources Management Program and Underground Test Area Project FY2001-2002 Progress Report, UCRL-ID-154357. Livermore, CA: Lawrence Livermore National Laboratory.

Rose, T.P., G.F. Eaton, and A.B. Kersting eds. 2004. Hydrologic Resources Management Program and Underground Test Area Project FY2003 Progress Report, UCRL-ID-206661. Livermore, CA: Lawrence Livermore National Laboratory.

Ross, W.C., and S.A. Wheatcraft. 1999. A Two-Dimensional Simulation and Tritium Transport in the Vadose Zone at the Nevada Test Site, DOE/NV/10162-21, Publication No. 45098. Las Vegas, NV: Desert Research Institute. 
Russell, C.E., and T. Minor. 2002. Reconnaissance Estimates of Recharge Based on an Elevation-dependent Chloride Mass-balance Approach, DOE/NV/11508-37, Publication No. 45164. Prepared for the U.S. Department of Energy, National Nuclear Security Administration Nevada Operations Office. Las Vegas, NV: Desert Research Institute.

Shott, G.J., C.J. Muller, L.E. Barker, D.E. Cawlfield, F.T. Lindstrom, D.G. Linkenheil, M.J. Sully, L. McDowell-Boyer, and D.J. Thune. 1995. Performance Assessment for the Area 5 Radioactive Waste Management Site at the Nevada Test Site, Nye County, Nevada, DOE/NV/11432-196.

Slate, J.L., M.E. Berry, P.D. Rowley, C.J. Fridrich, K. S. Morgan, J.B. Workman, O.D. Young, G.L. Dixon, V.S. Williams, E.H. McKee, D.A. Ponce, T.G. Hildenbrand, W.C. Swadley, S.C. Lundstrom, E.B. Ekren, R.G. Warren, J.C. Cole, R.J. Fleck, M.A. Lanphere, D.A. Sawyer, S.A. Minor, D.J. Grunwald, R.J. Laczniak, C.M. Menges, J.C. Yount, and A.S. Jayko. 1999. Digital Geologic Map of the Nevada Test Site and Vicinity, Nye, Lincoln, and Clark Counties, Nevada, and Inyo County, California. U.S. Geological Survey Open-File Report 99-554-A, scale 1:120,000.

Stoller-Navarro Joint Venture. 2004a. Integrated Analysis Report for Single and Multiple-Well Aquifer Testing at Frenchman Flat Well Cluster RNM-2s, Nevada Test Site, Nevada, S-N/99205-029, Rev. 0. Las Vegas, NV.

Stoller-Navarro Joint Venture. 2004b. Interpretation of Hydraulic Test and Multiple-Well Aquifer Test Data at Frenchman Flat Well Cluster ER-5-3, S-N/99205--028. Prepared for the U.S. Department of Energy, National Nuclear Security Administration Nevada Site Office. Las Vegas, NV.

Stoller-Navarro Joint Venture. 2004c. Phase II Hydrologic Data for the Groundwater Flow and Contamination Transport Model of CAU Unit 98: Frenchman Flat, Nye County, Nevada, S-N/99205-032, Revision 0. Las Vegas, NV.

Stoller-Navarro Joint Venture. 2004d. The Role of Dispersion in Radionuclide Transport-Data and Modeling Requirements, S-N/99205-003; Shaw/13052-200. Las Vegas, NV.

Stoller-Navarro Joint Venture. 2004e. Transferability of Data Related to the Underground Test Area Project, Nevada Test Site, Nye County, Nevada, Rev. 0, S-N/99205--020. Las Vegas, NV.

Stoller-Navarro Joint Venture. 2004f. Written communication. Subject: Interpretation of Hydraulic Test and Multiple-Well Aquifer Test Data at Frenchman Flat Well Cluster ER-5-3. Las Vegas, NV.

Stoller-Navarro Joint Venture. 2005a. Analysis of Hydraulic Responses from the ER-6-1 Multiple-Well Aquifer Test, Yucca Flat FY 2004 Testing Program, Nevada Test Site, Nye County, Nevada, Rev. 0, S-N/99205--051. Las Vegas, NV. 
Stoller-Navarro Joint Venture. 2005b. Analysis of Well ER-6-2 Testing, Yucca Flat FY 2004 Testing Program, Nevada Test Site, Nye County, Nevada, Rev. 0, S-N/99205--053. Las Vegas, NV.

Stoller-Navarro Joint Venture. 2005c. Geochem05.mdb and A User's Guide to the Comprehensive Water Quality Database for Groundwater in the Vicinity of the Nevada Test Site, Rev. 0, S-N/99205--059. Las Vegas, NV.

Stoller-Navarro Joint Venture. 2005d. Phase II Contaminant Transport Parameters for the Groundwater Flow and Contaminant Transport Model of Corrective Action Unit 98: Frenchman Flat, Nye County, Nevada, S-N/99205--043. Prepared for the U.S. Department of Energy. Las Vegas, NV.

Stoller-Navarro Joint Venture. 2005e. Unclassified Source Term and Radionuclide Data for Corrective Action Unit 98: Frenchman Flat Nevada Test Site, Nevada, S-N/99205--058. Las Vegas, NV.

Stoller-Navarro Joint Venture. 2005f. Underground Test Area Fracture Analysis Report for Frenchman Flat Well Clusters ER-5-3 and ER-5-4, Nevada Test Site, Nevada, S-N/99205--060. Las Vegas, NV.

Stoller-Navarro Joint Venture. 2005g. Written communication. Subject: Unclassified Source Term and Radionuclide Data for Corrective Action Unit 98: Frenchman Flat, Nevada. Las Vegas, NV.

Stoller-Navarro Joint Venture. 2006a. Digital Orthophoto of the CAMBRIC Site 1994, Nevada Test Site. Las Vegas, NV.

Stoller-Navarro Joint Venture. 2006b. Phase II Groundwater Flow Model of Corrective Action Unit 98: Frenchman Flat, Nevada Test Site, Nye County, Nevada, S-N/99205--074. Las Vegas, NV.

Stoller-Navarro Joint Venture. 2006c. Well ER-6-1 Tracer Test Analysis: Yucca Flat, Nevada Test Site, Nye County, Nevada, S-N/99205--084. Las Vegas, NV.

Thomas, J.M., F.C., Jr. Benedict, T.P. Rose, R.L. Hershey, J.B. Paces, Z.E. Peterman, I.M. Farnham, K.H. Johannesson, A.K. Singh, K.J. Stetzenbach, G.B. Hudson, J.M. Kenneally, G.F. Eaton, and D.K. Smith. 2002. Geochemical and Isotopic Interpretations of Groundwater Flow in the Oasis Valley Flow System, Southern Nevada, Water Resources Center, Publication 45190.

Las Vegas, NV: Desert Research Institute.

Thompson, J.L. 1995. Radionuclide Distribution in a Nuclear Test Cavity: The Baseball Event, LA-UR-95-744. Los Alamos, NM: Los Alamos National Laboratory. 
Tompson, A.F.B., C.J. Bruton, and G.A. Pawloski eds. 1999. Evaluation of the Hydrologic Source Term from Underground Nuclear Tests in Frenchman Flat at the Nevada Test Site: The CAMBRIC Test, UCRL-ID-132300. Prepared for the U.S. Department of Energy, Nevada Operations Office. Livermore, CA: Lawrence Livermore National Laboratory.

Tompson, A.F.B., D.K. Smith, and G.B. Hudson. 2002. Analysis of Radionuclide Migration through a 200-m Vadose Zone following a 16-Year Infiltration Event, UCRL-ID-146979. Livermore, CA: Lawrence Livermore National Laboratory.

Tompson, A.F.B., A.B. Kersting, D.L. Finnegan, B.K. Esser, D.K. Smith, M. Zavarin, C.J. Bruton, and G.A. Pawloski. 2003. Radionuclide Decay and In-Growth Technical Basis Document, UCRL-ID-153798. Livermore, CA: Lawrence Livermore National Laboratory.

Tompson, A.F.B., M. Zavarin, C.J. Bruton, and G.A. Pawloski. 2004. Methods for Calculating a Simplified Hydrologic Source Term for Frenchman Flat Sensitivity Studies of Radionuclide Transport Away from Underground Nuclear Tests, UCRL-TR-201817. Livermore, CA: Lawrence Livermore National Laboratory.

Tompson, A.F.B., S.F. Carle, R.M. Maxwell, G. Pawloski, and M. Zavarin. 2005. Evaluation of the Non-Transient Hydrologic Source Term from the CAMBRIC Underground Nuclear Test in Frenchman Flat, Nevada Test Site, UCRL-TR-217191. Livermore, CA: Lawrence Livermore National Laboratory.

Tonkin, M., and J. Doherty. 2009. “Calibration-Constrained Monte Carlo Analysis of Highly Parameterized Models Using Subspace Techniques." In Water Resources Research, Vol. 45, W00B10, doi:10.1029/2007WR006678.

Triay, I.R., A. Meijer, J.L. Conca, K.S. Kung, R.S. Rundberg, and E.A. Strietelmeier. 1997. Summary and Synthesis Report on Radionuclide Retardation for the Yucca Mountain Site Characterization Project, Draft, Milestone 3784. Los Alamos, NM: Los Alamos National Laboratory.

TRW Environmental Safety Systems, Inc. 2000. Unsaturated Zone Flow and Transport Process Model Report, TDR-NBS-HS-000002, REV00 ICN02. Las Vegas, NV: Civilian Radioactive Waste Management System, Management \& Operating Contractor.

U.S. Department of Energy, National Nuclear Security Administration Nevada Operations Office. 2001. Addendum to Revision 1 of the Corrective Action Investigation Plan for Corrective Action Unit 98: Frenchman Flat, Nevada Test Site, Nevada, Rev. 1, DOE/NV--478 REV. 1-ADD. Las Vegas, NV.

U.S. Department of Energy, National Nuclear Security Administration Nevada Site Office. 2005a. Well Completion Report for Well Cluster ER-5-3, DOE/NV/11718--1093. Prepared by Bechtel Nevada. Las Vegas, NV. 
U.S. Department of Energy, National Nuclear Security Administration Nevada Site Office. $2005 \mathrm{~b}$. Well Completion Report for Well Cluster ER-5-4, DOE/NV/11718--998. Prepared by Bechtel Nevada. Las Vegas, NV.

U.S. Department of Energy, Nevada Operations Office. 1997a. Regional Groundwater Flow and Tritium Transport Modeling and Risk Assessment of the Underground Test Area, Nevada Test Site, Nevada, DOE/NV--477, UC-700. Las Vegas, NV.

U.S. Department of Energy, Nevada Operations Office. 1997b. Shaft and Tunnel Nuclear Detonations at the Nevada Test Site: Development of a Primary Database for the Estimation of Potential Interactions with the Regional Groundwater System, DOE/NV--464 UC-700. Las Vegas, NV.

U.S. Department of Energy, Nevada Operations Office. 1999. Corrective Action Investigation Plan for Corrective Action Unit 98: Frenchman Flat, Nevada Test Site, Nevada, DOE/NV--478, Rev. 1. Las Vegas, NV.

U.S. Department of Energy, Nevada Operations Office. 2000a. Addendum to the Corrective Action Investigation Plan for Corrective Action Unit 98: Frenchman Flat, Nevada Test Site, Nevada, Addendum Rev. 0, DOE/NV--478 REV. 1-ADD. Las Vegas, NV.

U.S. Department of Energy, Nevada Operations Office. 2000b. United States Nuclear Tests, July 1945 through September 1992, DOE/NV-209, Revision 15. Las Vegas, NV.

U.S. Department of Energy, Office of Civilian Radioactive Waste Management, Office of Repository Development. 2001. Unsaturated Zone and Saturated Zone Transport Properties (U0100), ANL-NBS-HS-000019, Rev. 0, ICN 02. Las Vegas, NV.

U.S. Geological Survey. 2007. Mercury Core Library \& Data Center; Rock-Property Database. As accessed at http://nevada.usgs.gov/mercury/rock.html on 24 February.

Viani, B. 2006. Compilation of Partition Coefficients $\left(K_{d}\right)$ Applicable to Modeling Transport in the Basalt Lava Flow Aquifer Hydrostratigraphic Unit, 23 July. Livermore, CA: Lawrence Livermore National Laboratory.

Warren, R.G., F.C. Benedict Jr., T.P. Rose, D.K. Smith, S.J. Chipera, E.C. Kluk, and K.M. Raven. 2002. Alluvial Layering and Distribution of Reactive Phases within Drill Holes ER5/4 and UE5N of Frenchman Flat, LA-UR-02-6206. Los Alamos, NM: Los Alamos National Laboratory.

Warren, R.G., D.A. Sawyer, F.M. Byers, Jr., and J.C. Cole. 2003. A Petrographic, Geochemical and Geophysical Database, and Stratigraphic Framework for the Southwestern Nevada Volcanic Field, LA-UR-03-1503 as accessed at http://library.lanl.gov/cgi-bin/getfile?00852283.pdf on 6 December 2007. Los Alamos, NM: Los Alamos National Laboratory. 
Winograd, I.J., and W. Thordarson. 1975. Hydrogeologic and Hydrochemical Framework, South-Central Great Basin, Nevada-California, with Special Reference to the Nevada Test Site, Professional Paper 712-C. Denver, CO: U.S. Geological Survey.

Wolfsberg, A., L. Glascoe, G. Lu, A. Olson, P. Lichtner, M. McGraw, T. Cherry, and G. Roemer. 2002. TYBO/BENHAM Model Analysis of Groundwater Flow and Radionuclide Migration from Underground Nuclear Tests in Southwestern Pahute Mesa, NTS, LA-13977. Los Alamos, NM: Los Alamos National Laboratory.

Young, R.A., U.S. Geological Survey. 1972. Water Supply for the Nuclear Rocket Development Station at the U.S. Atomic Energy Commission's Nevada Test Site, USGS Water-Supply Paper 1938. Washington, DC.

Zavarin, M., and C.J. Bruton. 2004a. A Non-Electrostatic Surface Complexation Approach to Modeling Radionuclide Migration at the Nevada Test Site: I. Iron Oxides and Calcite, UCRL-TR-208673. 6 June. Livermore, CA: Lawrence Livermore National Laboratory

Zavarin, M., and C.J. Bruton. 2004b. A Non-Electrostatic Surface Complexation Approach to Modeling Radionuclide Migration at the Nevada Test Site: II. Aluminosilicates, UCRL-TR-208672. 6 June. Livermore, CA: Lawrence Livermore National Laboratory.

Zavarin, M., S.K. Roberts, T.P. Rose, D.L. Phinney. 2002. Validating Mechanistic Sorption Model Parameters and Process for Reactive Transport in Alluvium, UCRL-ID-149728.

Livermore, CA: Lawrence Livermore National Laboratory.

Zavarin, M., S.K. Roberts, P. Zhao, R.W. Williams, T.P. Rose, A. Rainer, and G.A. Pawloski. $2004 a$. High-Temperature Studies of Glass Dissolution Rates Close to Saturation, UCRL-TR-204874. Livermore, CA: Lawrence Livermore National Laboratory.

Zavarin, M., S.K. Roberts, B.E. Viani, G.A. Pawloski, and T.P. Rose. 2004b. Nuclear Melt Glass Dissolution and Secondary Mineral Precipitation at 40 to 200C, UCRL-TR-204870.

Livermore, CA: Lawrence Livermore National Laboratory.

Zavarin, M., S.F. Carle, and R.M. Maxwell. 2004c. Upscaling Radionuclide Retardation - Linking the Surface Complexation and Ion Exchange Mechanistic Approach to a Linear $K_{d}$ Approach, UCRL-TR-204713. Livermore, CA: Lawrence Livermore National Laboratory. 
Appendix C

CAU Model Naming Conventions and Comparison Table 


\section{C.1.0 InTROduction}

The Phase II CAI for Frenchman Flat incorporated many different HFMs and recharge models to produce calibrated models of groundwater flow that could be used for transport calculations. Phase II reports use a shorthand in the form of the HFM variant-recharge model to designate these models. Thus, the BASE-USGSD model uses the BASE HFM with the USGSD recharge model. Table C.1-1 describes the HFMs, and Table C.1-2 provides the four recharge models as described in SNJV (2006) that were used for groundwater flow models. The flow model calibration statistics and general remarks are in Table C.1-3.

Table C.1-1

Summary of HFMs

\begin{tabular}{|c|c|c|}
\hline Model Name & $\begin{array}{c}\text { Key Difference(s) } \\
\text { Compared to BASE Model }\end{array}$ & Potential Impacts on Flow and Transport Model \\
\hline Base (BASE) & $\mathrm{N} / \mathrm{A}$ & $\begin{array}{l}\text { Best interpretation of geological information available for } \\
\text { Frenchman Flat. Considered the baseline structural } \\
\text { interpretation that reflects the integrated knowledge of } 50 \text { of } \\
\text { basin characterization. }\end{array}$ \\
\hline $\begin{array}{l}\text { Basalt Lava-Flow Aquifer } \\
\text { (BLFA) }\end{array}$ & $\begin{array}{l}\text { The BLFA HSU is modeled } \\
\text { as a single continuous flow, } \\
\text { rather than three } \\
\text { separate zones. }\end{array}$ & $\begin{array}{l}\text { Located at or near the water table, which may affect flow and } \\
\text { transport of radionuclides away from underground nuclear } \\
\text { tests in the Northern Testing Area. Conceptually, the BLFA is } \\
\text { a fractured rock; thus, fracture/matrix processes are acting } \\
\text { over a larger area. This alternative primarily affects the MILK } \\
\text { SHAKE test, which overlies the BLFA. }\end{array}$ \\
\hline $\begin{array}{l}\text { Detachment Fault } \\
\text { (DETA) }\end{array}$ & $\begin{array}{l}\text { This alternative is a no } \\
\text { detachment fault model. }\end{array}$ & $\begin{array}{l}\text { In this alternative, removing the fault eliminates potential } \\
\text { hydrologic consequences of volcanic unit offsets across the } \\
\text { fault. Volcanic rocks were modeled as dipping moderately } \\
\text { southward from Area } 11 .\end{array}$ \\
\hline $\begin{array}{l}\text { Displacement Fault } \\
\text { (Aquifer Juxtaposition) } \\
\text { (DISP) }\end{array}$ & $\begin{array}{l}\text { This alternative is concerned } \\
\text { with the locations } \\
\text { and displacement of } \\
\text { basin-forming faults. }\end{array}$ & $\begin{array}{l}\text { This alternative juxtaposes shallow aquifers against deeper } \\
\text { aquifers, allowing a hydraulic connection between volcanic } \\
\text { aquifers underlying the AA in Frenchman Flat to carbonate } \\
\text { aquifers east and south from the Rock Valley fault system. } \\
\text { Juxtaposition removes the zeolitic LTCU and WCU from a } \\
\text { potential flow path, reducing the effects of sorption. }\end{array}$ \\
\hline $\begin{array}{l}\text { CP Thrust Fault } \\
\text { (CPBA) }\end{array}$ & $\begin{array}{l}\text { The CP basin alternative } \\
\text { extends the UCCU beneath all } \\
\text { of CP basin. }\end{array}$ & $\begin{array}{l}\text { Some uncertainty exists in the distribution of pre-Tertiary } \\
\text { HSUs, particularly the distribution of UCCU beneath CP basin. } \\
\text { This alternative results in a continuous sheet of UCCU } \\
\text { beneath CP basin. No direct transport consequences in terms } \\
\text { of materials, but broadly impacts the flow system. }\end{array}$ \\
\hline
\end{tabular}

Sources: BN, 2005; SNJV, 2005 
Table C.1-2

Recharge Models Used for Frenchman Flat Groundwater Flow Modeling

\begin{tabular}{|c|c|c|}
\hline \multirow{2}{*}{$\begin{array}{c}\text { Recharge Model } \\
\text { Dodified Maxey-Eakin from UGTA Regional Model (MME) }\end{array}$} & \multicolumn{2}{c|}{$\begin{array}{c}\text { Total Mass Flow } \\
\text { for CAU Model Area }\end{array}$} \\
\cline { 2 - 3 } & $\mathbf{k g} / \mathbf{s}$ & $\mathbf{~ m m} / \mathbf{y r}$ \\
\hline \hline DRI - Chloride Mass Balance with Alluvial Mask (DRIA) & 4.54 & 0.251 \\
\hline USGS - Rainfall-Infiltration with Redistribution (USGSD) & 8.63 & 0.478 \\
\hline USGS - Death Valley Regional Ground-Water Flow System (DVRFS) & 5.94 & 0.328 \\
\hline
\end{tabular}

Source: SNJV, 2006 
Table C.1-3

CAU Model Comparison

(Page 1 of 8)

\begin{tabular}{|c|c|c|c|c|c|c|}
\hline Model & HFM & $\begin{array}{l}\text { Recharge } \\
\text { Model }\end{array}$ & $\begin{array}{c}\text { Select } \\
\text { Calibration } \\
\text { Objective } \\
\text { Function (-) } \\
\text { Head/Flow }\end{array}$ & $\begin{array}{l}\text { Conceptual/ } \\
\text { Parametric } \\
\text { Model Tested }\end{array}$ & Flow Model Remarks & Transport Model Remarks \\
\hline $\begin{array}{l}\text { BASE-USGSD with } \\
\text { Alternative Boundary } \\
\text { Conditions }{ }^{\text {a }} \\
\text { (also referred to as } \\
\text { Alternative } \\
\text { BASE-USGSD) }\end{array}$ & BASE & USGSD & $55 / 0$ & $\begin{array}{l}\text { Boundary } \\
\text { conditions and } \\
\text { transport } \\
\text { parameters }\end{array}$ & $\begin{array}{l}\text { AA permeability } 1 \text { order of magnitude } \\
\text { lower than RNM-2S MWAT. TM-WTA } \\
\text { and TM-LVTA have nearly the same } \\
\text { permeability, which is } \\
\text { conceptually inconsistent. Average } \\
\text { agreement with geochemical data. }\end{array}$ & $\begin{array}{l}\text { Used in Central Testing Area analysis. } \\
\text { Contaminant boundary approximately } \\
\text { mid-range of models considered for } \\
\text { Northern Testing Area. }\end{array}$ \\
\hline $\begin{array}{l}\text { BASE-USGSD with } \\
\text { Alternative Boundary } \\
\text { Conditions - BLFA } \\
\text { HFM inserted a } \\
\text { (also referred to as } \\
\text { Alternative } \\
\text { BLFA-USGSD) }\end{array}$ & BLFA & USGSD & $55 / 0$ & $\begin{array}{l}\text { Boundary } \\
\text { conditions and } \\
\text { transport } \\
\text { parameters }\end{array}$ & $\begin{array}{l}\text { AA permeability } 1 \text { order of magnitude } \\
\text { lower than RNM-2S MWAT. TM-WTA } \\
\text { and TM-LVTA have nearly the same } \\
\text { permeability, which is } \\
\text { conceptually inconsistent. Average } \\
\text { agreement with geochemical data. }\end{array}$ & $\begin{array}{l}\text { Slightly larger contaminant boundary } \\
\text { than BASE-USGSD with alternative } \\
\text { boundary conditions. }\end{array}$ \\
\hline $\begin{array}{l}\text { BASE-USGSD without } \\
\text { AA/OAA Depth Decay }{ }^{a}\end{array}$ & BASE & USGSD & $230 / 164$ & $\begin{array}{l}\text { Permeability } \\
\text { depth decay and } \\
\text { transport } \\
\text { parameters }\end{array}$ & $\begin{array}{l}\text { AA permeability } 1 \text { order of magnitude } \\
\text { lower than RNM-2S MWAT - } \\
\text { sub-CAU model recalibrated to } \\
\text { RNM-2S MWAT and CAMBRIC RNM } \\
\text { experiment. AA/OAA anisotropy } \\
\text { ratios at least } 10 \text { times higher than } \\
\text { thought plausible. LTCU and VCU at } \\
\text { very low end of data. Average } \\
\text { agreement with geochemical data. }\end{array}$ & Used in Central Testing Area analysis. \\
\hline
\end{tabular}


Table C.1-3

CAU Model Comparison

(Page 2 of 8 )

\begin{tabular}{|c|c|c|c|c|c|c|}
\hline Model & HFM & $\begin{array}{l}\text { Recharge } \\
\text { Model }\end{array}$ & $\begin{array}{c}\text { Select } \\
\text { Calibration } \\
\text { Objective } \\
\text { Function (-) } \\
\text { Head/Flow }\end{array}$ & $\begin{array}{l}\text { Conceptual/ } \\
\text { Parametric } \\
\text { Model Tested }\end{array}$ & Flow Model Remarks & Transport Model Remarks \\
\hline DISP-USGSD a & DISP & USGSD & $\begin{array}{l}116 / 182 \\
{[19 / 0]^{b}}\end{array}$ & $\begin{array}{l}\text { HFM and } \\
\text { transport } \\
\text { parameters }\end{array}$ & $\begin{array}{l}\text { AA permeability } 1 \text { order of magnitude } \\
\text { lower than RNM-2S MWAT - } \\
\text { sub-CAU model recalibrated to } \\
\text { RNM-2S MWAT and CAMBRIC RNM } \\
\text { experiment. UTCU mildly less } \\
\text { permeable than LTCU. LTCU, UTCU, } \\
\text { and VCU permeabilities at lower end } \\
\text { of data range. TM-WTA and TM-LVTA } \\
\text { have the same permeability, which is } \\
\text { conceptually inconsistent. Poorer } \\
\text { agreement with geochemical data. }\end{array}$ & Used in Central Testing Area analysis. \\
\hline CPBA-USGSD a & CPBA & USGSD & $\begin{array}{l}1342 / 161 \\
{[321 / 0]^{b}}\end{array}$ & $\begin{array}{l}\text { HFM and } \\
\text { transport } \\
\text { parameters }\end{array}$ & $\begin{array}{l}\text { AA permeability } 1 \text { order of magnitude } \\
\text { lower than RNM-2S MWAT- sub-CAU } \\
\text { model recalibrated to RNM-2S MWAT } \\
\text { and CAMBRIC RNM experiment. } \\
\text { LTCU and UTCU permeabilities } \\
\text { outside or at low end of data. } \\
\text { TSA permeability at upper end of } \\
\text { data. TM-WTA similar to WW-4, -4a } \\
\text { data. Poorer agreement with } \\
\text { geochemical data. }\end{array}$ & Used in Central Testing Area analysis. \\
\hline CPBA-MME ${ }^{a}$ & CPBA & MME & $125 / 841$ & $\begin{array}{l}\text { Boundary } \\
\text { conditions and } \\
\text { transport } \\
\text { parameters }\end{array}$ & $\begin{array}{l}\text { TM-WTA and TM-LVTA have nearly } \\
\text { the same permeability, which is } \\
\text { conceptually inconsistent. Average } \\
\text { agreement with geochemical data. }\end{array}$ & Not considered for transport analysis. \\
\hline $\begin{array}{c}\text { CPBA-USGSD Central } \\
\text { Testing Area }\end{array}$ & CPBA & USGSD & & $\begin{array}{l}\text { HFM and } \\
\text { CAMBRIC RNM } \\
\text { Experiment }\end{array}$ & Model numerically unstable. & Not considered further. \\
\hline
\end{tabular}


Table C.1-3

CAU Model Comparison

(Page 3 of 8)

\begin{tabular}{|c|c|c|c|c|c|c|}
\hline Model & HFM & $\begin{array}{l}\text { Recharge } \\
\text { Model }\end{array}$ & $\begin{array}{c}\text { Select } \\
\text { Calibration } \\
\text { Objective } \\
\text { Function (-) } \\
\text { Head/Flow }\end{array}$ & $\begin{array}{l}\text { Conceptual/ } \\
\text { Parametric } \\
\text { Model Tested }\end{array}$ & Flow Model Remarks & Transport Model Remarks \\
\hline $\begin{array}{l}\text { DISP-USGSD Central } \\
\text { Testing Area }\end{array}$ & DISP & USGSD & & $\begin{array}{l}\text { HFM and } \\
\text { CAMBRIC RNM } \\
\text { Experiment }\end{array}$ & $\begin{array}{l}\text { Calibrated to RNM-2S MWAT, } \\
\text { CAMBRIC RNM experiment } \\
\text { water-level changes and tritium } \\
\text { breakthrough at UE- } 5 \mathrm{n} \text {. Ambient flow } \\
\text { conditions estimated to be } \\
\text { re-established by } 2015 \text {. }\end{array}$ & $\begin{array}{l}\text { Contaminant boundary symmetrical } \\
\text { and focused around ditch. }\end{array}$ \\
\hline $\begin{array}{l}\text { BASE-USGSD without } \\
\text { AA/OAA Depth Decay } \\
\text { Central Testing Area }\end{array}$ & BASE & USGSD & & $\begin{array}{l}\text { Permeability } \\
\text { depth decay and } \\
\text { CAMBRIC RNM } \\
\text { Experiment }\end{array}$ & $\begin{array}{l}\text { Calibrated to RNM-2S MWAT, } \\
\text { CAMBRIC RNM experiment } \\
\text { water-level changes and tritium } \\
\text { breakthrough at UE-5n. Ambient flow } \\
\text { conditions estimated to be } \\
\text { re-established by } 2015 \text {. }\end{array}$ & $\begin{array}{l}\text { Contaminant boundary symmetrical } \\
\text { and focused around ditch. }\end{array}$ \\
\hline $\begin{array}{l}\text { BASE-USGSD with } \\
\text { Alternative Boundary } \\
\text { Conditions Central } \\
\text { Testing Area } \\
\text { (also referred to as } \\
\text { Alternative } \\
\text { BASE-USGSD Central } \\
\text { Testing Area) }\end{array}$ & BASE & USGSD & & $\begin{array}{l}\text { HFM and } \\
\text { CAMBRIC RNM } \\
\text { Experiment }\end{array}$ & $\begin{array}{l}\text { Calibrated to RNM-2S MWAT, } \\
\text { CAMBRIC RNM experiment } \\
\text { water-level changes and tritium } \\
\text { breakthrough at UE-5n. Ambient flow } \\
\text { conditions estimated to be } \\
\text { re-established by } 2015 \text {. }\end{array}$ & $\begin{array}{l}\text { Contaminant boundary symmetrical } \\
\text { and focused around ditch. }\end{array}$ \\
\hline CPBA-DRIA a & CPBA & DRIA & $488 / 214$ & $\begin{array}{l}\text { Boundary } \\
\text { conditions and } \\
\text { transport } \\
\text { parameters }\end{array}$ & $\begin{array}{l}\text { TM-WTA and TM-LVTA have nearly } \\
\text { the same permeability, which is } \\
\text { conceptually inconsistent. Average } \\
\text { agreement with geochemical data. }\end{array}$ & Not considered for transport analysis. \\
\hline CPBA-DVRFS a & CPBA & DVRFS & $552 / 46$ & $\begin{array}{l}\text { Boundary } \\
\text { conditions and } \\
\text { transport } \\
\text { parameters }\end{array}$ & $\begin{array}{l}\text { TM-WTA and TM-LVTA have nearly } \\
\text { the same permeability, which is } \\
\text { conceptually inconsistent. Average } \\
\text { agreement with geochemical data. }\end{array}$ & Not considered for transport analysis. \\
\hline
\end{tabular}


Table C.1-3

CAU Model Comparison

(Page 4 of 8)

\begin{tabular}{|c|c|c|c|c|c|c|}
\hline Model & HFM & $\begin{array}{l}\text { Recharge } \\
\text { Model }\end{array}$ & $\begin{array}{c}\text { Select } \\
\text { Calibration } \\
\text { Objective } \\
\text { Function (-) } \\
\text { Head/Flow }\end{array}$ & $\begin{array}{l}\text { Conceptual/ } \\
\text { Parametric } \\
\text { Model Tested }\end{array}$ & Flow Model Remarks & Transport Model Remarks \\
\hline BLFA-USGSD a & BLFA & USGSD & $\begin{array}{c}135 / 299 \\
{[28 / 0]^{b}}\end{array}$ & $\begin{array}{l}\text { HFM and } \\
\text { transport } \\
\text { parameters }\end{array}$ & $\begin{array}{l}\text { AA permeability } 1 \text { order of magnitude } \\
\text { lower than RNM-2S MWAT. UTCU } \\
\text { mildly less permeable than LTCU. } \\
\text { LTCU, UTCU, and VCU permeabilities } \\
\text { at lower end of data range. TM-WTA } \\
\text { and TM-LVTA have the same } \\
\text { permeability, which is } \\
\text { conceptually inconsistent. Average } \\
\text { agreement with geochemical data. }\end{array}$ & Not considered for transport analysis. \\
\hline $\begin{array}{l}\text { BASE-USGSD with } \\
\text { Alternative Boundary } \\
\text { Conditions and Depth } \\
\text { Decay Floor c } \\
\text { (also referred to } \\
\text { as Floor) }\end{array}$ & BASE & USGSD & $16 / 0$ & $\begin{array}{l}\text { Boundary } \\
\text { conditions, } \\
\text { permeability } \\
\text { depth decay, } \\
\text { and transport } \\
\text { parameters }\end{array}$ & $\begin{array}{l}\text { Floor on permeability depth decay for } \\
\text { all but LCA HSUs. Good agreement } \\
\text { of AA permeability with RNM-2S } \\
\text { MWAT. Developed analog for BLFA } \\
\text { permeability from Well J-11, } \\
\text { increasing its permeability. One of } \\
\text { the worst agreements with } \\
\text { geochemical data. }\end{array}$ & Not considered for transport analysis. \\
\hline $\begin{array}{l}\text { BASE-USGSD with } \\
\text { Alternative Boundary } \\
\text { Conditions and } \\
\text { Prior Data } \\
\text { (also referred to } \\
\text { as Prior) }\end{array}$ & BASE & USGSD & $15 / 0$ & $\begin{array}{l}\text { Boundary } \\
\text { conditions, data } \\
\text { constraint, and } \\
\text { transport } \\
\text { parameters }\end{array}$ & $\begin{array}{l}\text { Prior data were added to constrain the } \\
\text { AA (from RNM-2S MWAT), BLFA } \\
\text { (from Well J-11), and TM-WTA (from } \\
\text { flow logging at ER-5-3) } \\
\text { permeability and the anisotropy } \\
\text { ratios for the basin-fill HSUs. One of } \\
\text { the worst agreements with } \\
\text { geochemical data. }\end{array}$ & Not considered for transport analysis. \\
\hline
\end{tabular}


Table C.1-3

CAU Model Comparison

(Page 5 of 8)

\begin{tabular}{|c|c|c|c|c|c|c|}
\hline Model & HFM & $\begin{array}{l}\text { Recharge } \\
\text { Model }\end{array}$ & $\begin{array}{c}\text { Select } \\
\text { Calibration } \\
\text { Objective } \\
\text { Function (-) } \\
\text { Head/Flow }\end{array}$ & $\begin{array}{l}\text { Conceptual/ } \\
\text { Parametric } \\
\text { Model Tested }\end{array}$ & Flow Model Remarks & Transport Model Remarks \\
\hline $\begin{array}{c}\text { Null-Space } \\
\text { Monte Carlo on } \\
\text { BASE-USGSD with } \\
\text { Alternative Boundary } \text { Conditions }^{\text {c }} \\
\text { (also referred to as } \\
\text { NHA BLFA NSMC) }\end{array}$ & BASE & USGSD & $19 / 0$ to $210 / 0$ & $\begin{array}{l}\text { Boundary } \\
\text { conditions and } \\
\text { flow model } \\
\text { parameter } \\
\text { uncertainty }\end{array}$ & $\begin{array}{l}\text { Calibrations range from best to } \\
\text { mediocre. AA permeability often } 1 \\
\text { order of magnitude lower than } \\
\text { RNM-2S MWAT. TM-WTA and } \\
\text { TM-LVTA have nearly the same } \\
\text { permeability, which is conceptually } \\
\text { inconsistent. Geochemical evaluation } \\
\text { scattered around BASE-USGSD with } \\
\text { alternative boundary conditions. }\end{array}$ & $\begin{array}{l}\text { Source term uncertainty } \\
\text { approximated. Contaminant boundary } \\
\text { similar to BASE-USGSD alternative } \\
\text { with only transport parameter and } \\
\text { source term uncertainty. One of the } \\
\text { overall smaller contaminant } \\
\text { boundaries, but the largest } \\
\text { contaminant boundary for } \\
\text { DERRINGER. }\end{array}$ \\
\hline $\begin{array}{c}\text { Northern Hydrologic } \\
\text { Alternative - BLFA } \\
\text { HFM with modified } \\
\text { USGSD recharge }^{c} \\
\text { (also referred to as } \\
\text { NHA BLFA) }\end{array}$ & BLFA & $\begin{array}{l}\text { USGSD } \\
\text { modified } \\
\text { to ensure } \\
\text { recharge } \\
\text { to } \\
\text { northern } \\
\text { portion of } \\
\text { model } \\
\text { area }\end{array}$ & & $\begin{array}{l}\text { HFM, boundary } \\
\text { conditions, } \\
\text { permeability } \\
\text { depth decay, } \\
\text { and transport } \\
\text { parameters }\end{array}$ & $\begin{array}{l}\text { Contrast in TM-WTA and TM-LVTA } \\
\text { about 10x; considered more } \\
\text { conceptually reasonable. } \\
\text { Incorporated hydraulic data from } \\
\text { UE-11b completion to constrain TSA } \\
\text { permeability. Used floor to limit depth } \\
\text { decay. Best match to ER-5-3 \#2 in the } \\
\text { LCA, and only model to overpredict } \\
\text { the vertical head gradient at ER-5-3. } \\
\text { Best agreement with geochemical } \\
\text { data - data used in model calibration. }\end{array}$ & $\begin{array}{l}\text { Intermediate size } \\
\text { contaminant boundary. }\end{array}$ \\
\hline
\end{tabular}


Table C.1-3

CAU Model Comparison

(Page 6 of 8)

\begin{tabular}{|c|c|c|c|c|c|c|}
\hline Model & HFM & $\begin{array}{l}\text { Recharge } \\
\text { Model }\end{array}$ & $\begin{array}{c}\text { Select } \\
\text { Calibration } \\
\text { Objective } \\
\text { Function (-) } \\
\text { Head/Flow }\end{array}$ & $\begin{array}{l}\text { Conceptual/ } \\
\text { Parametric } \\
\text { Model Tested }\end{array}$ & Flow Model Remarks & Transport Model Remarks \\
\hline $\begin{array}{l}\text { Null-Space } \\
\text { Monte Carlo on } \\
\text { Northern Hydrologic } \\
\text { Alternative - BASE } \\
\text { HFM with modified } \\
\text { USGSD recharge }{ }^{c} \\
\text { (also referred to as } \\
\text { NHA NSMC and } \\
\text { NHA-USGSD NSMC) }\end{array}$ & BASE & $\begin{array}{l}\text { USGSD } \\
\text { modified } \\
\text { to ensure } \\
\text { recharge } \\
\text { to } \\
\text { northern } \\
\text { portion of } \\
\text { model } \\
\text { area }\end{array}$ & & $\begin{array}{l}\text { Boundary } \\
\text { conditions, } \\
\text { permeability } \\
\text { depth decay, } \\
\text { and flow model } \\
\text { parameter } \\
\text { uncertainty }\end{array}$ & $\begin{array}{l}\text { Contrast in TM-WTA and TM-LVTA } \\
\text { about } 10 x \text {; considered more } \\
\text { conceptually reasonable. } \\
\text { Incorporated hydraulic data from } \\
\text { UE-11b completion to constrain TSA } \\
\text { permeability. Used floor to limit depth } \\
\text { decay. Best match to ER-5-3 \#2 in the } \\
\text { LCA, and only model to overpredict } \\
\text { the vertical head gradient at ER-5-3. } \\
\text { Geochemical evaluation scattered } \\
\text { around Northern Hydrologic } \\
\text { Alternative results. }\end{array}$ & $\begin{array}{l}\text { One of the smaller contaminant } \\
\text { boundaries. }\end{array}$ \\
\hline $\begin{array}{c}\text { Northern Hydrologic } \\
\text { Alternative - BASE } \\
\text { HFM with modified } \\
\text { USGSD recharge }{ }^{c} \\
\text { (also referred to as } \\
\text { NHA and } \\
\text { NHA-USGSD) }\end{array}$ & BASE & $\begin{array}{l}\text { USGSD } \\
\text { modified } \\
\text { to ensure } \\
\text { recharge } \\
\text { to } \\
\text { northern } \\
\text { portion of } \\
\text { model } \\
\text { area }\end{array}$ & & $\begin{array}{l}\text { HFM, boundary } \\
\text { conditions, } \\
\text { permeability } \\
\text { depth decay, } \\
\text { and transport } \\
\text { parameters. }\end{array}$ & $\begin{array}{l}\text { Contrast in TM-WTA and TM-LVTA } \\
\text { about 10x; considered more } \\
\text { conceptually reasonable. } \\
\text { Incorporated hydraulic data from } \\
\text { UE-11b completion to constrain TSA } \\
\text { permeability. Used floor to limit depth } \\
\text { decay. Best match to ER-5-3 \#2 in the } \\
\text { LCA, and only model to overpredict } \\
\text { the vertical head gradient at ER-5-3. } \\
\text { Best agreement with geochemical } \\
\text { data - data used in model calibration. }\end{array}$ & $\begin{array}{l}\text { The largest contaminant boundary - } \\
\text { especially at MILK SHAKE. }\end{array}$ \\
\hline
\end{tabular}


Table C.1-3

CAU Model Comparison

(Page 7 of 8)

\begin{tabular}{|c|c|c|c|c|c|c|}
\hline Model & HFM & $\begin{array}{l}\text { Recharge } \\
\text { Model }\end{array}$ & $\begin{array}{c}\text { Select } \\
\text { Calibration } \\
\text { Objective } \\
\text { Function (-) } \\
\text { Head/Flow }\end{array}$ & $\begin{array}{l}\text { Conceptual/ } \\
\text { Parametric } \\
\text { Model Tested }\end{array}$ & Flow Model Remarks & Transport Model Remarks \\
\hline $\begin{array}{l}\text { BASE-USGSD with } \\
\text { Alternative Boundary } \\
\text { Conditions a/Lower } \\
\text { Dispersivity }\end{array}$ & BASE & USGSD & $55 / 0$ & $\begin{array}{l}\text { Boundary } \\
\text { conditions and } \\
\text { transport } \\
\text { parameters }\end{array}$ & $\begin{array}{l}\text { AA permeability } 1 \text { order of magnitude } \\
\text { lower than RNM-2S MWAT. TM-WTA } \\
\text { and TM-LVTA have nearly the same } \\
\text { permeability, which is } \\
\text { conceptually inconsistent. Same } \\
\text { agreement with geochemistry as } \\
\text { BASE-USGSD with alternative } \\
\text { boundary conditions. }\end{array}$ & $\begin{array}{l}\text { Reduced dispersivity to lower value - } \\
\text { rest of transport parameters stayed } \\
\text { the same. Contaminant boundary } \\
\text { smaller, with higher exceedance } \\
\text { probabilities than base dispersivity } \\
\text { value. }\end{array}$ \\
\hline $\begin{array}{l}\text { BASE-USGSD with } \\
\text { Alternative Boundary } \\
\text { Conditions }{ }^{\text {aHigher }} \\
\text { Dispersivity }\end{array}$ & BASE & USGSD & $55 / 0$ & $\begin{array}{l}\text { Boundary } \\
\text { conditions and } \\
\text { transport } \\
\text { parameters }\end{array}$ & $\begin{array}{l}\text { AA permeability } 1 \text { order of magnitude } \\
\text { lower than RNM-2S MWAT. TM-WTA } \\
\text { and TM-LVTA have nearly the same } \\
\text { permeability, which is } \\
\text { conceptually inconsistent. Same } \\
\text { agreement with geochemistry as } \\
\text { BASE-USGSD with alternative } \\
\text { boundary conditions. }\end{array}$ & $\begin{array}{l}\text { Increased dispersivity to higher value } \\
\text { - rest of transport parameters stayed } \\
\text { the same. One of the largest } \\
\text { contaminant boundaries, with lower } \\
\text { exceedance probabilities than base } \\
\text { dispersivity value. }\end{array}$ \\
\hline BASE-USGSD a & BASE & USGSD & $135 / 238$ & $\begin{array}{l}\text { Boundary } \\
\text { conditions and } \\
\text { transport } \\
\text { parameters }\end{array}$ & $\begin{array}{l}\text { TM-WTA and TM-LVTA have nearly } \\
\text { the same permeability, which is } \\
\text { conceptually inconsistent. Average } \\
\text { agreement with geochemical data. }\end{array}$ & Not considered for transport analysis. \\
\hline BASE-MME a & BASE & MME & $83 / 1$ & $\begin{array}{l}\text { Boundary } \\
\text { conditions and } \\
\text { transport } \\
\text { parameters }\end{array}$ & $\begin{array}{l}\text { TM-WTA and TM-LVTA have nearly } \\
\text { the same permeability, which is } \\
\text { conceptually inconsistent. Average } \\
\text { agreement with geochemical data. }\end{array}$ & Not considered for transport analysis. \\
\hline BASE-DRIA a & BASE & DRIA & $144 / 187$ & $\begin{array}{l}\text { Boundary } \\
\text { conditions and } \\
\text { transport } \\
\text { parameters }\end{array}$ & $\begin{array}{l}\text { TM-WTA and TM-LVTA have nearly } \\
\text { the same permeability, which is } \\
\text { conceptually inconsistent. Average } \\
\text { agreement with geochemical data. }\end{array}$ & Not considered for transport analysis. \\
\hline
\end{tabular}


Table C.1-3

CAU Model Comparison

(Page 8 of 8 )

\begin{tabular}{|c|c|c|c|c|c|c|}
\hline Model & HFM & $\begin{array}{l}\text { Recharge } \\
\text { Model }\end{array}$ & $\begin{array}{l}\text { Select } \\
\text { Calibration } \\
\text { Objective } \\
\text { Function (-) } \\
\text { Head/Flow }\end{array}$ & $\begin{array}{l}\text { Conceptual/ } \\
\text { Parametric } \\
\text { Model Tested }\end{array}$ & Flow Model Remarks & Transport Model Remarks \\
\hline BASE-DVRFS a & BASE & DVRFS & $353 / 20$ & $\begin{array}{l}\text { Boundary } \\
\text { conditions and } \\
\text { transport } \\
\text { parameters }\end{array}$ & $\begin{array}{l}\text { TM-WTA and TM-LVTA have nearly } \\
\text { the same permeability, which is } \\
\text { conceptually inconsistent. Average } \\
\text { agreement with geochemical data. }\end{array}$ & Not considered for transport analysis. \\
\hline DETA-USGSD a & DETA & USGSD & $135 / 298$ & $\begin{array}{l}\text { HFM and } \\
\text { transport } \\
\text { parameters }\end{array}$ & $\begin{array}{l}\text { TM-WTA and TM-LVTA have nearly } \\
\text { the same permeability, which is } \\
\text { conceptually inconsistent. Average } \\
\text { agreement with geochemical data. }\end{array}$ & Not considered for transport analysis. \\
\hline $\begin{array}{l}\text { BASE-USGSD with } \\
\text { Alternative Boundary } \\
\text { Conditions a/2,000 } \\
\text { realizations } \\
\text { (also referred to as } \\
\text { Alternative } \\
\text { BASE-USGSD/2,000 } \\
\text { realizations) }\end{array}$ & BASE & USGSD & $55 / 0$ & $\begin{array}{l}\text { Boundary } \\
\text { conditions, } \\
\text { transport } \\
\text { parameters, and } \\
\text { number of } \\
\text { transport } \\
\text { realizations }\end{array}$ & $\begin{array}{l}\text { AA permeability } 1 \text { order of magnitude } \\
\text { lower than RNM-2S MWAT. TM-WTA } \\
\text { and TM-LVTA have nearly the same } \\
\text { permeability. Average agreement with } \\
\text { geochemical data. }\end{array}$ & $\begin{array}{l}\text { No significant difference in } \\
\text { contaminant boundary from } \\
1,000 \text { realizations. }\end{array}$ \\
\hline $\begin{array}{l}\text { BASE-USGSD with } \\
\text { Alternative Boundary } \\
\text { Conditions } a / 5,000 \\
\text { realizations } \\
\text { (also referred to as } \\
\text { Alternative } \\
\text { BASE-USGSD/5,000 } \\
\text { realizations) }\end{array}$ & BASE & USGSD & $55 / 0$ & $\begin{array}{l}\text { Boundary } \\
\text { conditions, } \\
\text { transport } \\
\text { parameters, and } \\
\text { number of } \\
\text { transport } \\
\text { realizations }\end{array}$ & $\begin{array}{l}\text { AA permeability } 1 \text { order of magnitude } \\
\text { lower than RNM-2S MWAT. TM-WTA } \\
\text { and TM-LVTA have nearly the same } \\
\text { permeability. Average agreement with } \\
\text { geochemical data. }\end{array}$ & $\begin{array}{l}\text { No significant difference in } \\
\text { contaminant boundary from } \\
1,000 \text { realizations. }\end{array}$ \\
\hline
\end{tabular}

a SNJV, 2006

${ }^{\mathrm{b}}$ Flow residual adjusted using weights from rest of models, WW-C and WW-C1 residuals reduced

${ }^{c}$ NNES, 2010 


\section{C.2.0 REFERENCES}

BN, see Bechtel Nevada.

Bechtel Nevada. 2005. A Hydrostratigraphic Framework Model and Alternatives for the Groundwater Flow and Contaminant Transport Model of Corrective Action Unit 98: Frenchman Flat, Clark, Lincoln and Nye Counties, Nevada, DOE/NV/11718--1064. Las Vegas, NV.

NNES, see Navarro Nevada Environmental Services, LLC.

Navarro Nevada Environmental Services, LLC. 2010. Phase II Transport Model of Corrective Action Unit 98: Frenchman Flat, Nevada Test Site, Nye County, Nevada, Rev.1, N-I/28091--004, S-N/99205--122. Las Vegas, NV.

SNJV, see Stoller-Navarro Joint Venture.

Stoller-Navarro Joint Venture. 2005. Phase II Contaminant Transport Parameters for the Groundwater Flow and Contaminant Transport Model of Corrective Action Unit 98:

Frenchman Flat, Nye County, Nevada, S-N/99205--043. Prepared for the U.S. Department of Energy. Las Vegas, NV.

Stoller-Navarro Joint Venture. 2006. Phase II Groundwater Flow Model of Corrective Action Unit 98: Frenchman Flat, Nevada Test Site, Nye County, Nevada, S-N/99205--074. Las Vegas, NV. 
Appendix D

Nevada Division of Environmental Protection Comment Responses

(5 Pages) 


\section{NEVADA ENVIRONMENTAL RESTORATION PROJECT DOCUMENT REVIEW SHEET}

\begin{tabular}{|c|c|c|c|c|c|c|}
\hline \multicolumn{2}{|c|}{ 1. Document Title/Number: } & \multicolumn{2}{|c|}{$\begin{array}{l}\text { Final Phase II Documentation Overview of Corrective Action Unit 98: Frenchman } \\
\text { Flat, Nevada Test Site, Nye Co., NV }\end{array}$} & \multirow{2}{*}{\begin{tabular}{|l|} 
2. Document Date: \\
4. Originator/Organization:
\end{tabular}} & \multicolumn{2}{|l|}{$2 / 18 / 2010$} \\
\hline \multicolumn{2}{|c|}{ 3. Revision Number: } & \multicolumn{2}{|l|}{0} & & \multicolumn{2}{|l|}{ Navarro-INTERA } \\
\hline \multicolumn{2}{|c|}{$\begin{array}{l}\text { 5. Responsible NNSA/NSO Federal } \\
\text { Sub-Project Director: }\end{array}$} & \multicolumn{2}{|l|}{ Bill Wilborn } & 6. Date Comments Due: & \multicolumn{2}{|l|}{$3 / 22 / 2010$} \\
\hline \multicolumn{2}{|l|}{ 7. Review Criteria: } & \multicolumn{2}{|l|}{ Full } & & & \\
\hline \multicolumn{2}{|c|}{ 8. Reviewer/Organization/Phone No: } & \multicolumn{2}{|l|}{ Chris Andres, NDEP, 486-2850 } & 9. Reviewer's Signature: & & \\
\hline $\begin{array}{l}\text { 10. Comment } \\
\text { Number/Locatio }\end{array}$ & 11. Type* & 12. Comment & \multicolumn{3}{|c|}{ 13. Comment Response } & 14. Accept \\
\hline $\begin{array}{l}\text { 1.) Section } 1.0 \\
\text { Page } 1-1,2 \text { nd } \\
\text { Paragraph, 2nd } \\
\text { Sentence }\end{array}$ & & $\begin{array}{l}\text { To be consistent with other citations in the document, } \\
\text { "...and a well used for a radionuclide migration } \\
\text { experiment..." should be changed to "...and a well used for } \\
\text { the CAMBRIC radionuclide experiment..." }\end{array}$ & \multicolumn{3}{|c|}{$\begin{array}{l}\text { Changed to "... and a well used for the CAMBRIC } \\
\text { radionuclide migration experiment ..." }\end{array}$} & \\
\hline $\begin{array}{l}\text { 2.) Section } 1.0 \\
\text { Page } 1-1,3 \text { rd } \\
\text { Paragraph, } 1 \text { st } \\
\text { Sentence }\end{array}$ & & $\begin{array}{l}\text { The "and vicinity" at the end of this sentence is unclear and } \\
\text { can be misleading. If it is referring to the Nevada Offsite } \\
\text { locations this should be stated. If it is not, "vicinity" should } \\
\text { be defined in some manner. }\end{array}$ & \multicolumn{3}{|c|}{ Deleted "and vicinity." } & \\
\hline $\begin{array}{l}\text { 3.) Section } 1.1 \text {, } \\
\text { Page } 1-8 \text {, Bullet } \\
\text { No. } 4\end{array}$ & & $\begin{array}{l}\text { "Identifying and documenting land-use policies (institutional } \\
\text { controls)..." is part of the UGTA strategy, but not part of the } \\
\text { Corrective Action Investigation (CAI) phase. Either Bullet } \\
\text { No. } 4 \text { should be removed or the CAI phase wording should } \\
\text { be removed. }\end{array}$ & \multicolumn{3}{|c|}{$\begin{array}{l}\text { The introductory text to the bullets now reads as in the } \\
\text { transport report: "The technical basis for achieving the } \\
\text { UGTA strategy is through an evaluation of each CAU using } \\
\text { a combination of approaches, including:" }\end{array}$} & \\
\hline $\begin{array}{l}\text { 4.) Section } 1.1 \\
\text { Page } 1-8,1 \text { st } \\
\text { Paragraph under } \\
\text { Bullets }\end{array}$ & & $\begin{array}{l}\text { This paragraph deals with decisions and approaches that } \\
\text { apply to the CADD and CAP phases, not just the CAI } \\
\text { phase. The manner in which the paragraph is written } \\
\text { implies that the CAI includes all the approaches and } \\
\text { regulatory decisions mentioned. The paragraph should be } \\
\text { rewritten to include only CAI approaches and decisions } \\
\text { given the bullet items it follows or the phase(s) the } \\
\text { paragraph refers to should be identified. }\end{array}$ & \multicolumn{3}{|c|}{$\begin{array}{l}\text { Add "(CADD/CAP phase)" after “... evaluation and } \\
\text { monitoring studies," and add "(CR phase)" after “... } \\
\text { groundwater contamination." }\end{array}$} & \\
\hline $\begin{array}{l}\text { 5.) Section 1.1, } \\
\text { Page 1-8, Last } \\
\text { Paragraph, 1st } \\
\text { Sentence }\end{array}$ & & $\begin{array}{l}\text { To be clear, "...has completed the first phase of the } \\
\text { strategy." should be changed to "...has completed the CAI } \\
\text { phase of the strategy." "First" could be interpreted to be } \\
\text { the CAIP phase looking looking at Figure } 1-3 \text {. }\end{array}$ & \multicolumn{3}{|c|}{ Changed as noted. } & \\
\hline
\end{tabular}


NEVADA ENVIRONMENTAL RESTORATION PROJECT

DOCUMENT REVIEW SHEET

\begin{tabular}{|c|c|c|c|c|c|c|}
\hline \multicolumn{2}{|c|}{ 1. Document Title/Number: } & \multicolumn{2}{|c|}{$\begin{array}{l}\text { Final Phase II Documentation Overview of Corrective Action Unit 98: Frenchman } \\
\text { Flat, Nevada Test Site, Nye Co., NV }\end{array}$} & \multirow{2}{*}{\begin{tabular}{|l|} 
2. Document Date: \\
4. Originator/Organization:
\end{tabular}} & \multicolumn{2}{|l|}{ 2/18/2010 } \\
\hline \multicolumn{2}{|l|}{ 3. Revision Number: } & \multicolumn{2}{|l|}{0} & & \multicolumn{2}{|l|}{ Navarro-INTERA } \\
\hline \multicolumn{2}{|c|}{$\begin{array}{l}\text { 5. Responsible NNSA/NSO Federal } \\
\text { Sub-Project Director: }\end{array}$} & \multicolumn{2}{|l|}{ Bill Wilborn } & 6. Date Comments Due: & \multicolumn{2}{|l|}{$3 / 22 / 2010$} \\
\hline \multicolumn{2}{|l|}{ 7. Review Criteria: } & \multicolumn{2}{|l|}{ Full } & & & \\
\hline \multicolumn{2}{|c|}{ 8. Reviewer/Organization/Phone No: } & : Chris Andres, NDEP, 486-2850 & & 9. Reviewer's Signature: & & \\
\hline $\begin{array}{l}\text { 10. Comment } \\
\text { Number/Locatio }\end{array}$ & 11. Type* & 12. Comment & \multicolumn{3}{|c|}{ 13. Comment Response } & 14. Accept \\
\hline $\begin{array}{l}\text { 6.) Section } 1.2 \text {, } \\
\text { Page } 1-9,1 \text { st and } \\
\text { 2nd Paragraphs }\end{array}$ & & $\begin{array}{l}\text { While remediation strategies are part of the UGTA } \\
\text { strategy, it should be noted that the listed alternatives are } \\
\text { part of the CADD/CAP phase and evaluated as "Corrective } \\
\text { Action Alternatives". The CAI does not include evaluation } \\
\text { of Corrective Action Alternatives as implied by this section. } \\
\text { Please rewrite the section to correctly identify what is in } \\
\text { which phase. }\end{array}$ & \multicolumn{3}{|c|}{ Deleted "... and the Phase II CAI." } & \\
\hline $\begin{array}{l}\text { 7.) Section 1.2, } \\
\text { Page 1-10, } \\
\text { Intrinsic } \\
\text { Remediation } \\
\text { Alternative - } \\
\text { Natural } \\
\text { Attenuation, 2nd } \\
\text { Sentence }\end{array}$ & & $\begin{array}{l}\text { It is not clear why it is stated that this alternative is } \\
\text { assessed (present tense) using a description in the } \\
\text { "original FFACO strategy." It appears that there is a } \\
\text { picking-and-choosing of past and present FFACO } \\
\text { strategies in this document. If the alternative was (past } \\
\text { tense) evaluated at a time when a different FFACO } \\
\text { strategy was in effect then this fact should be stated, } \\
\text { especially since 5-year and 50-year monitoring programs } \\
\text { are no longer specified in the current (2010) FFACO } \\
\text { strategy. }\end{array}$ & \multicolumn{3}{|c|}{$\begin{array}{l}\text { Deleted the sentence, "The alternative is assessed } \\
\text { assuming implementation of the four-stage UGTA strategy, } \\
\text { which includes long-term closure monitoring, and is } \\
\text { described in the original FFACO strategy (FFACO, 1996; } \\
\text { amended February 2008) including identification of } \\
\text { contaminant boundaries and both a 5-year and a 50-year } \\
\text { monitoring program." }\end{array}$} & \\
\hline $\begin{array}{l}\text { 8.) Section } 2.3 \text {, } \\
\text { Page } 2-4,2 \text { nd } \\
\text { Sentence at top } \\
\text { of Page }\end{array}$ & & $\begin{array}{l}\text { It is not clear why the FFACO citation in this sentence is } \\
\text { present since no reference to a regional risk assessment } \\
\text { of the UGTA subproject sites could be found in that version } \\
\text { of the FFACO. It it is a typographical error, it should be } \\
\text { corrected or the reference should be explained further. }\end{array}$ & \multicolumn{3}{|c|}{$\begin{array}{l}\text { The FFACO citation was deleted. The risk assessment } \\
\text { took place under the } 1997 \text { regional model work. }\end{array}$} & \\
\hline $\begin{array}{l}\text { 9.) Section 2.3, } \\
\text { Page 2-7, 2nd } \\
\text { Paragraph, 2nd } \\
\text { Sentence }\end{array}$ & & $\begin{array}{l}\text { What documents does "Under the initial agreements from } \\
\text { the } 1990 \text { s,..." refer to? Is/are they the initital FFACO? If } \\
\text { so, why is "agreements" plural? It is also not clear what } \\
\text { the "second statge of the CAI" is referring to. This } \\
\text { sentence should be clarified. }\end{array}$ & \multicolumn{3}{|c|}{$\begin{array}{l}\text { Deleted the sentence. Changed the following sentence, } \\
\text { "Model validation under the FFACO (1996) (called model } \\
\text { verification) preceded closure." Also changed the FFACO } \\
\text { reference in the first sentence to be only "(1996)"; the } \\
\text { Frenchman Flat Phase II CAI started before the } 2008 \\
\text { revision. }\end{array}$} & \\
\hline
\end{tabular}


NEVADA ENVIRONMENTAL RESTORATION PROJECT

DOCUMENT REVIEW SHEET

\begin{tabular}{|c|c|c|c|c|c|c|}
\hline \multicolumn{2}{|c|}{ 1. Document Title/Number: } & \multicolumn{2}{|c|}{$\begin{array}{l}\text { Final Phase II Documentation Overview of Corrective Action Unit 98: Frenchman } \\
\text { Flat, Nevada Test Site, Nye Co., NV }\end{array}$} & \multirow{2}{*}{\begin{tabular}{|l|} 
2. Document Date: \\
4. Originator/Organization:
\end{tabular}} & \multicolumn{2}{|l|}{$2 / 18 / 2010$} \\
\hline \multicolumn{2}{|l|}{ 3. Revision Number: } & \multicolumn{2}{|l|}{0} & & \multicolumn{2}{|l|}{ Navarro-INTERA } \\
\hline \multicolumn{2}{|c|}{$\begin{array}{l}\text { 5. Responsible NNSA/NSO Federal } \\
\text { Sub-Project Director: }\end{array}$} & \multicolumn{2}{|l|}{ Bill Wilborn } & 6. Date Comments Due: & \multicolumn{2}{|l|}{$3 / 22 / 2010$} \\
\hline \multicolumn{2}{|l|}{ 7. Review Criteria: } & \multicolumn{2}{|l|}{ Full } & & & \\
\hline \multicolumn{2}{|c|}{ 8. Reviewer/Organization/Phone No: } & \begin{tabular}{l|l} 
o: & Chris Andres, NDEP, 486-2850
\end{tabular} & & 9. Reviewer's Signature: & & \\
\hline $\begin{array}{l}\text { 10. Comment } \\
\text { Number/Locatio }\end{array}$ & 11. Type* & 12. Comment & \multicolumn{3}{|c|}{ 13. Comment Response } & 14. Accept \\
\hline $\begin{array}{l}\text { 10.) Section 2.3, } \\
\text { Page 2-8, Last } \\
\text { Paragraph }\end{array}$ & & $\begin{array}{l}\text { Any references to "institutional controls" should also } \\
\text { include the information that the institutional controls are } \\
\text { part of the CADD/CAP decision (as referenced in the } \\
\text { Frenchman Flat Phase II Transport Model document, } \\
\text { Executive Summary, Page ES-1). }\end{array}$ & \multicolumn{3}{|c|}{$\begin{array}{l}\text { Add the text "in the CADD/CAP and CR stages" at the end } \\
\text { of the paragraph. }\end{array}$} & \\
\hline $\begin{array}{l}\text { 11.) Section } \\
\text { 3.4.1, Page 3-13, } \\
\text { 1st Partial } \\
\text { Paragraph, Last } \\
\text { Sentence }\end{array}$ & & $\begin{array}{l}\text { How are PIN STRIPE and MILK SHAKE different? Please } \\
\text { explain the difference. }\end{array}$ & \multicolumn{3}{|c|}{$\begin{array}{l}\text { Text changed as follows: "... the source to the water table. } \\
\text { Two tests, PIN STRIPE and MILK SHAKE, are treated } \\
\text { differently because their exchange volumes intersect } \\
\text { fractured volcanic rock, which, conceptually, allows more } \\
\text { potential radionuclide migration than accounted for in the } \\
\text { CAMBRIC conceptual model. Process models that } \\
\text { consider both the unsaturated and saturated zones were } \\
\text { used for source-term analysis of these two tests." }\end{array}$} & \\
\hline $\begin{array}{l}\text { 12.) Section } \\
\text { 4.2.3.3, Page 4- } \\
13, \text { 3rd } \\
\text { Paragraph, 2nd } \\
\text { Sentence }\end{array}$ & & $\begin{array}{l}\text { In its comments on the December } 2009 \text { Draft version of } \\
\text { the document, the NDEP commented in regards to this } \\
\text { sentence that the "Text indicates that the sub-CAU model } \\
\text { area was extended to include three additional wells. } \\
\text { However, in Figure } 3-1 \text { (which was referenced) WW-5A is } \\
\text { not located within the model area. Please correct either } \\
\text { the text or the figure." In the February } 2010 \text { Revision No. } 0 \\
\text { version of the document, the reference to Figure } 3-1 \text { was } \\
\text { removed but the substance of the comment still remains in } \\
\text { that the location of the Sub-CAU model for the Central } \\
\text { Testing Area shown on Figure } 4-3 \text { does not encompass } \\
\text { water-supply well WW-5A. }\end{array}$ & \multicolumn{3}{|c|}{$\begin{array}{l}\text { Figure 4-3 was replaced with Figure 5-37 from the } \\
\text { transport report. }\end{array}$} & \\
\hline $\begin{array}{l}\text { 13.) Section } \\
\text { 4.3.4, Page 4-24, } \\
\text { Last Sentence }\end{array}$ & & $\begin{array}{l}\text { The FFACO citation should be FFACO, 1996; amended } \\
2010 .\end{array}$ & \multicolumn{3}{|c|}{$\begin{array}{l}\text { Changed to read "FFACO, 1996; as amended March } \\
\text { 2010." Because the revisions are final, the FFACO } \\
\text { citations have been requested to be updated throughout } \\
\text { the document by NNSA/NSO. }\end{array}$} & \\
\hline
\end{tabular}

Tuesday, April 06, 2010

Page 3 of 5 
NEVADA ENVIRONMENTAL RESTORATION PROJECT

DOCUMENT REVIEW SHEET

\begin{tabular}{|c|c|c|c|c|c|c|}
\hline \multicolumn{2}{|c|}{ 1. Document Title/Number: } & \multicolumn{2}{|c|}{$\begin{array}{l}\text { Final Phase II Documentation Overview of Corrective Action Unit 98: Frenchman } \\
\text { Flat, Nevada Test Site, Nye Co., NV }\end{array}$} & \multirow{2}{*}{\begin{tabular}{|l|} 
2. Document Date: \\
4. Originator/Organization: \\
\end{tabular}} & \multicolumn{2}{|l|}{$2 / 18 / 2010$} \\
\hline \multicolumn{2}{|c|}{ 3. Revision Number: } & \multicolumn{2}{|l|}{0} & & \multicolumn{2}{|l|}{ Navarro-INTERA } \\
\hline \multicolumn{2}{|c|}{$\begin{array}{l}\text { 5. Responsible NNSA/NSO Federal } \\
\text { Sub-Project Director: }\end{array}$} & \multicolumn{2}{|l|}{ Bill Wilborn } & 6. Date Comments Due: & \multicolumn{2}{|l|}{$3 / 22 / 2010$} \\
\hline \multicolumn{2}{|l|}{ 7. Review Criteria: } & \multicolumn{2}{|l|}{ Full } & & & \\
\hline \multicolumn{2}{|c|}{ 8. Reviewer/Organization/Phone No: } & \multicolumn{2}{|l|}{ Chris Andres, NDEP, 486-2850 } & \multicolumn{3}{|l|}{ 9. Reviewer's Signature: } \\
\hline $\begin{array}{l}\text { 10. Comment } \\
\text { Number/Locatio }\end{array}$ & 11. Type* & 12. Comment & \multicolumn{3}{|c|}{ 13. Comment Response } & 14. Accept \\
\hline $\begin{array}{l}\text { 14.) Section } \\
\text { 5.1.2, Page } 5-10, \\
\text { 1st Full } \\
\text { Paragraph, 1st } \\
\text { Sentence }\end{array}$ & & $\begin{array}{l}\text { It appears that the FFACO citation should be FFACO, } \\
\text { 1996; amended } 2010 .\end{array}$ & \multicolumn{3}{|c|}{ (Changed to read "FFACO, 1996; as amended March 2010." } & \\
\hline $\begin{array}{l}\text { 15.) Section } \\
\text { 5.3.2, Page 5-38, } \\
\text { Table 5-1 }\end{array}$ & & $\begin{array}{l}\text { Although the Safe Drinking Water Standards Maximum } \\
\text { Contamination Levels are presented in the format used by } \\
\text { the U.S. E.P.A., to be consistent and to provide easily } \\
\text { comparable units, list the Beta/Photon Emitter MCL in } \\
\text { pCi/L as well as mrem/yr (see Table 10-2, "Activity } \\
\text { Concentrations Equal to } 4 \text { mrem/yr Dose" in the Phase II } \\
\text { Transport Model of Corrective Action Unit 98: Frenchman } \\
\text { Flat, Nevada Test Site, Nye County, Nevada, Rev. 1, } \\
\text { January 2010). }\end{array}$ & \multicolumn{3}{|c|}{$\begin{array}{l}\text { Table } 10-2 \text { from the transport report was inserted as Table } \\
5-2 \text {. Additionally, the callout text was added as follows: “.... } \\
\text { in Table 5-1. Table 5-2 shows the activity to dose } \\
\text { conversion factors for beta emitters that correspond to the } \\
\text { Safe Drinking Water Act standards." }\end{array}$} & \\
\hline $\begin{array}{l}\text { 16.) Section } \\
\text { 5.3.1.2, Page 5- } \\
\text { 33, 2nd } \\
\text { Paragraph, 2nd } \\
\text { Sentence }\end{array}$ & & $\begin{array}{l}\text { The word "and" should be included between "(Figure 5- } \\
\text { 18a)(Figure 5-18b). }\end{array}$ & \multicolumn{3}{|c|}{ Changed to read "(Figures 5-18a and 5-18b)." } & \\
\hline 17.) Page 5-44 & & $\begin{array}{l}\text { In the December } 2009 \text { Draft version of the document there } \\
\text { was a Section } 5.3 .3 \text { titled "Transport Model Uncertainty } \\
\text { and Sensitivity." This section has been removed in the } \\
\text { February } 2010 \text { Revision No. } 0 \text {. The NDEP believes } \\
\text { strongly that the information in the deleted Section is } \\
\text { important for the reviewers and should be included in the } \\
\text { document. }\end{array}$ & \multicolumn{3}{|c|}{ Put section from draft report back in. } & \\
\hline
\end{tabular}




\section{NEVADA ENVIRONMENTAL RESTORATION PROJECT}

DOCUMENT REVIEW SHEET

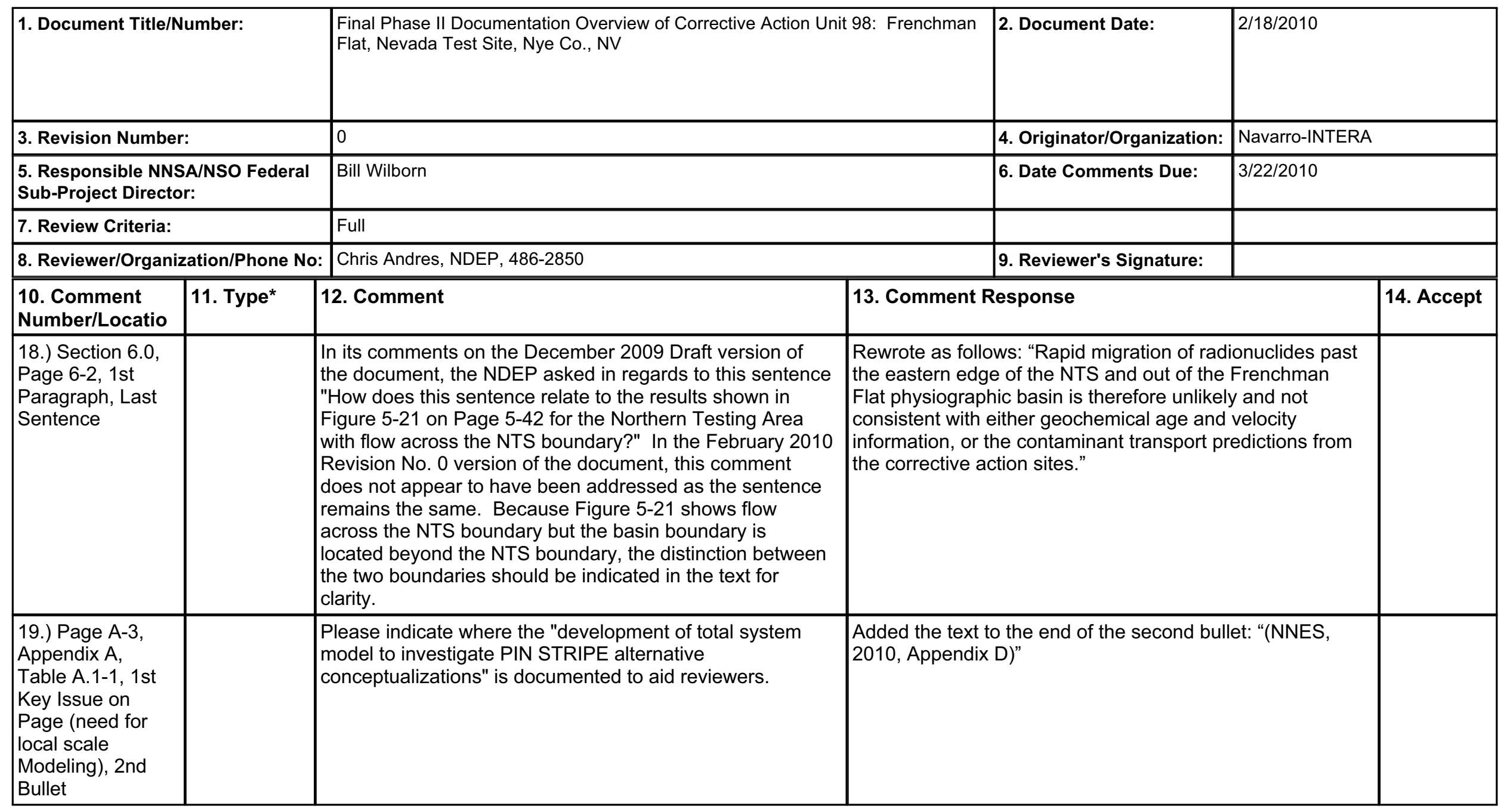




\section{Plates}




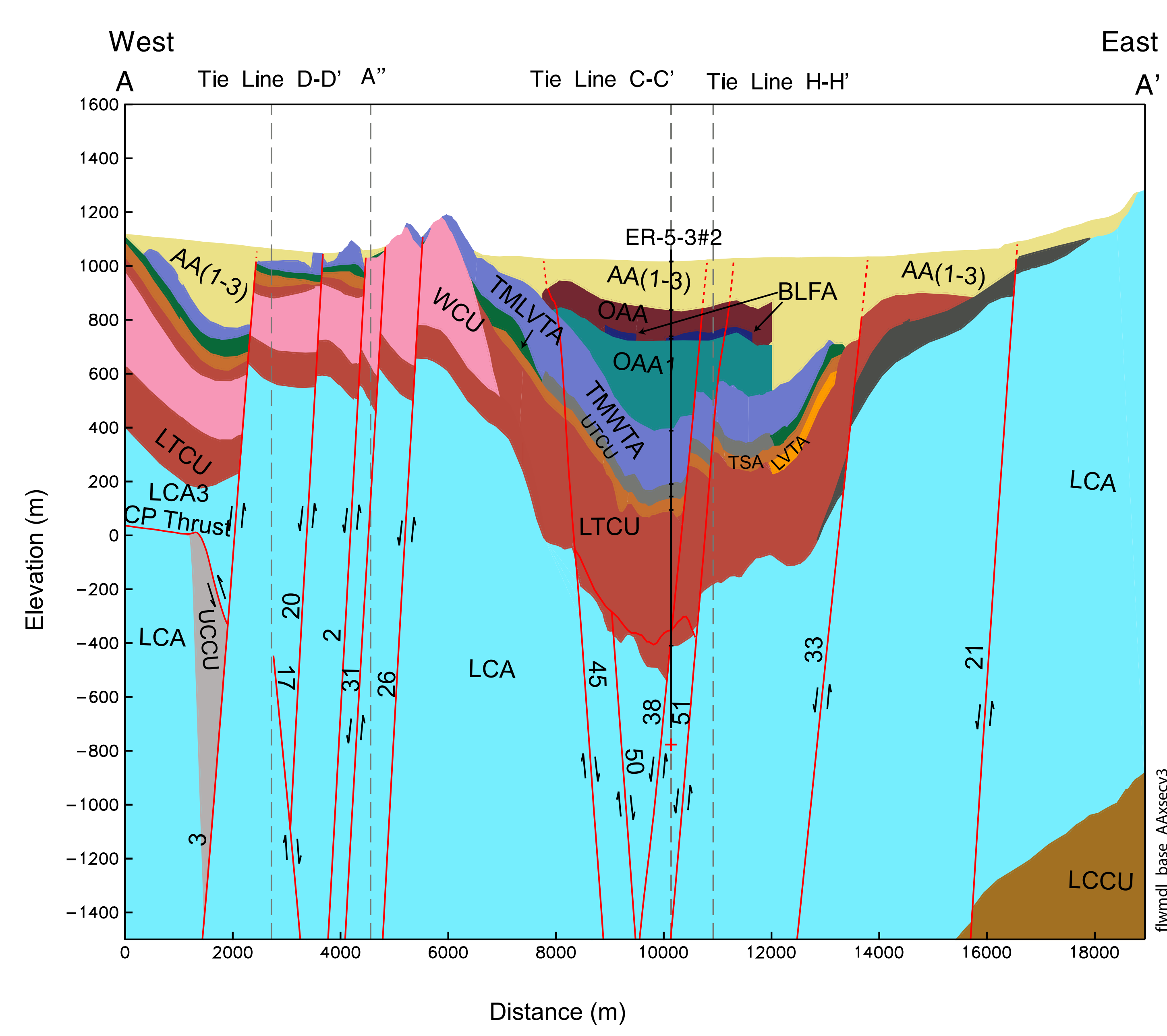

West-to-East Profile (B-B') through Drill Hole ER-5-4

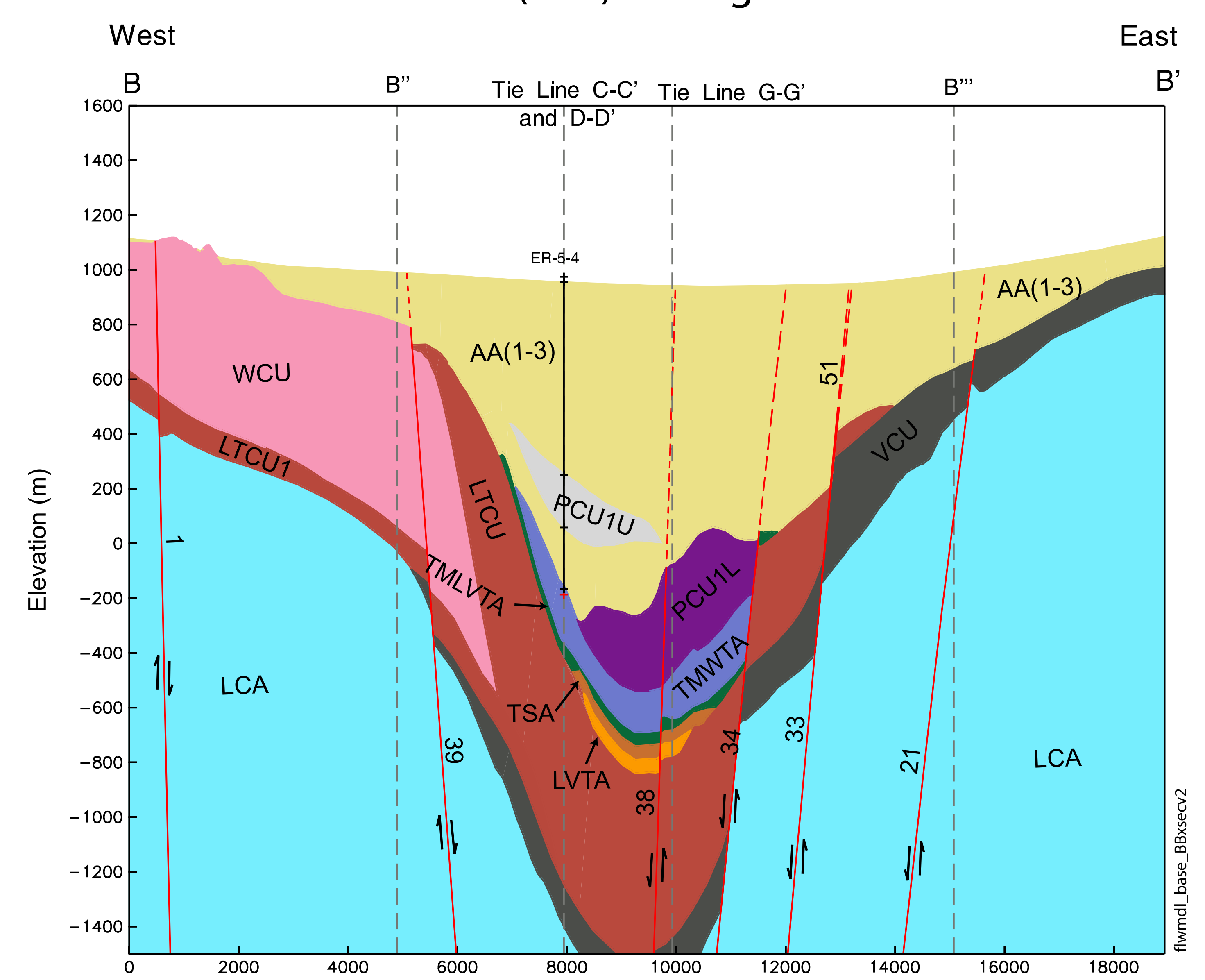

Distance ( $m$ )

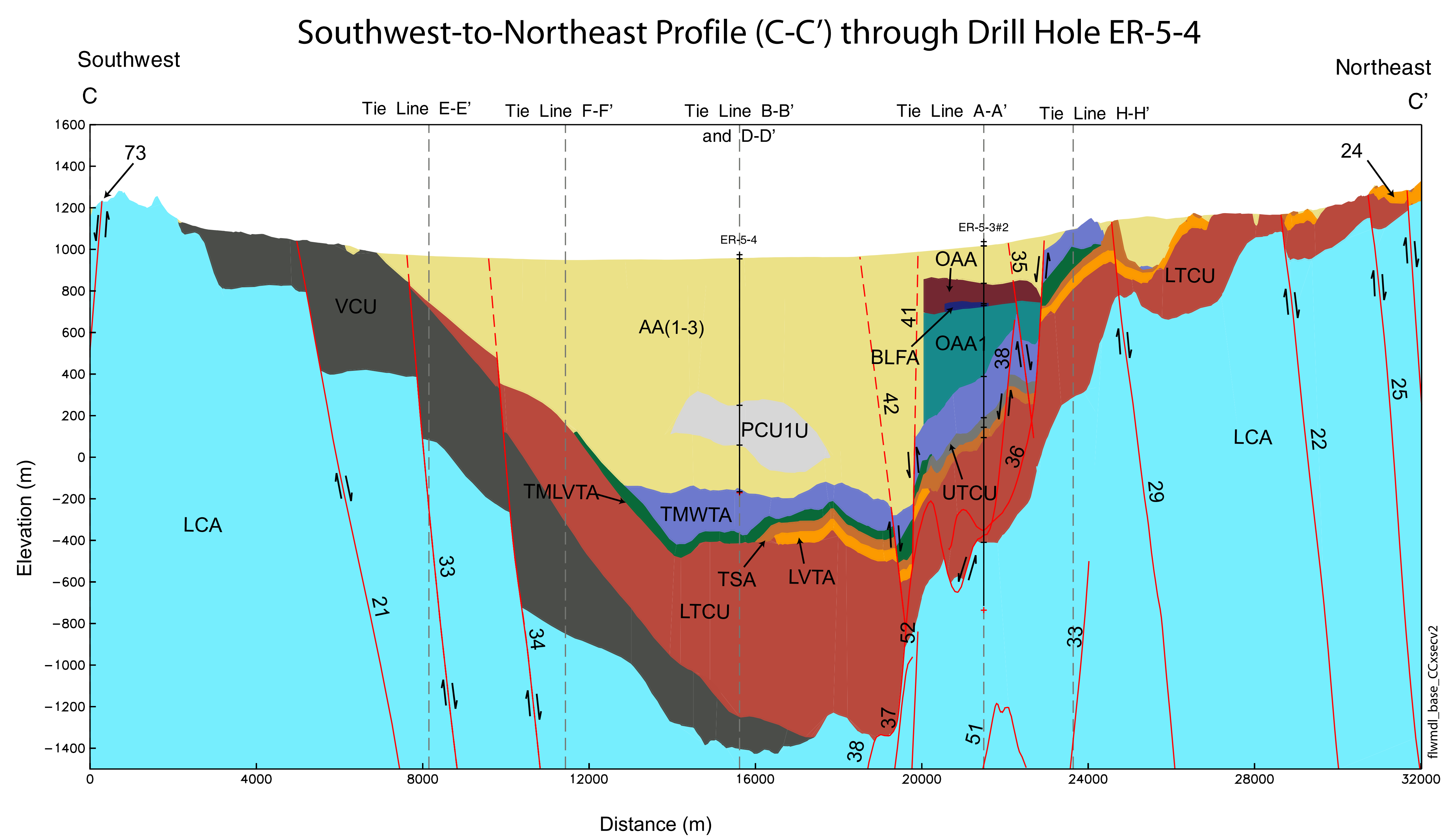

Northwest-to-Southwest Profile (D-D') through Drill Hole ER-5-4

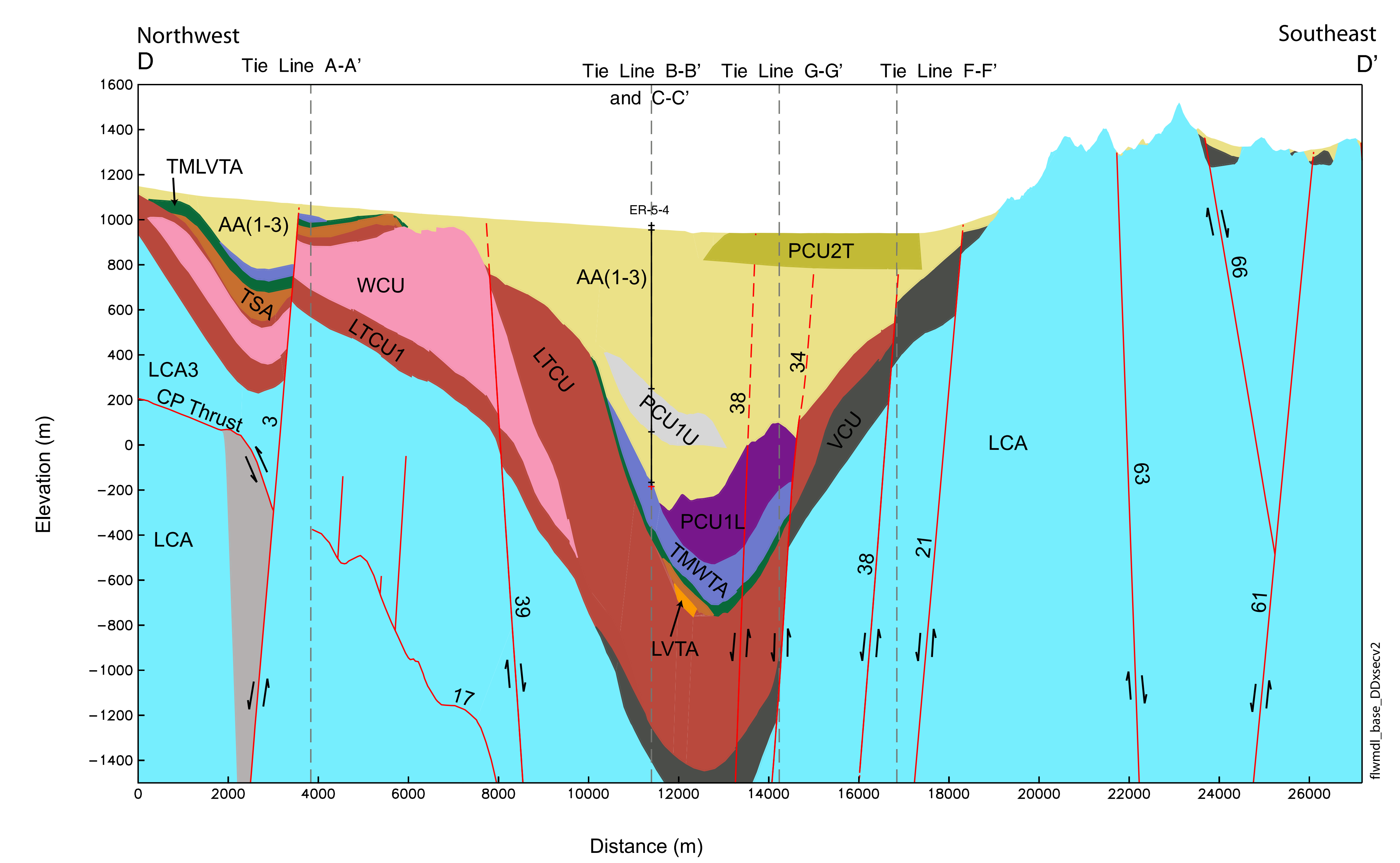

Northwest-to-Southeast Profile (E-E') through Southwest Frenchman Flat
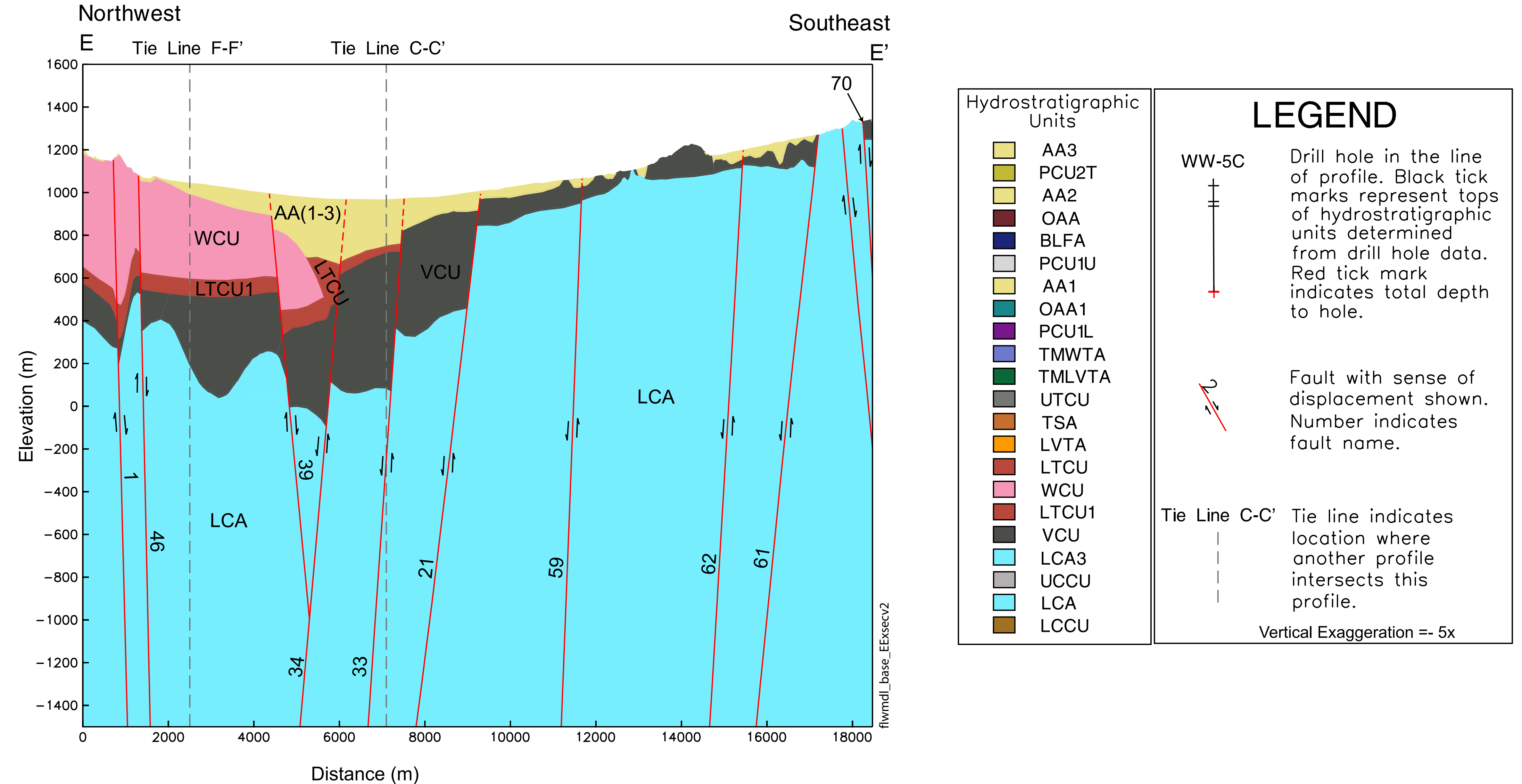

West-to-East Profile (F-F') through Drill Hole WW-5C

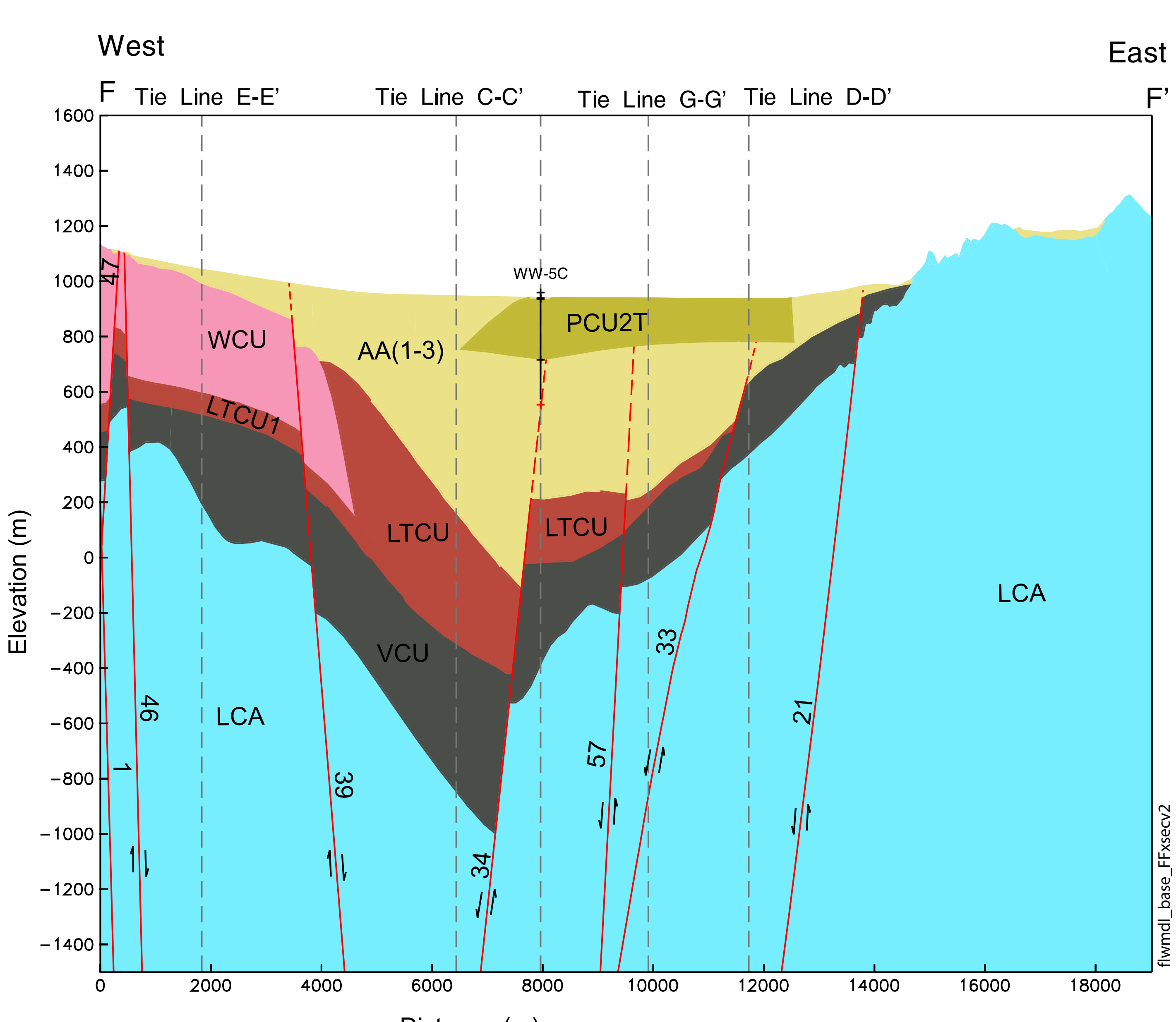

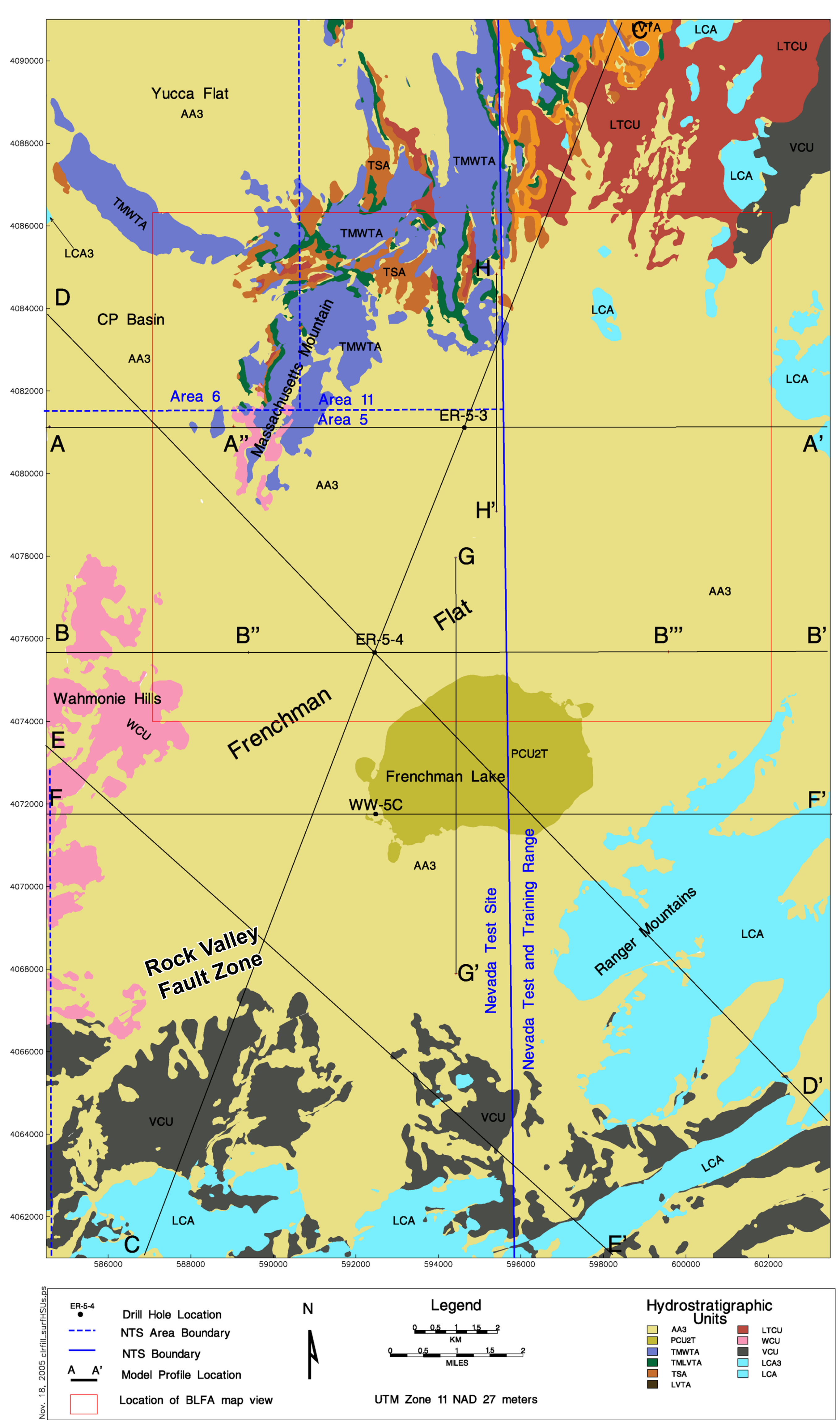

Map of Hydrostratigraphic Units at the Surface with Profile Locations 


\section{Base Model}
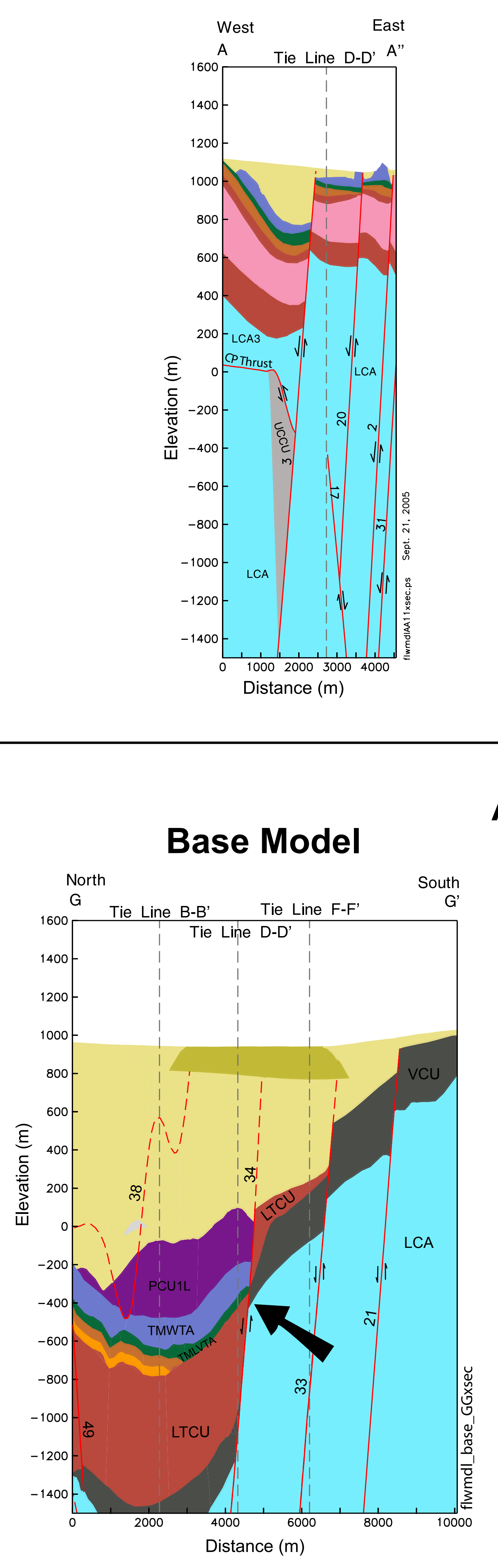

CP Basin

Alternative Model

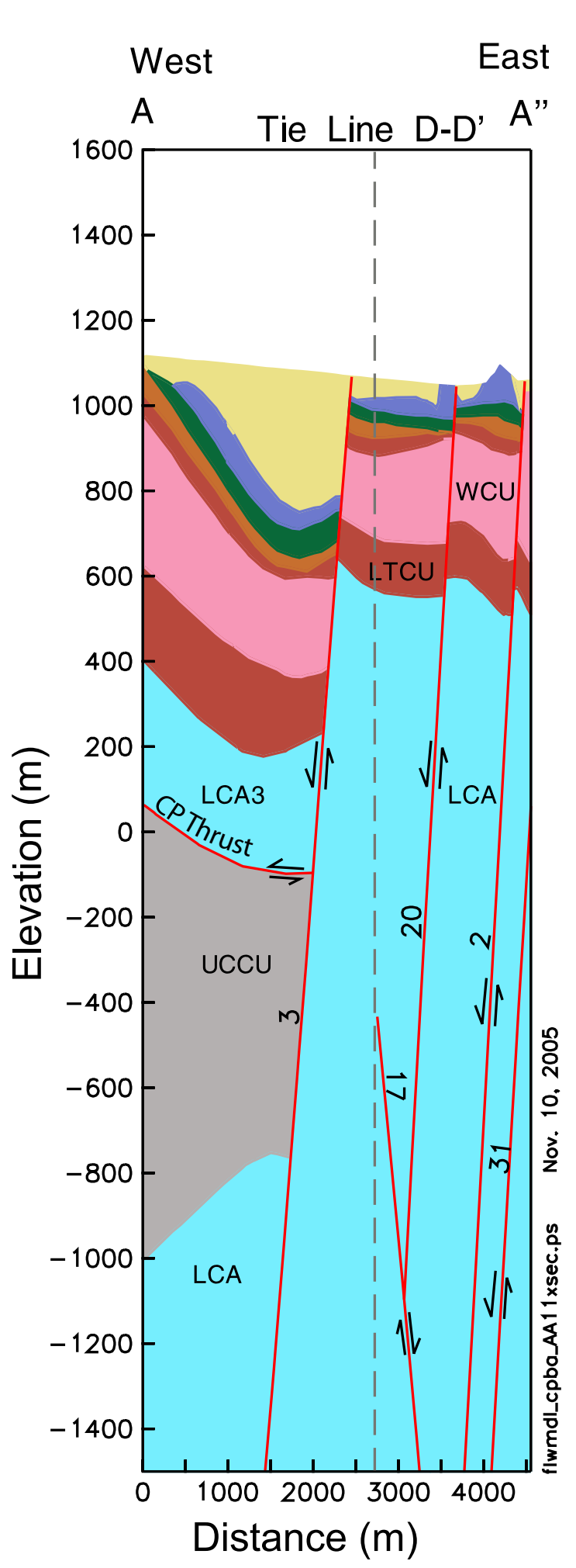

Base Model

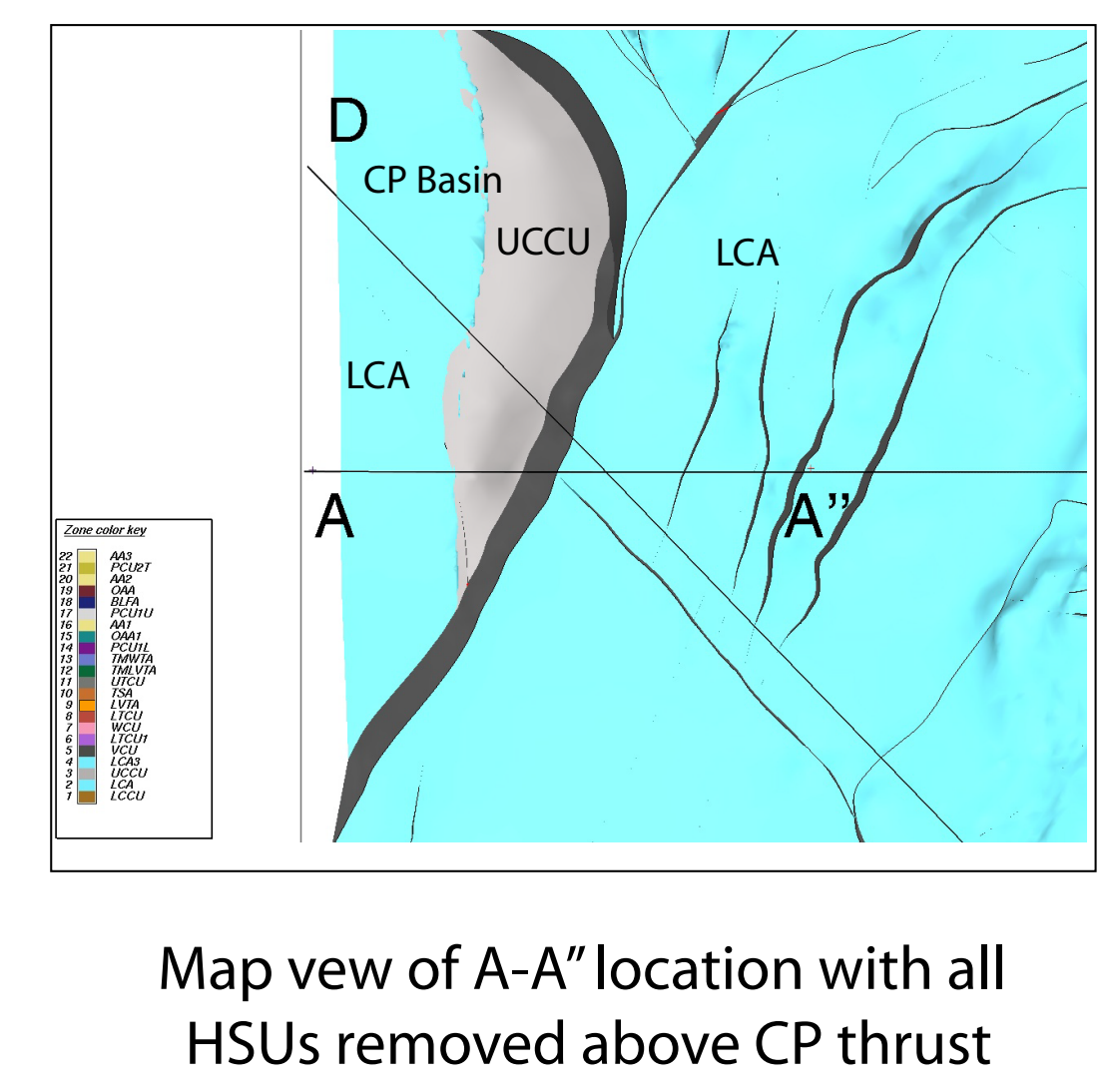

Map of Hydrostratigraphic Units at the Surface with Profile Locations

Aquifer Displacement (Juxtaposition)
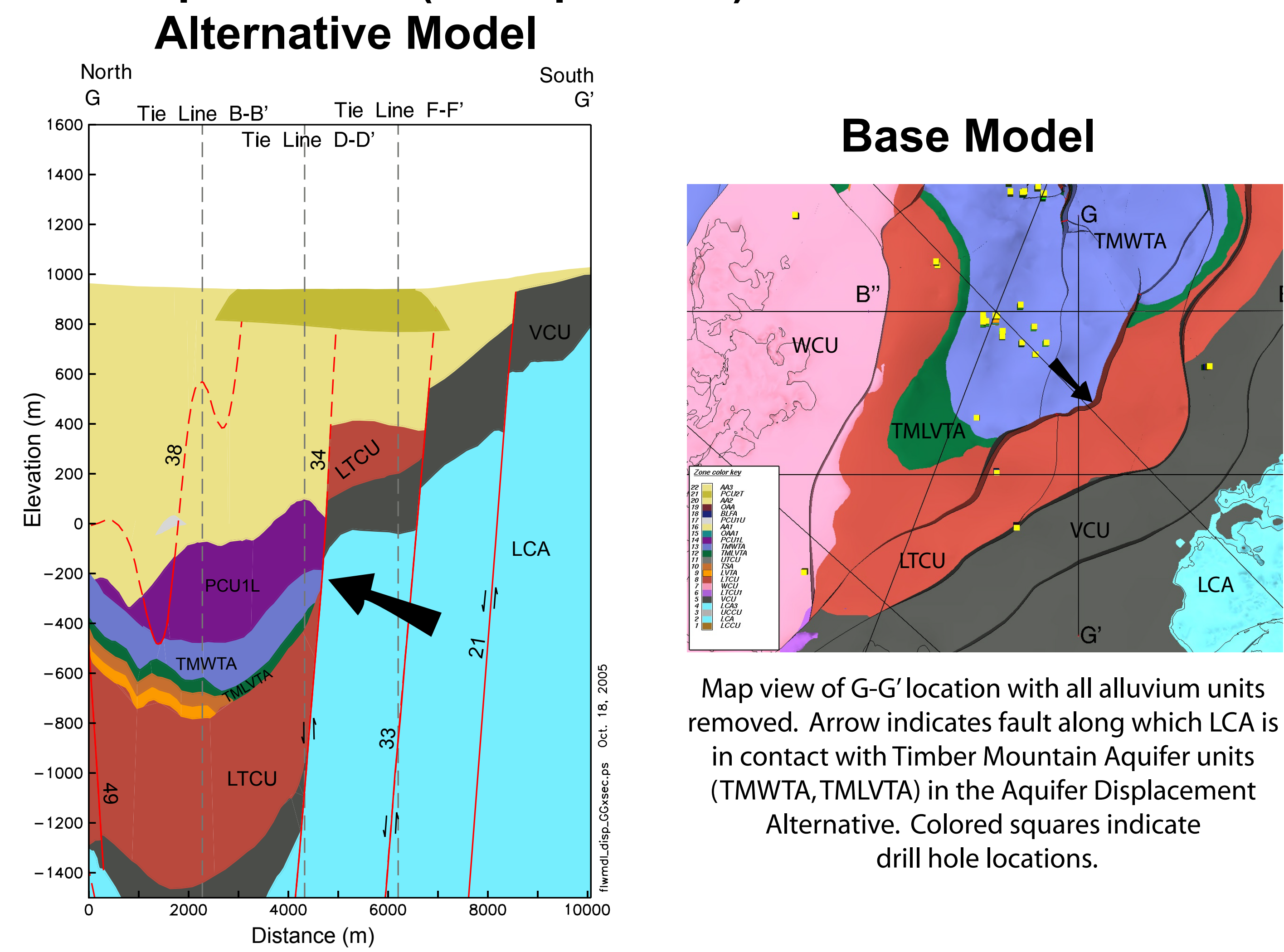

Map view of G-G'location with all alluvium units emoved. Arrow indicates fault along which LCA is (TMWTA TMLVTA) in the Aquifer Displacement Alternative. Colored squares indicate drill hole locations.
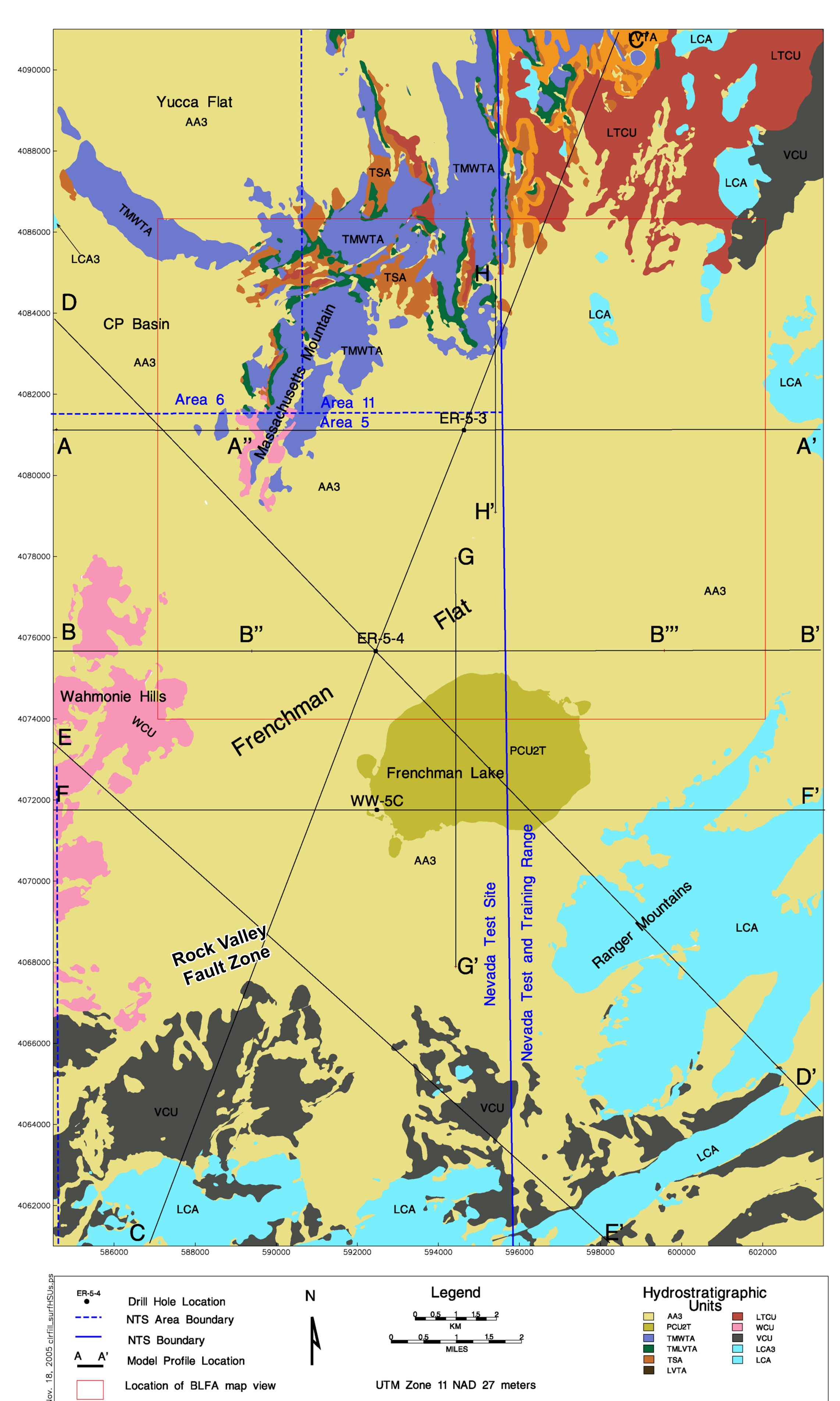

Base Model

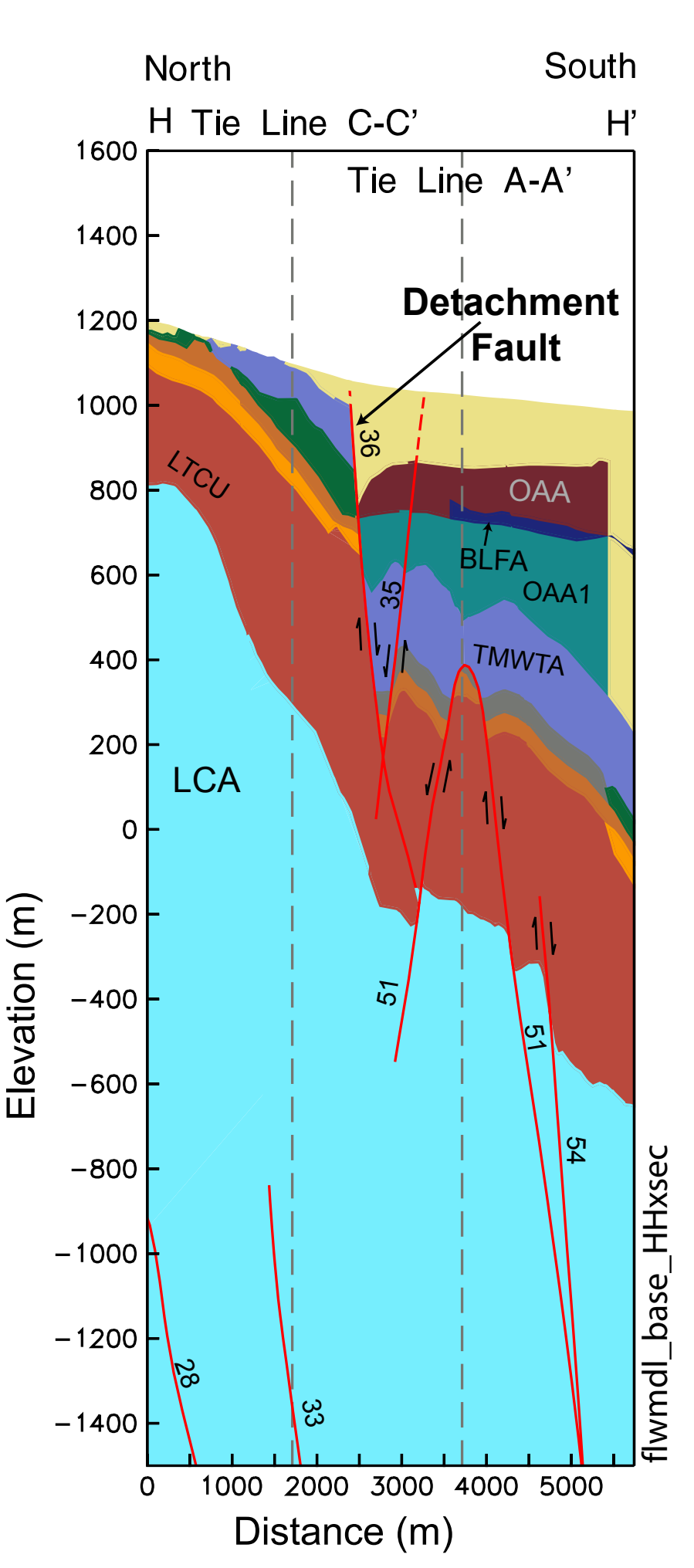

No Detachment Alternative Model

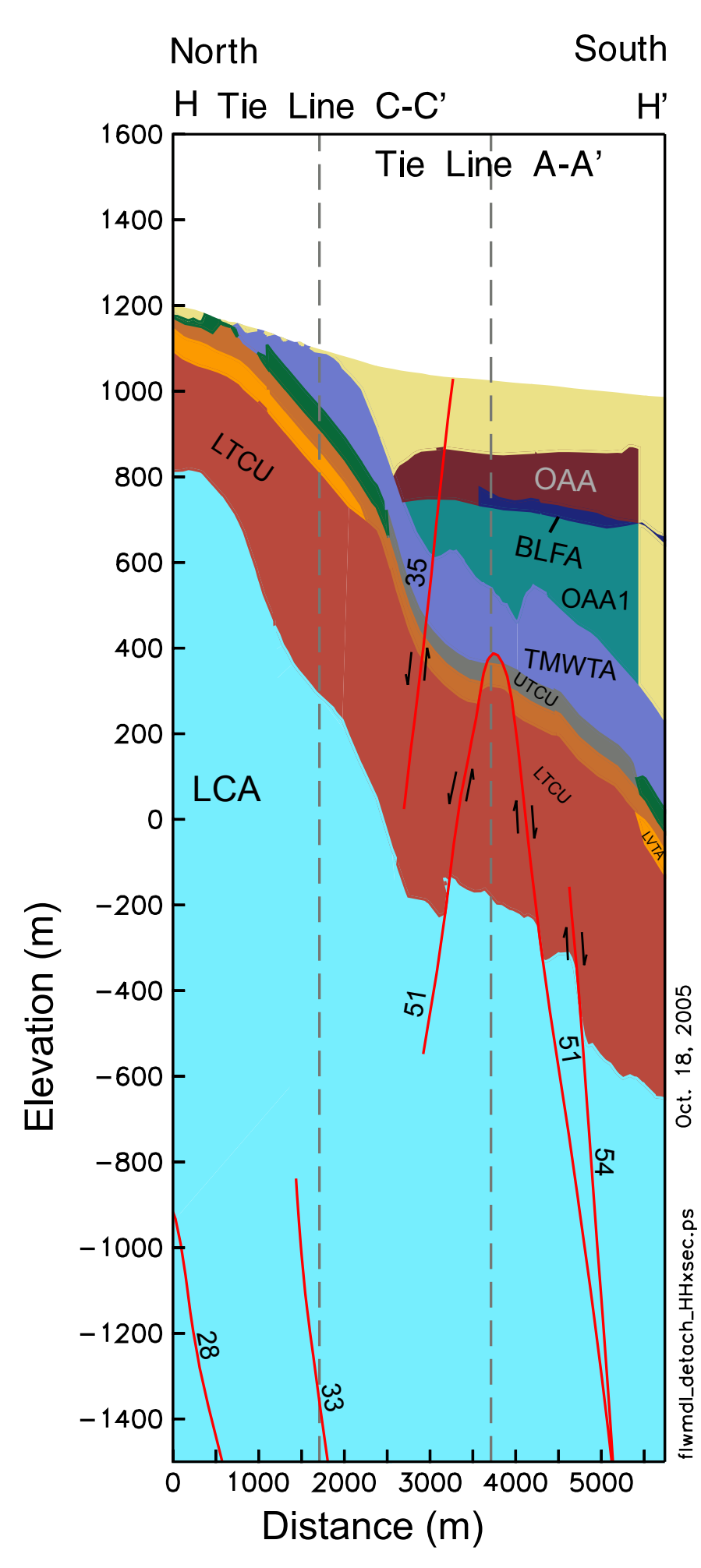

Base Model

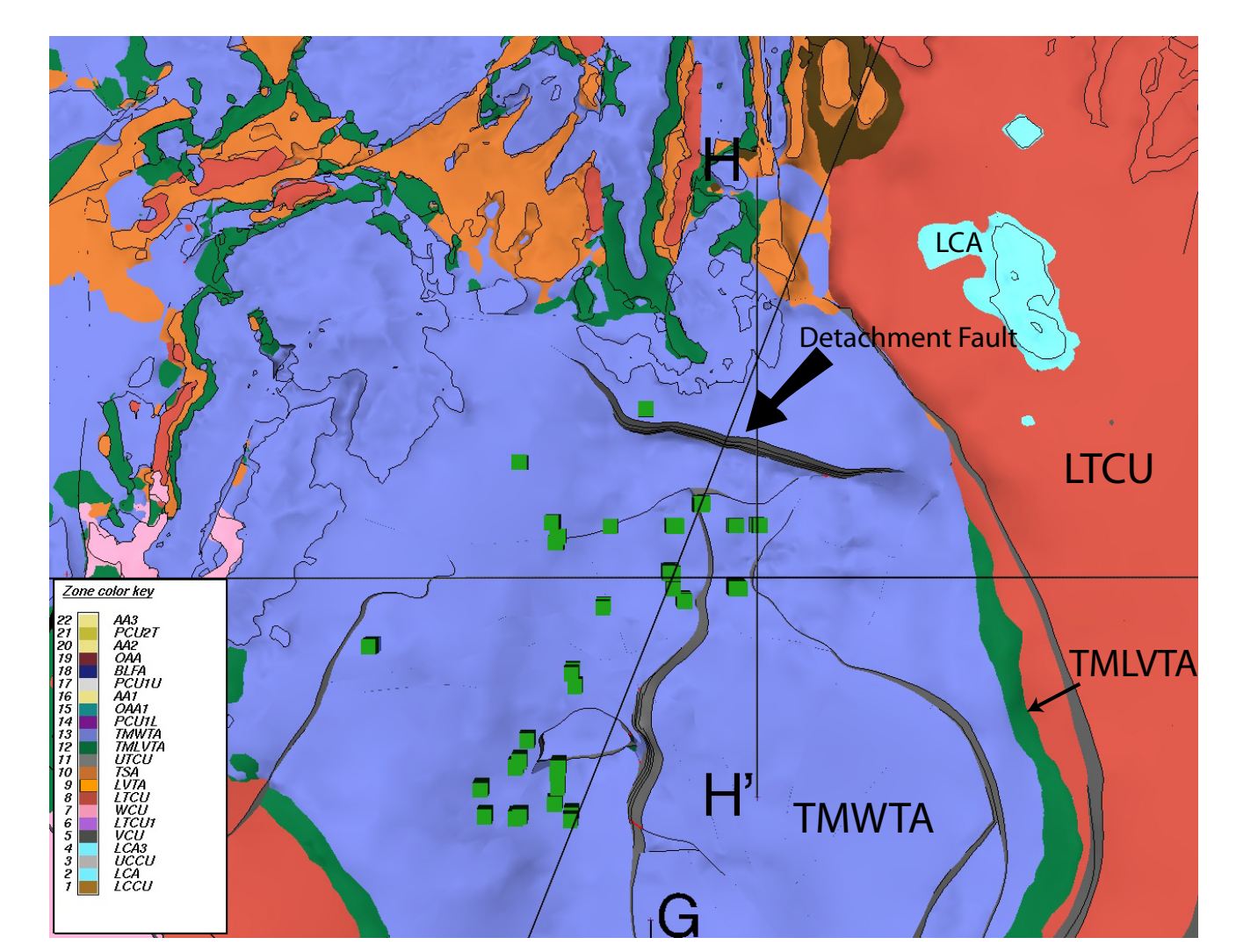

Map view of $\mathrm{H}-\mathrm{H}^{\prime}$ location with all alluvium units removed. Arrow indicates location of Detachment Fault in base model. The Detachment Fault is removed in the indicate drill hole locations.

\section{Profile Legend}

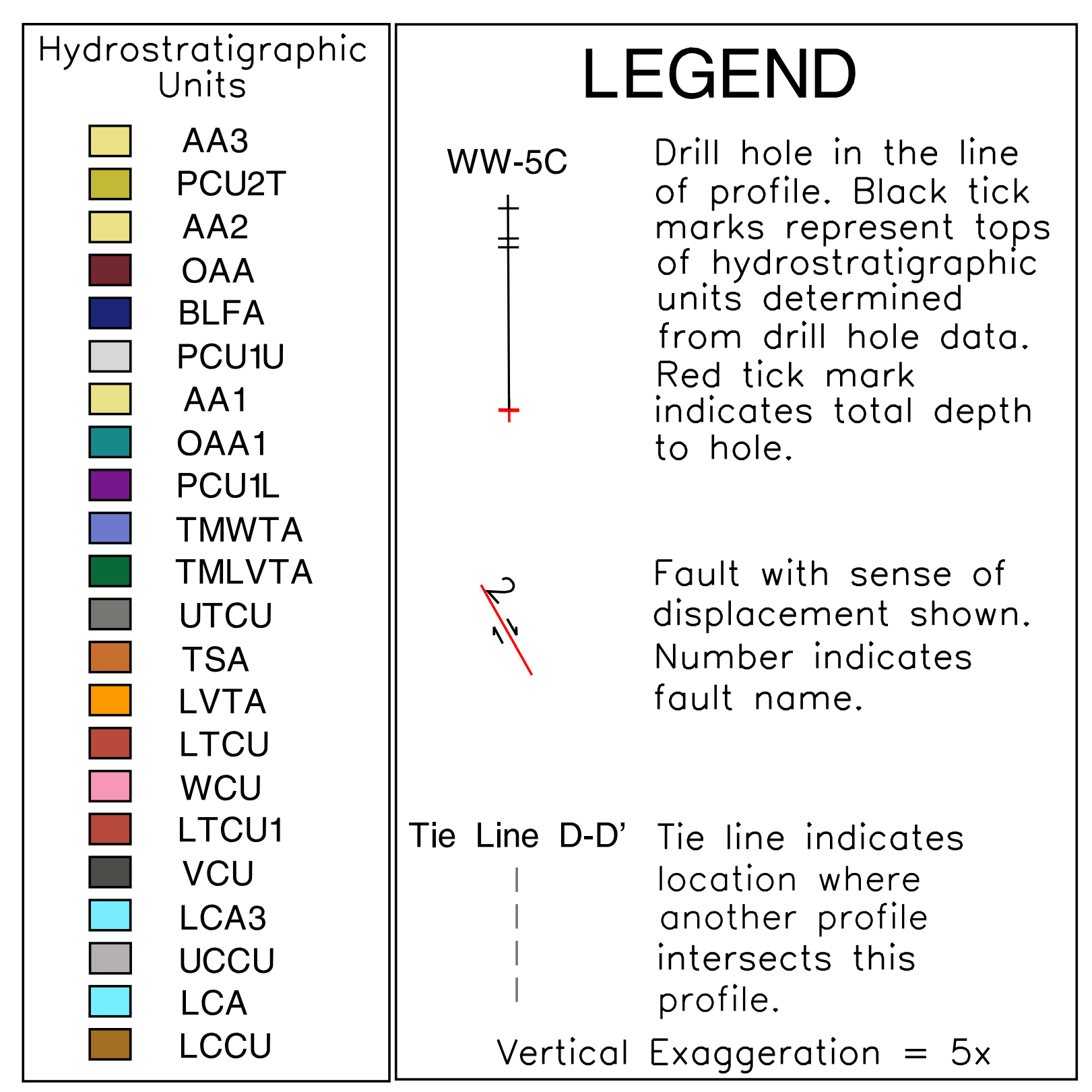

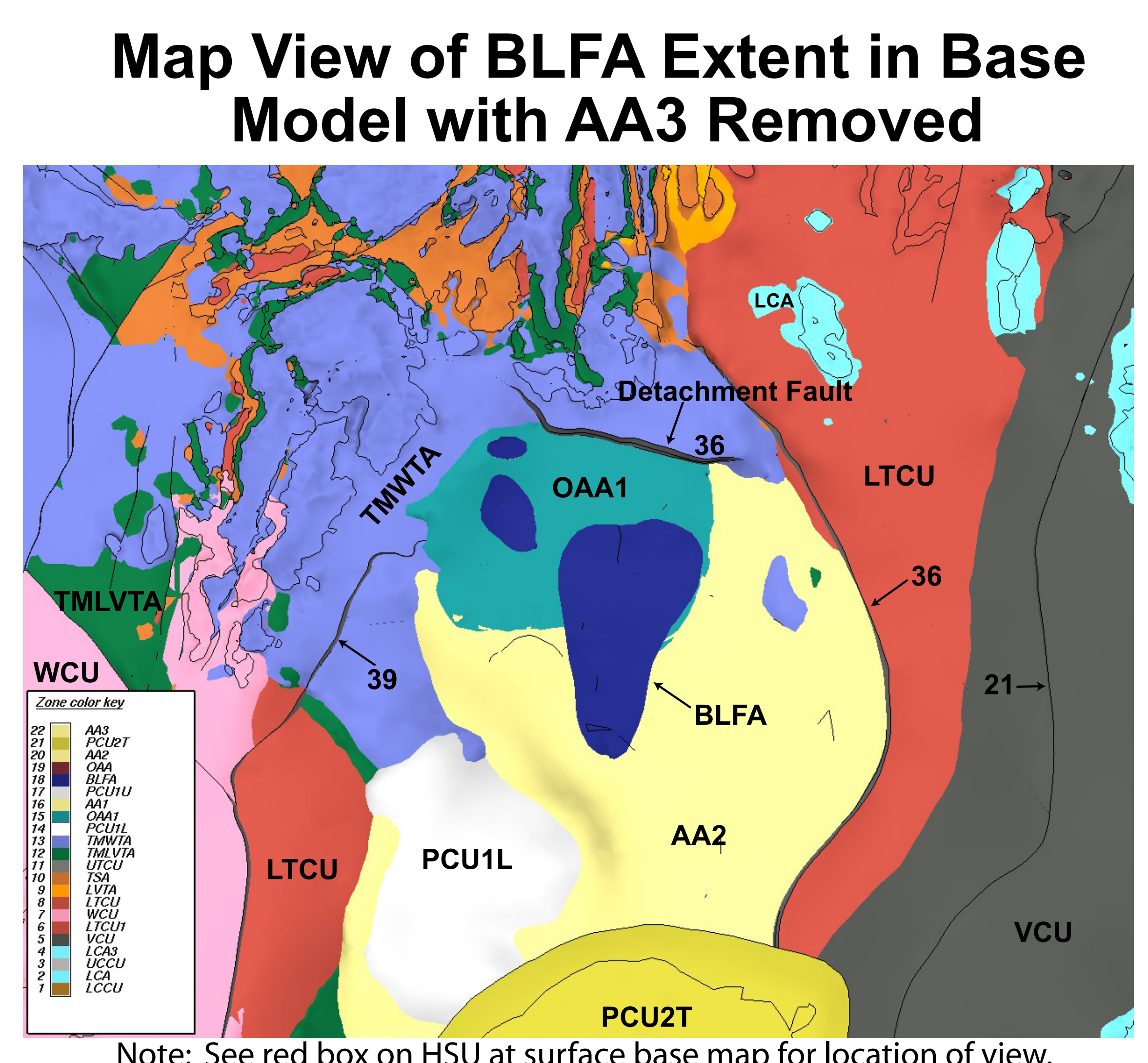

Map View of BLFA Extent in BLFA Alternative Model with AA3 Removed

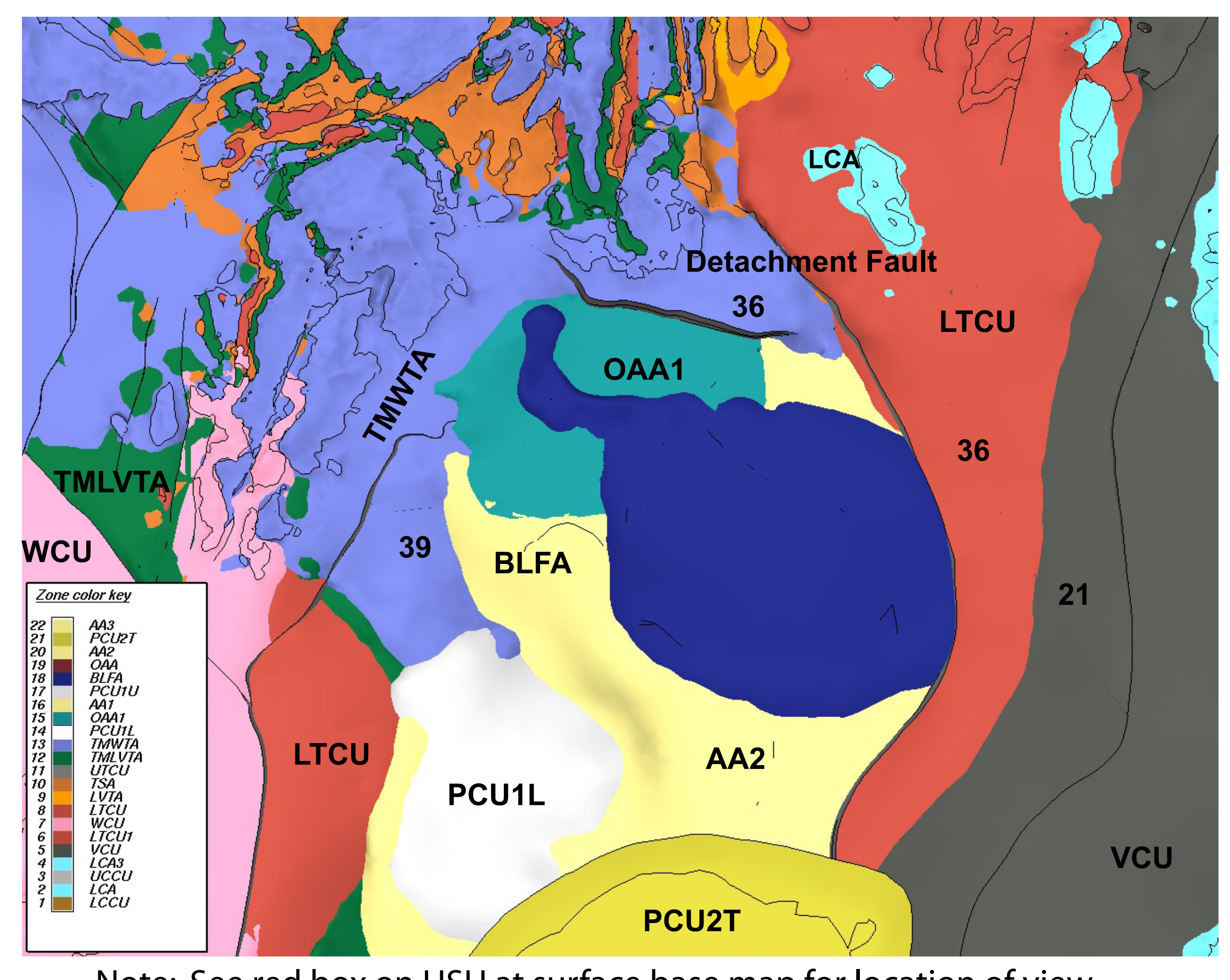

Plate 3

Cross Sections and Plan View for Alternative HFMs Compared with BASE HFM 


\section{DISTRIBUTION}

$\underline{\text { Copies }}$

W.R. Wilborn

Environmental Restoration Project

U.S. Department of Energy

National Nuclear Security Administration

Nevada Site Office

P.O. Box 98518, M/S 505

Las Vegas, NV 89193-8518

K.C. Thompson

Environmental Restoration Project

U.S. Department of Energy

National Nuclear Security Administration

Nevada Site Office

P.O. Box 98518, M/S 505

Las Vegas, NV 89193-8518

U.S. Department of Energy

Office of Scientific and Technical Information

P.O. Box 62

Oak Ridge, TN 37831-0062

U.S. Department of Energy

National Nuclear Security Administration

Nevada Site Office

Technical Library

P.O. Box 98518, M/S NSF 151

Las Vegas, NV 89193-8518

Southern Nevada Public Reading Facility

c/o Nuclear Testing Archive

P.O. Box 98521, M/S NLV 400

Las Vegas, NV 89193-8521

Northern Nevada Public Reading Facility

c/o Nevada State Library \& Archives

100 N Stewart Street

Carson City, NV 89701-4285
3 Hard copies w/3 Electronic media

1 Electronic media

1 Electronic media

1 Electronic media

2 Electronic media

1 Electronic media 


\section{$\underline{\text { Copies }}$}

Celeste Sandoval

1 Electronic media

Nye County

Nuclear Waste Repository Project Office

1210 E. Basin Road, Suite \#6

Pahrump, NV 89060

Naomi Becker

1 Electronic media

Los Alamos National Laboratory

Bikini Atoll Rd., SM30

Los Alamos, NM 87545

Walt McNab

1 Electronic media

Lawrence Livermore National Laboratory

7000 East Avenue, L-530

Livermore, CA 94550-9234

Bonnie Thompson

1 Electronic media

U.S. Geological Survey

Water Resources Division

160 North Stephanie Street

Henderson, NV 89074

Chuck E. Russell

1 Electronic media

Desert Research Institute

755 E. Flamingo

Las Vegas, NV 89119

Ken Ortego

1 Electronic media

National Security Technologies, LLC

P.O. Box 98521, M/S NLV 082

Las Vegas, NV 89193-8521

Nicole DeNovio

1 Electronic media

Golder Associates Inc.

18300 NE Union Hill Road, Suite 200

Redmond, WA 98052

Ed Kwicklis

1 Electronic media

Los Alamos National Laboratory

Hydrology, Geochemistry, and Geology Group, EES-6

Earth and Environmental Sciences Division

Bikini Atoll Rd., SM-30

Los Alamos, NM 87545 


\section{$\underline{\text { Copies }}$}

Sam Marutzky

Navarro Nevada Environmental Services, LLC

P.O. Box 98518, NSF 167

Las Vegas, NV 89193-8518

Greg Ruskauff

Navarro Nevada Environmental Services, LLC

P.O. Box 98518, M/S NSF167

Las Vegas, NV 89193-8518

Environmental Management Records

U.S. Department of Energy

National Nuclear Security Administration

Nevada Site Office

P.O. Box 98518, M/S 505

Las Vegas, NV 89193-8518

NNSA/NSO, Read File

U.S. Department of Energy

National Nuclear Security Administration

Nevada Site Office

P.O. Box 98518, NSF 161

Las Vegas, NV 89193-8518

Navarro Nevada Environmental Services, LLC

Central Files

P.O. Box 98518, NSF 156

Las Vegas, NV 89193-8518
1 Hard copy w/Electronic media

1 Electronic media

1 Hard copy w/Electronic media

1 Hard copy w/Electronic media 